SERVIÇO DE PÓS-GRADUAÇÃO DO ICMC-USP

Data de Depósito: 19/04 /2007

Assinatura:

\title{
Estudos e avaliações de compiladores para arquiteturas reconfiguráveis
}

\author{
Joelmir José Lopes
}

Orientador: Prof. Dr. Jorge Luiz e Silva

Dissertação apresentada ao Instituto de Ciências Matemáticas e de Computação - ICMC-USP, como parte dos requisitos para obtenção do título de Mestre em Ciências - Ciências de Computação e Matemática Computacional.

USP - São Carlos

Maio/2007 
Estudos e avaliações de compiladores para arquiteturas reconfiguráveis

\author{
Joelmir José Lopes
}


A mente que se abre a uma nova idéia jamais voltará ao seu tamanho original...

(Albert Einstein) 


\section{Agradecimentos}

Ao amigo, incentivador e orientador, Prof. Dr. Jorge Luiz e Silva, que pacientemente soube transmitir seus conhecimentos.

Ao Prof. Dr. Eduardo Marques e ao Prof. Dr. João Manuel Paiva Cardoso por terem acreditado em minha capacidade.

Ao CNPq pelo apoio financeiro recebido.

Aos funcionários do ICMC, sempre prestativos e eficientes.

À minha família, fonte de incentivo e carinho.

A Deus pelas oportunidades e dádivas em minha vida.

A todos que de alguma forma colaboraram com este trabalho, seja com sugestões, esclarecimentos, incentivo ou ajuda direta como ocorreu em algumas implementações. 


\section{RESUMO}

Com o aumento crescente das capacidades dos circuitos integrado e conseqüente complexidade das aplicações, em especial as embarcadas, um requisito tem se tornado fundamental no desenvolvimento desses sistemas: ferramentas de desenvolvimento cada vez mais acessíveis aos engenheiros, permitindo, por exemplo, que um programa escrito em linguagem $C$ possa ser convertido diretamente em hardware. Os FPGAs (Field Programmable Gate Array), elemento fundamental na caracterização de computação reconfigurável, é um exemplo desse crescimento, tanto em capacidade do $\mathrm{Cl}$ como disponibilidade de ferramentas. Esse projeto teve como objetivos: estudar algumas ferramentas de conversão C, C++ ou Java para hardware reconfigurável; estudar benchmarks a serem executadas nessas ferramentas para obter desempenho das mesmas, e ter o domínio dos conceitos na conversão de linguagens de alto nível para hardware reconfigurável. A plataforma utilizada no projeto foi a da empresa Xilinx XUP V2P. 


\section{ABSTRACT}

With the growing capacities of Integrated Circuits (IC) and the complexity of the applications, especially in embedded systems, there are now requisites for developing tools that convert algorithms $C$ direct into the hardware. As a fundamental element to characterize Reconfigurable Computing, FPGA (Field Programmable Gate Array) is an example of those $\mathrm{Cls}$, as well as the tools that have been developed. In this project we present different tools to convert $C$ into the hardware. We also present benchmarks to be executed on those tools for performance analysis. Finally we conclude the project presenting results relating the experience to implement $C$ direct into the hardware. The Xilinx XUP V2P platform was used in the project. 


\section{Sumário}

Resumo

Abstract

1. Introdução

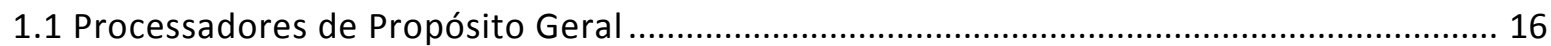

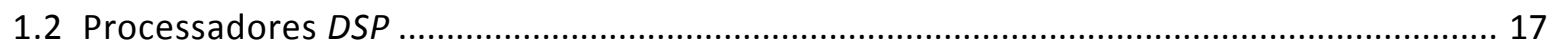

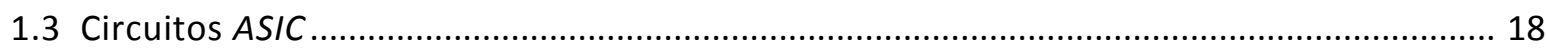

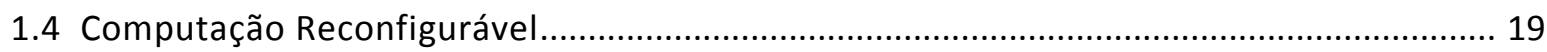

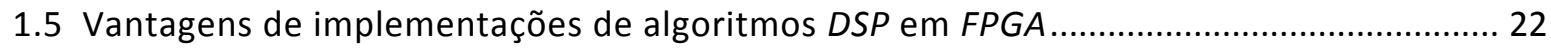

1.6 Desvantagens de implementações de algoritmos DSP em FPGA …................................... 23

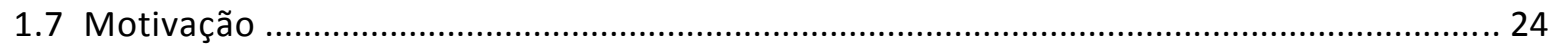

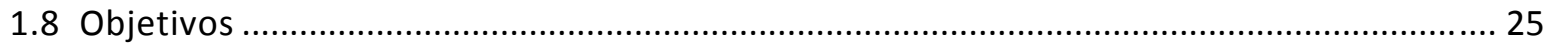

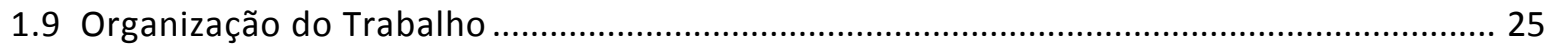

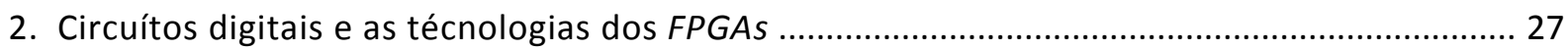

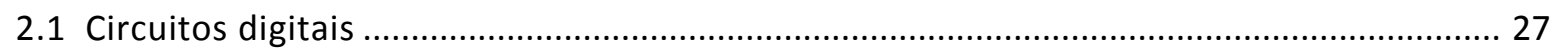

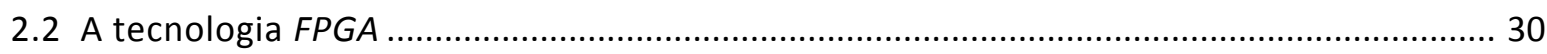

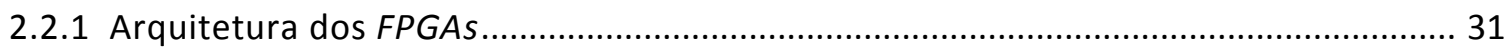

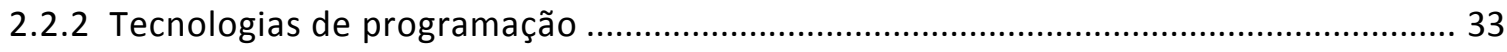

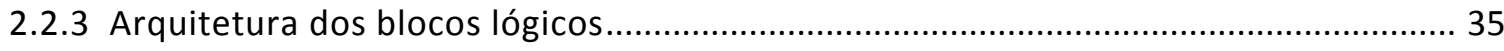

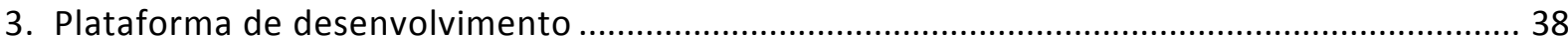

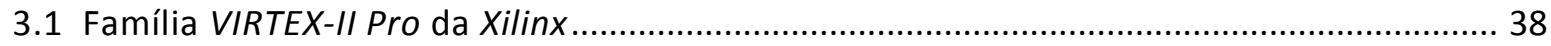

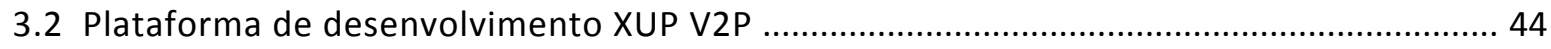

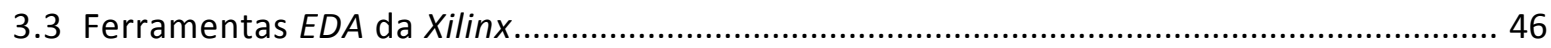

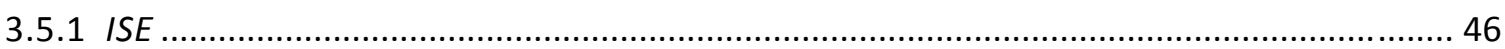

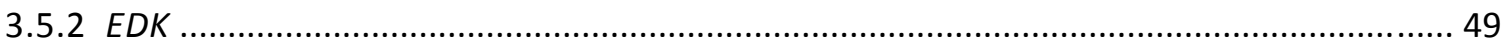

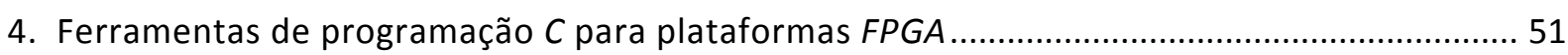

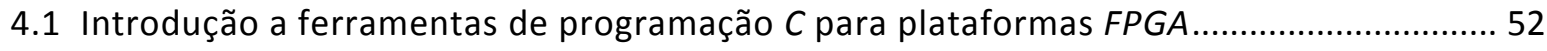

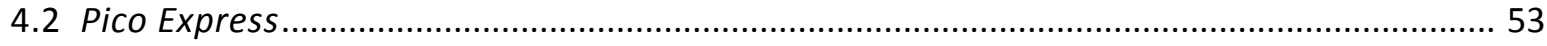

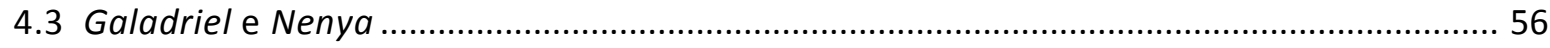

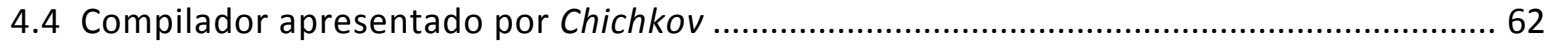

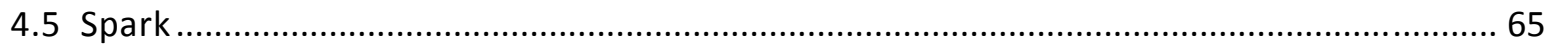

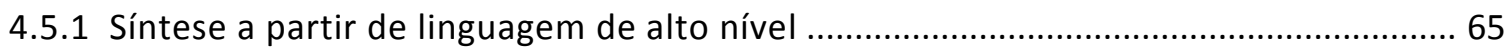

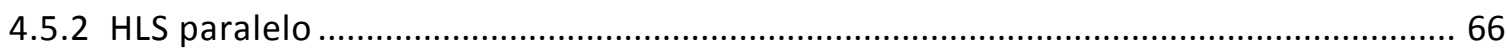

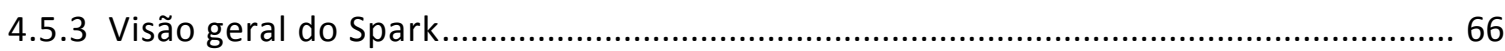




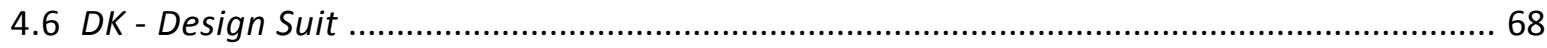

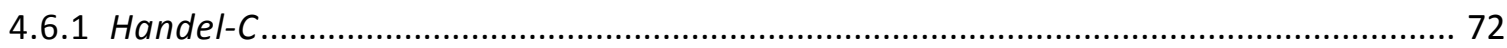

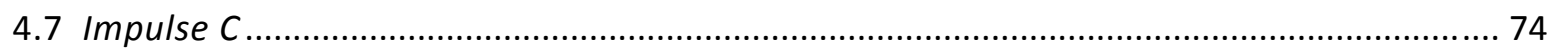

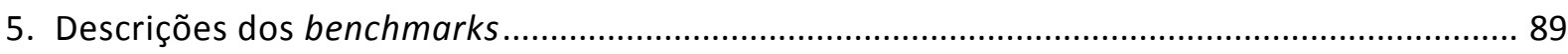

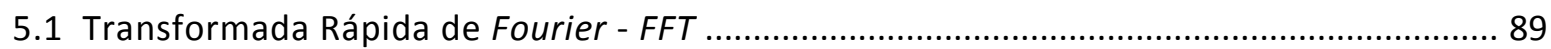

5.2 Adaptative Differencial Pulse Code Modulation - ADPCM ................................................ 94

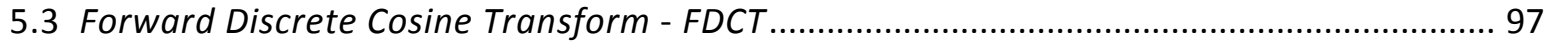

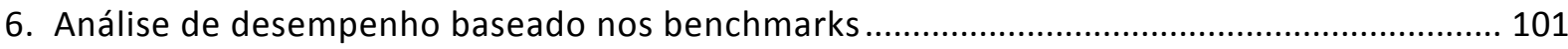

6.1 Análise dos benchmarks nos processadores embarcados ............................................... 101

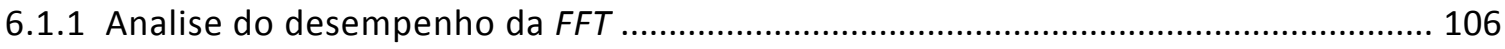

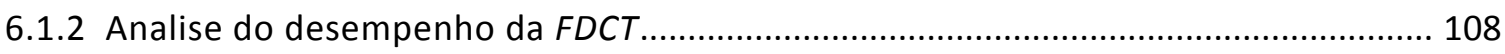

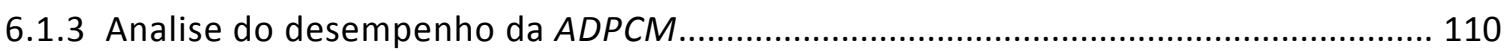

6.1.4 Resultados de desempenho nos Processadores embarcados ..................................... 112

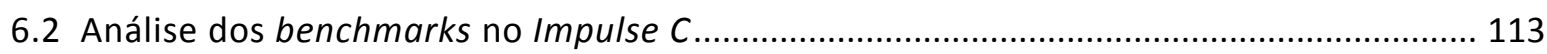

6.2.1 Implementação do benchmark FFT no Impulse C ...................................................... 115

6.2.2 Implementação do benchmark FDCT no Impulse C ..................................................... 124

6.2.3 Implementação do benchmark ADPCM no Impulse C ................................................. 134

6.2.4 Resultados de desempenho no Impulse C ............................................................. 139

6.3 - Análise comparativa entre os processadores embarcados e o Impulse C ....................... 141

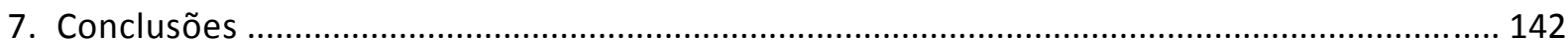

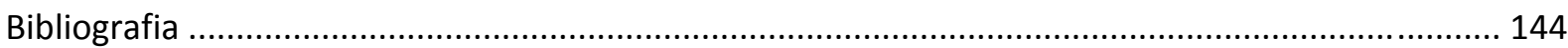

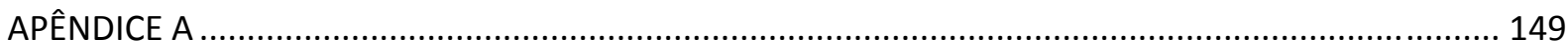

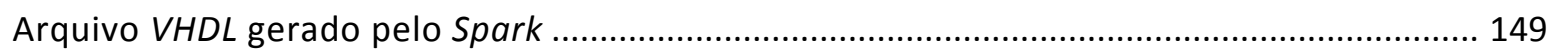

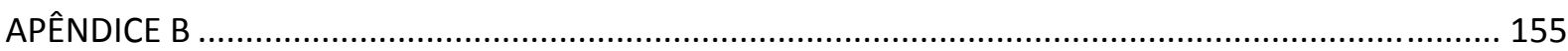

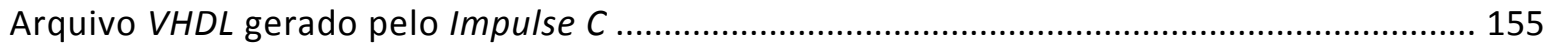

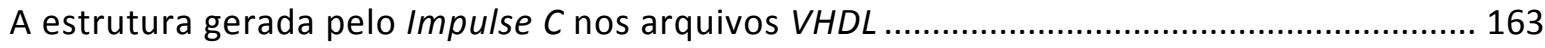

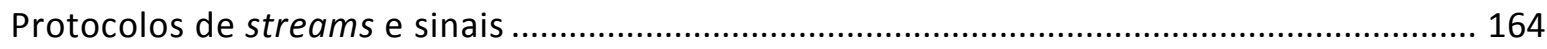

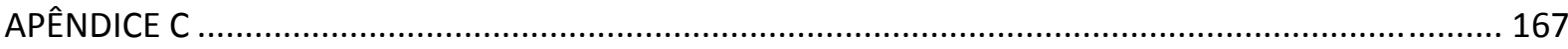

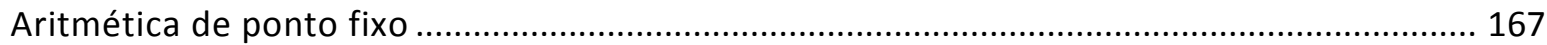




\section{Lista de figuras}

Figura 1. Número de transistores integrados em um único dispositivo. ............................................. 16

Figura 2. Flexibilidade versos desempenho dos sistemas programáveis.............................................. 20

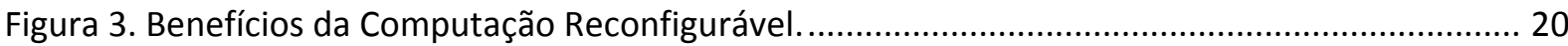

Figura 4. Comparação de desempenho entre computadores de alto desempenho (Bolsens, 2006) .. 21

Figura 5. Evolução dos FPGAs em número de transistores. (Bolsens, 2006) ....................................... 28

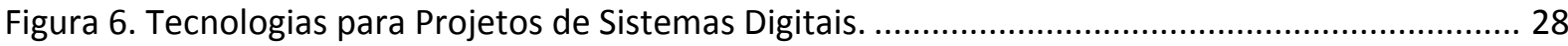

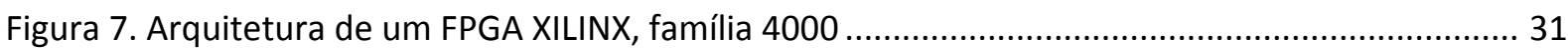

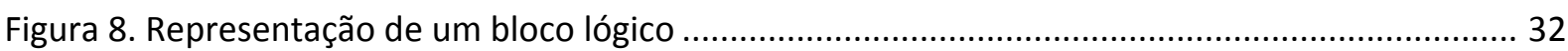

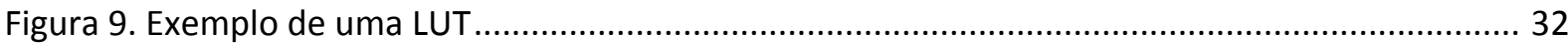

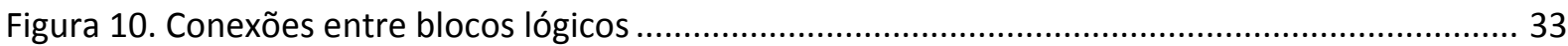

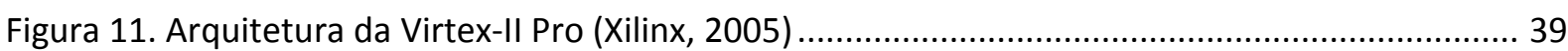

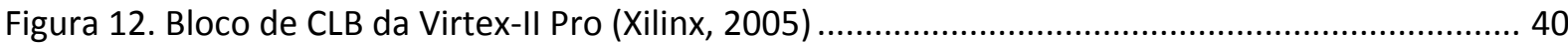

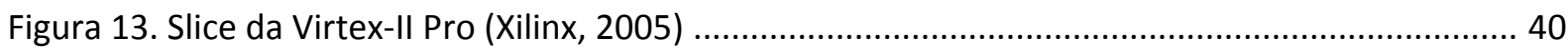

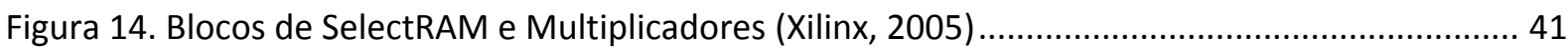

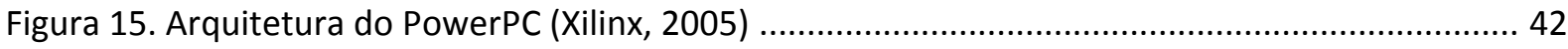

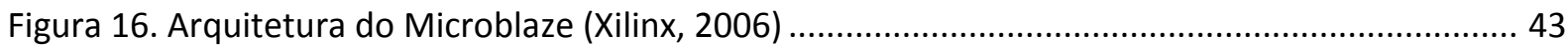

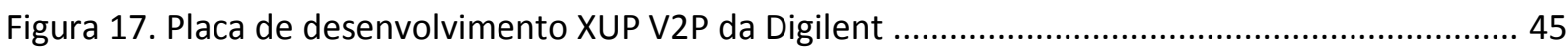

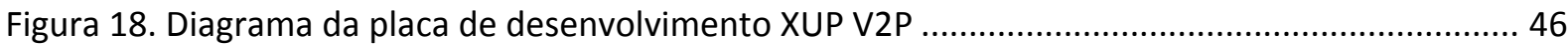

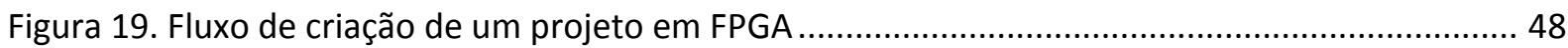

Figura 20. Fluxo de desenvolvimento de projetos em FPGA com ISE e EDK ….................................... 50

Figura 21. Possíveis implementações geradas por Pico Express.......................................................... 54

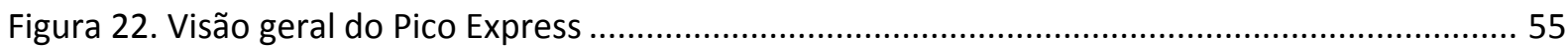

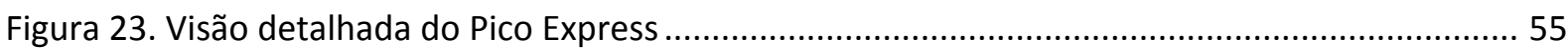

Figura 24. Arquitetura do hardware gerado pelos compiladores Galadriel e Nenya ........................... 56

Figura 25. Fluxo de compilação feitos por Galadriel e Nenya............................................................ 58

Figura 26. Estrutura utilizada pelo compilador Nenya para implementar o hardware gerado pelo

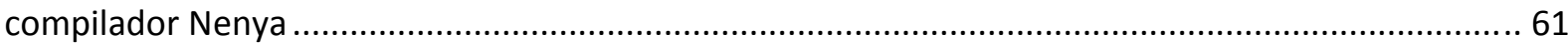

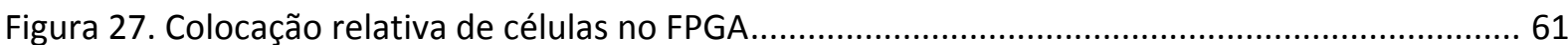

Figura 28. Arquitetura de configuração do compilador apresentado por Chichkov. (Chichkov, et al.,

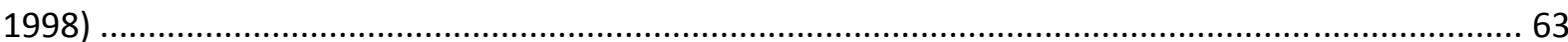

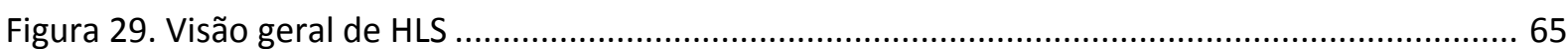

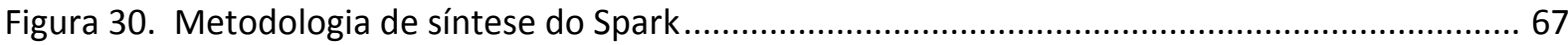

Figura 31. Co-simulação através do DSM. Descrição no DK Design Suit (a); Descrição no Microsoft

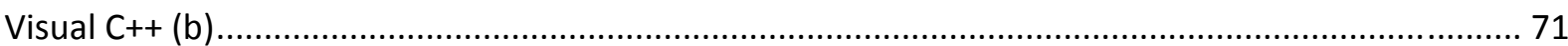

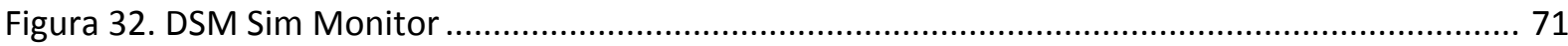

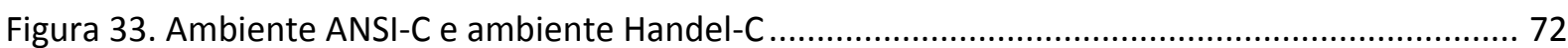

Figura 34. Exemplo da descrição e execução de programas escritos em Handel-C ............................. 73

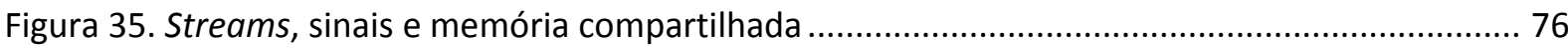

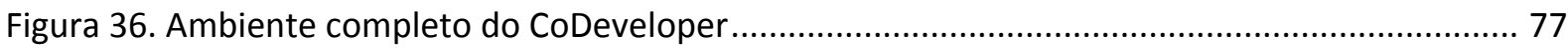

Figura 37. Ambiente de implementação do CoDeveloper (CoDeveloper Application Manager) ......... 78

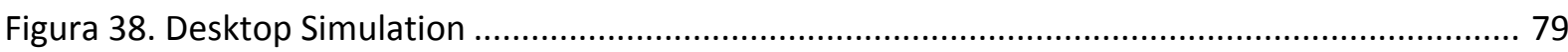

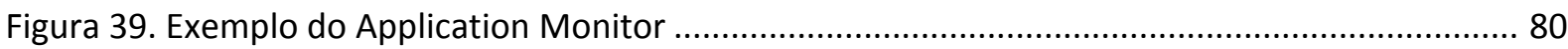

Figura 40. Diagrama de uma simplificada descrição de como os processos trabalham no CoDeveloper 
Figura 41. Plataform Support Package.

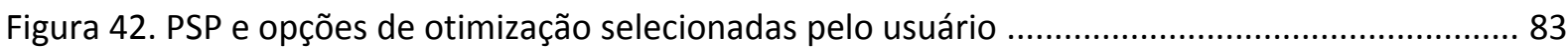

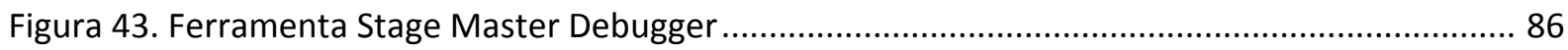

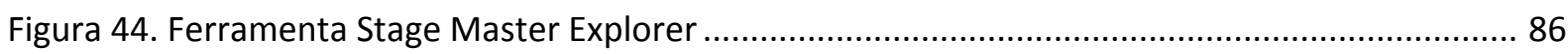

Figura 45. Ferramenta Stage Master Explorer - análise mais detalhada sobre o hardware gerado .... 87

Figura 46. Exemplo de um sinal no domínio do tempo e no domínio da freqüência............................90 90

Figura 47. Resultado gerado pelo algoritmo split radix do (Martinian, 2006) ..................................... 93

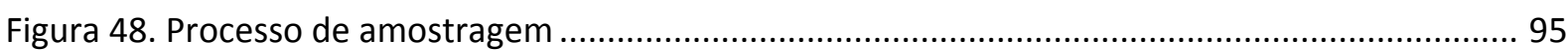

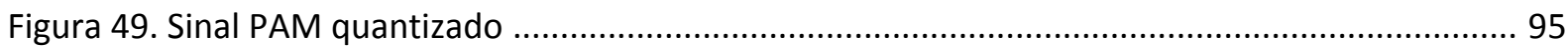

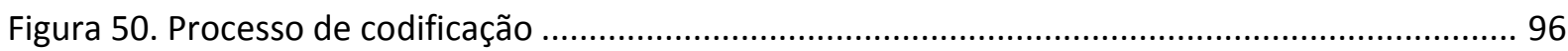

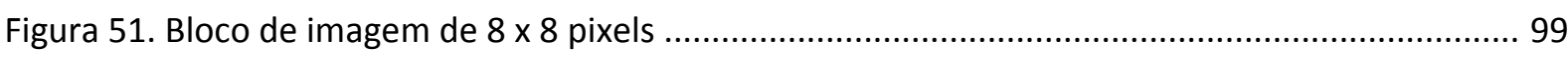

Figura 52. Gráfico de desempenho dos benchmarks sob diferentes configurações de processadores

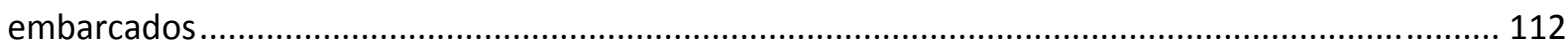

Figura 53. Comunicação entre processos presentes no FPGA e no processador embarcado ............. 113

Figura 54. Exemplo de comunicação entre a placa de prototipação e demais dispositivos................ 115

Figura 55. Imagem do Application Monitor da implementação do FFT .......................................... 116

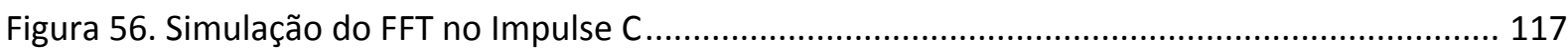

Figura 57. Diagrama de bloco feito pelo Application Monitor, mostrando o funcionamento do FFT 118 Figura 58. Simulação do hardware gerado pelo Impulse do benchmark FFT pela ferramenta VHDL

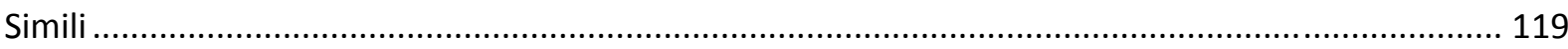

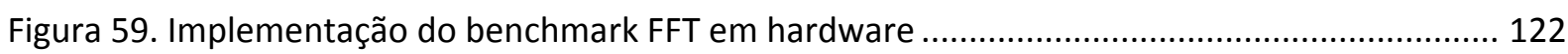

Figura 60. Primeira implementação do benchmark FDCT no Impulse C............................................ 125

Figura 61. Segunda implementação do benchmark FDCT no Impulse C .......................................... 126

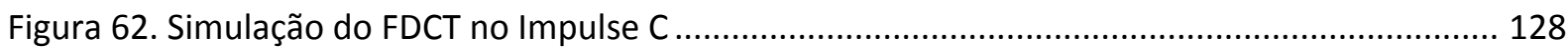

Figura 63. Diagrama de bloco feito pelo Application Monitor, mostrando o funcionamento da

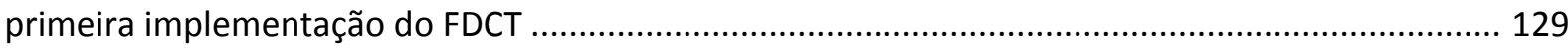

Figura 64. Diagrama de bloco feito pelo Application Monitor, mostrando o funcionamento da

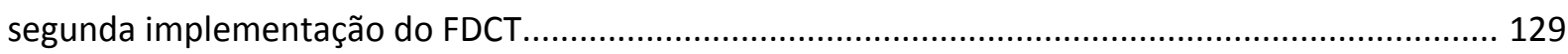

Figura 65. Simulação do hardware gerado pelo Impulse do benchmark ADPCM pela ferramenta VHDL

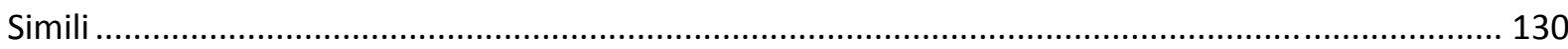

Figura 66. Implementação do benchmark ADPCM no Impulse C ................................................. 134

Figura 67. Diagrama de bloco feito pelo Application Monitor, mostrando o funcionamento do ADPCM

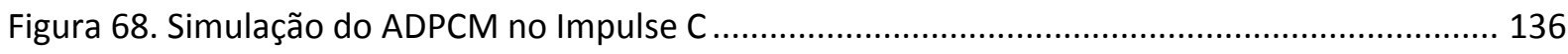

Figura 69. Simulação do hardware gerado pelo Impulse do benchmark ADPCM pela ferramenta VHDL

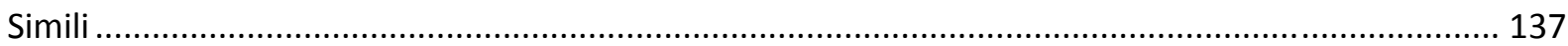

Figura 70. Gráfico de utilização de recursos de hardware gastos pelos benchmarks no FPGA.......... 140

Figura 71. Gráfico de utilização de tempo de processamento gastos pelos benchmarks no FPGA ... 140

Figura 72. Análise Global dos Resultados para Processador Embarcado e Impulse C........................ 141

Figura 73. Implementação do algoritmo de ordenação implementado no Impulse C ....................... 155

Figura 74. Relação entre os componentes gerados como HDL pelo Impulse C.................................. 164

Figura 75. Múltiplos processos de hardware conectados via buffer de stream compartilhadas ....... 165

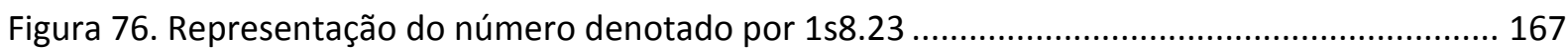




\section{Lista de tabelas}

Tabela 1. Comparação de desempenho entre Microprocessadores e FPGAs (Bolsens, 2006) ............ 21

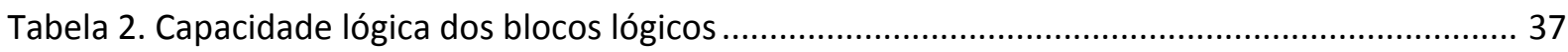

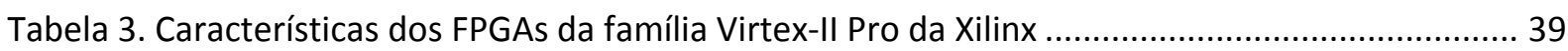

Tabela 4. Tipos de dados, operações e controles suportados pelo compilador Galadriel .................... 58

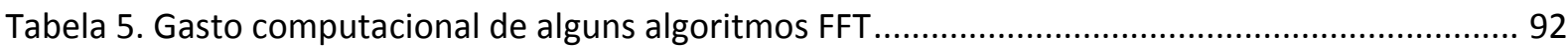

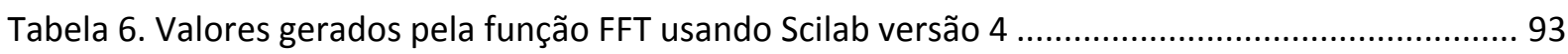

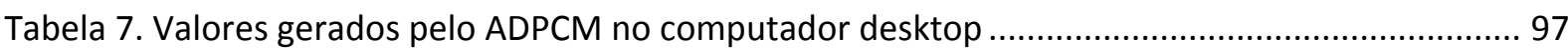

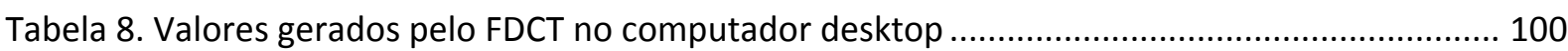

Tabela 9. Exemplo do Perfil plano (flat profile) gerado pelo Gprof ................................................. 105

Tabela 10. Tempo de execução do benchmark FFT no processador Microblaze ............................... 106

Tabela 11. Tempo de execução do benchmark FFT no processador PowerPC a $100 \mathrm{MHz}$................ 107

Tabela 12. Tempo de execução do benchmark FFT no processador PowerPC a $300 \mathrm{MHz}$................. 108

Tabela 13. Tempo de execução do benchmark FDCT no processador Microblaze ............................. 109

Tabela 14. Tempo de execução do benchmark FDCT no processador PowerPC a 100MHz............... 109

Tabela 15. Tempo de execução do benchmark FDCT no processador PowerPC a 300MHz................ 110

Tabela 16. Tempo de execução do benchmark ADPCM no processador Microblaze........................... 111

Tabela 17. Tempo de execução do benchmark ADPCM no processador PowerPC a 100MHz........... 111

Tabela 18. Tempo de execução do benchmark ADPCM no processador PowerPC a 300MHz........... 112

Tabela 19. Resumo dos recursos de hardware usado pelo benchmark FFT com o uso do pipeline .. 120 Tabela 20. Resumo dos recursos de hardware usado pelo benchmark FFT sem o uso do pipeline... 120 Tabela 21. Tempo de execução do FFT hardware/software codesign com pipeline executado na XUPV2P.

Tabela 22. Tempo de execução do FFT hardware/software codesign sem pipeline executado na XUP$\mathrm{V} 2 \mathrm{P}$

Tabela 23. Implementação tradicional do benchmark FFT envolvendo os processos produtor, hardware e consumidor

Tabela 24. Implementação do benchmark FFT envolvendo os processos hardware e consumidor .. 123 Tabela 25. Resumo dos recursos de hardware usado pelo benchmark FDCT, na primeira implementação, com o uso do pipeline.

Tabela 26. Resumo dos recursos de hardware usado pelo benchmark FDCT, na primeira implementação, com o uso do unroll

Tabela 27. Resumo dos recursos de hardware usado pelo benchmark FDCT, na primeira implementação, sem opções de otimização nos laços de repetição...

Tabela 28. Tempo de execução do FDCT hardware/software codesign para as três primeiras implementações executados na XUP-V2P

Tabela 29. Resumo dos recursos de hardware usado pelo benchmark FDCT, na segunda implementação, com o uso do pipeline

Tabela 30. Resumo dos recursos de hardware usado pelo benchmark FDCT, na segunda implementação, com o uso do unroll

Tabela 31. Resumo dos recursos de hardware usado pelo benchmark FDCT, na segunda implementação, sem opções de otimização nos laços de repetição

Tabela 32. Tempo de execução do FDCT hardware/software codesign para as três últimas implementações executados na XUP-V2P 
Tabela 33. Resumo dos recursos de hardware usado pelo benchmark ADPCM com o uso do pipeline 137

Tabela 34. Resumo dos recursos de hardware usado pelo benchmark FFT sem o uso do pipeline... 138 Tabela 35. Tempo de execução do ADPCM hardware/software codesign com pipeline executado na XUP-V2P 138

Tabela 36. Tempo de execução do ADPCM hardware/software codesign sem pipeline executado na XUP-V2P 


\section{Lista de abreviações}

ADPCM Adaptive differential pulse code modulation

ALU Arithmetic and Logic Unit

API Application Program Interface

ASIC Application Specific Integrated Circuit

BRAM Block RAM

CAD Computer Aided Design

CFG Control-Flow Graph

$\mathrm{Cl} \quad$ Circuito Integrado

CLB Configurable Logic Block

CPLD Complex Programmable Logic Devices

CPU Central Processing Unit

CSP Communicating Sequential Processes

DCM Digital Clock Manager

DCM Digital Clock Manager

DCR Device Control Register Bus

DCT Discrete Cosine Transform

DFG Data Flow Graph

DFG Data-Flow Graph

DFT Discrete Fourier Transform

DPCM Differential pulse code modulation

DSM Data Streaming Manager

DSP Digital Signal Processor

DVD Digital Versatile Disc

EDA Electronic Design Automation

EDIF Electronic Design Interchange Format

EDK Embedded Development Kit

EEPROM Electrical Erasable PROM

EEPROM Electrical Erasable PROM

ENPC École Nationale des Ponts et Chaussées

EPROM Erasable PROM

EPROM Erasable PROM

FDCT Forward Discrete Cosine Transform

FFT Fast Fourier transform

FIR Finite Impulse Response

FPGA Field Programmable Gate Array

FPSoC Field Programmable System on Chip

FPU Unidade de Ponto Flutuante

GOPS Giga-operations per second

GPP General Purpose Processor 


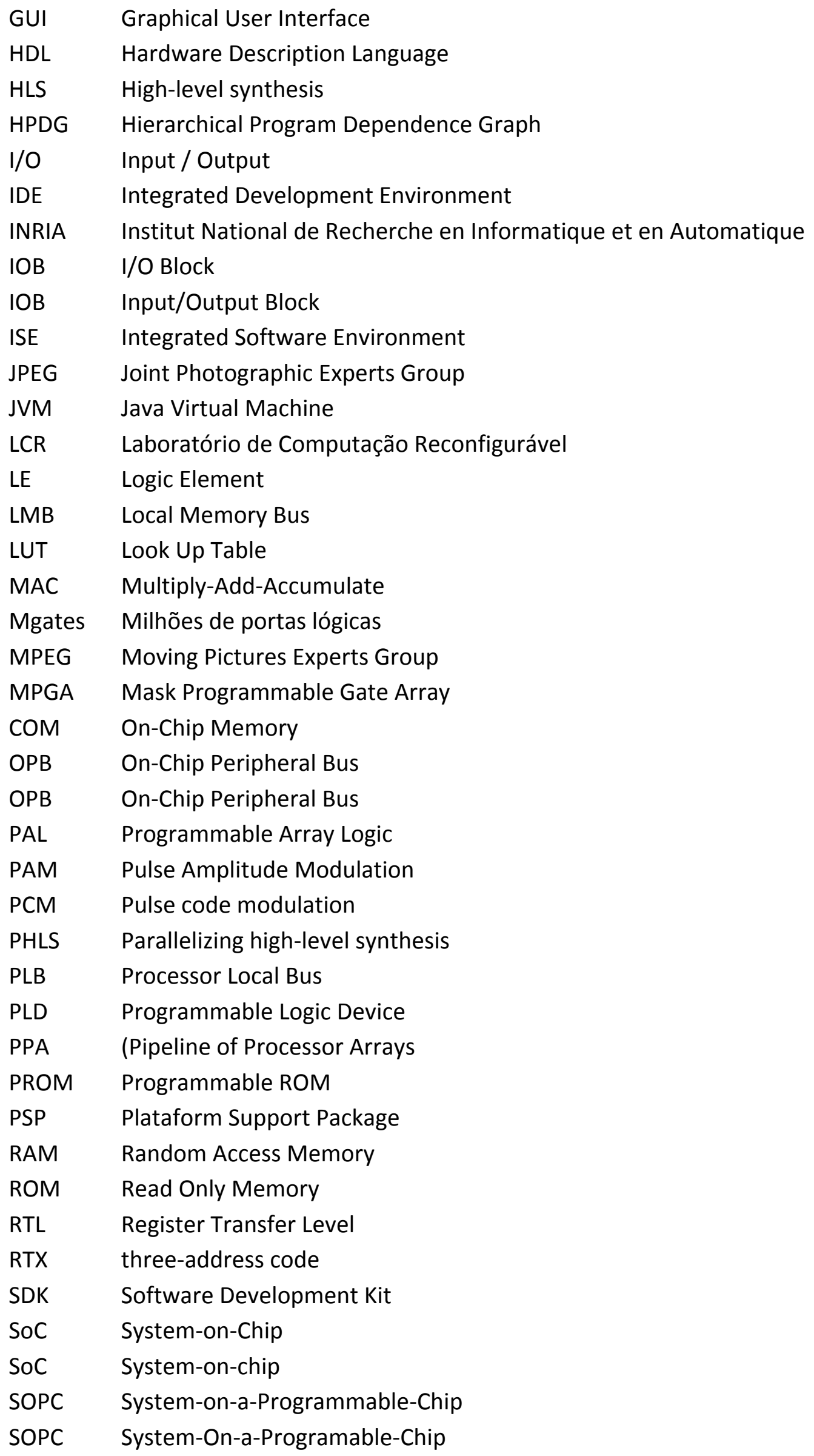


SPLD Simple Programmable Logic Devices

SPLD Simple PLD

SRAM Static RAM

SUIF Stanford Universal Intermediate Format

UART Universal Assynchronous Receiver Transmiter

ULA Unidade Lógica Aritmética

VHDL VHSIC Hardware Description Language

VLIW Very Long Instruction Width

VLSI Very Large Scale Integration

XCL Xilinx CacheLink

XPS Xilinx Platform Studio

XUP V2P Xilinx Universiry Program Virtex 2 Pro 


\section{Capítulo 1}

\section{Introdução}

Originalmente FPGA - (Field Programmable Gate Array) vinha sendo utilizado como dispositivo "glue logic", reduzindo significantemente o número de componentes em um sistema, e diminuindo os riscos de desenvolvimento de projetos, ao mesmo tempo em que proporcionava a flexibilidade para correções e atualizações de forma rápida e mais segura. Agora os FPGAs são utilizados no projeto e controle de inúmeros sistemas com aplicações específicas, significativamente complexas, e dedicadas (Piacentino, et al., 1999)

Com a evolução da microeletrônica, os FPGAs surgiram como um elemento intermediário entre os processadores de propósito geral, em inglês GPP (General Purpose Processor) e os ASIC (Application Specific Integrated Circuit) (Hauck, 1998); (Hauck, 2002); (Villasenor, et al., 1997); (Hauck, et al., 2006).

Com os últimos avanços na tecnologia dos FPGAs, é possível programar sistemas altamente poderosos, com grande capacidade de processamento e flexibilidade, além de custo reduzido, comparado, por exemplo, aos ASICs.

Os FPGAs tem tido sua capacidade aumentada em número de transistores no mesmo circuito integrado de forma mais acentuado do que os próprios microprocessadores, conforme descrito na Figura 1 (Cardoso, 2000). Este crescimento (apenas comparável ao das memórias RAM) deve-se à regularidade da estrutura dos FPGAs e ao fato destes dispositivos não terem custos de teste tão elevados como os microprocessadores. A taxa de crescimento da capacidade dos FPGAs acentua cada vez mais a discrepância entre as capacidades atuais 
do projeto de hardware e de área disponível. (Hartenst, et al., 1996)

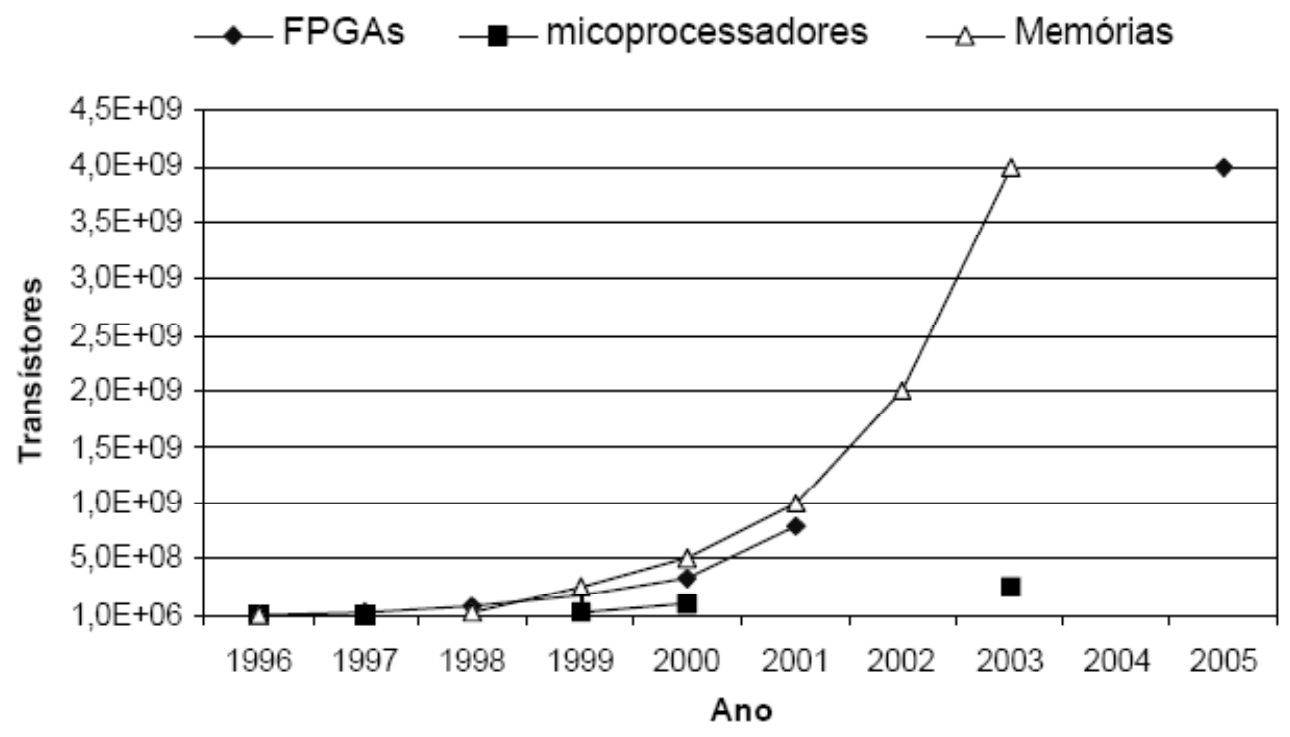

Figura 1. Número de transistores integrados em um único dispositivo.

Nos sistemas paralelos tradicionais o caminho para se obter maior desempenho é a exploração do paralelismo da aplicação através de múltiplos microprocessadores; nos sistemas computacionais reconfiguráveis o caminho é a implementação em hardware das partes do programa de aplicação computacionalmente mais intensivas. Nos sistemas computacionais reconfiguráveis a exploração do paralelismo existente em uma aplicação tem a característica de ser um modelo intrinsecamente concorrente (hardware) em vez dos modelos baseados na estrutura seqüencial de Von Neumann utilizados pela maioria dos sistemas de suporte ao processamento paralelo. As máquinas personalizadas ao nível da porta lógica não possuem a limitação de largura de banda no carregamento de instruções, fato que limita o desempenho das arquiteturas paralelas baseadas em vários microprocessadores. Contudo, apesar de novas arquiteturas terem sido propostas e novos conceitos apresentados (Radunovic, et al., 1998); (Hauck, et al., 2006), a utilização dos sistemas computacionais reconfiguráveis requer etapas morosas e complexas e conhecimentos específicos de projeto de hardware (Cardoso, et al., 2003).

\subsection{Processadores de Propósito Geral}

Os Processadores de Propósito Geral possuem, em geral, uma grande quantidade de instruções e são programados pelo usuário para solucionar muitas tarefas computacionais. 
A funcionalidade do sistema é alterada mudando-se as instruções de software, ou seja, sem mudar o hardware. Já a grande quantidade de instruções o permite ser flexível e atender a uma grande quantidade de aplicações. (Ribeiro, 2002)

A flexibilidade funcional pode ser conseguida através de atualizações de software, mas desta forma a mudança é limitada somente à parte programável dos sistemas.

Devido ao grande conjunto de instruções, o GPP possui um desempenho menor, maior consumo de energia, comparado ao ASIC. (Romer, et al., 2000)

O ciclo de instruções dos GPP é seqüencial, o que se torna uma das maiores limitações desses dispositivos. A arquitetura desse sistema é baseada na clássica arquitetura Von Neumann. Para executar uma instrução, o processador realiza os seguintes passos:

1. Busca a próxima instrução na memória principal;

2. Atualiza o contador de programas para a próxima posição de memória, para que este referencie a instrução seguinte;

3. Determina o tipo de instrução;

4. Se a instrução usa dados da memória principal, então, determina em que posição eles estão;

5. Busca os dados, se houver, e envia aos registradores internos da UCP;

6. Executa a instrução;

7. Armazena o(s) resultado(s) em determinadas posições da memória principal ou registradores da UCP;

8. Volta ao passo 1 para iniciar a execução da próxima instrução.

\subsection{Processadores DSP}

DSP, em inglês (Digital Signal Processor) é um microprocessador especializado em processamento digital de sinal, usado principalmente para processar sinais de áudio, vídeo.

Um DSP pode ser programado tanto em assembler como em linguagem $C$. Cada família de DSP tem seu próprio assembler e suas próprias ferramentas de desenvolvimento fornecidas pelo fabricante.

Os modernos algorítmos necessários para a implementação dos novos padrões de sistemas de comunicação de dados com e sem fios, compressão de som e imagem, sistemas 
criptográficos e sistemas de transmissão de imagens com resoluções cada vez maiores, exigem capacidade de processamento DSP cada vez maiores. (Duarte, 2006).

Alguns exemplos de sistemas que exigem capacidade de processamento muito superior à capacidade dos processadores DSP atuais de alto desempenho são sistemas de compressão de imagem em tempo real para imagens de alta resolução, tais como compressão nos padrões H.264 para as resoluções maiores que (1920x1080), sistemas de modulação e demodulação OFDM para comunicação sem fio e transmissão de sinais de TV digital em banda larga e sistemas criptográficos necessários à implementação de VPNs em sistemas ethernet de banda larga (1 Gbps e 10 Gbps). (Duarte, 2006)

Segundo (Duarte, 2006), atualmente o DSP com maior poder de processamento tem implementadas internamente seis $M A C s^{1}$, em inglês (Multiply-Add-Accumulate), que operam em paralelo sobre conjuntos de dados, permitindo a execução simultânea de seis operações de processamento DSP em um ciclo de clock. Um exemplo de processadores DSP com esta característica são os processadores da linha TMS320C6xx, da Texas Instruments. Entretanto, a maioria dos processadores DSP disponíveis no mercado, possuem uma MAC. Isso faz com que apenas uma operação DSP pode ser realizada em um determinado ciclo de clock.

Ainda segundo (Duarte, 2006), outra limitação dos DSPs é que, antes de executar uma operação sobre um conjunto de dados, o dado ou conjunto de dados deve inicialmente ser carregado em um registrador ou em uma memória interna dele, antes de ser processado, o que acarreta em um tempo maior de processamento, isso porque os DSPs, assim como os GPPs são inerentemente lentos, porque são baseados na clássica arquitetura de Von Neumann. (Pellerin, et al., 2005)

\subsection{Circuitos ASIC}

A tecnologia $A S I C$ atinge alto desempenho na resolução específica de problemas. São projetados para substituírem uma grande quantidade de lógica digital.

ASICs são projetados especificamente para executar uma dada tarefa computacional, por isso eles são extremamente rápidos.

\footnotetext{
${ }^{1}$ São sistemas complexos, capazes de executar operações de multiplicação, soma, deslocamento e acumular o resultado em pipeline, com a execução em média de uma operação por ciclo de relógio, em freqüências de até $370 \mathrm{MHz}$. (DSPBuilder)
} 
Porém, depois do circuito ser projetado, não poderá mais ser alterado, porque eles necessitam de um processo de fabricação especial, que requer máscaras específicas para cada projeto.

Em geral, eles provocam atrasos na introdução do produto no mercado, devido ao tempo consumido no seu desenvolvimento.

Características desse tipo de implementação são os custos de projeto extremamente altos e o tempo de desenvolvimento longo. Em aplicações que requerem um grande volume de produção, o alto custo do projeto e dos testes é amortizado. (Ribeiro, 2003)

\subsection{Computação Reconfigurável}

Os dispositivos mais utilizados atualmente para computação reconfigurável são os $F P$ GAs. As configurações deles são feitas pelo usuário final.

Os FPGAs foram projetados inicialmente para prototipação de circuitos. Apesar de não serem inicialmente projetados e recomendados para computação reconfigurável, devido ao seu custo e fácil acesso, foi e está sendo amplamente utilizado para implementar o paradigma de computação reconfigurável. (Aragão, 1998)

Os FPGAs combinam o desempenho do hardware dedicado com graus de flexibilidade alcançados nos softwares. Enquanto que os componentes de software estão limitados à arquitetura do microprocessador utilizado, a utilização de hardware reconfigurável permite ter arquiteturas adaptadas às aplicações. Essa característica pode ser verificada na Figura 2. Ao se comparar os ASICS com os GPPS, verifica-se que este oferece uma grande flexibilidade, porém, um baixo desempenho enquanto que aquele oferece um maior desempenho, porém, uma menor flexibilidade. (Romer, et al., 2000)

Segundo (Ribeiro, 2002); (Hauck, et al., 2006), os sistemas de computação reconfigurável são plataformas, nas quais a arquitetura pode ser modificada em tempo real, para meIhor se adequar à aplicação que será executada. Assim, o processador reconfigurável passa a trabalhar com uma arquitetura desenvolvida exclusivamente para aquele determinado tipo de aplicação, permitindo uma eficiência muito maior do que a normalmente encontrada em processadores de uso geral. Essa característica pode ser visto na Figura 3. 
Flexibilidade

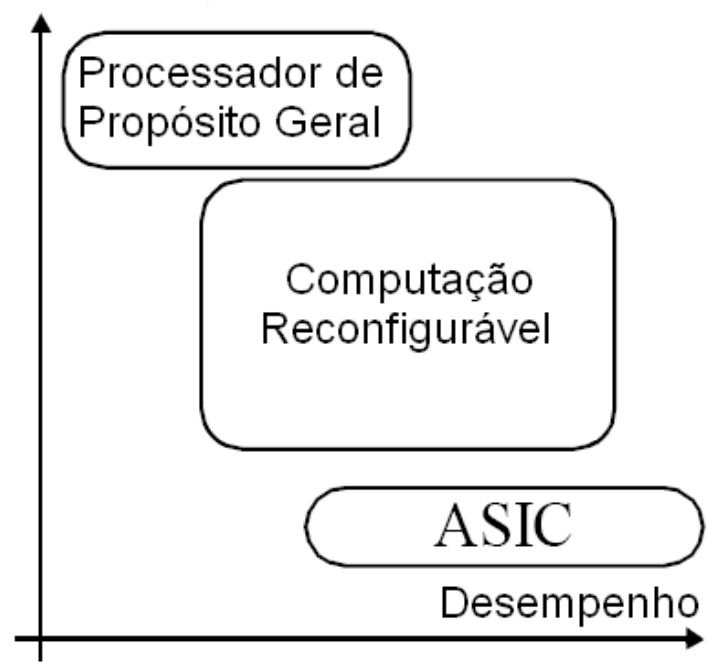

Figura 2. Flexibilidade versos desempenho dos sistemas programáveis

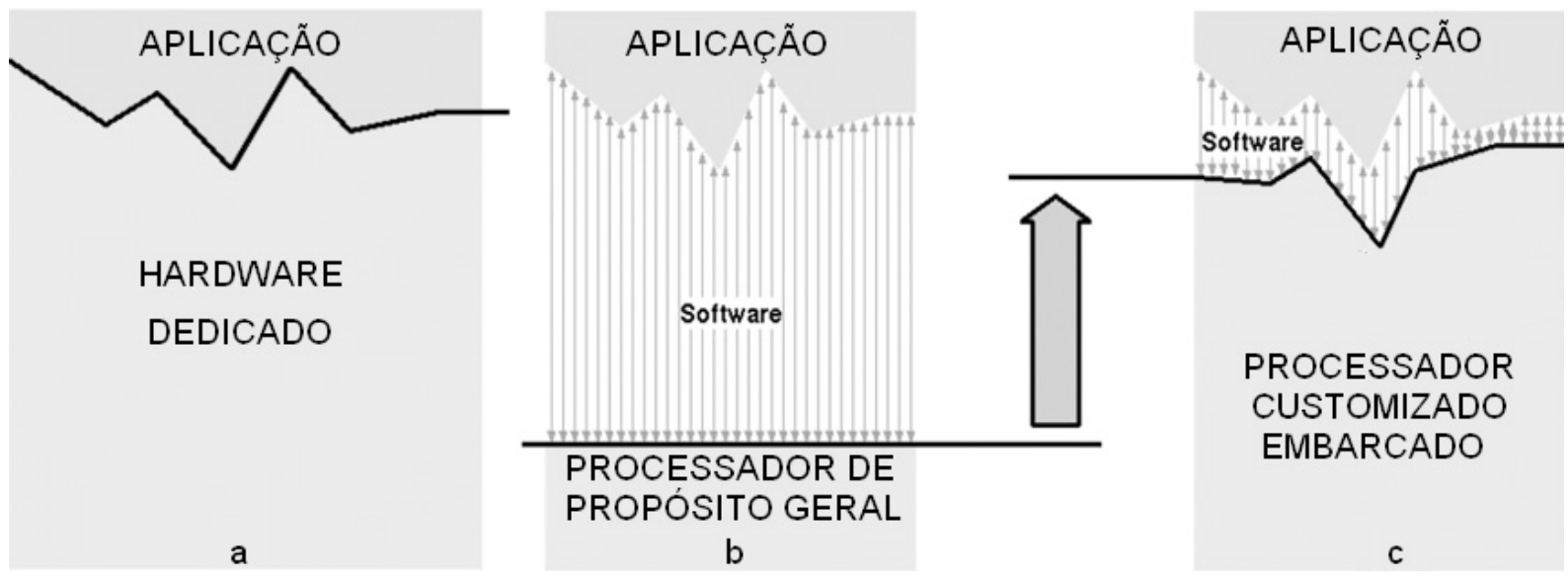

Figura 3. Benefícios da Computação Reconfigurável.

Na Figura 3, são mostrados três sistemas: o primeiro sistema, Figura 3-a, representa um ASIC; o segundo sistema, Figura 3-b representa um GPP e no terceiro sistema, Figura 3-c representa um processador customizado em um FPGA. O primeiro sistema é o que tem o maior desempenho, menor flexibilidade, menor gasto de energia, porém, longo time-tomarquet, além do fato de não puder ser mudado, tanto para atender outras aplicações quanto para futuras melhorias. O segundo sistema é o que possui menor desempenho dos três mostrados na Figura 3 e o que possui maior flexibilidade, porém, é o que possui menor time-to-marquet e as mudanças são facilmente aplicadas, bastando mudar os programas que executam nele. O terceiro sistema possui características importantes comparadas aos dos dois primeiros, ou seja, possui um grande desempenho, um time-to-marquet curto além de permitir alterações, mas ainda perde pelo consumo, apesar de já estar sendo superados pelos novos modelos 65mn FPGA. (Xilinx Inc., 2007) 
Conforme visto na Figura 3, observa-se que o primeiro sistema o hardware é modelado perfeitamente na aplicação. Esse fato possibilita que o hardware seja customizado para essa dada aplicação, ou seja, o processador desse hardware possui apenas as instruções que essa aplicação necessita, além dessas instruções serem otimizadas para o mesmo. O segundo sistema, pelo fato de possuir um processador de propósito geral, com muitas instruções para atender muitas aplicações, a camada de software necessária para esse hardware se adequar a aplicação pode ser grande e necessita de longo tempo de desenvolvimento. Esse fato contribui para o seu baixo desempenho. Já no terceiro sistema, um processador customizado pode ser programado para uma determinada aplicação, além de permitir futuras alterações em seu hardware.

Devido à possibilidade de reconfiguração dos circuitos, um FPGA pode operar como uma variedade de arquiteturas computacionais específicas. (Cappelatt, 2001)

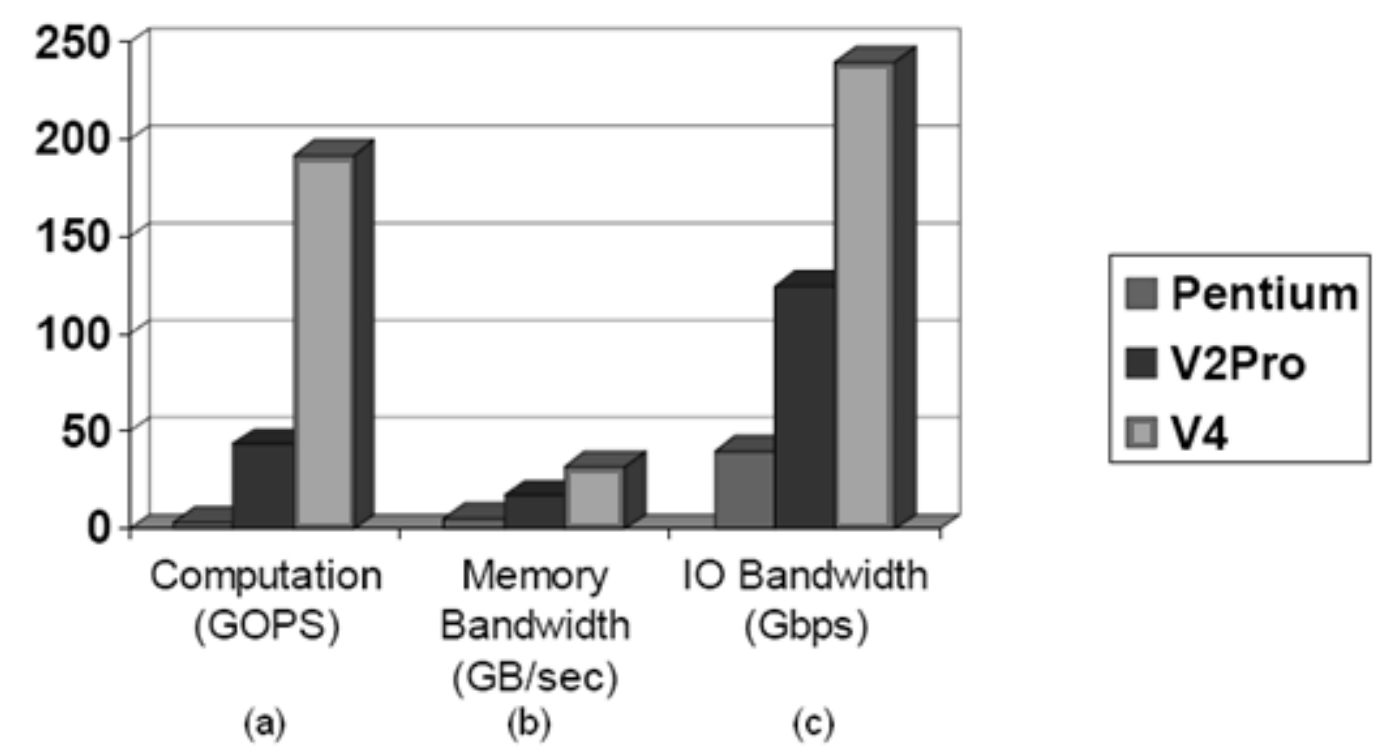

Figura 4. Comparação de desempenho entre computadores de alto desempenho (Bolsens, 2006)

Tabela 1. Comparação de desempenho entre Microprocessadores e FPGAs (Bolsens, 2006)

\begin{tabular}{|ccc|} 
& $\begin{array}{c}\text { Microprocessador } \\
\text { Itanium 2 }\end{array}$ & $\begin{array}{c}\text { FPGA Virtex } \\
\text { 2VP100 }\end{array}$ \\
\hline Velocidade de clock & $1.6 \mathrm{GHz}$ & $180 \mathrm{MHz}$ \\
Largura de banda (memória interna) & $102 \mathrm{GBytes} / \mathrm{seg}$ & $7.5 \mathrm{TBytes} / \mathrm{seg}$ \\
Unidades de processameto & $5 \mathrm{FPU}$ & $212 \mathrm{FPU}$ \\
Consumo de energia & $130 \mathrm{Watts}$ & $15 \mathrm{Watts}$ \\
Pico de desempenho & $8 \mathrm{GFLOPs}$ & $38 \mathrm{GFLOPs}$ \\
Desempenho normal & $\sim 2 \mathrm{GFLOPs}$ & $\sim 19 \mathrm{GFLOPs}$ \\
E/S / largura de banda (memória externa) & $6.4 \mathrm{GBytes} / \mathrm{seg}$ & $67 \mathrm{GBytes} / \mathrm{seg}$ \\
\hline
\end{tabular}

\footnotetext{
${ }^{2}$ Unidade de ponto flutuante, em inglês floating point unit
} 
Na Figura 4 é mostrado a comparação de desempenho entre o microprocessador Itanium 2 da Intel e os FPGAs Virtex-II Pro e Virtex-4 da Xilinx. (Bolsens, 2006)

A Figura 4-a mostra a comparação entre os três sistemas, com relação ao GOPS (gigaoperations per second). As Figuras 4-b e 4-c mostram a largura de banda de memória e a largura de banda de $E / S$, respectivamente dos três sistemas.

A Tabela 1 complementa as informações fornecidas pela Figura 4.

\subsection{Vantagens de implementações de algorit-}

\section{mos DSP em FPGA}

Os algoritmos que programam processamento de sinais podem ser implementados em processadores DSP ou FPGA, sendo o último a melhor alternativa. Sua principal característica é maior capacidade de processamento, superior ao dos DSPs, além do baixo custo de implementação quando comparados aos ASICs. (Duarte, 2006)

Enquanto o processador DSP, atualmente com maior poder de processamento tem implementado internamente seis MACs, nos FPGAs podem-se implementar o número de MACs desejado, limitando-se apenas aos recursos finitos dele, sendo que cada MAC ou conjunto de MACs podem ser usados para implementar partes do algoritmo seqüencialmente ou em paralelo. Por exemplo, o FPGA da Altera, família Stratix II, modelo EP2S180, com 180K LEs (Logic Element), disponibiliza 96 MACs de 36 bits, e estas MACs podem ser utilizadas como recurso de processamento. (Altera, 2006) Além da vantagem de possuir maior número de MACs que um processador DSP, os FPGAs atuais ainda contam com memória interna que pode ser utilizada em conjunto com as MACs permitindo assim a criação de módulos de processamento compostos por memória, lógica de controle e blocos de memória que armazenam blocos de dados de entrada e de saída. Isto permite reduzir em muito o tempo gasto por um processador DSP normal para ler os dados a serem processados e escrever os resultados na memória. (Duarte, 2006)

Ainda pelo fato do processamento nos FPGAs ser inerentemente paralelo, se a expressão 1 , descrita a seguir, for executada em um processador $D S P$, isso iria gerar um substancial número de operações e ciclos de clock para ser executado. 


$$
y=(a * b)+(c * d)+(e * f)+(g * h)
$$

Agora se essa mesma expressão fosse implementada em um FPGA, no qual todas as multiplicações são executadas em paralelo, sem a necessidade do ciclo de busca-decodificaexecuta instruções, apresentado no modelo Von Neumann, esse resultado teria um desempenho superior ao resultado do processador DSP. (Pellerin, et al., 2005)

No artigo (Duarte, 2006) é apresentado um exemplo de implementação de um filtro $F I R$, no qual é executa a expressão 2 abaixo em um conjunto de 16 números:

$$
\text { Dout }=\sum \mathrm{Di}{ }^{*} \mathrm{Ci}
$$

Na Expressão 2, Di representa os dados de entrada e Ci coeficientes. Para $i$ variando de 0 a 15, cada passo do loop necessita de pelo menos três outros passos, se a implementação fosse feita em um processador DSP: um passo para ler o dado da memória e armazenálo em um registrador, outro para ler o coeficiente da memória e armazená-lo em outro registrador e finalmente um terceiro passo para calcular o resultado intermediário e armazená-lo na MAC. (Duarte, 2006)

Se esse algoritmo fosse implementado em um FPGA, por outro lado, seria necessário apenas um único ciclo de clock, no qual o dado seria lido de um registrador de deslocamento, ao mesmo tempo em que o coeficiente seria lido da memória e o resultado seria armazenado na $M A C$, ou seja, seriam gastos no total 16 ciclos de clock para os 16 números processados. Se fosse paralelizado essa implementação com 16 MACs, o cálculo de uma nova saída do filtro gastaria apenas um ciclo de clock na implementação em FPGA, para os 16 números; contra os 48 ciclos de clock gastos para calcular o mesmo resultado em um processador DSP. (Duarte, 2006)

\subsection{Desvantagens de implementações de algo-}

\section{ritmos DSP em FPGA}

Embora o alto desempenho dos FPGAs comparados aos dos DSPs, a implementação de sistemas em FPGAs, comparados a implementação de algoritmos em processadores DSP tem suas desvantagens, entre elas: “o tempo de desenvolvimento para a implementação de algoritmos DSP em FPGA é, em geral, muito maior que a implementação do mesmo algoritmo 
DSP em processadores DSP; a complexidade da implementação de um algoritmo em FPGA é maior que a implementação do mesmo algoritmo em processadores DSP, por envolver além do fluxo de projeto normal do algoritmo, o fluxo de projeto de hardware em FPGA; existem disponíveis, de forma gratuita, muito mais projetos e programas referentes à implementação de algoritmos em DSP que modelos HDL que implementam esses algoritmos em FPGA; para processamento de algoritmos que envolvam baixa capacidade de processamento, por exemplo, para processamento de som para poucos canais ou de imagem de baixa resolução, a solução implementada em processadores DSP tem um custo menor que a mesma implementação em FPGA." (Duarte, 2006)

\subsection{Motivação}

Como discutido nos itens acima, embora os FPGAs sejam uma ótima alternativa para implementação dos algoritmos $D S P$, a utilização dos sistemas computacionais reconfiguráveis requer etapas morosas e complexas e conhecimentos específicos de projeto de hardware (Cardoso, et al., 2003)

Ainda, segundo (Cardoso, 2000), acredita-se que a comunidade de software tem o predomínio no desenvolvimento de sistemas eletrônicos digitais.

Enquanto não existir um suporte a implementação de sistemas reconfiguráveis a partir de algoritmos em alto nível, os programadores de software não se sentirão atraídos pelo desenvolvimento de aplicações neste modelo. Para tornar esse processo mais atrativo, seriam necessárias ferramentas que a partir de uma descrição de uma aplicação em uma linguagem de alto nível gerasse o código objeto para ser executado em um microprocessador embarcado e os arquivos de descrição de hardware necessários para programação em sistemas reconfiguráveis.

Para o projetista de hardware, essas ferramentas auxiliariam no desenvolvimento rápido desses algoritmos, evitando a conversão manual de algoritmos de software para hardware. Com o aumento da complexidade dos projetos, há uma necessidade de aumentar a abstração do mesmo. Com isso, o projetista pode concentrar-se nas especificações do projeto em detrimento aos detalhes de arquitetura do sistema. 
Ferramentas de compilação de software para hardware são alternativas para aumentar a abstração do projeto de sistemas. Essas ferramentas são capazes de gerar a descrição do hardware a partir de linguagens de alto nível, como $C$ ou $C++$.

Segundo (Cardoso, 2000), as ferramentas para geração automática de linguagens de descrição de hardware a partir de linguagens de alto nível têm sido desenvolvidas e ganham cada vez mais adeptos pelos seguintes fatores:

- Necessidade de aumentar os níveis de abstração, para que possam facilitar a especificação de sistemas cada vez mais complexos;

- Necessidade de proliferar o conceito de hardware reconfigurável a comunidades de software, devido à disparidade entre as semânticas dos modelos de computação;

- Reutilização de inúmeros algoritmos já implementados em linguagens com grande utilização, tal como linguagem $C$;

\subsection{Objetivos}

Esse trabalho teve como um dos objetivos estudar algumas ferramentas disponíveis no meio acadêmico e comercial para a conversão de linguagens de alto nível como $C, C++$ ou Java para linguagens de descrição de hardware, as HDLs.

A partir desses estudos, foram implementados três benchmarks em hardware/software codesign com a ajuda da ferramenta Impulse $C$, tendo como arquitetura alvo a placa de prototipação XUP V2P (Xilinx Universiry Program Virtex 2 Pro).

Finalmente ter o domínio dos conceitos na conversão de linguagens de alto nível para hardware reconfigurável, a conseqüente verificação dos mesmos na executacao da ferramenta Impulse $C$ na plataforma XUP V2P e geração de dados de desempenho a partir dos benchmarks conhecidos gerando assim uma avaliação de desempenho em compiladores para hardware reconfigurável.

\subsection{Organização do Trabalho}

No capítulo 2 é apresentada a evolução dos circuitos digitais, tendências futuras, tecnologias de fabricação dos circuitos digitais, as características de reconfigurabilidade dos 
FPGAs, tecnologias de fabricação e por fim a arquitetura interna dos blocos lógicos dos $F P$ GAs.

No capitulo 3 são discutidas as características do FPGA Virtex-Il e as ferramentas, ambos da Xilinx, utilizados nessa dissertação.

No capitulo 4 são apresentados as ferramentas automáticas de geração de arquivos de descrição de hardware a partir de linguagens de alto nível como C e Java.

No capítulo 5 são apresentados os programas benchmarks que foram utilizados para medidas de desempenhos dos resultados gerados pela ferramenta Impulse $C$, discutida no capitulo 4.

No capítulo 6 são apresentadas as diferentes possibilidades de implementrações dos benchmarks na placa de prototipação XUP V2P.

Finalmente no capítulo 7 são apresentadas as conclusões e trabalhos futuros. 


\section{Capítulo 2}

\section{Circuítos digitais e as técnologias dos FPGAs}

Nesse capítulo será mostrada a evolução dos circuitos digitais em números de transistores, a evolução dos dispositivos FPGAs e as tendências futuras.

\subsection{Circuitos digitais}

Os circuitos digitais têm sofrido grande evolução nas últimas décadas.

Os componentes dos circuitos digitais evoluíram de transistores individuais para circuitos integrados VLSI (Very Large Scale Integration). (Aragão, 1998)

Segundo (Ribeiro, 2003), os FPGAs têm evoluído significativamente, alcançando elevados níveis de densidade, altos índices de desempenho e menores custos de fabricação. Devido a essa evolução, é cada vez menor à distância entre FPGAs e Cls (Circuitos Integrados) customizados.

A Figura 5 mostra a evolução dos FPGAs da Xilinx em números de transistores. Segundo (Bolsens, 2006), os FPGAs da família Virtex-5 da Xilinx foram desenvolvidos utilizando-se a tecnologia de fabricação de transistores em camadas de silício na ordem de $65 \mathrm{~nm}$, o que significa mais de um bilhão de transistores na pastilha do FPGA. Ainda segundo (Bolsens, 2006), estima-se que no ano 2010 os FPGAs da Xilinx estejam utilizando camadas de silício na ordem de $32 \mathrm{~nm}$, o que significa mais de cinco bilhões de transistores na pastilha do FPGA. Esses novos processos de tecnologia proporcionam baixos custos e a meta para o ano de 2010 é atingir o custo de 2 dólares por Mgates (Milhões de portas lógicas). (Bolsens, 2006) 


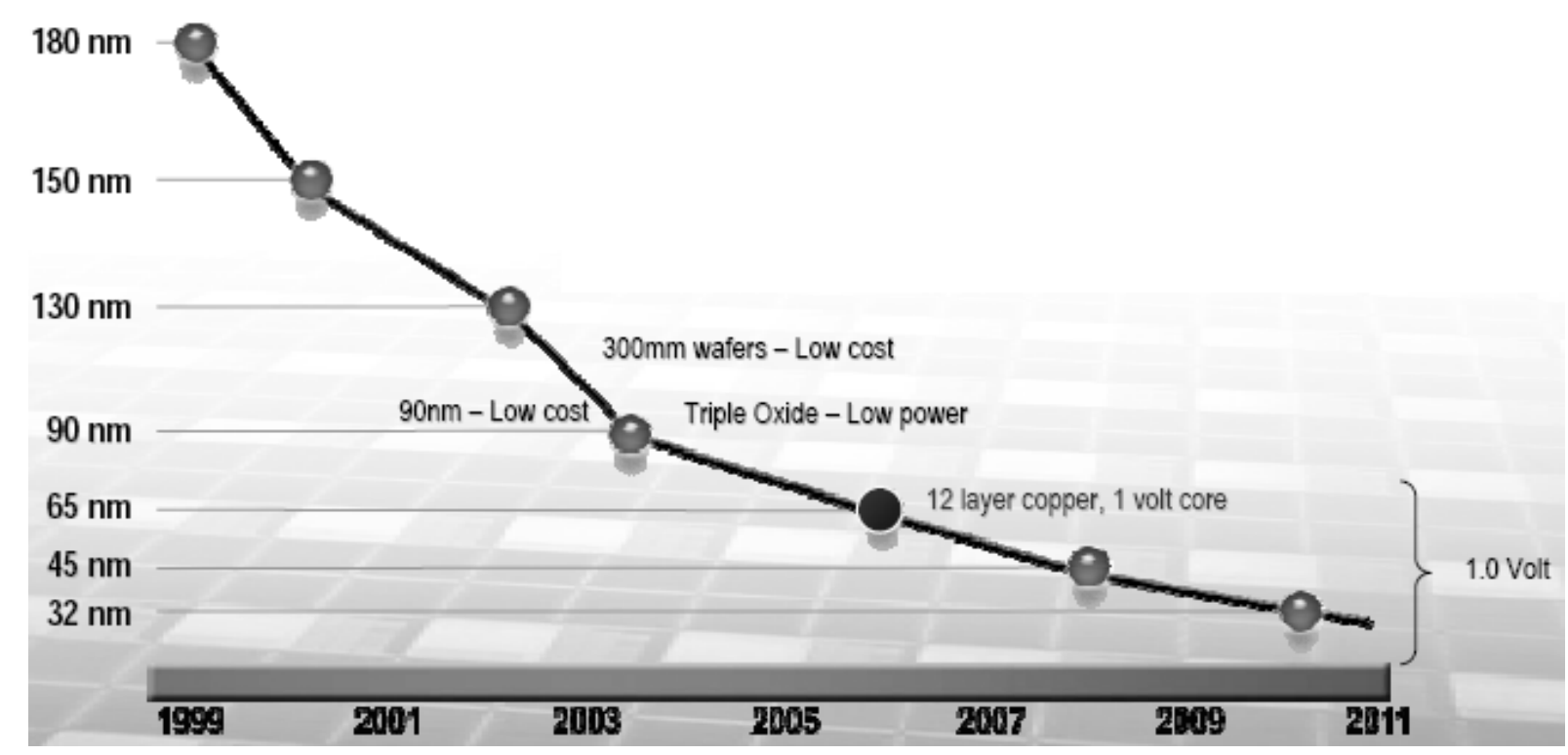

Figura 5. Evolução dos FPGAs em número de transistores. (Bolsens, 2006)

Os $\mathrm{Cl}$ s digitais podem ser construídos utilizando-se de diversas tecnologias diferentes, como mostra a Figura 6, a escolha da tecnologia adequada deve ser realizada com base no tipo de projeto que se pretende executar. (Ribeiro, 2003), (Ribeiro, 2002).

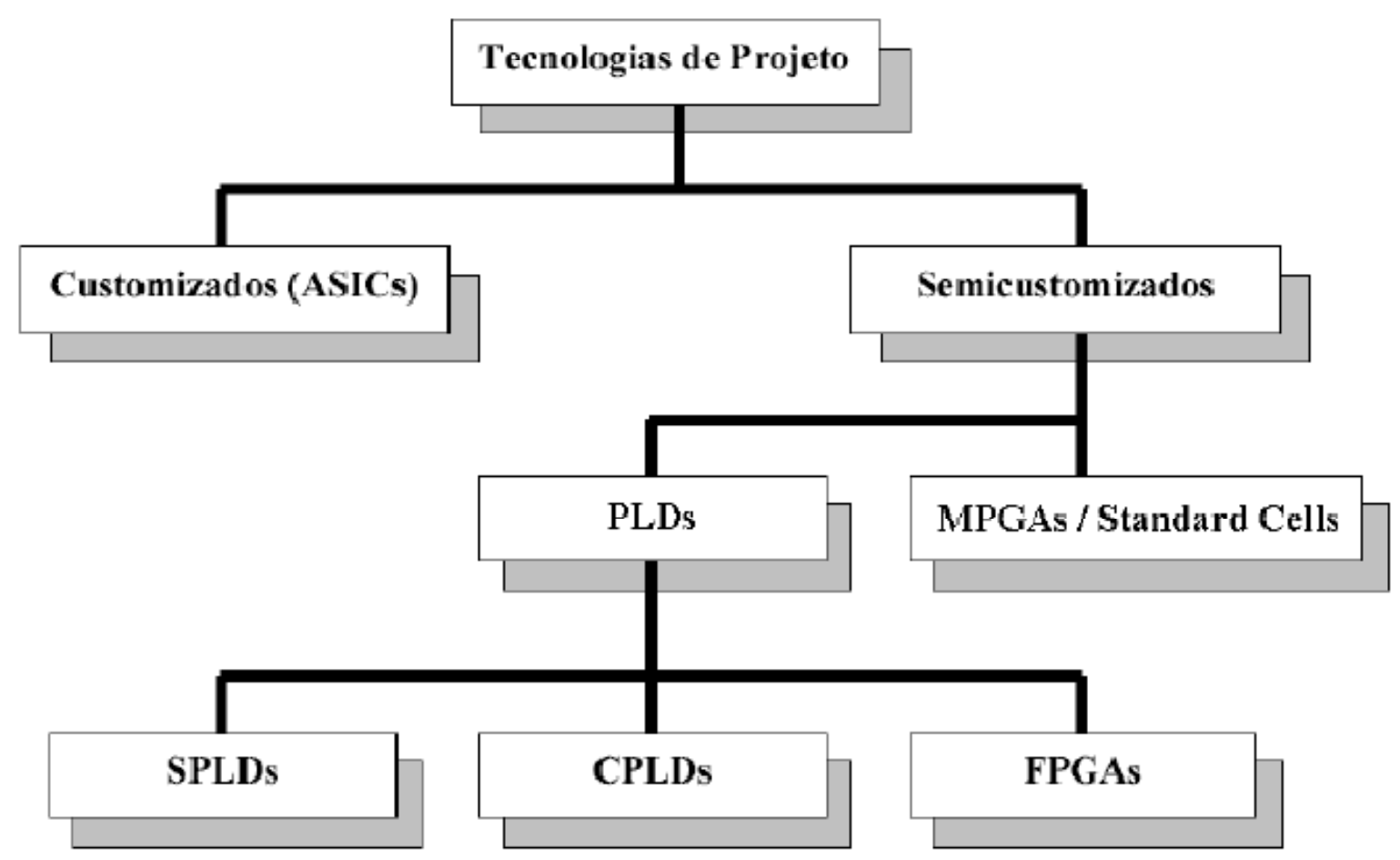

Figura 6. Tecnologias para Projetos de Sistemas Digitais.

A implementação de um sistema digital não é independente do estilo de projeto. Dependendo de fatores como tamanho, função, desempenho e custo, requeridos pelo projeto, os circuitos digitais podem ser construídos sob diferentes tecnologias. (Aragão, 1998). As 
tecnologias de implementação de circuitos digitais, conforme a Figura 6 (Ribeiro, 2002), podem ser agrupadas em dois grandes grupos: circuitos customizados ASICS e circuitos semicustomizados.

Os circuitos customizados são indicados para aplicações e sistemas que necessitam de grande desempenho, baixo consumo de energia. As características desse tipo de implementação são os custos de projeto extremamente altos e o tempo de desenvolvimento longo. Em aplicações que requerem um grande volume de produção, o alto custo do projeto e dos testes é amortizado;

Os circuitos semi-customizados, se dividem ainda em outras duas categorias: PLDs, MPGAs/Standard Cells:

Os MPGAs e Standard Cells foram agrupadas, devido suas semelhanças. Em comparação aos circuitos customizados, esses circuitos são menos eficientes em tamanho e desempenho, entretanto, seu custo de desenvolvimento é menor;

Os PLDs possuem como principal característica a capacidade de programação (configuração) pós-fabricação pelo usuário, facilitando assim as eventuais mudanças de projetos. Eles Possibilitam colocar muitas portas em um único circuito integrado e controlar eletronicamente a conexão entre elas. Em comparação com outras tecnologias, os PLDs apresentam ciclo de projeto muito curto com baixos custos de desenvolvimento.

Os PLDs se dividem em três categorias: SPLDs, CPLDs e FPGAs. (Ribeiro, 2002), (Aragão, 1998) e (Ribeiro, 2003).

Os SPLDs, em inglês (Simple Programmable Logic Devices) correspondem a categoria de todos os pequenos PLDs como PLAs, PALs. As características mais importantes dessa categoria é o baixo custo e alto desempenho.

Os CPLDs, em inglês (Complex Programmable Logic Devices) são constituídos de múltiplos SPLDs integrados em um único chip, apresentam interconexões programáveis para conectar os blocos SPLDs. Sua capacidade lógica é de até 50 SPLDs típicos.

Já os FPGAs são constituídos de um arranjo de elementos de circuitos não conectados: blocos lógicos e recursos de interconexão. A configuração é feita pelo usuário. A seguir são descritos detalhes do FPGA que foi a base do projeto aqui desenvolvido. 


\subsection{A tecnologia FPGA}

Um FPGA é um circuito integrado digital que contém uma estrutura regular de células configuráveis e de interligações programáveis pelo usuário, e que podem ser usados para construir sistemas digitais arbitrários, apenas limitados pelo número de células e ligações disponíveis. Os FPGAs podem ser personalizados como diferentes ASICs. (Cappelatt, 2001)

Equipamentos computacionais baseados em FPGAs são também denominados Máquinas Computacionais Especializadas. (Ribeiro, 2002)

Todos os dispositivos FPGAs são por definição programáveis, ou seja, configurável pelo menos uma única vez.

Os conceitos de reconfiguração estão relacionados com a possibilidade de reconfigurar-se o dispositivo muitas vezes ou constantemente se necessário.

Muitas aplicações emergentes em multimídia e processamento de imagens necessitam que suas funcionalidades permaneçam flexíveis mesmo depois que o sistema tenha sido manufaturado. Tal flexibilidade é fundamental, uma vez que os requisitos das aplicações e as características dos sistemas podem mudar durante a vida do produto. Essa flexibilidade propicia novas abordagens de projeto voltadas para ganhos de desempenho, redução dos custos do sistema e/ou redução do consumo geral de energia.

Os FPGAs fornecem um chip pré-fabricado e totalmente reprogramável por milhares de vezes, essa capacidade é sua maior característica. Na realidade, um mesmo chip poderia assumir arquiteturas e funções completamente diferentes, sem a necessidade de mudanças do mesmo, em função apenas da necessidade do usuário, dessa forma facilita as mudanças em projetos, o que possibilita um curto ciclo de projeto e conseqüentemente baixo custo.

Essas características garantem a atualização constante do produto com um mesmo estoque de Cls. Como nos processadores, FPGAs são programados após a fabricação para solucionar virtualmente qualquer tarefa computacional, isto é, qualquer tarefa que caiba nos recursos finitos do dispositivo. (Aragão, 1998)

Os FPGAs possuem desempenho menor e gastam mais energia comparados com os $A$ SICS. Utilizados em grande escala, os FPGAs também se tornam mais caros do que os ASICs. Mesmo assim, eles apresentam uma boa opção para o desenvolvimento de protótipos e para produção em pequena escala. 


\subsubsection{Arquitetura dos FPGAs}

Segundo (Ribeiro, 2002), a arquitetura básica de um FPGA, ilustrada na Figura 7, consiste de um arranjo 2-D de blocos lógicos. A comunicação entre blocos é feita através dos recursos de interconexão (interconexão programável). A borda externa do arranjo consiste de blocos especiais capazes de realizar operações de entrada e saída (blocos de $I / O$ ), esses blocos fazem a interface do FPGA com o mundo externo, em placas de prototipação, eles fazem a interface do FPGA com os demais recursos da placa, como por exemplo, memórias externas.

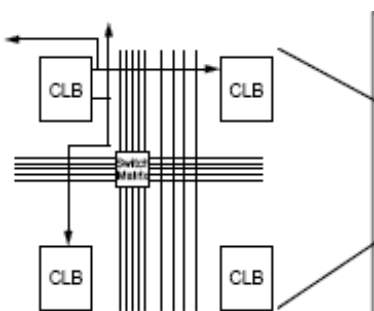

Interconexão Programável
부부부해배쑤래

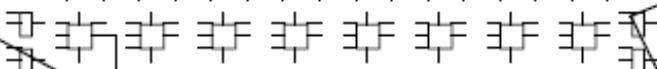

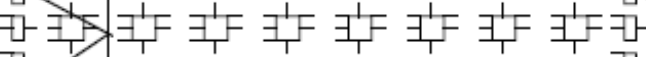
카

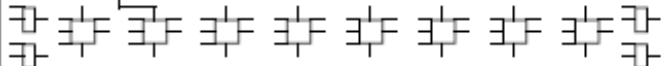
카 $\frac{1}{\exists_{1}} \exists_{1}^{1}$

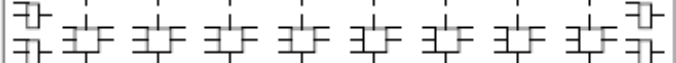

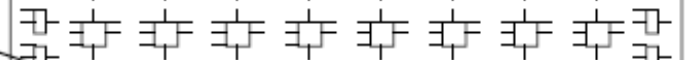

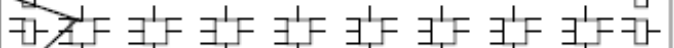
부부부부부루후부루라

\section{Blocos Lógicos}

Figura 7. Arquitetura de um FPGA XILINX, família 4000

A arquitetura de um FPGA está, basicamente, dividida em 3 partes:

Blocos Lógicos Configuráveis (Blocos lógicos): Um bloco lógico de um FPGA pode ser tão simples como um transistor ou tão complexo quanto um microprocessador. Ele é capaz de implementar várias funções lógicas combinacionais (tipicamente através de LUT - Look Up Table) ou seqüenciais (através de flip-flops). As funções lógicas são implementadas no interior dos Blocos Lógicos. Em algumas arquiteturas os Blocos Lógicos possuem recursos seqüenciais tais como flip-flop ou registradores. O fabricante Xilinx chama seu Bloco Lógico de CLB (Configurable Logic Block). Cada bloco lógico está conectado a um número determinado de matrizes de conexões programáveis, que, por sua vez, estão ligadas a um número de matrizes de chaveamento programáveis. Programando as conexões apropriadas, cada bloco pode fornecer uma variedade de funções lógicas combinacionais e/ou seqüenciais, ou seja, qualquer função lógica desejada. A Figura 8 ilustra um exemplo de um bloco lógico. Esse bloco 
lógico é composto por uma LUT de 4 entradas, um flip-flop, um latch e um multiplexador $2 \times 1$.

A LUT é uma memória do tipo SRAM, que implementa qualquer função booleana de até " $n$ " variáveis. O seu formato é $2^{n} \times 1$, ou seja, uma memória com $2^{n} \times 1$ posições, sendo " $n$ " o número de entradas. Essa memória é carregada com os valores dados pelo arquivo de configurações bitstream. Esse arquivo é gerado pelas ferramentas de síntese de FPGAs e é composto pelas funcionalidades implementadas pelo usuário nessas ferramentas. As entradas do LUT são entradas do bloco lógico e endereçam uma das $2^{n}$ posições de memória.

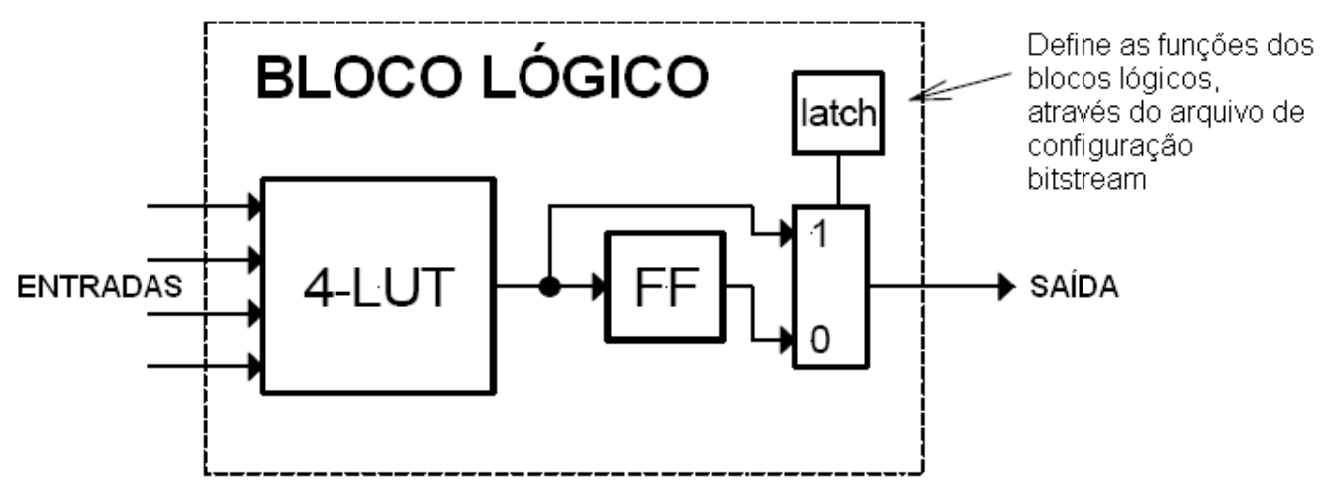

Figura 8. Representação de um bloco lógico

Um exemplo de uma LUT é ilustrada na Figura 9.

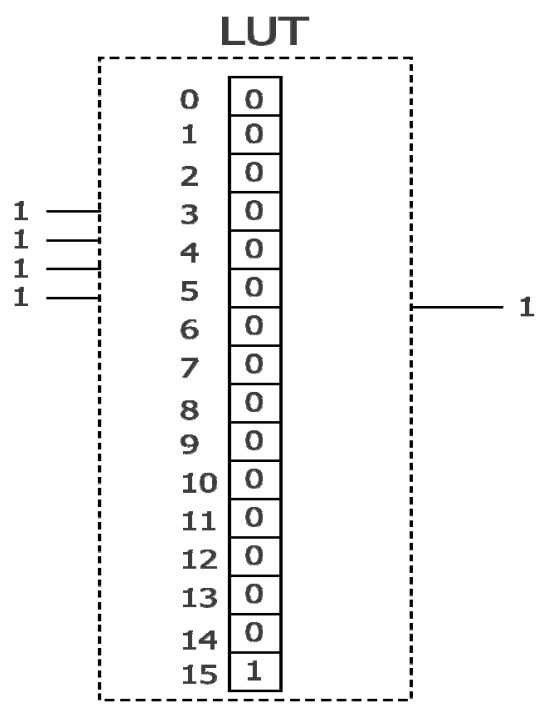

Figura 9. Exemplo de uma LUT

Essa LUT implementa uma função AND de 4 entradas. Quando as entradas endereçam o valor "1111", a saída é o valor "1", armazenada na posição 15 da memória. Qualquer outra combinação de entradas terá como saída o valor "0". (Plotkin, 2003)

Interconexões Programáveis (Programmable Interconnect): as matrizes de conexões programáveis são usadas para estabelecer ligações entre entradas e saídas dos blocos lógi- 
cos, enquanto as matrizes de chaveamento programáveis são empregadas para rotear os sinais entre as várias matrizes de conexões, conforme a Figura 10;

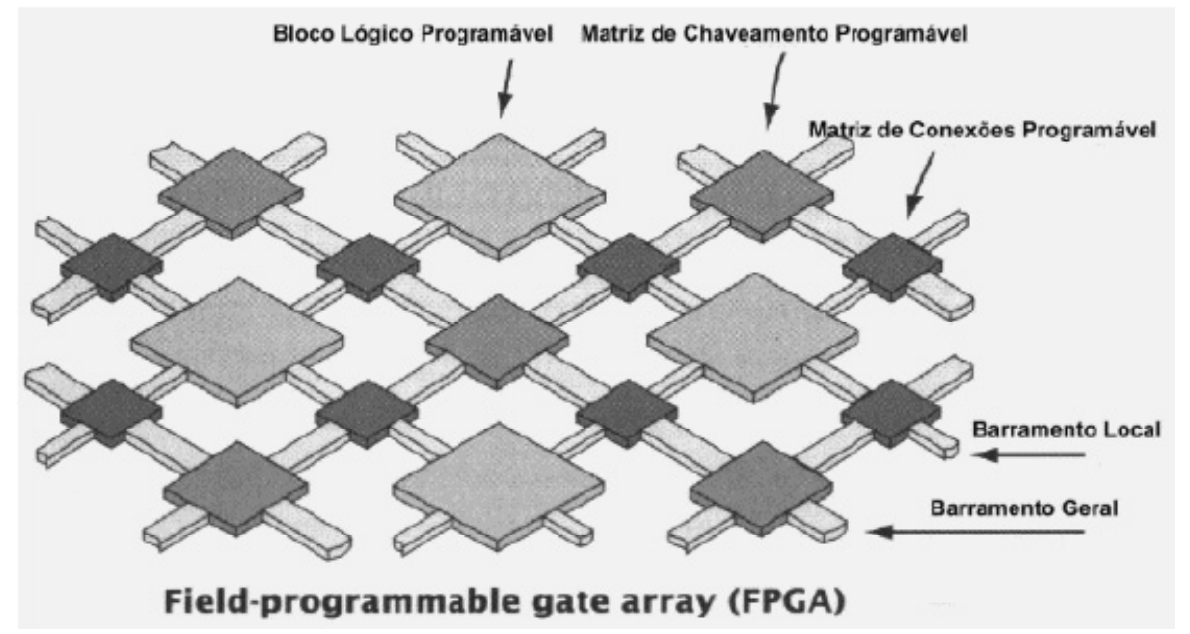

Figura 10. Conexões entre blocos lógicos

Blocos de Entrada/Saída Configuráveis (I/O Blocks): os FPGAs possuem componentes de entrada/saída chamados I/O Blocks, formados por estruturas bidirecionais que incluem buffer, flip-flop de entrada, buffer tri-state e flip-flop de saída. Ou seja, assim como os CLBs, cada pino de E/S do componente pode ser programado pelo usuário. Um FPGA pode dispor de dezenas a centenas de pinos programáveis.

Estes aspectos influenciam diretamente no desempenho e na densidade das diferentes arquiteturas de FPGAs, entretanto não se pode afirmar que há uma melhor arquitetura, e sim a mais adequada para uma determinada aplicação. (Ribeiro, 2002)

As famílias de FPGAs diferem principalmente nas formas de realizar a programação, nas formas de organização dos condutores de interconexão e no funcionamento dos blocos lógicos.

\subsubsection{Tecnologias de programação}

Um FPGA é programado usando comutadores programáveis eletricamente. As propriedades desses comutadores, tais como tamanho, resistência, capacitância, tecnologia, afetam principalmente o desempenho e definem características como volatilidade e capacidade de reprogramação, que devem ser avaliadas na fase inicial do projeto para a escolha do dispositivo. (Aragão, 1998), (Ribeiro, 2002), (Ribeiro, 2003) 
Em todos os tipos de FPGAs os comutadores programáveis ocupam uma grande área. O desempenho de um FPGA é menor do que o desempenho de um MPGA, devido os elevados valores de resistência e capacitância.

Existem basicamente três tipos de tecnologias de programação: Antifuse, Gate flutuante e SRAM. (Aragão, 1998)

Tecnologia Antifuse: O antifuse é um dispositivo de dois terminais, que no estado não programado apresenta uma alta impedância entre seus terminais. Quando aplicado uma tensão entre 11 e 20 Volts o antifuse "queima", criando uma conexão de baixa impedância, não permitindo reprogramações posteriores.

Entre as vantagens do antifuse está o seu tamanho reduzido.

A desvantagem está no espaço extra gasto para conseguir isolar os transistores no circuito de programação, já que eles trabalham com tensão de até $20 \mathrm{~V}$.

Tecnologia Gate Flutuante: Nesta tecnologia, os comutadores programáveis são baseados em transistores com gate flutuante iguais aos usados nas memórias PROM (Erasable) e EEPROM (Electrical Erasable PROM). A maior vantagem da tecnologia EPROM (Erasable PROM) é sua capacidade de reprogramação e a retenção dos dados. Os dados são gravados eletricamente. Nos circuitos baseados em EPROMs, os dados são apagados do chip fora da placa, quando submetidos à luz ultravioleta. Nos circuitos baseados em EEPROM, por outro lado, os dados são apagados eletricamente, ou seja, sem necessidade de remover o chip da placa ou aplicação de luz ultravioleta. Como desvantagem, o consumo de energia dos circuitos baseados em EPROM é alto e nos EEPROMs, cada célula ocupa o dobro de espaço de uma célula EPROM. (Ribeiro, 2002)

Tecnologia SRAM: A tecnologia de programação SRAM, utiliza células memória SRAM para controlar transistores de passagem ou multiplexadores. A SRAM apresenta duas grandes vantagens: é rapidamente reprogramável, comparada com a tecnologia EPROM ou EEPROM, requer apenas a tecnologia padrão de circuitos integrados para a sua fabricação (Ribeiro, 2002). Como desvantagem, a SRAM, ao contrário das duas tecnologias acima, é uma memória volátil, portanto perde sua configuração na ausência de eletricidade. Portanto, ela necessita de uma memória externa, como uma EPROM ou EEPROM para guardar suas configurações na ausência de eletricidade. Outra desvantagem é que essa tecnologia ocupa muito espaço no chip, pois para cada comutador estão associados pelo menos 6 transistores. 


\subsubsection{Arquitetura dos blocos lógicos}

Os FPGAs possuem uma grande variedade de tamanhos e com muitas combinações diferentes de características internas e externas. O que eles têm em comum é o fato de serem compostos por blocos lógicos configuráveis. Em um FPGA, a estrutura interna dos blocos lógicos, como por exemplo, LUTs, registradores, multiplexadores, podem ser replicadas miIhares de vezes para construir um grande dispositivo reconfigurável. (Pellerin, et al., 2005)

Em FPGAs mais complexos, esses blocos lógicos são combinados com lógicas digitais maiores, como lógicas aritméticas, estruturas de controles, tais como multiplicadores e contadores.

Com a finalidade de classificar os FPGAs quanto à capacidade lógica dos blocos lógicos, pode-se dividi-los em três categorias de granularidade: fina, media e grossa. (Ribeiro, 2003), (Ribeiro, 2002).

Cada bloco lógico pode ser simples como um LUT de três entradas ou complexo como uma Unidade Lógica e Aritmética de 4 bits. Essas diferenças entre os blocos podem ser referenciadas como granularidade do bloco lógico, no qual uma LUT de 3 entradas é um exemplo de um bloco lógico de granularidade fina e uma Unidade Lógica e Aritmética de 4 bits é um exemplo de bloco lógico de granularidade grossa. (Compton, et al., 2000)

Os blocos de granularidade fina são úteis para manipulações em nível de bits. Eles manipulam apenas 2 ou 3 valores de 1 bit. (Compton, et al., 2000).

O melhor exemplo para um bloco de granularidade fina seria um bloco contendo alguns transistores interconectáveis ou portas lógicas básicas. Para se implementar um somador, deve-se utilizar várias dessas células. (Cardoso, 2000). Como vantagem, esse tipo de bloco é quase totalmente utilizado, fornecendo um alto grau de funcionalidade com um número relativamente pequeno de transistores. A desvantagem principal é que por serem muito pequenos, eles tem baixa capacidade lógica, assim, podem ser requeridos muitos blocos lógicos em uma determinada aplicação, elevando a quantidade de trilhas de conexões e comutadores programáveis o que sobrecarrega o roteador. Um roteador desse tipo de FPGA se torna lento e ocupa grande área do chip. Assim, a tecnologia Antifuse é a mais adequada para a fabricação desse tipo de FPGA devido o seu tamanho reduzido. Um exemplo de um FPGA fabricado com essa granularidade é o FPGA XC6200 da Xilinx. (Ribeiro, 2002) 
Os blocos de granularidade media operam com 2 ou mais dados com 4 bits de tamanho. Isso aumenta o número total de linhas de entrada do circuito e prove estruturas computacionais mais eficientes para problemas computacionais mais complexos. Similares aos blocos lógicos com granularidade fina, porém, esses podem executar operações mais complexas com um grande número de entradas. Esses blocos podem implementar operações lógico-aritméticas. (Cardoso, 2000). Esse tipo de estrutura também pode ser usada para implementar operações mais complexas, tais como máquinas de estado finito. (Compton, et al., 2000).

Os FPGAs da família Virtex da Xilinx são exemplos de dispositivos de granularidade média. (Ribeiro, 2002)

Os blocos de granularidade grossa são úteis para aplicações que manipulam grandes quantidades de bits, porque o bloco lógico é otimizado para aplicações computacionais grandes, por isso eles executam as operações dessas aplicações muito rapidamente, consumindo menos área. Porém, devido a sua composição ser estática, eles são incapazes de ser otimizados para se adequar aos tamanhos dos operandos. Se, por exemplo, somadores, multiplicadores forem compostos por 16 bits e apenas valores de 1 bit forem processados, então o uso dessa arquitetura tem prejuízo, devido ao fato de todos os 16 bits serem computados e o gasto desnecessário de área e overhead. (Compton, et al., 2000)

Segundo (Cardoso, 2000) (Xilinx Inc., 1997), esses blocos são verdadeiros núcleos de processamento, que muitas vezes incorporam processadores e memórias acoplados a uma matriz de lógica reconfigurável com arquiteturas que podem ser blocos de granularidades finas e medias.

Os blocos de granularidade grossa requerem menos overhead de comunicação entre os processos no FPGA. Se cada processo mantiver sua memória local e tiver delineado uma tarefa para ser executada, então, a aplicação poderá ser facilmente particionada entre diferentes áreas do FPGA. Esse tipo de granularidade é útil para aplicações com algoritmos DSP. (Pellerin, et al., 2005). Os dispositivos de granularidade grossa podem possuir blocos lógicos que sejam unidades lógicas aritméticas (ULAs) e/ou pequenos microprocessadores e/ou memórias. (Ribeiro, 2002).

A Tabela 2 mostra algumas famílias de FPGAs dos dois maiores fabricantes do mundo, quanto a sua granularidade. (Ribeiro, 2003) 
Tabela 2. Capacidade lógica dos blocos lógicos

\begin{tabular}{|ccc|}
\hline Família & Fabricante & Granularidade \\
XC6200 & Xilinx & Fina \\
Virtex & Xilinx & Média \\
Virtex II & Xilinx & Média \\
Virtex II Pro & Xilinx & Média / Grossa \\
APEX 20K & Altera & Média \\
APEX 20K & Altera & Média \\
Stratix & Altera & Média / Grossa \\
\hline
\end{tabular}




\section{Capítulo 3}

\section{Plataforma de desenvolvimento}

Nesse capítulo serão mostradas algumas características dos FPGAs da família Virtex da Xilinx, seus processadores embarcados, tais como Microblaze e PowerPC, a plataforma de desenvolvimento XUP V2P e finalmente as ferramentas da Xilinx usadas para projetar sistemas reconfiguráveis no FPGA.

\subsection{Família VIRTEX-II Pro da Xilinx}

A família de dispositivos de FPGAs da empresa Xilinx (Xilinx, Inc, 2007), para grande desempenho e densidade, é a Virtex e o seu lançamento foi no ano de 1998.

Das famílias de FPGA Virtex existente, como Virtex, Virtex-E, Virtex-E Extended Memory, Virtex-II, Virtex-II Pro, Virtex-4, Virtex-5, apenas a Virtex-II Pro será abordada nesse trabalho, porque os resultados apresentados nessa dissertação foram gerados pelo FPGA XC2VP30 dessa família de FPGA.

A família Virtex-Il Pro faz parte da quarta geração de dispositivos do grupo Virtex (Bonato, 2004) e é fabricada com a tecnologia de SRAM.

Essa família possui arquitetura híbrida de granularidade média com alguns elementos de granularidade grossa. (Ribeiro, 2002)

Conforme a Tabela 3, essa família pode variar de 11.088 a 125.136 células lógicas, de 1 a 4 processadores RISC PowerPC da IBM (hard core) e 44 a 556 multiplicadores de 18x18 bits.

Os FPGAs da família Virtex-Il Pro possuem processador embutido, como parte do hardware do FPGA. Conforme o FPGA dessa família, o número de processadores pode variar. 
Além disso, os FPGAs dessa família possuem blocos de multiplicadores de 18x18 bits, presentes em hardware e são utilizados para operacoes DSP.

Tabela 3. Características dos FPGAs da família Virtex-II Pro da Xilinx

\begin{tabular}{|cccccc|}
\hline Família & FPGA & $\begin{array}{c}\text { Células } \\
\text { Lógicas }\end{array}$ & $\begin{array}{c}\text { BRAM } \\
\text { (Kbits) }\end{array}$ & $\begin{array}{c}\text { Processadores } \\
\text { PowerPC }\end{array}$ & $\begin{array}{c}\text { Multiplicadores } \\
\mathbf{1 8 x 1 8} \text { Bits }\end{array}$ \\
\hline \multirow{5}{*}{ Virtex-II Pro } & XC2VP7 & 11.088 & 792 & 1 & 44 \\
& XC2VP20 & 20.880 & 1.584 & 2 & 88 \\
& XC2VP30 & 30.816 & 2.448 & 2 & 136 \\
& XC2VP40 & 43.632 & 3.456 & 2 & 192 \\
& XC2VP50 & 53.136 & 4.176 & 2 & 232 \\
& XC2VP70 & 74.448 & 5.904 & 2 & 328 \\
& XC2VP100 & 99.216 & 7.992 & 2 & 444 \\
& XC2VP125 & 125.136 & 10.008 & 4 & 556 \\
\hline
\end{tabular}

Como ilustra na Figura 11, o Virtex-II Pro possui dois processadores PowerPC, CLBs, Select I/O, Rocket I/O, DCMs, SelectRAM.

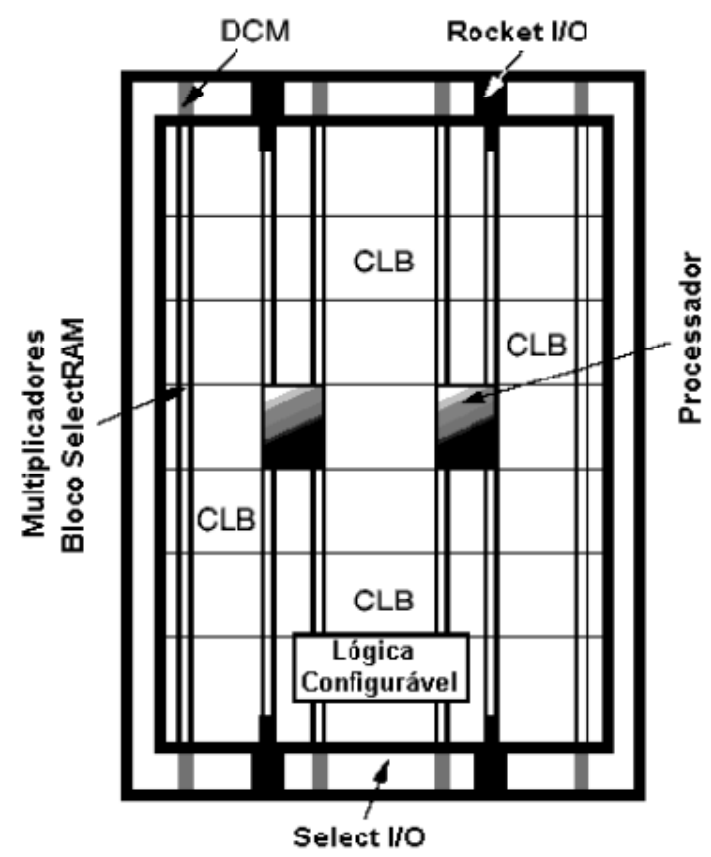

Figura 11. Arquitetura da Virtex-II Pro (Xilinx, 2005)

Cada CLB contém quatro slices e dois buffers tri-state, conforme descrito na Figura 12.

Cada slice contém: 2 geradores de funções $F$ e $G$, dois elementos de armazenamento, portas lógicas aritméticas, multiplexadores, entre outros. Os geradores de funções $F$ e $G$ podem ser configurados como LUTs de 4 entradas, registradores de 16 bits ou SelectRAM de 16 bits, um exemplo de slice é dado na Figura 13. 


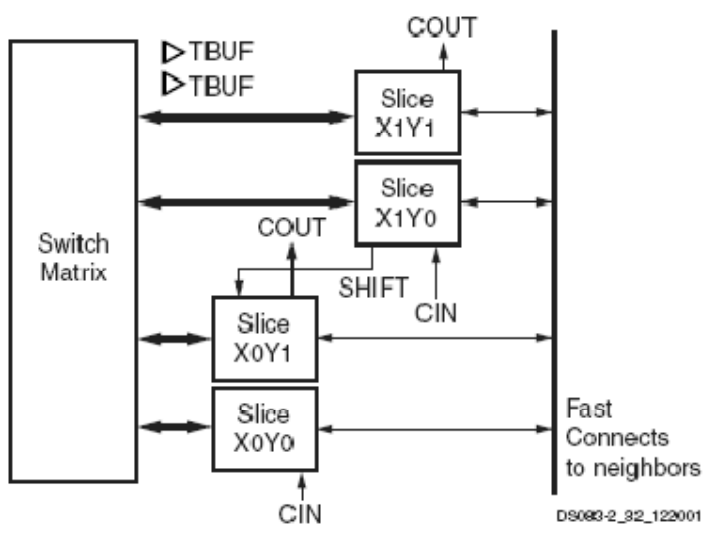

Figura 12. Bloco de CLB da Virtex-II Pro (Xilinx, 2005)

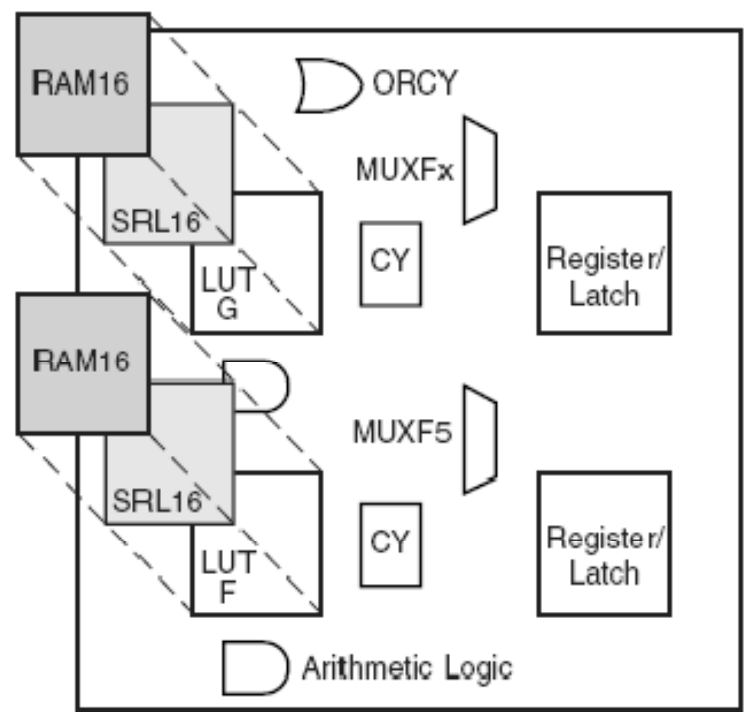

Figura 13. Slice da Virtex-II Pro (Xilinx, 2005)

Os blocos de SelectRAM, na Figura 11 são blocos de memória RAM que permitem armazenamento de $18 \mathrm{kbits}$, distribuídos em colunas por todo o FPGA. Além de blocos multiplicadores de 18x18 bits. Blocos de SlectRAM e recursos de multiplicação são conectados a quatro matrizes de interconexões para acessar os recursos de roteamento global, como mostra a Figura 14.

Os blocos de multiplicação podem ser associados com um bloco SelectRAM ou pode ser utilizado independentemente. Interconexões permitem que os blocos de memória SelectRAM e blocos de multiplicadores $18 \times 18$ bits sejam utilizados ao mesmo tempo. 0 uso da SelectRAM e dos multiplicadores, juntamente com um acumulador em uma LUT permite a implementação de um MAC (Xilinx, 2005) 


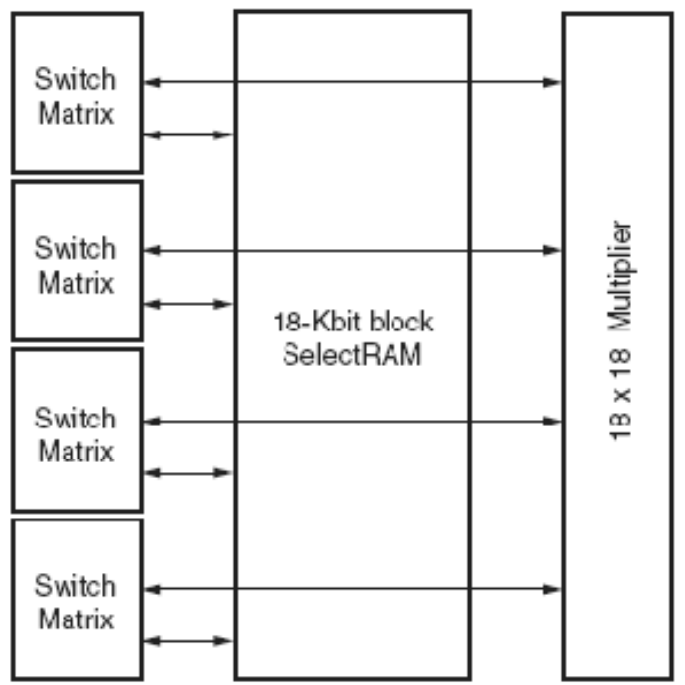

Figura 14. Blocos de SelectRAM e Multiplicadores (Xilinx, 2005)

Os blocos DCMs (Digital Clock Manager), na Figura 11, fornecem atrasos do clock global, para blocos que necessitam de valores menores de clock.

Os blocos de Rocket $I / O$, também mostrado na Figura 11, implementam um conversor paralelo-serial e vice-versa, que junto aos blocos IOBs proporcionam comunicação do FPGA com dispositivos externos.

O processador PowerPC, implementado nos FPGAs da família Virtex-II Pro, tem a arquitetura harvard, na qual possui barramentos separados para instruções e dados. Esse processador possui 32 bits, cinco estágios de pipeline, unidade de multiplicação e divisão. Ele trabaIha no máximo a $300 \mathrm{MHz}$ e possui cachê de instruções e dados.

Na Figura 15 é ilustrada a arquitetura do processador PowerPC. Como esse processador é embutido no FPGA, ele não usa recursos reconfiguráveis do mesmo. Embora esse processador esteja presente fisicamente no FPGA, há necessidade de lógica programável para implementar os periféricos, tais como o controlador da memória SDRAM, ethernet, UART. (Szewinski, et al., 2005)

Até quatro processadores PowerPC podem estar em uma única FPGA. Ele é cercado de $C L B s$, blocos de RAMs e recursos de roteamento geral. O PowerPC trabalha com operações de 32 bits em ponto-fixo. Operações de 64 bits e operações de ponto flutuante podem ser emuladas em software. 


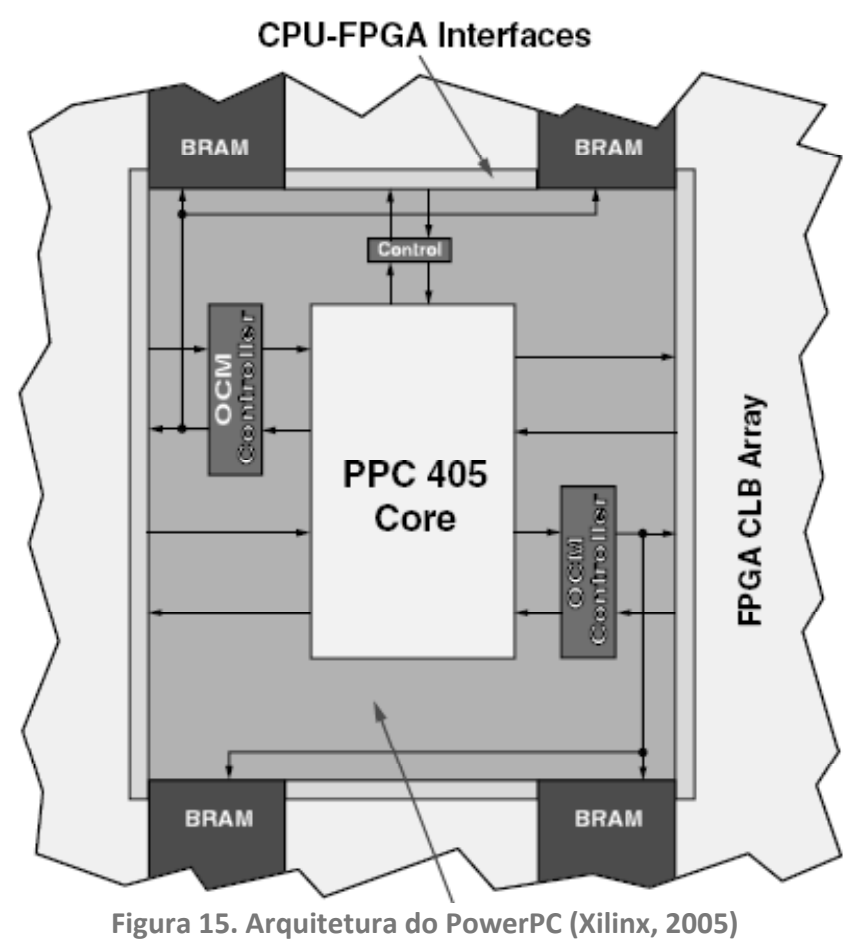

O controlador OCM (On-Chip Memory) serve como interface dedicada entre os blocos RAMs nos FPGAs e os sinais OCM disponíveis no core do PowerPC.

Existem algumas arquiteturas de barramento, de domínio público, para guiar os fabricantes de cores, que podem ser projetados com muitas e diferentes interfaces e protocolos de comunicação. Entre essas arquiteturas de barramentos está o CoreConnect da IBM que é vinculada a arquitetura do processador PowerPC. Segundo (Palma, et al., 2002), (Mesquita, 2002), a arquitetura CoreConnect da IBM fornece três barramentos para interconectar cores e lógica personalizável:

Barramento Local do processador PLB (Processor Local Bus) é usado para interconectar cores com alto desempenho, grande largura de banda, tais como o PowerPC, controladores $D M A$ e interfaces de memória externa.

Barramento Periférico (OPB - On-Chip Peripheral Bus) é usado para interconectar periféricos que trabalham com baixas taxas de dados, tais como portas seriais, portas paralelas, UARTs (Universal Assynchronous Receiver Transmiter), e outros cores com pequena largura de banda. Esses periféricos são conectados nesse barramento, reduzindo o tráfego no barramento $P L B$, o que aumenta o desempenho global do sistema.

Barramento de Controle de Registros de Dispositivos (DCR - Device Control Register Bus) é usado para passar configuração e informações de estado entre um core processador e outros cores. 
O princípio de funcionamento do CoreConnect, segundo (Mesquita, 2002), baseia-se em um árbitro, que decide qual core vai fazer acesso o barramento.

Além do hardware core do processador PowerPC, as famílias Spartan e Virtex contam com um software core do processador Microblaze.

O processador Microblaze é um software core RISC de 32 bits. Sua versão 4.0 possui uma FPU (Unidade de Ponto Flutuante). Essa FPU trás maior performance a operações de ponto flutuante.

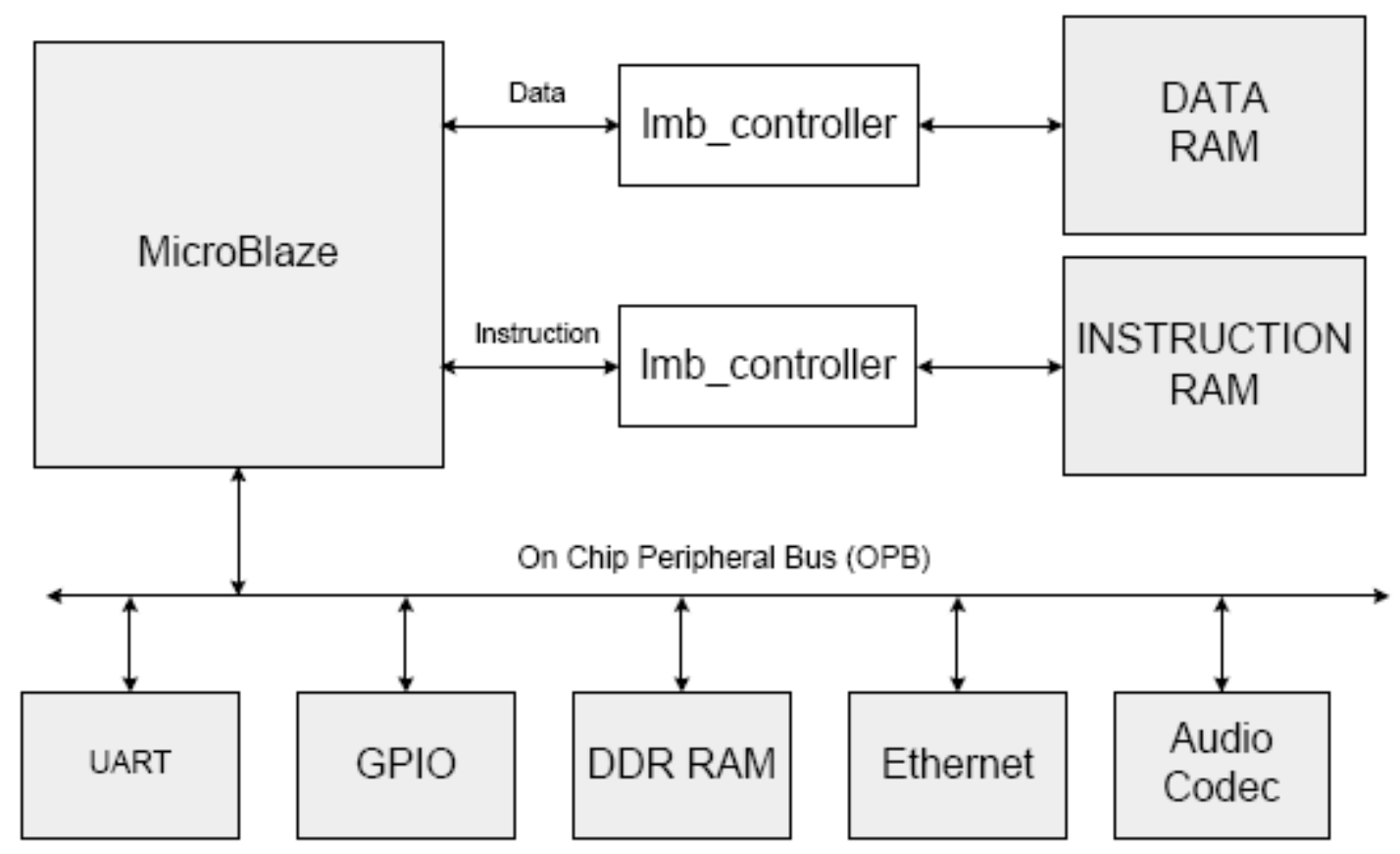

Figura 16. Arquitetura do Microblaze (Xilinx, 2006)

A Figura 16 mostra a arquitetura do Microblaze. O Microblaze é um processador configurável, permite ao usuário selecionar um grupo de características úteis ao projeto. A arquitetura do Microblaze é harvard.

Como características, esse processador possui:

- 32 bits de instruções, com três operandos e três modos de endereçamento;

- 32 bits de instruções e dados com barramentos separados;

- 32 bits de barramento de endereço;

- 3 estágio de pipeline para a versão 4 e 5 estágios de pipeline para a versão 5 do processador.

Além dessas características físicas, o processador é parametrizado, ou seja, permite habilitar funcionalidades adicionais. 
São suportados três barramentos: LMB (Local Memory Bus), OPB (On-Chip Peripheral Bus) e XCL (Xilinx CacheLink). LMB é um barramento síncrono, usado primariamente para acesso a blocos de RAM on-chip. Há dois barramentos $L M B$ usados para conectar instruções e dados na memória. O tamanho da memória bem como o número de periféricos utilizados no projeto é definido pelo usuário. (Calderón, et al., 2005)

O barramento $O P B$ é um barramento síncrono de propósito geral, projetado para conectar periféricos on-chip. As principais características do barramento $O P B$ são:

- Barramento de 32 ou 64 bits de dados;

- Até 64 bits de endereço;

- Suporta 8, 16, 32, 64 bits escravo;

- Suporta 32 ou 64 bits mestre;

- Um único ciclo de transferência entre $O P B$ mestre e $O P B$ escravo, entre outras.

O barramento CacheLink é usada com controladores especializados de memória externa. (Xilinx, 2006)

\subsection{Plataforma de desenvolvimento XUP V2P}

O FPGA utilizado nesse trabalho é o XC2VP30 da família Virtex-Il Pro da Xilinx. A plataforma de desenvolvimento é a placa XUP-V2P da Digilent (Xilinx, 2007), Figura 17.

As características dessa placa de prototipação são:

- FPGA XC2VP30 Virtex-II Pro da Xilinx, já discutido nos itens anteriores;

- Slot para até $2 G B$ de memória DDR SDRAM;

- Compact Flash para armazenamento de dados e armazenamento da configuração do $F P G A$.

- Porta USB para entrada de configuração do FPGA.

- Ethernet 10/100;

- Porta serial RS-232 com conector DB9;

- 2 portas PS-2;

- 4 LEDs conectados ao FPGA, 4 switchs, 5 push buttons;

- Codificador AC-97 de áudio, com entrada de microfone e saída de áudio;

- Saída de Vídeo XSGA com 1200x1600 pixels e $70 \mathrm{~Hz}$ de refresh; 
- 3 portas serial SATA;

- $100 \mathrm{MHz}$ de clock.

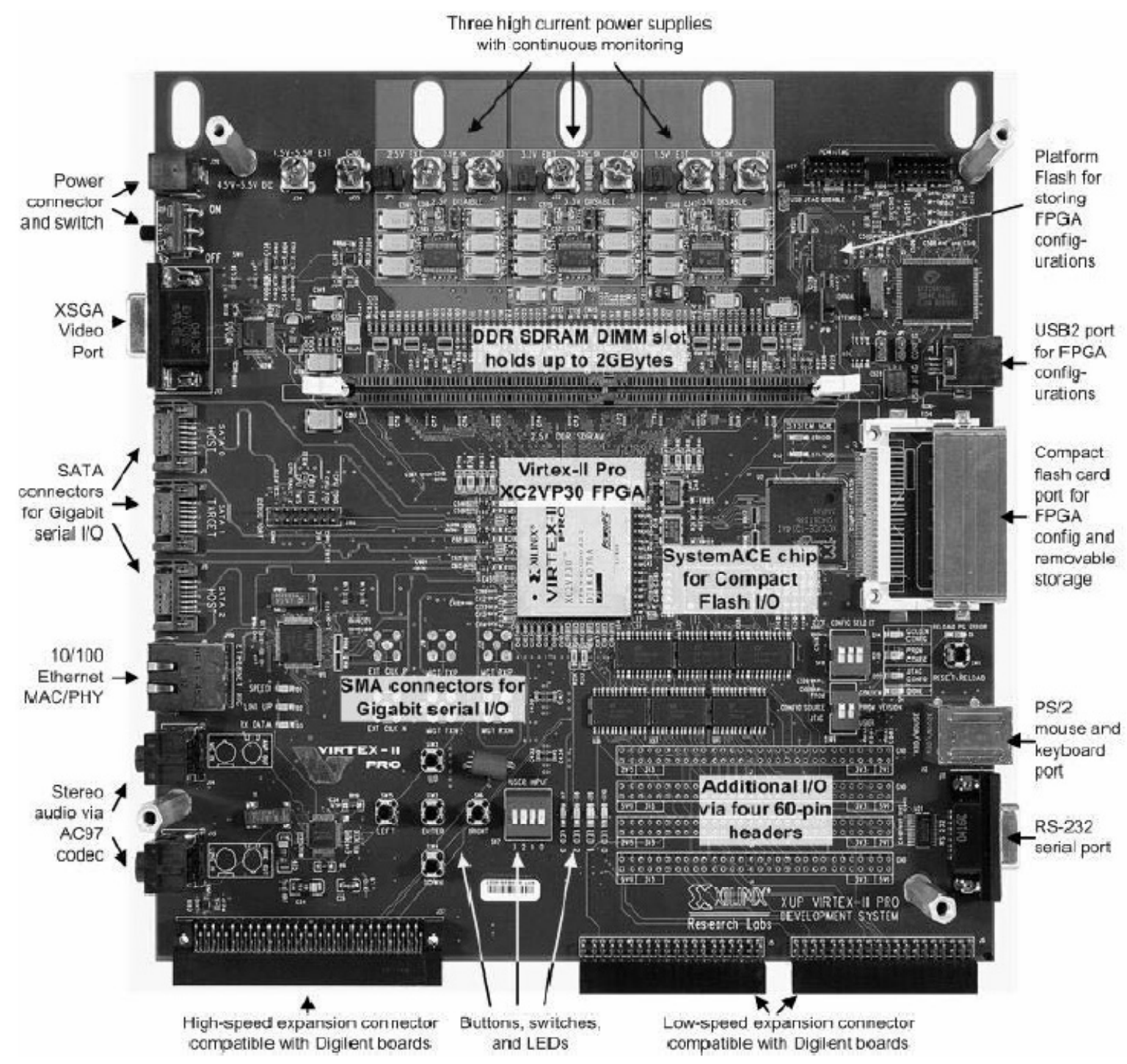

Figura 17. Placa de desenvolvimento XUP V2P da Digilent

A Figura 18 mostra o diagrama dos dispositivos da placa conectados no FPGA.

A placa de desenvolvimento XUP V2P provê uma avançada plataforma para desenvolvimento de hardware. Ela consiste de um FPGA interconectado com vários periféricos, como mostra a Figura 18, que podem ser usados para implementar um sistema complexo, ao mesmo tempo em que demonstra a capacidade do dispositivo FPGA Virtex-Il Pro. (Xilinx, 2007)

A XUP V2P oferece um ambiente de prototipação FPSoC (Field Programmable System on Chip). Hoje, SoC (System-on-chip) e FPSoC incorporam varias combinações de sistemas computacionais, tais como ASIC, memórias, processadores customizados ou reconfiguráveis, lógica programável tal como FPGA ou CPLD. (Chappell, et al., 2002) 


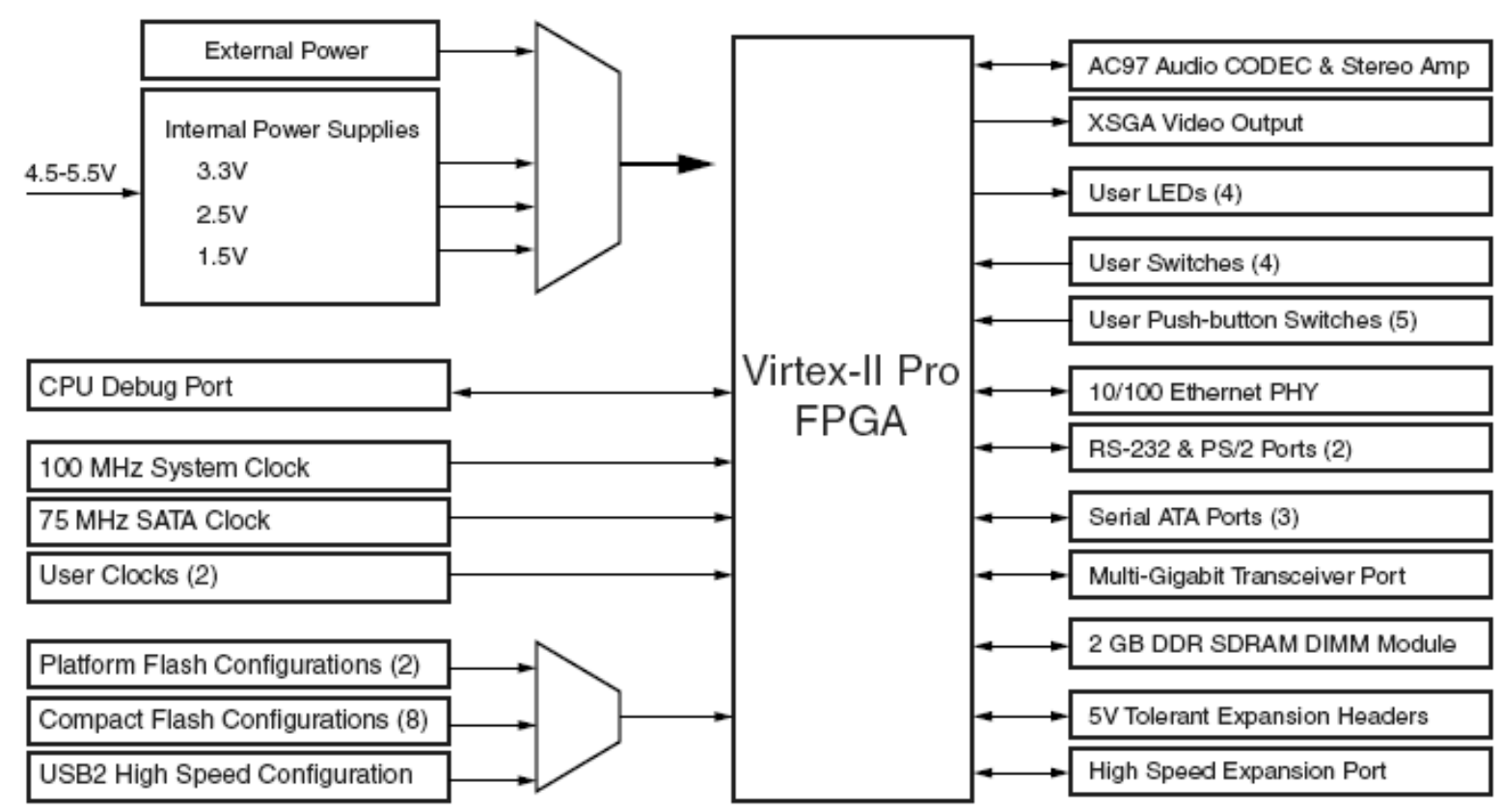

Figura 18. Diagrama da placa de desenvolvimento XUP V2P

O propósito dessa placa, juntamente com suas ferramentas EDA (Electronic Design Automation) de desenvolvimento, é fornecer uma estrutura para acelerar o desenvolvimento de sistemas embarcados em chips, conhecidos como SOPC (System-On-a-Programable-Chip).

Na próxima seção serão mostradas algumas ferramentas da Xilinx para desenvolver sistemas nessa placa.

\subsection{Ferramentas EDA da Xilinx}

FPSOC incluem processadores embutidos (hard ou soft), barramentos, memória embutidas e podem incluir outros periféricos. Porém, para implementar esse complexo sistema em um FPGA, é necessário o conhecimento de ferramentas e linguagens de descrição de hardware.

\subsubsection{ISE}

O ISE (Integrated Software Environment) é um ambiente integrado que permite projetar sistemas reconfiguráveis nos FPGAs da Xilinx. (Xilinx, 2007)

Os passos para se projetar sistemas reconfiguráveis na ferramenta ISE, resumidamente são: 
Entrada de projeto: a entrada de projeto é o primeiro passo no fluxo de projeto ISE. Nessa fase o projeto será modelado para atender aos requisitos de hardware necessários ao usuário. O projeto pode ser escrito através de HDL (Hardware Description Language), tais como VHDL, Verilog ou ABEL. Outra forma de se modelar o projeto é através do diagrama esquemático, dessa forma, o projeto não é descrito através de uma linguagem, mas desenhado a nível de portas lógicas, megafunções (megafunctions), linhas e barramentos. Além disso o projetista também pode combinar HDL e o diagrama esquemático para descrição de hardware.

Síntese: depois de modelar o projeto, o próximo passo é a síntese. Nesse passo, a descrição em $H D L$ ou esquemático feito na fase acima é gerado um arquivo netlist, que é a entrada para o passo de implementação. $O$ arquivo netlist descreve as varias portas lógicas do projeto e as suas interconexões.

Implementação: na fase de implementação, o projeto lógico (arquivo netlist) é mapeado com as portas lógicas e interconexões reais do FPGA escolhido pelo usuário. Depois da fase de implementação, um arquivo é gerado: o bitstream. Esse arquivo é carregado no $F P$ GA e contém as funcionalidades implementadas pelo usuário.

Simulação: a simulação serve para o usuário verificar se o seu projeto está funcionando corretamente, além de permitir ao usuário aperfeiçoar-lo, por exemplo, reescrevendo o código VHDL para diminuir os atrasos entre os sinais do seu projeto.

A Figura 19 resume os passos necessários ao ISE para a geração do arquivo bitstream e download na placa.

As fases para implementar sistemas em hardware permitem otimização lógica, mapeamento, posicionamento e roteamento. Elas possibilitam ao projetista se concentrar nas especificações do projeto e trabalhar em alto nível, ou seja, o projetista não precisa saber com detalhes como configurar cada bit do FPGA.

Segundo (Aragão, 1998), a captura de esquemático não é o modo ideal para projeto de grandes circuitos, e é uma tarefa muito tediosa quando se projeta grandes blocos regulares repetidamente. À medida que os projetos ficam mais complexos, as descrições em nível de portas tornam-se inviáveis, fazendo com que seja necessário descrever os projetos em modos mais abstratos.

As linguagens de descrição de hardware (HDLs) foram desenvolvidas para auxiliar os projetistas a documentarem projetos e simularem grandes sistemas, principalmente em pro- 
jetos de $A S I C$, mas também são adequadas para projetos em outras tecnologias, como os FPGAs. Muitos engenheiros ainda usam esquemáticos para descrição de projetos e sentemse desconfortáveis com a mudança para linguagens de alto nível devido à falta de conhecimentos de conceitos de programação concorrente. Porém, com o crescente aumento da complexidade dos projetos, essa transição parece ser inevitável. Projetos com mais de 8000 portas são inviáveis utilizando-se apenas esquemáticos.
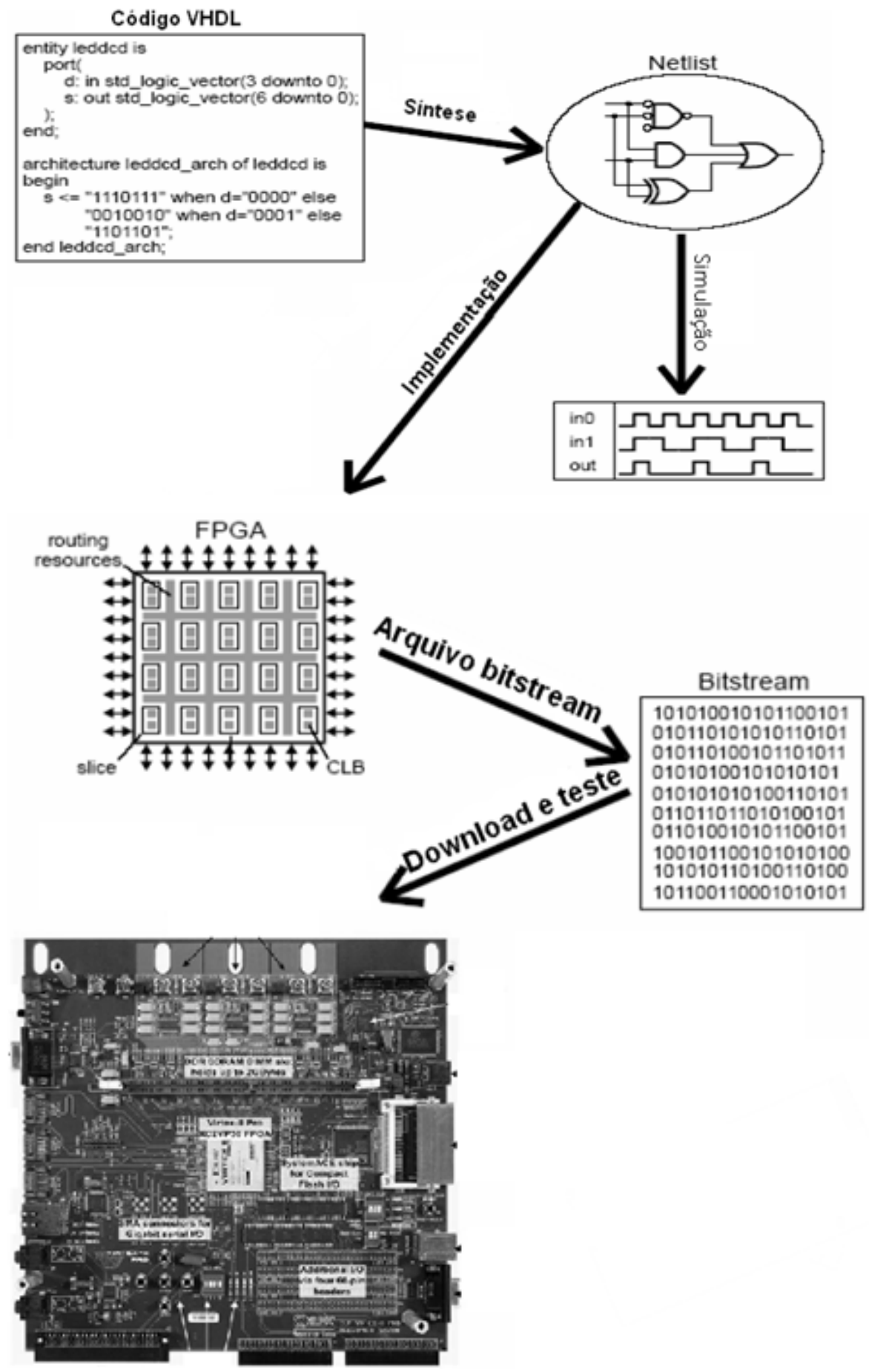

Figura 19. Fluxo de criação de um projeto em FPGA 


\subsubsection{EDK}

Resumidamente, o EDK (Embedded Development Kit) possibilita configurar os processadores PowerPC e Microblaze no FPGA, além dos periféricos, tais como memória embutida e os periféricos da placa de prototipação. (Xilinx, 2007)

O EDK suporta várias placas de prototipação com FPGAs da Xilinx, assim reconhece os periféricos em torno do FPGA na placa.

O EDK inclui o XPS (Xilinx Platform Studio), e inclui ferramenta visual GUI (Graphical User Interface) e outras ferramentas que possibilitam configurar os processadores PowerPC e Microblaze, além de compilar programas em $C$ para eles. Além disso são disponíveis IP cores, tais como processadores e periféricos.

O SDK (Software Development Kit) faz parte da ferramenta EDK e é baseado no Eclipse, o qual pode ser utilizado opcionalmente para desenvolver aplicações embutidas de software para os processadores PowerPC e Microblaze.

O XPS depende do ISE para sintetizar os processadores no FPGA, ou seja, mapea-los para o FPGA escolhido pelo usuário, gerando o arquivo bitstream para ser descarregado no nele.

Se o projeto do usuário consistir apenas de um processador no FPGA, então, o usuário usará apenas o XPS para desenvolver o projeto. O XPS se encarregará de usar as ferramentas de síntese e as demais ferramentas necessárias do ISE para gerar o arquivo bitstream.

O projeto do usuário pode combinar processador embutido com outras lógicas customizadas feitas por ele. Assim, após definido as configurações do processador e demais periféricos, o XPS preparará o ISE para que o usuário faça a sua lógica customizada, permitindo o usuário combiná-los.

A Figura 20 mostra um diagrama de fluxo de projeto utilizando-se das ferramentas ISE e $E D K$, bem como a integração entre elas, a fim de combinar uma lógica customizada com processadores embarcados. (Xilinx, 2007) 


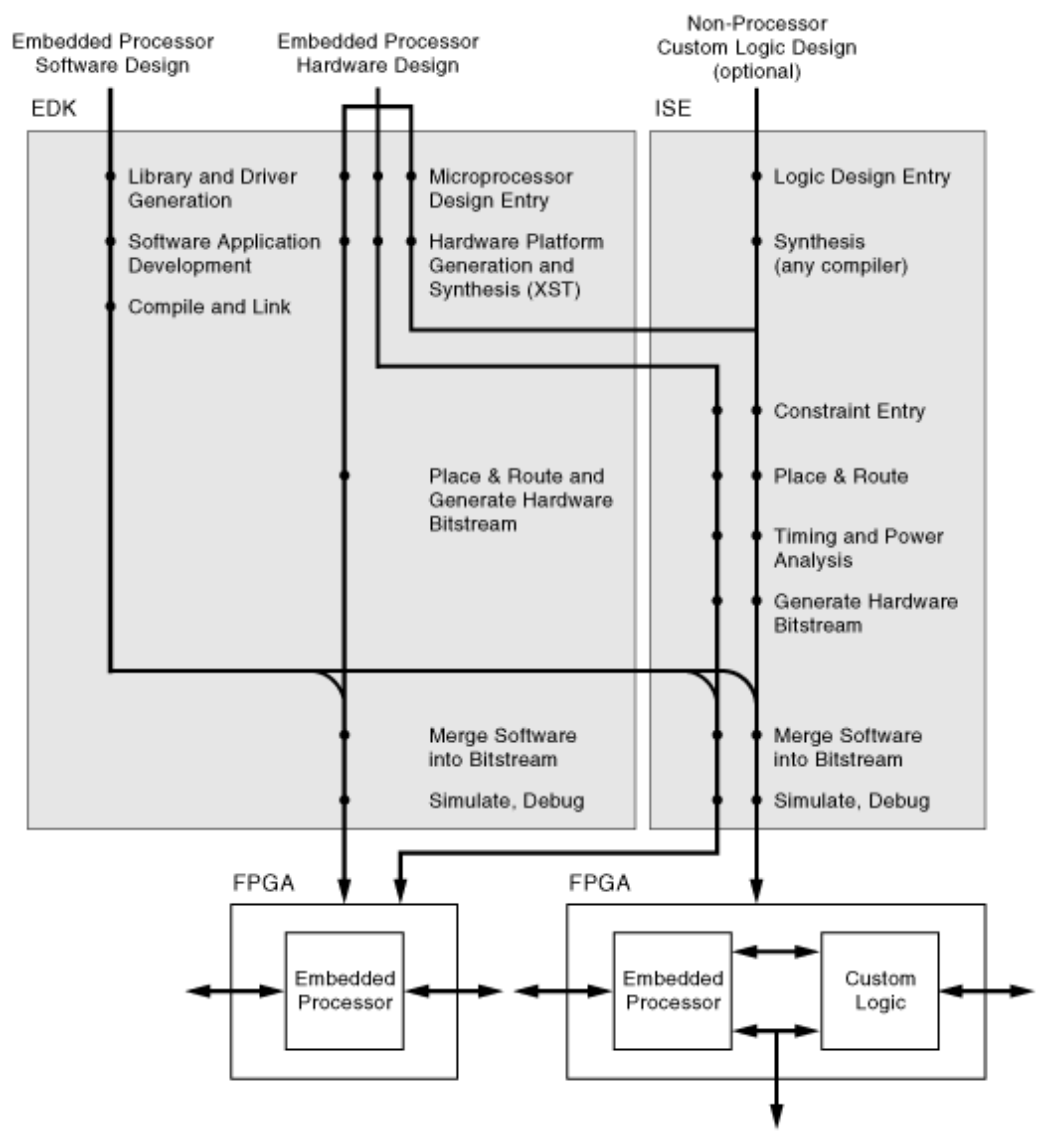

Figura 20. Fluxo de desenvolvimento de projetos em FPGA com ISE e EDK

Projetar um sistema nesse método exige um conhecimento profundo sobre a utilizacao da placa de prototipação, nos detalhes dos processadores, nos detalhes de funcionamento de linguagens $H D L$, nas ferramentas de prototipação e síntese. 


\section{Capítulo 4}

\section{Ferramentas de programação $C$ para plataformas FPGA}

Ferramentas já disponíveis, como o ISE (Xilinx, 2007) e EDK (Xilinx, 2007), permitem implementar, testar, simular e corrigir projetos eletrônicos computacionais com grande facilidade sem que se tenham gastos elevados como no desenvolvimento de ASICs. É possível simular a funcionalidade do projeto antes de produzi-lo, evitando assim desperdícios de recursos.

Hoje, é possível desenvolver rapidamente um projeto de sistema digital empregandose novas metodologias como linguagens de descrição de hardware, as $H D L s$, ferramentas de síntese lógica e simulação.

Não é mais necessário desenhar portas lógicas individuais e montar diferentes componentes. As linguagens de descrição de hardware estão se consolidando como forma padrão de descrição de projetos.

Ferramentas de síntese lógica automática estão disponíveis para mapear circuitos em diversas tecnologias. Além das mudanças na tecnologia, o ciclo de vida dos produtos modernos está tornando-se mais curto que os tradicionais ciclos de projeto, exigindo uma rápida prototipação.

Apesar de novas arquiteturas terem sido propostas e novos conceitos apresentados (Radunovic, et al., 1998), a utilização dos sistemas computacionais reconfiguráveis requer etapas morosas e complexas e conhecimentos específicos de projeto de hardware (Cardoso, et al., 2003). 
Esse capítulo destina-se a investigar algumas ferramentas comerciais e acadêmicas, disponíveis para conversão de algoritmos escritos em linguagens de alto nível, $\operatorname{como} C, C++$ e Java para linguagens de descrição de hardware.

Serão apresentadas algumas ferramentas, funcionalidades e objetivos.

Será dada maior destaque a ferramenta CoDeveloper da empresa Impulse $C$, devido a cooperação da empresa em tirar dúvidas relacionadas a descrição de algoritmos utilizados no CoDeveloper, por ter disponibilizado o CoDeveloper na forma de trial e ainda pelo autor dessa dissertação ter tido acesso a livros e tutoriais sobre essa ferramenta, coisa que não aconteceu, por exemplo, com a ferramenta DK Design Suit da Celoxica.

\subsection{Introdução a ferramentas de programação}

\section{$C$ para plataformas FPGA}

Muitas aplicações embutidas, geralmente aplicações científicas, de processamento de imagens, entre outras, são escritas em linguagem $C$ e são executadas por processadores $D S P$. Quando detectado gargalos nessas aplicações, os trechos de código mais críticos são escritos em linguagem assembler, aumentando assim o desempenho da aplicação.

Há casos em que a aplicação exige tempo crítico para executar, por exemplo, aplicações de processamento de imagens de tempo real, a solução então, é reescrever essa aplicação ou parte dela em linguagem de descrição em hardware e implementar essa aplicação em um $\mathrm{Cl}$, por exemplo, um $F P G A$.

O problema é que para reescrever essa aplicação em linguagem de descrição de hardware exige-se o conhecimento específico para tal finalidade, além do conhecimento exigido em ferramentas EDA para prototipação em FPGA, como dito acima. A utilização dos sistemas computacionais reconfiguráveis requer etapas morosas e complexas e conhecimentos específicos de projeto de hardware (Cardoso, 2000).

As ferramentas de programação $C$ para plataformas FPGA podem ajudar na diminuição do tempo para reescrever esses códigos em linguagem $C$ para $H D L s$, além do tempo, elas diminuem também os custos do projeto, já que não há necessidade de se contratar uma equipe ou empresa especializada em projetos de hardware. 
Os projetistas de software, com a ajuda dessas ferramentas, poderão ver os FPGAs como apenas mais um sistema programável, por exemplo, um processador. (Pellerin, et al., 2005)

As HDLs oferecem ao projetista de hardware o controle explícito e preciso sobre o hardware gerado. Porém, esse controle explícito sobre a geração de hardware nem sempre é necessário. Do mesmo modo que um programa é escrito em linguagem $C$ e somente depois são reescritos em assembler os trechos que causam gargalo no sistema, um sistema poderia ser escrito em linguagem HDL utilizando ferramentas automáticas e depois ser reescritos por um projetista de hardware os trechos que causassem gargalo, caso fosse necessário. (Pellerin, et al., 2005)

De qualquer forma, essas ferramentas permitem ao projetista de hardware explorar o espaço do projeto, por exemplo, movendo porções do código para a parte reconfigurável do FPGA ou para um processador embarcado, tal como PowerPC. Isso permite ao projetista fazer protótipos e explorar a melhor alternativa de implementação do sistema na plataforma FPSOC.

Para a computação reconfigurável ser adotada como um paradigma de computação é necessário o desenvolvimento de ferramentas que acelerem o desenvolvimento de hardware e que eleve o nível de abstração necessário ao projeto.

\subsection{Pico Express}

Pico Express é comercializado pela empresa Synfora, fundada em Janeiro de 2003. (Synfora, 2007)

Segundo o fabricante, a ferramenta possibilita a geração automática de arquiteturas otimizadas e sintetizáveis RTL (Register Transfer Level) a partir de algoritmos escritos em linguagem $A N S I-C$, e combina $I P^{3}$ configuráveis que são projetados para uma implementação eficiente de algoritmos complexos.

O Pico Express consegue a partir de um algoritmo produzir múltiplos projetos com diferentes características, tais como custo e desempenho. Um exemplo pode ser visto na Figura 21.

\footnotetext{
${ }^{3}$ Um IP (intellectual property) é bloco lógico pré-fabricado, sintetizado e testado que pode ser utilizado na construção de projetos de sistemas em FPGA.
} 
Um algoritmo $M P E G^{4}$ pode ser implementado de um modo para um $D V D^{5}$ player e de outro modo para uma câmera de vídeo. O algoritmo é o mesmo, porém, a característica da arquitetura muda. (Synfora, 2007)

A ferramenta tem como entrada um algoritmo em linguagem $C$ e um arquivo de restrições sobre custo de área e tempo de ciclos, definidos pelo usuário; explora o paralelismo em vários níveis do algoritmo para criar um grupo de alternativas de implementação com diferentes graus de paralelismo. Cada grupo de implementações geradas tem uma característica diferente, em relação à área, desempenho e energia consumida pelo hardware gerado, implementações são construídas com a ajuda dos IPs configuráveis. Após isso, o programa determina a área e o desempenho de cada implementação e permite ao usuário decidir qual a melhor implementação para o seu sistema. Com isso, ao usuário é oferecido algumas alternativa de implementações, cada uma tendo a melhor área de implementação e desempenho. Essas alternativas de implementações ficam em uma lista de possíveis implementações.

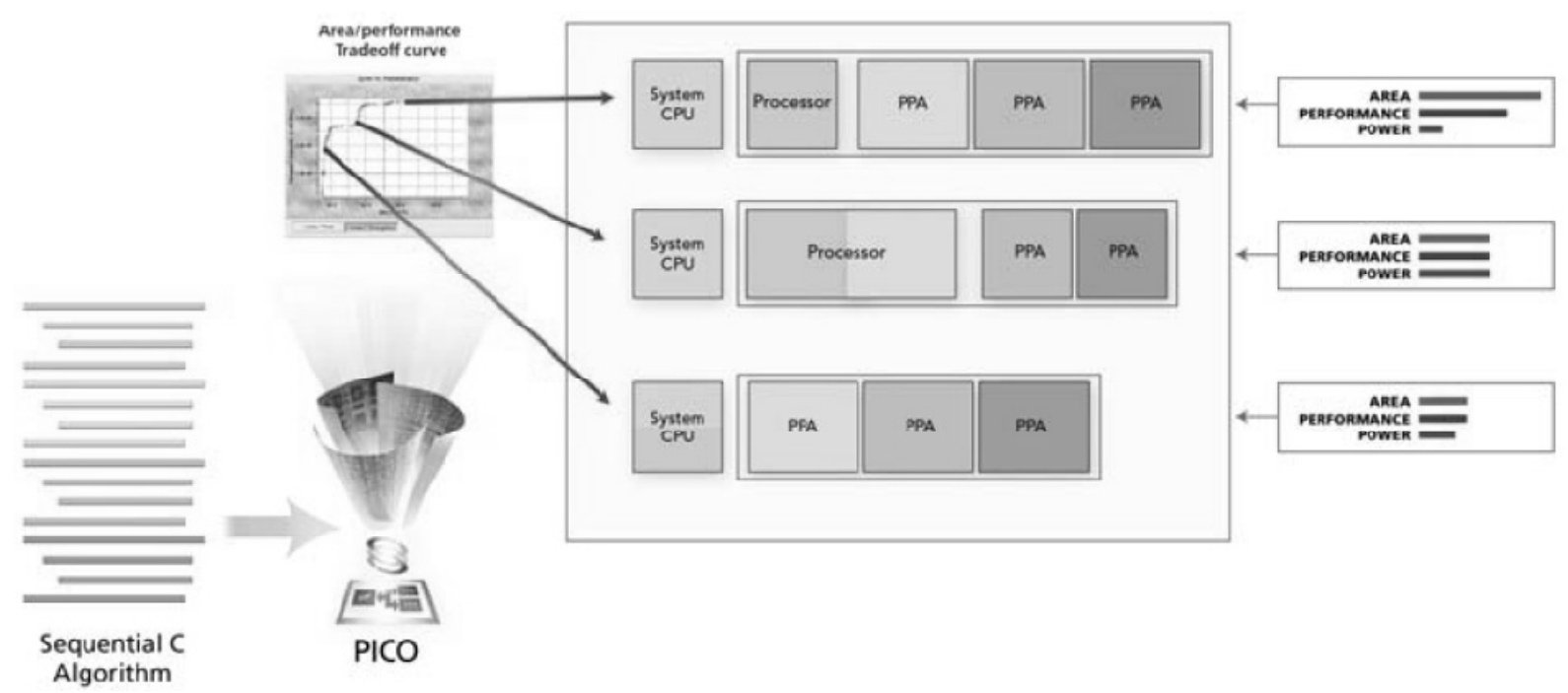

Figura 21. Possíveis implementações geradas por Pico Express

Para uma implementação selecionada pelo usuário é criado o arquivo $R T L$ e arquivos testbenches, necessários para testar em simuladores o arquivo RTL gerado e implementar o hardware no FPGA.

O resultado da construção do RTL é correto, porque Pico Express tem IPs préconfigurados para adequar as funcionalidades requeridas. Cada IP configurável é projetado

\footnotetext{
${ }^{4}$ Do Inglês: Moving Picture Experts Group - estabelece normas para compressão e armazenamento de vídeo.

${ }^{5}$ Do Inglês: Digital Versatile Disc - disco óptico digital com capacidade de armazenamento muito maior do que um $C D$ comum.
} 
para atingir as necessidades de um estilo computacional específico e para ser eficiente em área/performance para o dado estilo. Cada IP é projetado para ser escalonável e suportar diferentes níveis de paralelismo.

Há dois tipos de IPs inclusos no Pico Express: os não-programáveis (fixos) e programáveis e são altamente paralelos. Esses IPs são totalmente compatíveis com outros blocos no projeto.

O IP não-programável é um PPA (Pipeline of Processor Arrays) projetado para computações intensivas do código $C$, tais como multiplicações.

O IP programável é uma arquitetura VLIW (Very Long Instruction Width) que é usada para acelerar o controle intensivo do código $C$.

PICO permite uma junção do PPA e do VLIW para criar uma solução completa para algoritmos mais complexos, como por exemplo, MPEG.

A Figura 22 mostra o funcionamento geral do PICO Express. Como pode ser observado, Pico Express analisa o algoritmo escrito em linguagem $C$ e transforma as partes que necessitam de um processamento mais pesado, tais como multiplicação, em blocos que executam diretamente no FPGA - "accelerator 1 e 2"; as partes do código que não necessitam de um processamento tão intenso, são compiladas e executadas em um processador de propósito geral embarcado no FPGA. (Synfora, 2007)

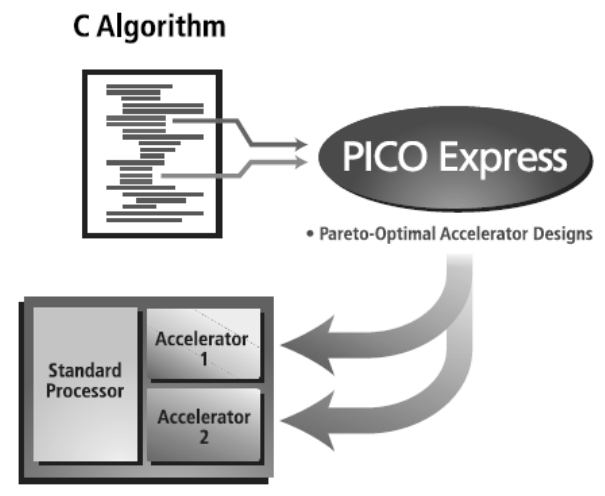

Figura 22. Visão geral do Pico Express

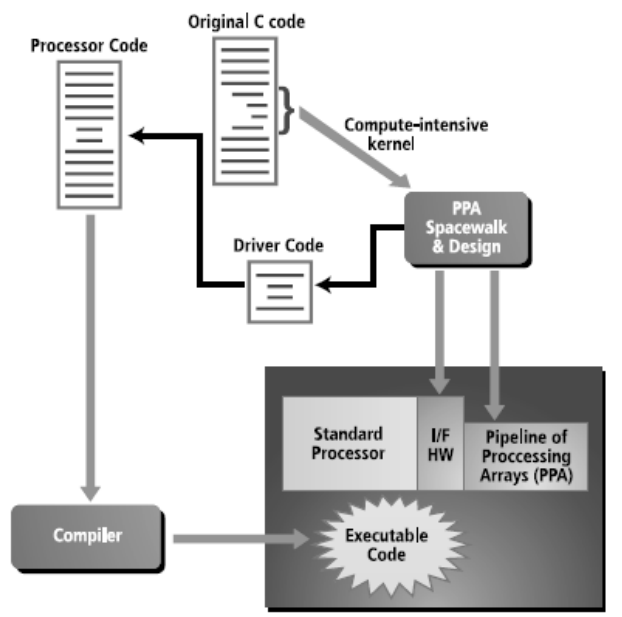

Figura 23. Visão detalhada do Pico Express

Na Figura 23 pode ser visto detalhadamente o funcionamento do Pico Express. A ferramenta analisa um código escrito em ANSI-C e, ao apontar as partes críticas do código, gera o hardware para elas em FPGA e o driver com as interfaces do hardware. Da parte menos 
crítica do software, o compilador gera um arquivo objeto que pode ser executado diretamente no processador embarcado, além de gerar o driver em software. Os drivers servem para a comunicação entre as partes do programa que executam no FPGA e no processador.

O hardware customizado é então chamado pelo programa no processador sob a forma de instrução. Pode se dizer que o Pico Express gera um ambiente $h w / s w$ codesign.

No ambiente $h w / s w$ codesign, como explicado acima, o código original é dividido. A parte do software que necessita de mais desempenho é sintetizada no FPGA e executada como hardware puro, enquanto que a parte que não necessita de tanto desempenho é compilada e executada sob a forma de programa no processador de propósito geral embarcado no FPGA.

\subsection{Galadriel e Nenya}

Galadriel e Nenya são compiladores que atuam em série e tem como objetivo gerar um hardware reconfigurável constituído por um FPGA acoplado a uma ou mais memórias a partir de um algoritmo representado por bytecodes de Java. (Cardoso, 2000). Um exemplo da arquitetura do hardware gerado pelos compiladores Galadriel e Nenya podem ser vistos na Figura 24. As memórias permitem que pequenas partes da execução de um programa possam ser computadas diretamente no FPGA, sem intervenção do processador. Desse modo, não são necessárias as transferências dos dados entre memória e processador. Na Figura 24, sistema de hospedagem é um computador, por exemplo, o computador ligado a uma placa de prototipação.

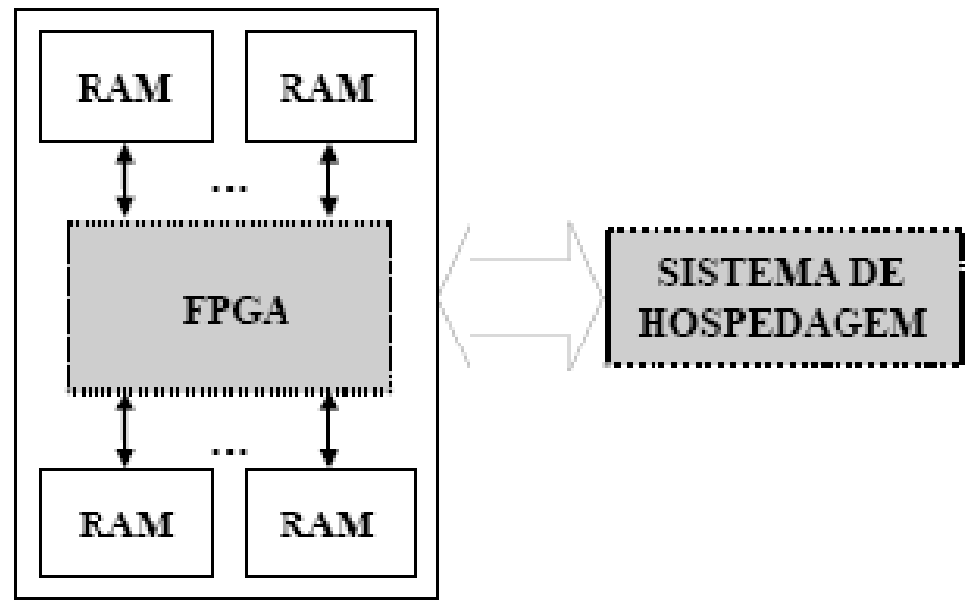


Segundo (Cardoso, 2000), a adoção da linguagem Java como linguagem de programação de sistemas computacionais reconfiguráveis se devem a:

- Simplicidade da linguagem;

- Ausência de ponteiros;

- Nível de abstrações elevado;

- Suporte a programação concorrente, pela utilização de threads;

- Portabilidade entre diversos sistemas operacionais;

- Sintaxe parecida com a da linguagem $\mathrm{C} / \mathrm{C}++$.

E a utilização dos bytecodes de Java, em particular, se deve a:

- Manter quase todas as informações do programa fonte;

- É um modelo de execução na internet;

- Suporta várias linguagens de programação de software. Além do fato da representação em bytecodes de uma aplicação ser fruto de algumas etapas iniciais de compilação, foi um dos pontos chaves, segundo (Cardoso, 2000), que originou a adoção desse modelo como formato de entrada para o compilador Galadriel.

O compilador Galadriel recebe um algoritmo em bytecodes do Java, efetua várias etapas que produzem alguns arquivos intermediários. O objetivo do compilador Galadriel é extrair dos bytecodes do Java, o paralelismo existente através de alguns métodos empregados pelo compilador.

Nenya é um compilador que gera a arquitetura mostrada na Figura 24, a partir dos arquivos intermediários gerados pelo compilador Galadriel.

A Figura 25 representa o fluxo completo de compilação executados por Galadriel e Nenya. Nessa figura também é possível ver que os bytecodes do Java são as entradas do compilador de anteguarda (Galadriel) e que esse gera como produtos o HPDG e o DFG, que irão em seguida servir de entrada para o compilador Nenya, o qual produzirá o hardware reconfigurável, como na Figura 24.

Vários graus de paralelismo são expostos pelo compilador Galadriel para que se obtenham implementações eficientes em hardware reconfigurável. Também é feito a análise de inferência do número de bits suficientes para cada operando de forma a preservar a funcionalidade original. 


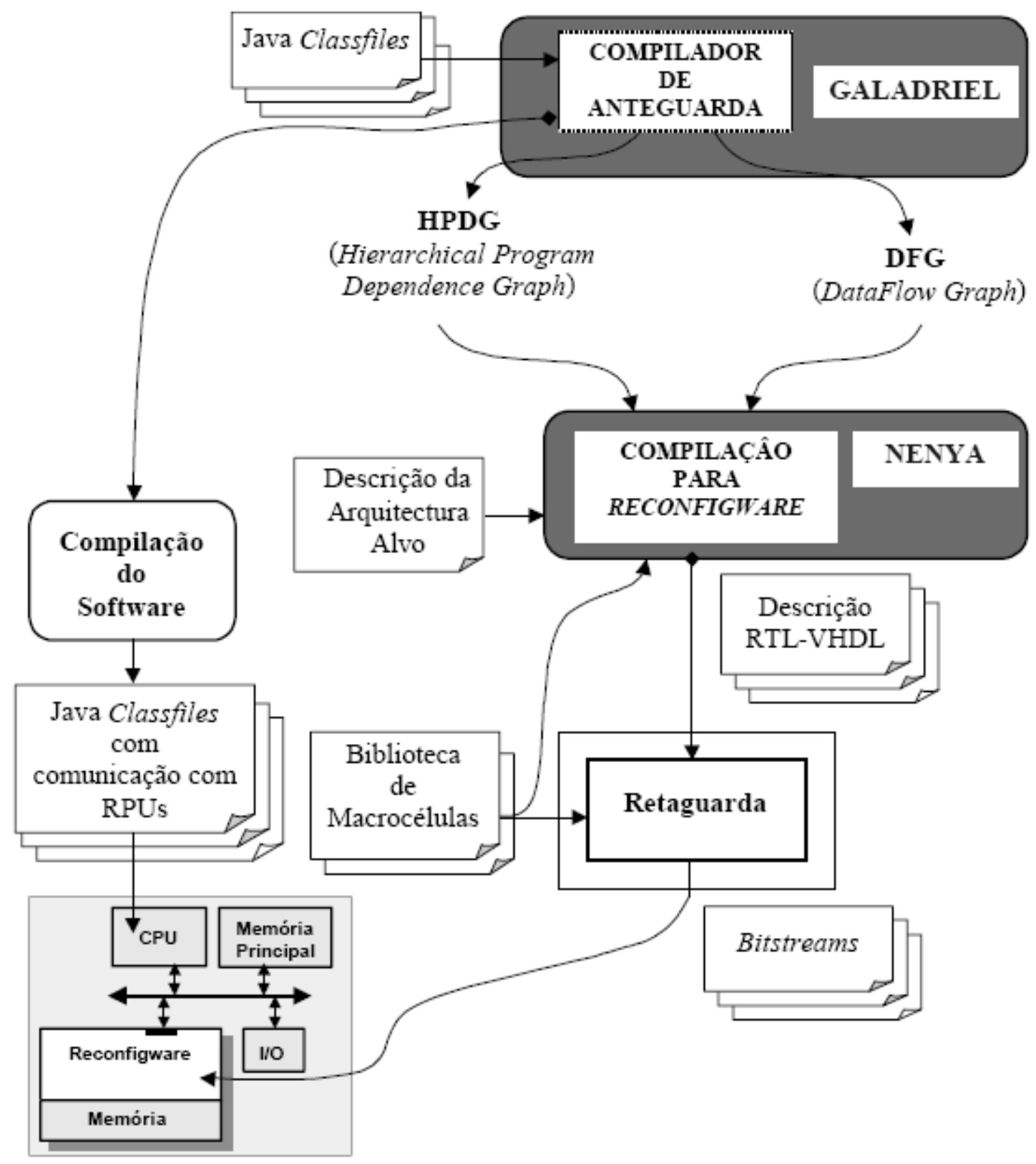

Figura 25. Fluxo de compilação feitos por Galadriel e Nenya

Tabela 4. Tipos de dados, operações e controles suportados pelo compilador Galadriel

\begin{tabular}{|lll|}
\hline \multicolumn{1}{|c}{ Tipos de dados } & Operações & Controle e outros mecanismos \\
\hline Boolean & $\mid, \%,{ }^{\prime}$, & Tratamento de exceções \\
Byte &,,,++--+- & Invocação de métodos \\
Short &,$<<,>>$, & Criação de objetos \\
Int & $>>$, & Criação de arrays unidimensio- \\
char & $\|, \& \&, \&$, & nais \\
Long & $\mid, \wedge, \sim$, & While, for, do while \\
Float, double, & $<,>,<=$, & Break, continue \\
Referências a arrays & $>=,==, !=$ & If, ?:, switch \\
unidimensionais & & Conversões (cast) \\
Referências a objetos & & \\
\hline
\end{tabular}


Na Tabela 4 é mostrado o subconjunto de instruções correspondentes ao JVM (Java Virtual Machine) do Java que são corretamente suportadas pelo compilador Nenya. (Cardoso, 2000).

Cada tipo primitivo da linguagem Java (byte, short, int, boolean, long, e char) é traduzido para o tipo correspondente em VHDL. (Cardoso, 2000)

Nos compiladores Galadriel + Nenya o programador escolhe uma função ou segmento de código para ser gerado o hardware correspondente a ela.

Basicamente o compilador Galadriel através de passos de compilação, gera arquivos intermediários, os quais exibem explicitamente o paralelismo a nível de operação, entre os blocos básicos e entre ciclos considerando sempre a granulosidade da operação e permite a exploração eficiente de implementações em hardware específico. Para tal, são utilizados dois modelos de representação: HPDF e DFG, os quais permitem lidar com a hierarquia definida pelos ciclos no programa fonte e com o paralelismo ao nível da operação nos agrupamentos de blocos básicos. (Cardoso, 2000)

O compilador GALADRIEL considera o escopo do bloco de código especificado pelo programador para ser compilado para hardware reconfigurável. O usuário pode utilizar rótulos especiais (pragmas) para identificar a região do código Java que deseja compilar para hardware reconfigurável. (Cardoso, 2000)

Dos arquivos intermediários com representações, gerados pelo compilador Galadriel, o HPDG (Hierarchical Program Dependence Graph) é um grafo que exibe explicitamente as dependências de dados, fluxo de controles e os ciclos existentes no programa fonte.

O DFG (Data Flow Graph) global incorpora explicitamente os predicados (condições segundo as quais determinada instrução é executada) para operações cuja execução dependa de construções condicionais acíclicas. Um predicado de uma operação define se essa operação será executada com base na avaliação de uma função lógica cujas variáveis são resultados de comparações. Ou seja, o DFG global representa as operações do programa original e a forma como estão interligadas e com algumas transformações, já especificadas anteriormente, permite fornecer a imagem da unidade de dados específica.

Segundo (Cardoso, 2000), "as análises consideradas pelo compilador GALADRIEL são 'intraprocedimentais', ou seja, apenas são realizadas ao longo da estrutura interna dos métodos e não incluem análises 'interprocedimentais' (entre métodos/funções)”. 
O compilador Nenya gera um hardware reconfigurável especializado a partir dos modelos de representação apresentados pelos arquivos gerados pelo compilador Galadriel. Nenya suporta a compilação para uma arquitetura constituída por um FPGA acoplado a uma ou mais memórias RAM via barramentos independentes, a Figura 26 é um exemplo da arquitetura gerada pelo compilador Nenya. (Cardoso, 2000)

Nenya pode ser usado para compilar um programa completo ou segmento de código para hardware reconfigurável, desde que o programa respeite o subconjunto de instruções Java, apresentados na Tabela 4.

Antes da execução, o compilador Nenya necessita das especificações do ciclo de clock do hardware reconfigurável, das memórias externas, da área máxima do FPGA, e da caracterização dos componentes responsáveis pelos operadores existentes no programa fonte em linguagem Java. (Cardoso, 2000)

O compilador NENYA recebe os grafos gerados pelo compilador GALADRIEL para um dado método em Java e a identificação do segmento de código desse método que o programador deseja compilar para hardware reconfigurável.

A Figura 26 mostra a estrutura utilizada pelo compilador Nenya para implementar o hardware reconfigurável relativo a uma dada descrição em linguagem Java. Nessa figura é possível ver duas unidades: unidade de controle e unidade de dado.

Essas unidades interagem entre si. A unidade de dados pode incorporar, por exemplo, componentes que acessem dispositivos externos ao FPGA - quadrado preto na Figura 26. Um desses componentes é a macrocélula de acesso a uma memória externa. (Cardoso, 2000)

O endereçamento de dados armazenados em uma memória é realizado por circuitos especializados (constituídos por macrocélulas) presentes na unidade de dados. O compilador baseia-se numa biblioteca de macrocélulas parametrizáveis, definidas sob a forma de geradores de circuitos, para produzir a unidade de dados.

A unidade de controle é responsável pelo controle dos acessos a memórias externas, pelo controle de escritas em registros e pela execução correta dos ciclos. (Cardoso, 2000) 


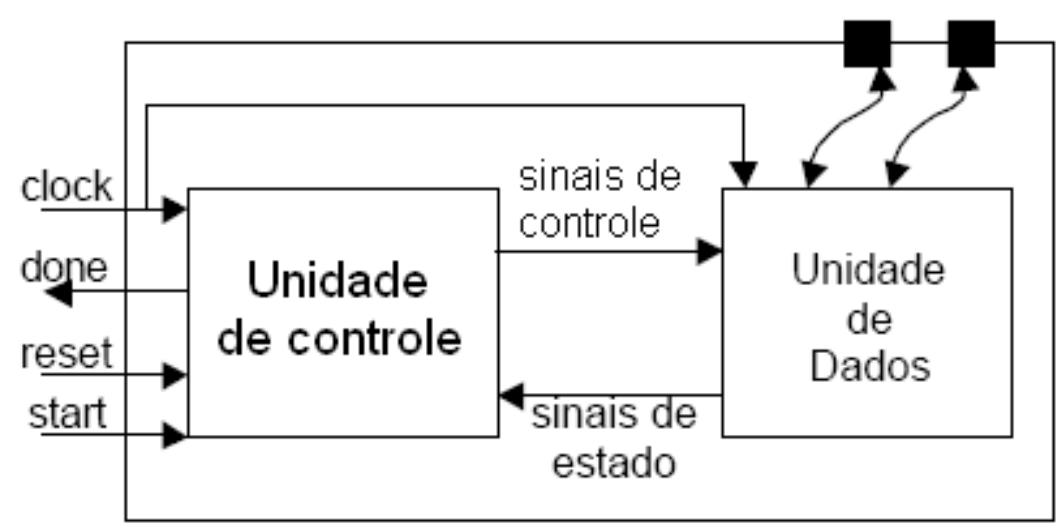

Figura 26. Estrutura utilizada pelo compilador Nenya para implementar o hardware gerado pelo compilador Nenya

O compilador NENYA baseia-se em uma biblioteca de macrocélulas sob a forma de geradores de circuitos para produzir a unidade de dados. (Cardoso, 2000)

A biblioteca considerada tem como alvo a família XC6000 de FPGAs da Xilinx. (Xilinx Inc., 1997)

A biblioteca inclui operadores inteiros (aritméticos, lógicos, comparadores, deslocadores), uma macrocélula de acesso a memórias externas acopladas ao FPGA, multiplexadores, entre outros.

Cada operador tem uma descrição estrutural em linguagem VHDL com as seguintes propriedades:

- Parametrização: de acordo com o número de bits dos operandos de entrada/saída é gerado um circuito especializado.

- Colocação relativa: A colocação do elemento no FPGA é sempre relativa ao posicionamento do nível imediatamente a seguir na hierarquia de componentes, Figura 27.

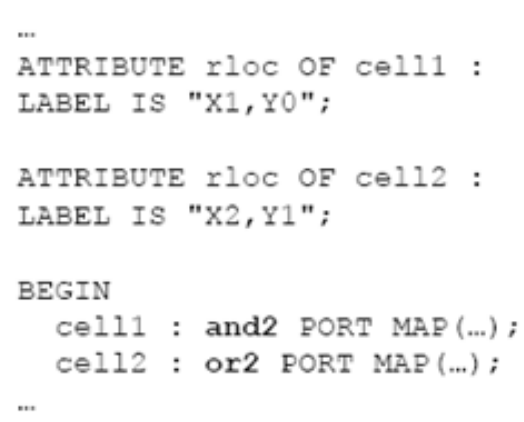

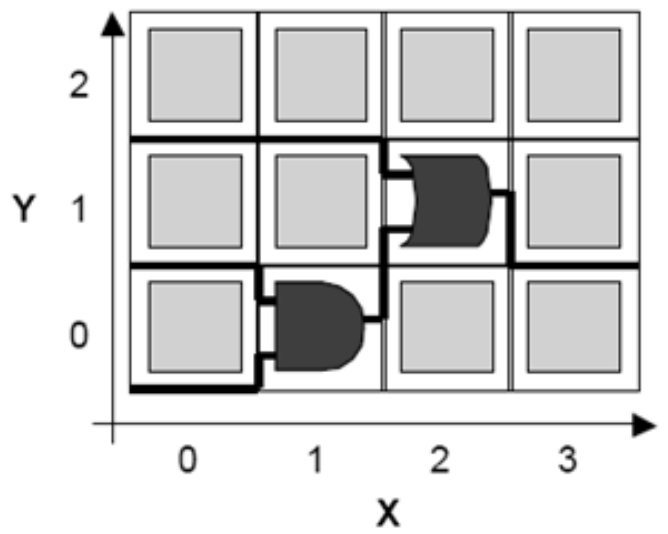

b) 
A Figura 27 mostra um exemplo da colocação relativa de elementos lógicos no FPGA. A Figura 27-a mostra um exemplo da descrição do programa de usuário em Java. Na Figura 27b é mostrado o exemplo da colocação relativa. Como mostra a Figura 27, a porta $O R$ de duas entradas foi especificada depois da porta AND de duas entradas. A propriedade de colocação relativa, a porta $O R$ é ligada logo e após a porta $A N D$.

Segundo (Cardoso, 2000), a colocação relativa permite encaminhamentos com menores variações, e por isso maiores previsibilidades nos atrasos das ligações, e reduz os tempos de colocação e encaminhamento globais.

\subsection{Compilador apresentado por Chichkov}

O compilador apresentado por Chichkov, em (Chichkov, et al., 1998) teve sua primeira publicação em 1997. (Chichkov, et al., 1997)

Em (Chichkov, et al., 1998) é apresentado um compilador que utiliza um subconjunto de comandos da Linguagem $C$ e que ajuda no processo de hardware/software codesign de sistemas digitais.

O compilador apresentado por Chichkov apresenta grandes limitações no suporte a construções da linguagem C. (Cardoso, 2000)

Esse compilador tem por objetivo traduzir uma especificação escrita em linguagem em ANSI-C e transformar essa descrição em dois arquivos: um VHDL e um programa $C$ que juntos executarão a mesma função de entrada, mas com um significativo ganho de desempenho. (Chichkov, et al., 1998)

A metodologia completa do compilador é mostrada na Figura 28 e consiste das seguintes partes principais: um front-end GNU C; um compilador paralelizável (parallelising compiler); algoritmo de particionamento em hardware/software codesign e uma ferramenta de implementação. Primeiramente a linguagem de programação ANSI-C é usada como entrada do compilador. Durante a compilação do programa escrito em linguagem $C$, o código no formato RTX (three-address code) é gerado. Este código é usado na fase de modelagem e análise do sistema, para gerar o arquivo VHDL comportamental da parte do código original que é implementado em hardware específico. O compilador usa o modelo de fluxo de grafos para capturar o comportamento do sistema. Esse modelo de fluxo de grafos tem a capacida- 
de de descrever as estruturas seqüenciais e paralelas, correspondentes a clássica descrição hardware e software. (Chichkov, et al., 1998)

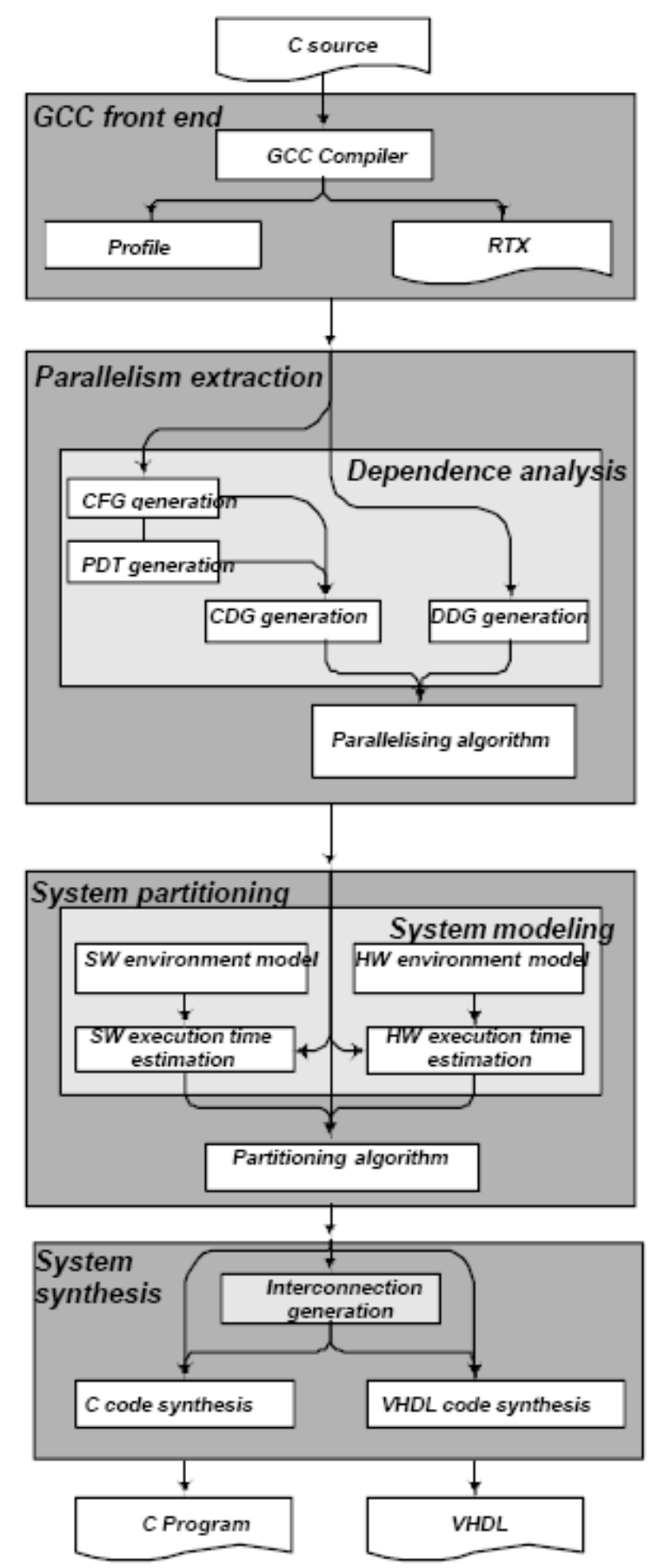

Figura 28. Arquitetura de configuração do compilador apresentado por Chichkov. (Chichkov, et al., 1998)

Após ter gerado o código no formato $R T X$, esses resultados intermediários gerados pelo GCC Front-end vão servir de entrada para a fase "Parallelism Extraction", que como o nome diz, tem a função de extrair o paralelismo dos arquivos correspondentes aos resultados intermediários, gerados na fase anterior. Os arquivos correspondentes aos resultados da 
fase "Parallelism Extration" então, servirão como arquivos de entrada para a fase "System Partitioning", o qual é responsável por fazer o particionamento em $h w / s w$ codesign.

Após essas fases, os arquivos originados na fase anterior serão utilizados na fase "System Synthesis", no qual o arquivo VHDL será gerado. (Chichkov, et al., 1998)

O compilador possui algumas limitações, como por exemplo, não aceita como entrada, descrições em linguagem $C$, tais como arrays, ponteiros, chamadas a funções, recursividade, entre outras. (Cardoso, 2000)

O compilador GCC foi usado como front-end para: assegurar a correlação léxica e sintática do código fonte, gerar o "three-adress code" do arquivo de entrada e aproveitar os algoritmos de otimização do compilador.

O compilador assume que a implementação em hardware de cada bloco básico executa em um ciclo de clock, fato que degrada a execução global, pois o ciclo de clock do hardware reconfigurável para uma região tem de ter período igual ao maior dos atrasos dos blocos básicos pertencentes a essa região. (Cardoso, 2000)

Para implementar o hardware reconfigurável no FPGA são utilizadas ferramentas comerciais de síntese lógica.

A falta de informação de tempo na especificação inicial define a implementação de um ramo de um programa C em hardware como um problema de síntese de alto nível.

A implementação de um ramo de um programa $C$ em hardware incluem três passos principais: atribuição de recursos, tradução do código intermediário GCC para VHDL e definição de tempo. A atribuição de recursos consiste na definição do local exato para armazenamento dos componentes (registradores). A definição de tempo é a atribuição de um período de clock apropriado para o sistema. A realização desses dois passos requerem a analise de dependência de controle e dados, analise do tempo de vida das variáveis e a estimação do desempenho. A analise de dependência de dados e controle provêem as informações da implementação do caminho de dados e controle da estrutura. A analise do tempo de vida das variáveis determinam a atribuição de recursos, enquanto a estimação de desempenho decide o ciclo de clock para o sistema. 


\subsection{Spark}

Spark é uma ferramenta acadêmica que gera arquivos $V H D L$ a partir de algoritmos escritos em linguagem ANSI-C. (Gupta, et al., 2004)

\subsubsection{Síntese a partir de linguagem de alto nível}

HLS (High-level synthesis) é um processo na ferramenta Spark para se construir circuitos eletrônicos a partir de descrições comportamentais, essas descrições são freqüentemente escritas em linguagens de programação. (Gupta, et al., 2004)

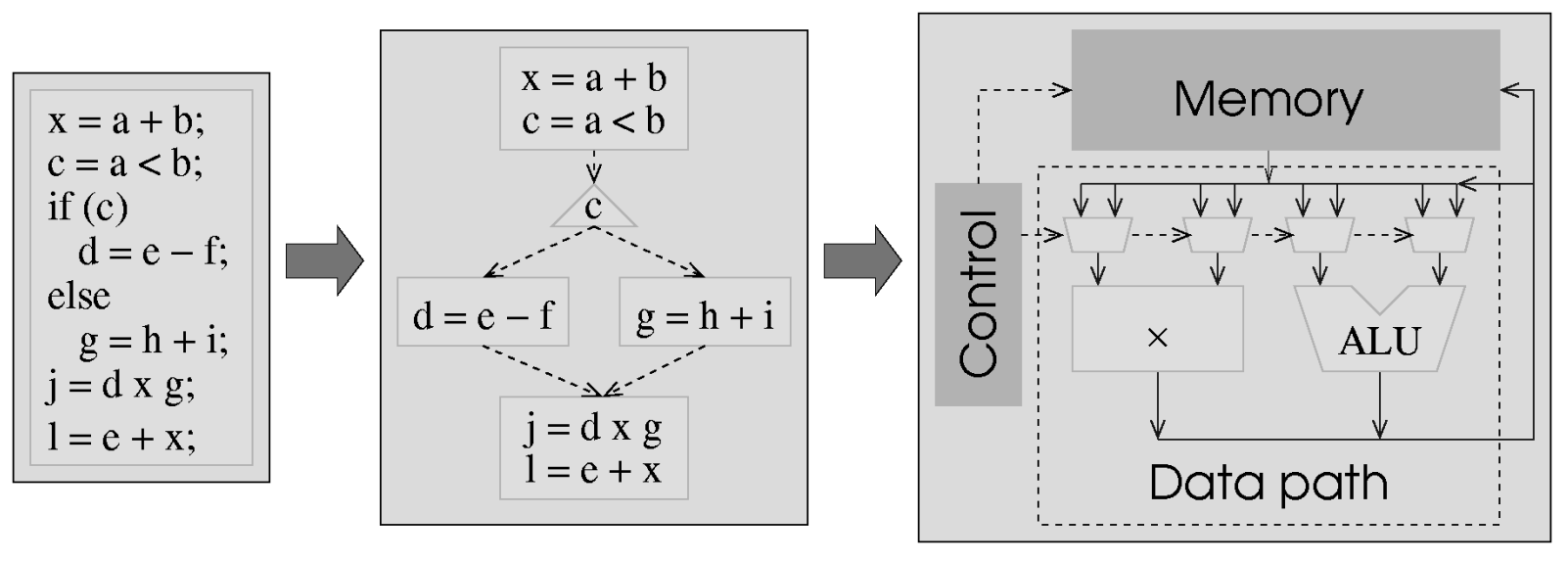

Figura 29. Visão geral de HLS

Na Figura 29 pode ser visto um exemplo de HLS. Mais detalhadamente, HLS é um processo para conversão de uma descrição comportamental em um circuito digital que consiste de um data path, um controle e elementos de memória. (Gupta, et al., 2004).

O primeiro passo de HLS é capturar as representações de fluxo de controle e fluxo de dados a partir da descrição comportamental, como descrito acima e depois essas representações intermediárias são passadas para outras atividades, tais como:

Alocação (allocation): Esse passo consiste em determinar o número de recursos que tem que ser alocados para sintetizar o circuito. Os recursos consistem não apenas de unidades funcionais, tais como somadores e multiplicadores, mas podem incluir registradores e componentes de interconexão, tais como multiplexadores e barramentos;

Sincronização (Scheduling): o problema de sincronização e determinar o tempo ou ciclo de clock, o qual cada operação pode ser executada;

Seleção de Modulo (Module Selection): Nesse passo se determina os tipos de recursos da biblioteca de recursos que uma operação pode executar. Por exemplo: uma adição pode ser 
executada em um somador, em uma ALU (Arithmetic and Logic Unit) ou em uma MAC. A escolha de um componente determina desempenho, gasto de energia e gasto de área no chip.

Binding: determina o mapeamento entre as operações, variáveis e transferências de dados e controle no projeto. Nesse passo as operações são mapeadas para especificar as unidades funcionais, variáveis e registradores e transferência de dado ou controle para componentes interconectados;

Geração de controle e otimização: Síntese de controle gera uma unidade de controle que implementa o sincronismo (schedule). Essa unidade de controle gera sinais que controlam o fluxo de dados através do data path, por exemplo, através de multiplexadores. Otimizações no controle tentam minimizar o tamanho da unidade de controle.

Cada uma dessas tarefas é interconectada e são freqüentemente dependentes uma das outras. (Gupta, et al., 2004)

\subsubsection{HLS paralelo}

Spark permite também uma nova abordagem ao HLS que é o PHLS (Parallelizing highlevel synthesis). Segundo (Gupta, et al., 2004), essa abordagem emprega códigos agressivos de paralelização, através de compiladores paralelizáveis ${ }^{6}$ e técnicas de movimentação de códigos para otimizações de circuitos, mais do que no modelo tradicional HLS. (Gupta, et al., 2004)

Essa ferramenta é particularmente interessante para aplicações multimídia e aplicações de processamento de imagens. Essas aplicações tipicamente consistem de operações aritméticas embutidas em loops alinhados com uma complexa mistura de construções condicionais, tais como if-then-else. (Gupta, et al., 2004) Essas construções tem um grande efeito na qualidade dos resultados de síntese de hardware.

\subsubsection{Visão geral do Spark}

Como será mostrado mais adiante, na Figura 30, o Spark emprega transformações e técnicas que exploram o paralelismo a nível de instruções, tais como speculative code motions, percolation scheduling e transformações de granularidade grossa, tais como loop transformation. (Gupta, et al., 2004)

\footnotetext{
${ }^{6}$ Compiladores paralelizáveis são compiladores que produzem código para execução em máquinas paralelas. (Gupta, et al., 2004)
} 
O Spark permite ao projetista controlar as transformações aplicadas no código fonte de uma descrição escrita em $A N S I-C$, isso possibilita ao projetista experimentar diversas transformações e algoritmos em sua descrição. Então, o projetista pode fazer a analise do impacto dessas transformações no controle e custo de área do circuito. Além da descrição comportamental em linguagem $C$, o projetista pode controlar as transformações que serão aplicadas pelo Spark, através de scripts.

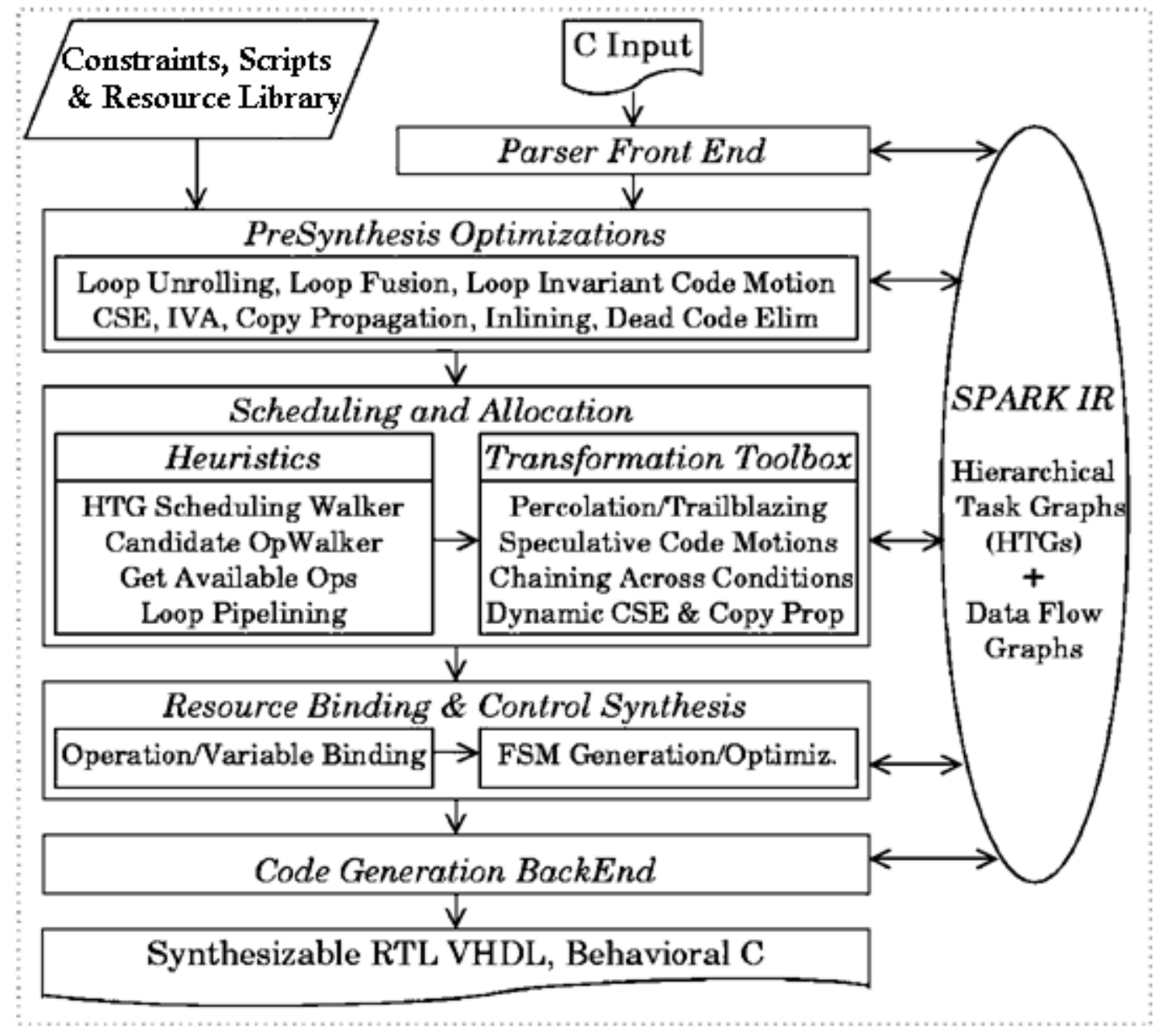

Figura 30. Metodologia de síntese do Spark

A descrição comportamental em linguagem $C$, aceita pelo Spark tem algumas restrições, tais como: não suporta ponteiros, funções recursivas e gotos.

Além do algoritmo que será convertido em $V H D L$, o projetista tem que especificar uma lista de recursos alocados para síntese do projeto em uma biblioteca de recursos de hardware, junto com a informação de tempo e a faixa de valores de vários tipos de dados, usado no algoritmo em $C$.

Como mostrado na última Figura 30, além do código fonte C, o Spark também aceita como entrada informações adicionais, tais como recursos de bibliotecas de hardware, restri- 
ção de tempo, informações de tipos de dados e scripts usados pelo usuário como controle para guiar as heurísticas e transformações.

A partir das entradas, são gerados o fluxo de controle e fluxo de dados a partir da descrição. Fluxo de controle e o fluxo de dados são salvos em representações intermediarias, mostrados em Spark IR. O CFG (Control-Flow Graph), que armazena Grafo de Fluxo de Controle e o DFG (Data-Flow Graph), que armazena o Grafo de Fluxo de Dados, respectivamente.

Na fase de PreSynthesis é aplicado um grupo de transformações nas informações armazenadas no Spark IR, com base nas restrições e biblioteca de recursos de hardware dadas como script pelo projetista. Essas transformações, tais como common sub-expression elimination, copy propagation, dead code elimination e loop-invariant code motion ajudam a reduzir o número de operações executadas e remove as operações redundantes e desnecessárias.

A fase de Scheduling reduz o impacto da variação sintática ou estilo de programação na qualidade dos resultados de síntese.

A fase de Binding mapeia as operações e variáveis em unidades funcionais e registradores, respectivamente. Além disso, a fase de Binding minimiza a complexidade das interconexões entre as unidades funcionais e registradores. (Gupta, et al., 2004)

A fase de Control Syntesis gera o controle baseado no estilo de máquina de estado finito. Esse controle executa as operações conforme o timing especificado e gera sinais de controle para guiar os dados através das interconexões como especificado pelo resource binding.

A fase Code Generation BackEnd gera o código em VHDL.

Um exemplo de descrição em linguagem $C$ e os arquivos gerados pelo Spark são mostrados no APÊNDICE A.

\subsection{DK - Design Suit}

DK Design Suit, versão 4.0 SP2 é uma ferramenta gráfica para projetar e criar sistemas eletrônicos e é baseada na plataforma Windows,. Essa ferramenta utiliza a linguagem Handel$C$ como entrada de descrição de projeto. Segundo (Celoxica Ltd, 2006), essa ferramenta prove facilidades para a criação, simulação de depuração (debugging simulation) e compilação da linguagem Handel-C para EDIF netlist, VHDL ou Verilog. Ainda a ferramenta permite a simulação de códigos escritos em $C++, A N S I-C$ e Handel-C, juntos, além de co-simulação com outras ferramentas de simulação e depuração. (Celoxica Ltd, 2006) 
DK Design Suit inclui ferramenta de profile, a qual dá a estimativa de gasto de área e atrasos de clock. (Celoxica Ltd, 2002)

Depois de verificada as características e funcionalidades do sistema em linguagem de alto nível, como $C$, os módulos individuais podem ser selecionados para implementação em hardware, usando-se Handel-C. (Chappell, et al., 2002)

O DK Design Suite prove um ambiente de desenvolvimento integrado - IDE (Integrated Development Environment), a qual permite o usuário editar e compilar programas escritos em Handel-C para produzir o EDIF netlist, VHDL ou Verilog correspondente. O usuário pode simular e depurar aplicações escritas em Handel-C. O IDE também fornece ferramentas de configuração para administrar a construção das aplicações com muitos arquivos. (Celoxica Ltd, 2006)

O IDE é composto pelos seguintes componentes: interface gráfica de usuário $G U I$, compilador Handel-C, simulador Handel-C, depurador Handel-C.

A interface gráfica permite ao usuário interagir com o IDE para criar e editar o algoritmo da aplicação, compilar, fazer simulação e depuração.

O compilador Handel-C é responsável por traduzir algoritmos escritos em Handel-C para arquivos de descrição de hardware, tais como (EDIF/VHDL/Verilog) ou permite a simulação de algoritmos escritos em $C++, A N S I-C$, os quais podem ser compilados futuramente para códigos executáveis. O compilador Handel-C pode ser utilizado com DK Design Suit ou com linha de comando. A tradução para hardware inclui: tecnologia de mapeamento, estimação da lógica, otimização.

A tecnologia de mapeamento permite ao DK Design Suit gerar saída no formato EDIF para os seguintes dispositivos: Xilinx: Virtex, VirtexII-Pro, Virtex-4, entre outros; Altera: Stratix, Stratix-GX, StratixII, entre outros.

A estimação da lógica é a habilidade do compilador Handel-C poder dar as informações da lógica utilizada e ajudar a otimizar o projeto. Essas informações são baseadas em estimativas, ou seja, place and route é necessário para saber com exatidão as informações sobre lógica e área ocupadas.

Algumas técnicas de otimização do compilador podem ser selecionadas pelo usuário, tais como: retiming, mapeamento automático para $A L U s$ embarcadas, pipelining automático para acesso a memória $R A M$.

Retiming é uma transformação que faz um balanço quanto ao uso de registradores no circuito a fim de obter uma taxa de clock especificada, enquanto minimiza o número de flipflops requeridos para o circuito. (Celoxica Ltd, 2004) 
Alguns dispositivos FPGAs possuem ALUs embarcadas. Em vez de deixar o usuário especificar onde utilizar essas unidades, o compilador as usa automaticamente nos locais onde o desempenho será maior. (Celoxica Ltd, 2006)

O simulador Handel-C permite ao usuário abrir e executar um código escrito em Handel-C/ C++ / ANSI-C.

O depurador de Handel-C provê janelas que mostram informações quando a operação de um programa compilado pelo compilador Handel-C for simulada. A depuração mostra os passos de execução do programa através de ciclos de clock e permite que o conteúdo de qualquer variável que está no escopo do programa seja visto na janela de variáveis.

A Figura 31 mostra a co-simulação de um projeto de processamento de imagens escrito em linguagem $C$. A Figura 31-a corresponde a parte da descrição que será escrita em Handel$C$ e depois executada no hardware. Essa parte do algoritmo descreve o processamento da imagem. A Figura 31-b corresponde a parte da descrição que será compilada e executada em um processador embarcado, tal como PowerPC e Microblaze, ou seja, essa parte corresponde ao software do projeto de processamento de imagem. Sua função é pegar partes da imagem da memória ou de algum dispositivo e enviar ao hardware para que seja processada e/ou pegar os resultados gerados pelo hardware e mostrá-los em algum dispositivo de $E / S$ especificado pelo usuário.

Para fazer a co-simulação da descrição do projeto, o projetista pode escrever a parte do projeto correspondente ao hardware no DK Design Suit, no formato Handel-C (Figura 31-a) e a parte do projeto correspondente ao software em um compilador, tal como Microsoft Visual $C++$ (Figura 31-b).

A Figura 31 corresponde a API DSM (Data Streaming Manager). A API DSM é usada para fazer a interface entre o hardware e o software, por exemplo, entre o FPGA e o processador embarcado.

A API DSM também permite que seja feita a co-simulação entre o hardware e o software. Nesse caso, a descrição do projeto correspondente ao software poderá ser executado e compilado no Microsoft Visual $C++$, enquanto que o a descrição do projeto correspondente ao hardware será escrita em Handel-C e compilada pelo DK Design Suit, a essa característica, dá-se o nome de co-simulação.

O DSM Sim Monitor é uma das camadas do DSM e permite que sejam mostrados os dados sendo transferidos entre as partes hardware/software co-simuladas. Um exemplo do DSM Sim Monitor é mostrado na Figura 32. No lado direito da Figura 32 é mostrado a parte do 
programa que está sendo simulado, correspondente ao software. No lado esquerdo é mostrada a parte do programa que está sendo simulado e corresponde ao hardware.

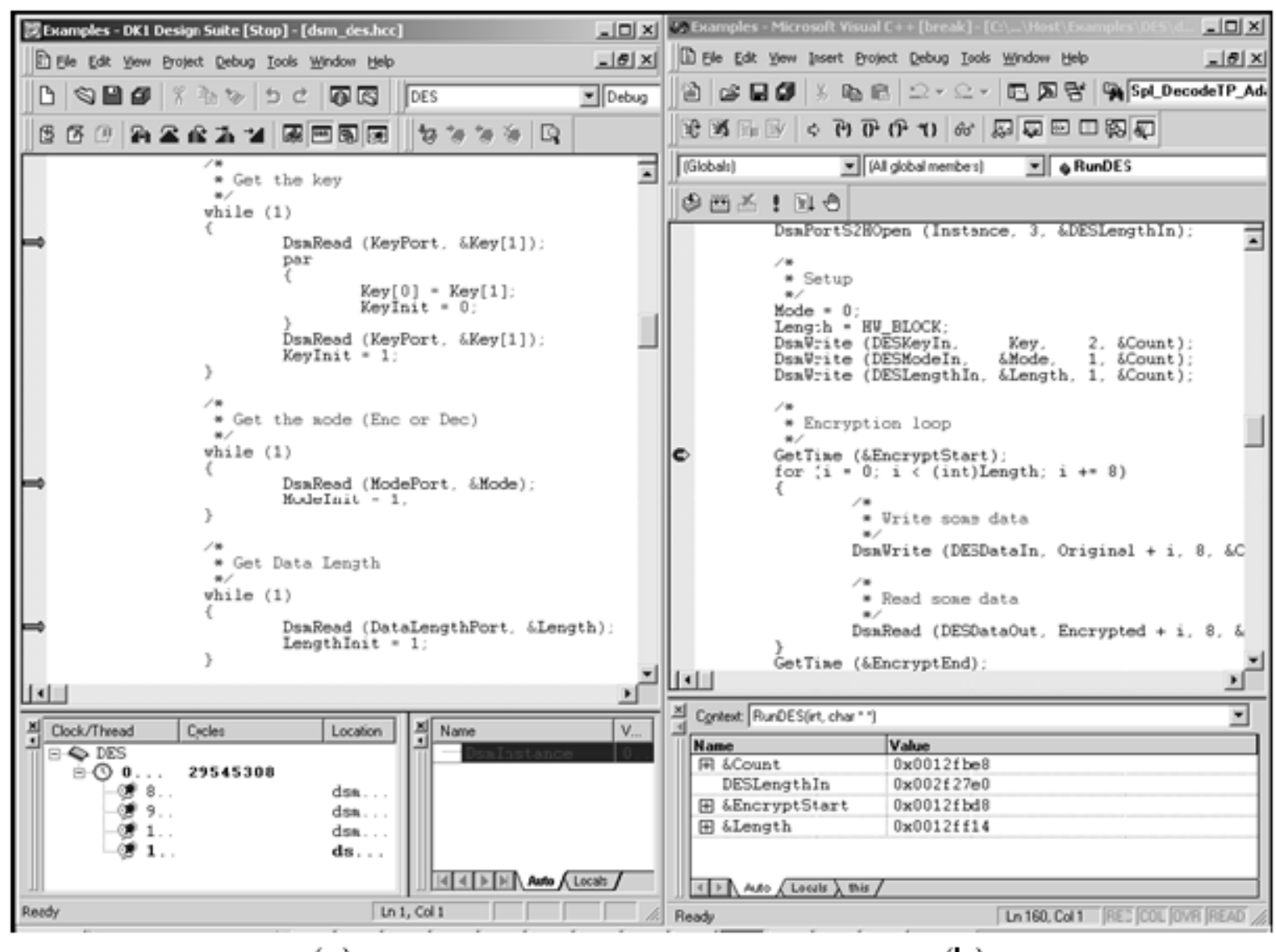

(a)

(b)

Figura 31. Co-simulação através do DSM. Descrição no DK Design Suit (a); Descrição no Microsoft Visual C++ (b)

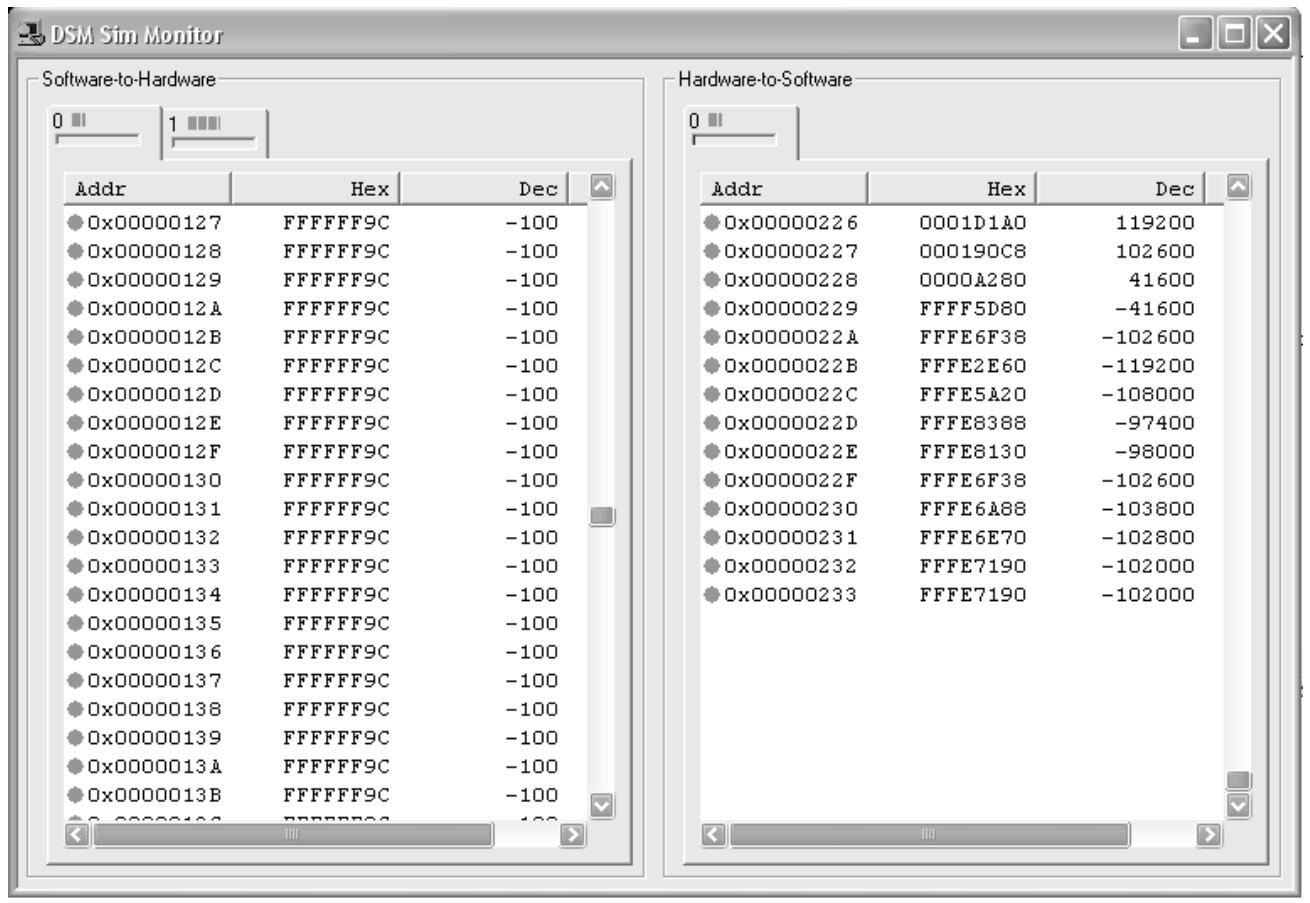

Figura 32. DSM Sim Monitor 


\subsubsection{Handel-C}

A linguagem $C$ tem 20 anos de história e domina o campo de projeto para sistemas embarcados, aplicações de software e sistemas operacionais. (Chappell, et al., 2002) Porém, a linguagem $C$ não tem construções para descrever projetos em hardware.

Handel-C, é baseada no padrão $A N S I-C$ e é uma linguagem de alto nível para implementação de projeto de hardware em alto-nível, ou seja, Handel-C traz extensões a linguagem $C$, com a finalidade de projetar hardware. (Celoxica Ltd., 2004)

Handel-C adiciona instruções de paralelismo e instruções especiais para descrição em hardware na sintaxe de $C$. Podem-se escrever programas seqüenciais em Handel- $C$, mas para ganhar o máximo beneficio em desempenho em hardware, devem-se usar construções paralelas. Na Figura 33 pode ser visto a intersecção da linguagem $A N S I-C$ com o Handel-C, ou seja, o que é suportado pela linguagem $A N S I-C$, o que é suportado pelo Handel-C e o que é suportado por ambos (na intersecção). (Chappell, et al., 2002)

Handel-C é um subconjunto de Occam2. Handel-C permite paralelização de operações, permitindo ao programador especificar concorrência a níveis de abstração baixos. (Cardoso, 2000)
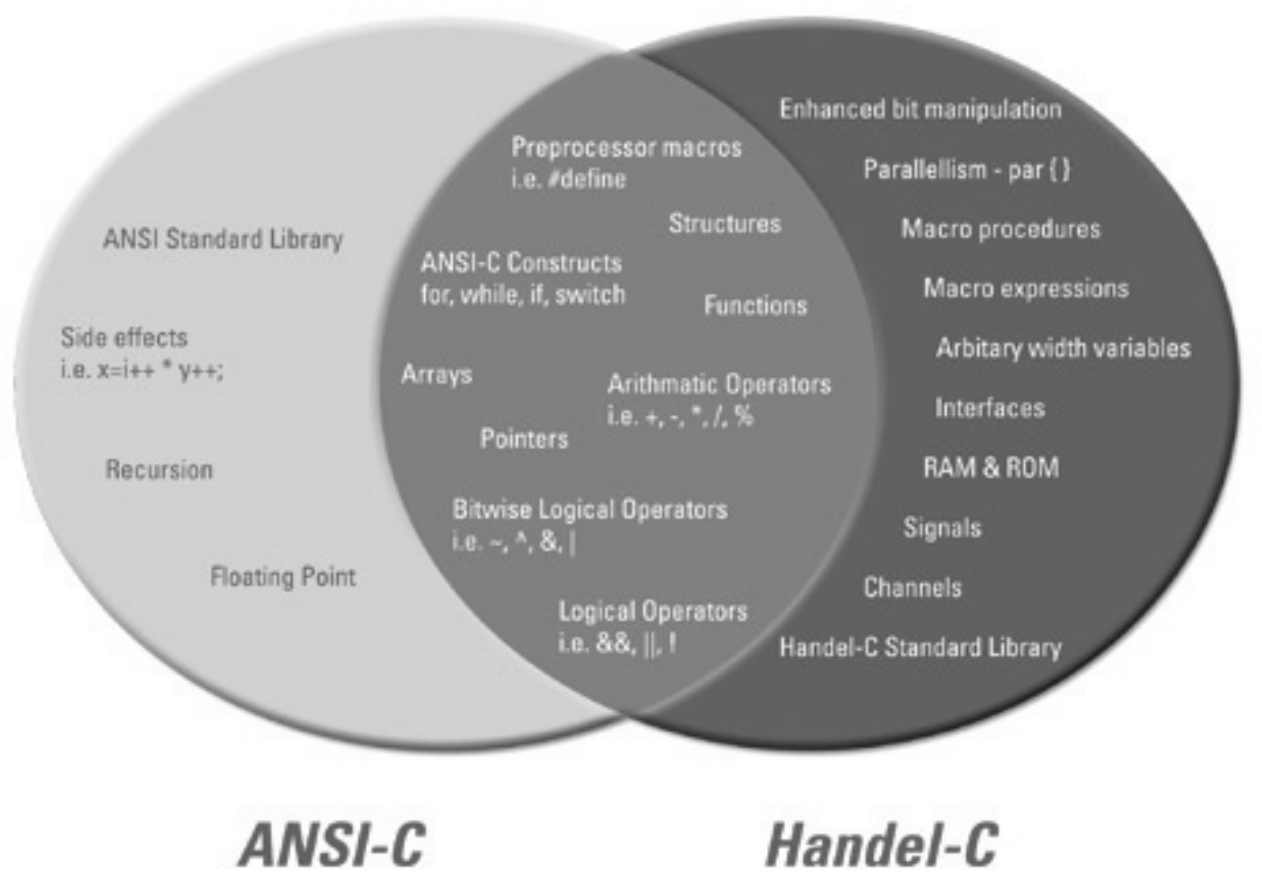

Figura 33. Ambiente ANSI-C e ambiente Handel-C 
Com o Handel-C os algoritmos podem ser codificados no estilo seqüencial, porém, nas partes que devem ser executadas em paralelo, utiliza a construção "par" para programar o paralelismo. (Chappell, et al., 2002)

A instrução "chan" forma um canal e permite a comunicação e sincronização entre ramos paralelos do programa.

Na Figura 34 é mostrado um exemplo de um algoritmo escrito em Handel-C e o modo de execução desse algoritmo. (Chappell, et al., 2002)

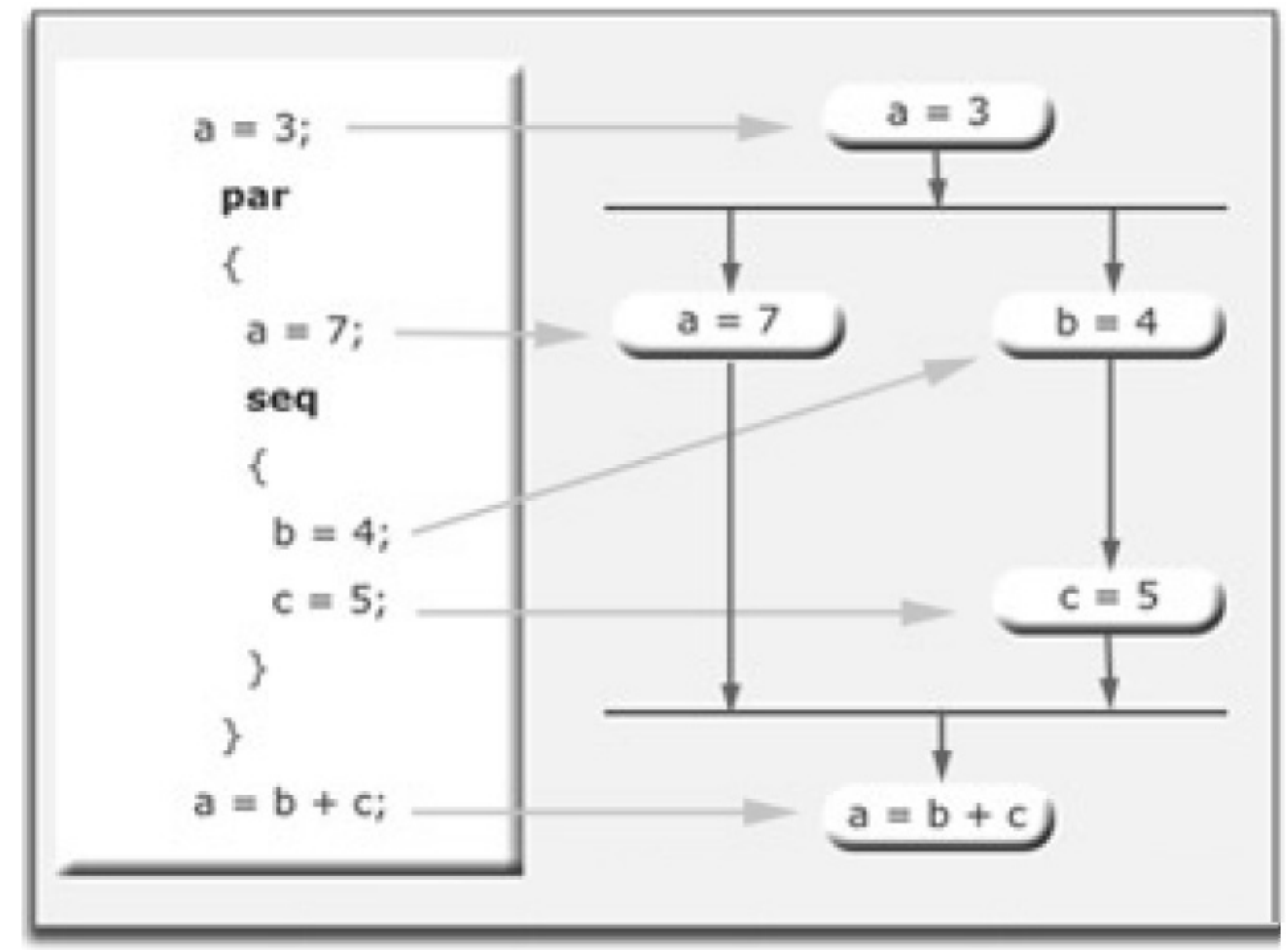

Figura 34. Exemplo da descrição e execução de programas escritos em Handel-C

Segundo (Chappell, et al., 2002), em Handel-C cada tarefa infere um registrador e leva um ciclo de clock para completar. Uma simples expressão de sincronização no Handel-C da ao projetista controle completo sobre a exatidão no ciclo de clock da implementação, permitindo exploração rápida e eficiente de diferentes arquiteturas de projetos. Uma vantagem significante é o determinismo do resultado. 


\subsection{Impulse $C$}

Há um problema fundamental quando se tenta programar um hardware de propósito geral (maquinas não Von Neumann), usando linguagem $C$. O problema é como expressar paralelismo. Processamento paralelo e programação de sistemas paralelos requerem suporte para concorrência na linguagem a ser utilizada e um entendimento pelo programador de como administrar múltiplos elementos computacionais quase independentes. (Pellerin, et al., 2005) A linguagem $C$, como discutido nos capítulos anteriores, não contém tais características.

Linguagens de descrição de hardware, por outro lado, são projetadas para descrever sistemas altamente paralelos, embora possuam baixo nível de abstração. (Pellerin, et al., 2005)

Segundo (Pellerin, et al., 2005), para fazer sentido programar hardware baseado em FPGA, utilizando-se linguagem de alto nível, é necessário criar um modelo de máquina abstrata e escolher um modelo de programação de software apropriada para essa máquina abstrata.

O modelo de programação usado pelo Impulse $C$ é o modelo de processo de comunicação seqüencial, CSP (Communicating Sequential Processes) (Pellerin, et al., 2005)

Segundo (Pellerin, et al., 2005), CSP foi descrito por Anthony Hoare em 1978. CSP, segundo Hoare é um modelo de programação e uma linguagem para descrever padrões das interações entre processos (componentes operacionais independentes). Cada processo em um sistema pode representar um programa com software tradicional (que opera seqüencialmente), mas são limitados em termos de comunicação, uma vez que só podem comunicar uns com os outros através de canais de comunicação bem definidos.

Ainda segundo (Pellerin, et al., 2005), cada programa em um CSP pode ser executado em seu processo de hardware, independente uns dos outros e atuar como uma máquina tradicional Von Neumann atuaria. Em lugar de ter um processo principal controlando a chamada de outros processos como subrotinas, a aplicação como um todo é projetada de tal forma que os movimentos dos dados através do sistema (e através de vários processos na aplicação) são feitos via canais de dados buferizados (buffered). Enquanto cada processo em execução tiver recursos de acesso a memória local (para fazer o processamento e armazenar resultados intermediários), há pouca ou nenhuma comunicação entre os processos independentes, exceto via canais de dados, os quais são chamados algumas vezes de streams.

O modelo CSP, segundo (Pellerin, et al., 2005), é conceitualmente similar ao modelo de programação dataflow, mas menos restritivo e mais fácil de suportar sincronização de proces- 
sos (através de buffer de dados e passagem de mensagens), com isso é simplificada a expressão de algoritmos paralelos em alto nível através do uso bem definido de comunicação de dados, passagem de mensagens e mecanismos de sincronização.

Impulse $C$ estende o $A N S I C$, usando funções de bibliotecas para suporte à comunicação seqüencial de processos.

O Impulse $C$ teve sua raiz filosofal na pesquisa realizada no laboratório Los Alamos $\mathrm{Na}$ tional Laboratories sobre a direção do Dr. Maya Gokhale. Esta pesquisa culminou na disponibilidade pública do compilador Streams-C (Gokhale, 2006) e se tornou uma metodologia para aplicações baseadas em plataformas FPGA. Aplicações desenvolvidas usando Streams-C estão no domínio da criptografia de dados, processamento de imagens, astrofísica entre outras. (Pellerin, et al., 2005)

Funções de monitoramento incluídas com as bibliotecas do Impulse $C$ permitem especificar processos em uma aplicação paralela para ser utilizada na depuração. Os resultados dos processamentos são mostrados em janelas, enquanto a aplicação esta em execução sobre o controle do depurador padrão de $C$.

Para a geração de hardware, o Impulse $C$ inclui um compilador de linguagem $C$ que é baseado na parte pública disponível da ferramenta SUIF (Stanford Universal Intermediate Format) (Stanford Compiler Group, 1994), as quais são combinadas com otimizações proprietárias e ferramentas de geração de código desenvolvida pela empresa Impulse Accelerated Technologies. (Pellerin, et al., 2005)

O coração do modelo de programação do Impulse C, como mostrado na Figura 35, são processos e streams.

Os processos são independentemente sincronizados e executam de forma concorrente. Esses processos são como subprogramas que aceitam vários dados, executam um processamento especifico e geram saídas, nas streams de dados, nas memórias ou outro recurso de sistema. Diferentemente dos subprogramas tradicionais de software, esses processos não são "chamados" (repetidamente invocados durante a execução de um programa), mas estão sempre ativos (em execução) e constantemente respondem quando dados aparecem em suas entradas. (Pellerin, et al., 2005)

Como mostrado na Figura 35, o fluxo de dados entre os processos no Impulse $C$ são feitos por streams, mas em alguns casos por sinais e/ou memória compartilhada.

Os sinais são usados quando o projetista necessita de um controle direto sobre o inicio e o termino de um processo e a sincronização dos processos para eventos externos. O uso de sinais possibilita ao projetista comunicar informações de um processo para outro, usando o 
esquema de passagem de mensagens, através das funções co_signal_post e co_signal_wait. Quando um processo encontra uma função co_signal_wait, ele fica bloqueado a espera de uma mensagem (valor) vinda de outro processo pela função co_signal_post (a qual manda um determinado valor). Isso garante o sincronismo entre processos, quando, por exemplo, um processo tem que esperar o outro terminar de processar uma informação antes de começar a lê-la. Os sinais servem para dois propósitos: permitem a sincronização de processos e suportam a passagem de valores de dados.

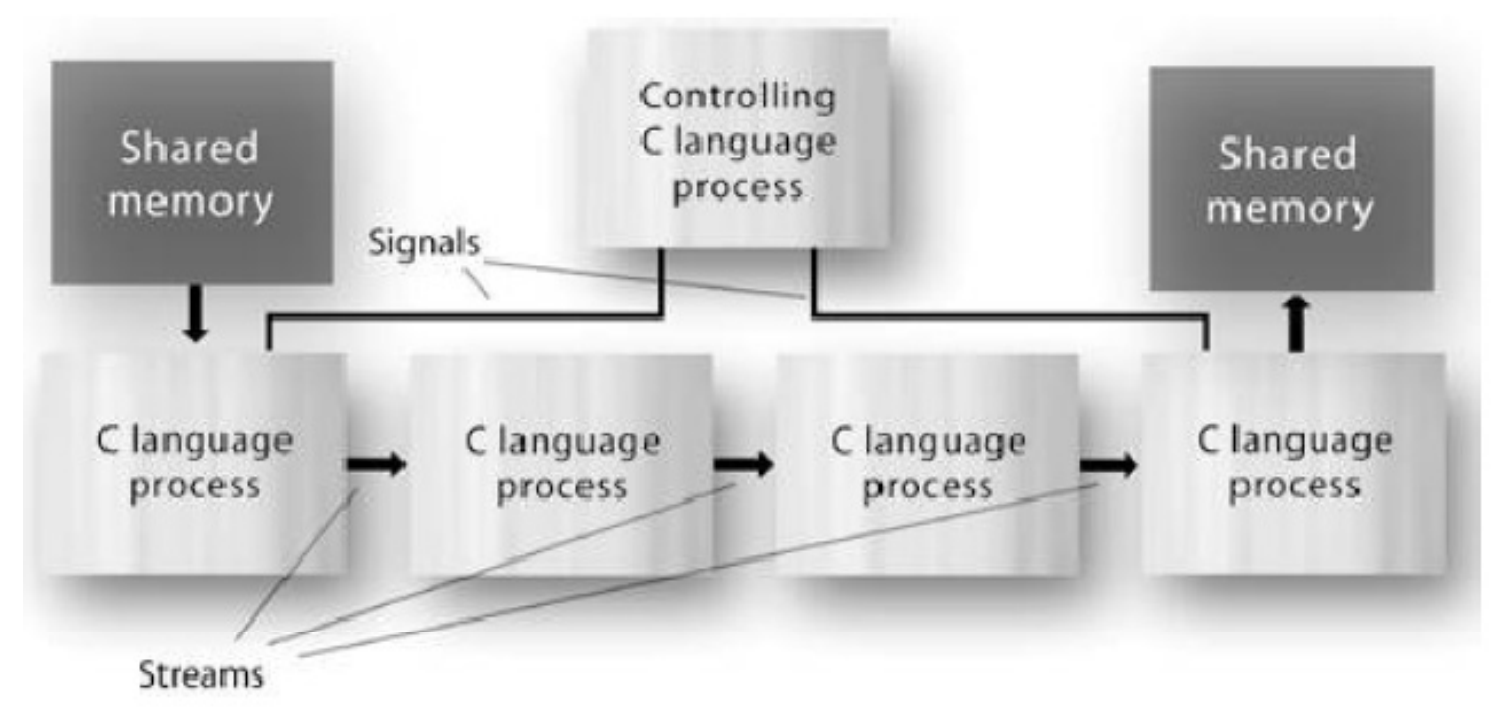

Figura 35. Streams, sinais e memória compartilhada

A função co_signal_wait é bloqueante, ou seja, o processo que "ler" essa função será bloqueado (não executará) até receber sinal da função co_signal_post, a qual não é bloqueante. (Pellerin, et al., 2005)

O uso da memória compartilhada é uma alternativa a streams. A função co_memory_create aloca um número específico de bytes de memória para serem lidos e escritos. Vários processos podem ler e escrever na memória compartilhada. As funções co_memory_readblock e co_memory_writeblock lêem e escrevem dados na memoria, respectivamente. Essas funções permitem especificar o número de bytes de dados para serem lidos e escritos.

As bibliotecas de Impulse $C$ suportam plataformas de FPGA, como os da família Virtex da Xilinx, com os processadores MicroBlaze e PowerPC, bem como plataformas de FPGAs Altera, com os processadores Nios e Nios II. Impulse C também pode ser usado para gerar módulos de hardware que não fazem interface com processos de software.

A Figura 36 mostra um ambiente de desenvolvimento, o CoDeveloper, que permite que uma descrição em linguagem Impulse $C$ seja compilada para FPGAs, listado na Plataform 
Support Package, que serão detalhado mais adiante. A Plataform Support Package permite selecionar o fabricante, família e algumas características tais como o processador embarcado e o barramento usado para comunicação entre os componentes internos no FPGA. Com essas informações, o CoDeveloper pode gerar o projeto completo para a plataforma FPGA escolhida, tal como código fonte para o processador embarcado, arquivo de descrição de hardware para o FPGA, arquivo de descrição de hardware contendo a interface no $F P G A$ e drivers para que o software gerado para o processador embarcado possa se comunicar eficientemente com o projeto no FPGA. Os arquivos de descrição de hardware correspondente ao barramento utilizado também são gerados, bastando especificar uma das alternativas de projeto disponíveis no Plataform Support Package.

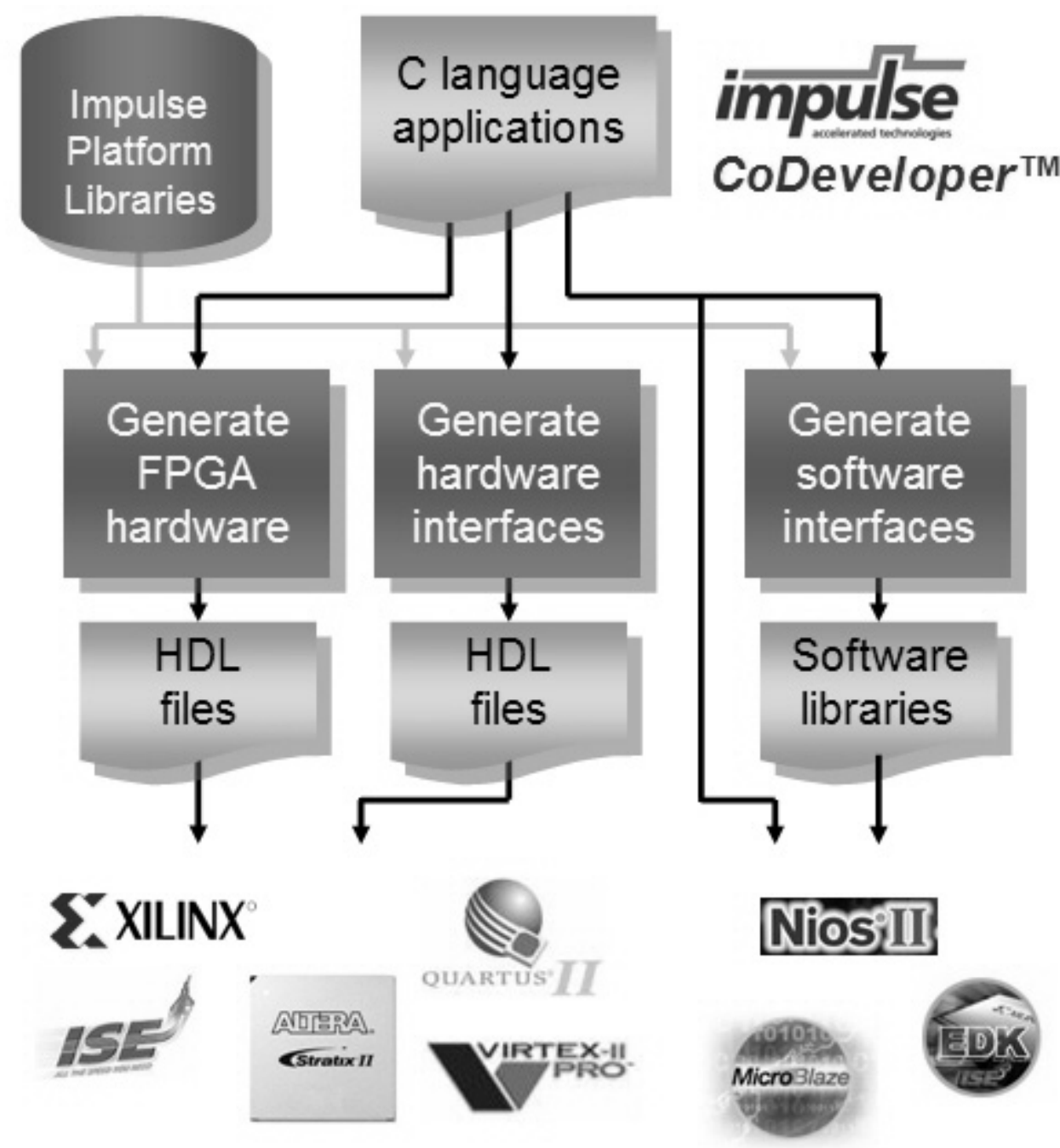

Figura 36. Ambiente completo do CoDeveloper

A Figura 37 mostra o ambiente CoDeveloper, com uma aplicação chamada HelloWorld. Em source files, pode ser visto os arquivos que compõem as descrições das funcionalidades dessa aplicação: HelloWorld.c, HelloWorld_sw.c e HelloWorld_hw.c. 
No lado esquerdo dos nomes dos arquivos, pode ser visto um ícone "sw" e um ícone " $h w$ ". O ícone " $s w$ " indica que o processo servirá como testbench, com o objetivo de validar o comportamento da aplicação ou pode ser usado para gerar um programa para ser executado em um processador embarcado no $F P G A$; “ $h w$ ” indica que o arquivo será sintetizado para o FPGA escolhido em Plataform Support Package. A simulação do comportamento da aplicação pode ser feita por ferramentas de desenvolvimento C, tais como Microsoft Visual Studio e gcc ou ainda pelo próprio ambiente de implementação do CoDeveloper, clicando-se no ícone launch simulation executable, indicado pela flecha na Figura 37. O resultado da simulação é mostrado no prompt do $M S$-DOS, como qualquer programa compilado e executado em um compilador $C$.

Desktop simulation, no ambiente CoDeveloper, refere ao método de depurar uma aplicação Impulse $C$, representada por processos de hardware e software operando em paralelo, compilada sobre um ambiente de desenvolvimento $C$ (uma $I D E$ ).

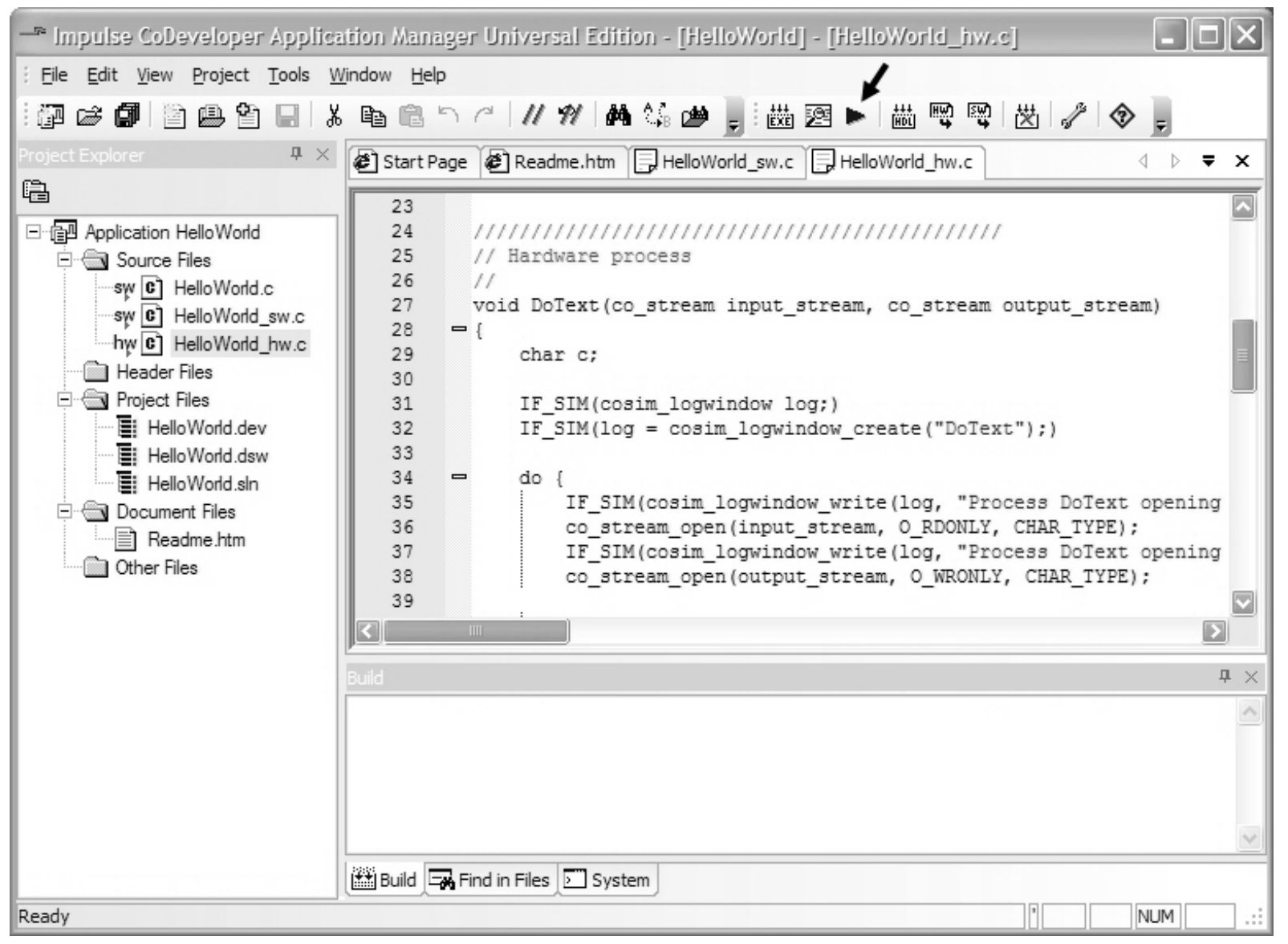

Figura 37. Ambiente de implementação do CoDeveloper (CoDeveloper Application Manager)

Na Figura 38 pode ser visto um exemplo de Desktop Simulation, na qual uma aplicação do Impulse C é depurada na ferramentas de desenvolvimento C - Microsoft Visual Studio. Isso é possível graças às bibliotecas do Impulse $C$. 
A Figura 39 permite a visualização do ambiente de monitoramento do CoDeveloper, chamado Application Monitor. O Application Monitor permite visualizar a execução dos processos, tanto os processos de hardware quanto os de software. O monitor permite a visualização de processos individuais ou de todos eles ao mesmo tempo, mostra a interface entre os processos (entradas/saídas, através de streams, sinais ou memória compartilhada).

Com o Impulse $C$ o projetista pode experimentar diferentes abordagens de algoritmos, diferentes alternativas de particionamento hardware e software, além de permitir utilização de diferentes plataformas, suportadas pelo CoDeveloper e selecionadas através do Plataform Support Package.

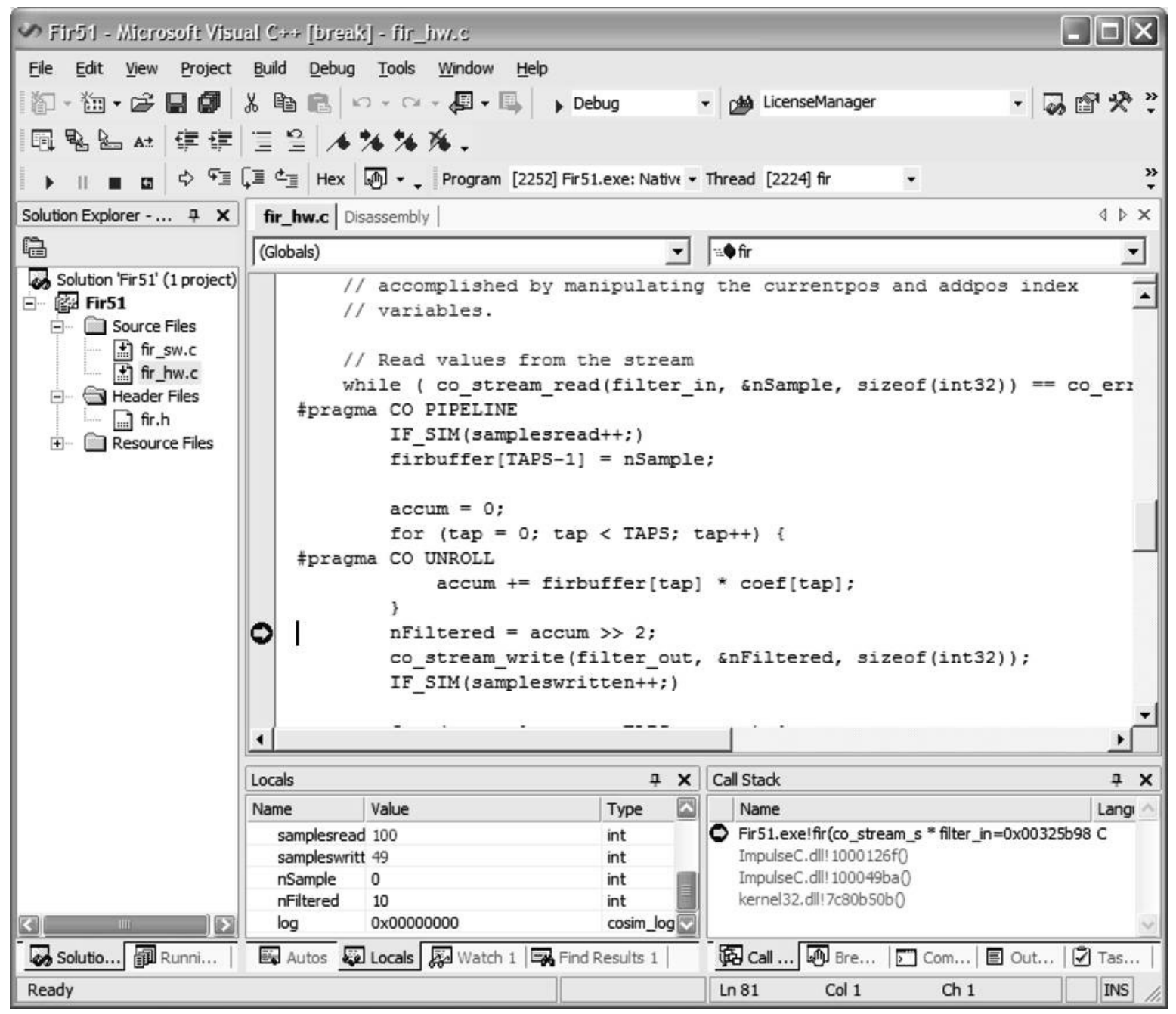

Figura 38. Desktop Simulation

Assim como a maioria das ferramentas de conversão $C$ para $F P G A$, o Impulse $C$ exige do programador pelo menos um entendimento rudimentar de como detalhar a otimização, geração de código e mapeamento de processos, para obter alto desempenho. Os programadores devem exercer algum nível de controle sobre os processos, seja ajustando o fluxo ou revi- 
sando a aplicação original e otimizando os algoritmos. O projetista também deve indicar quais processos formarão hardwares e quais formarão softwares, afim de que seja feito o particionamento hardware e software.

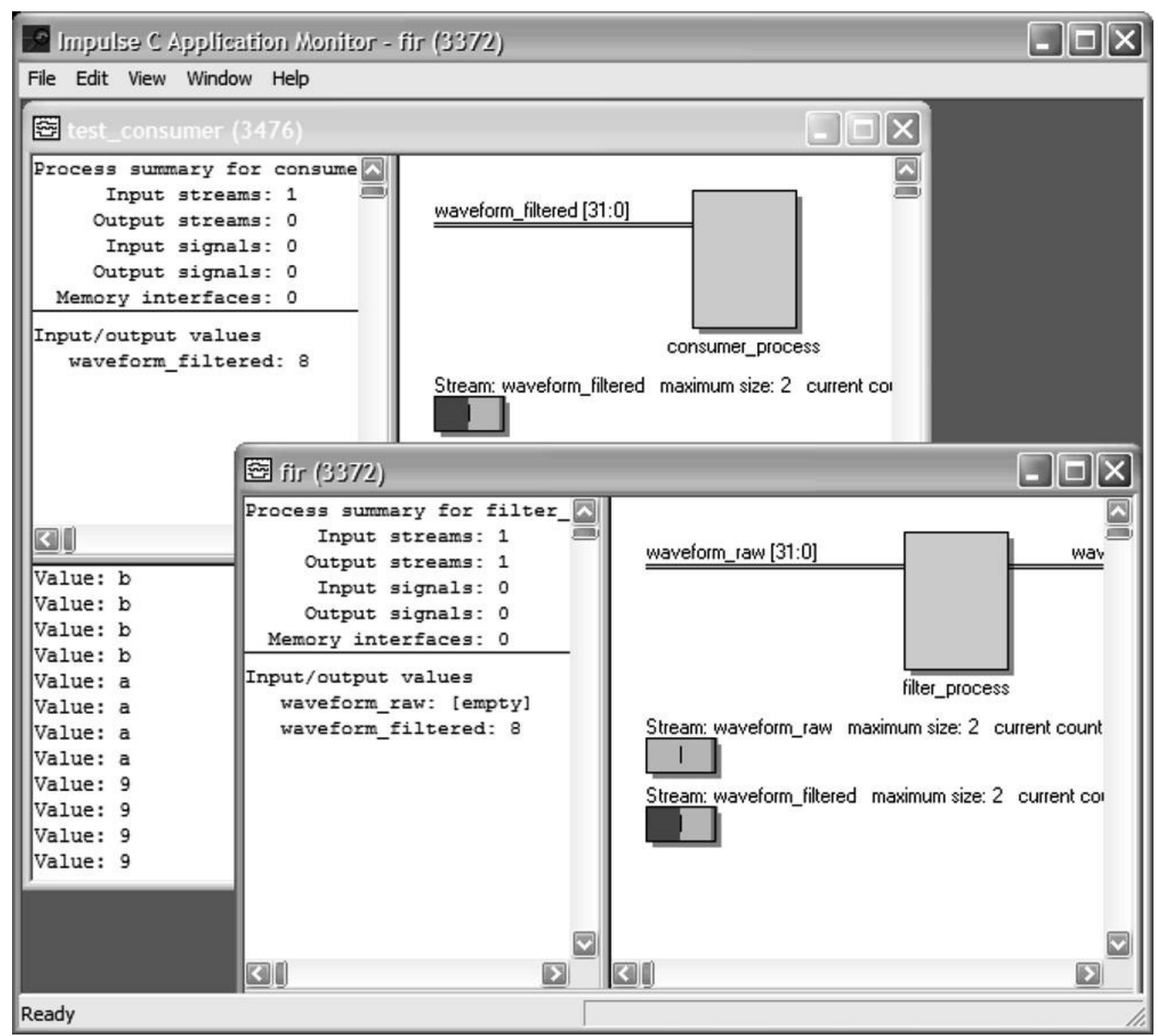

Figura 39. Exemplo do Application Monitor

Se não forem escritas aplicações com técnicas de paralelismo, não é provável que as ferramentas automáticas de conversão $C$ para $F P G A$ produzam uma implementação eficiente. $\mathrm{O}$ compilador não tem o mesmo conhecimento da aplicação que o programador.

As ferramentas de compiladores para FPGA, incluindo Impulse $C$ ainda são prematuras. (Pellerin, et al., 2005) E os resultados não alcançam a qualidade da implementação manual.

Assim como o Desktop Simulation e Application Monitor, o CoBuilder do CoDeveloper consiste de uma seqüência de processos de traduções e compilações que analisam a aplicação escrita em Impulse $C$ e extrai o processo que o projetista configurou como processo de hardware e gera a descrição de hardware equivalente no formato $H D L$. Dependendo da informação da arquitetura que o projetista selecionou no Platform Support Package, o CoBuilder gera 
os arquivos de interface de hardware/software, incluindo bibliotecas $C$ e vários componentes de hardware que possibilitam a comunicação hardware/software na plataforma escolhida.

CoBuilder analisa a aplicação, extrai os processos especificados para implementação em hardware e cria o arquivo de descrição de hardware otimizado pronto para ser sintetizado pelas ferramentas de síntese do FPGA escolhido pelo usuário.

Quando CoBuilder é aberto no CoDeveloper, apenas os processos que foram especificados pelo projetista, indicados pelo ícone " $h w$ ”, na janela de projeto, são analisados pelo compilador de hardware. Os outros processos são ignorados pelo compilador de hardware.

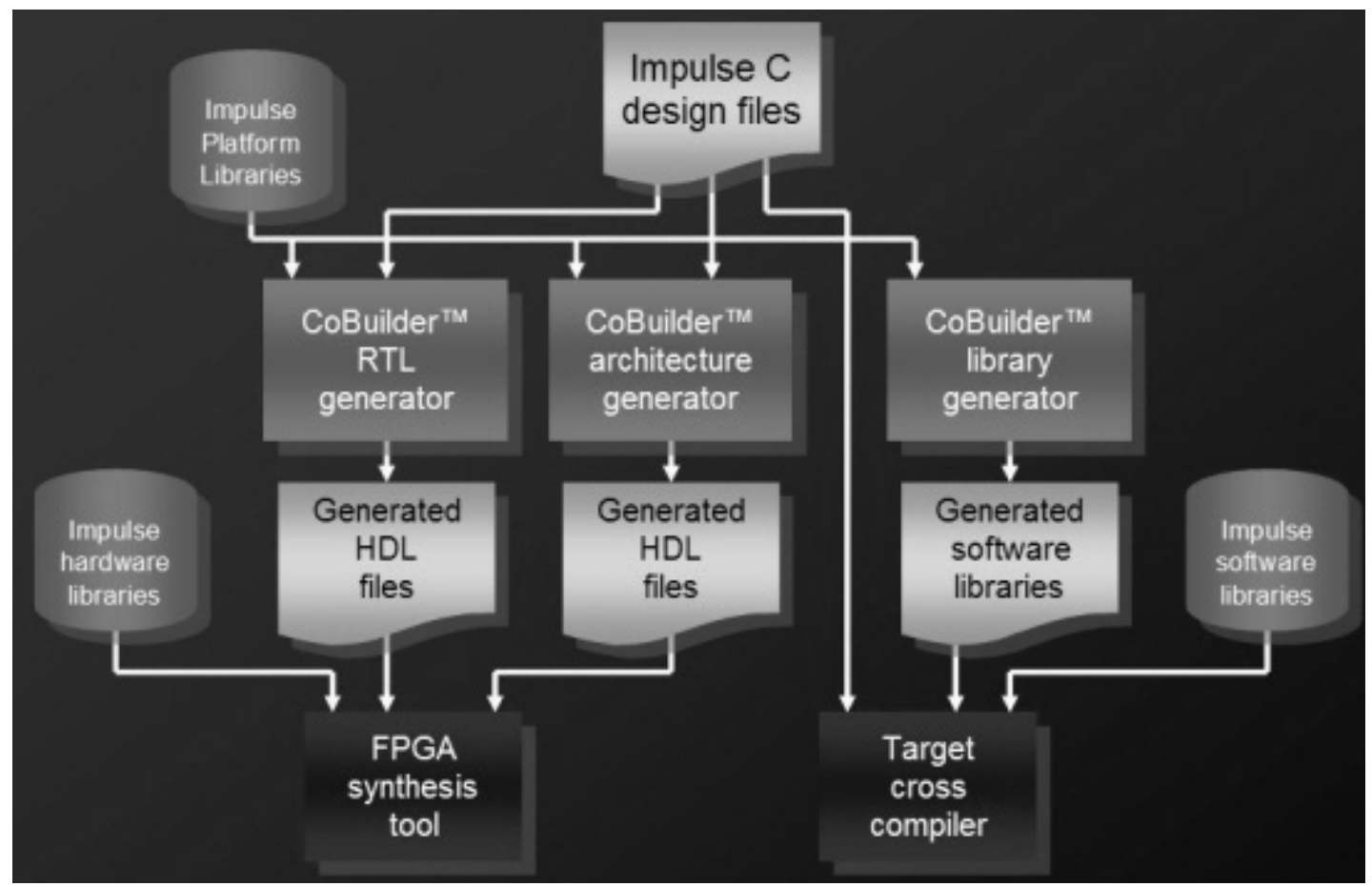

Figura 40. Diagrama de uma simplificada descrição de como os processos trabalham no CoDeveloper

Como mostrado na Figura 40, há atualmente três grandes operações executadas como parte da execução típica do CoBuilder:

1. Os processos da aplicação do usuário escrita em Impulse $C$ são compilados e é gerada a descrição de hardware (CoBuilder RTL generator);

2. Arquivos adicionais são gerados para a interface de hardware para o barramento onchip da plataforma FPGA (CoBuilder architecture generator);

3. Bibliotecas e outros arquivos $C$ são gerados para a interface software para fazer a comunicação hardware/software (Generated software libraries).

Enquanto a primeira dessas três operações é relativamente genérica, a segunda e terceira operação são customizadas para uma plataforma especifica, selecionada pelo projetista no Platform Support Package. 
O PSP (Plataform Support Package) é composto por pacotes opcionais que provêem bibliotecas para uma plataforma especifica. O PSP simplifica a criação de aplicações hardware/software, porque fornece as interfaces necessárias para o hardware (FPGA) e o software (processador embarcado). A Figura 41 mostra um exemplo do PSP.

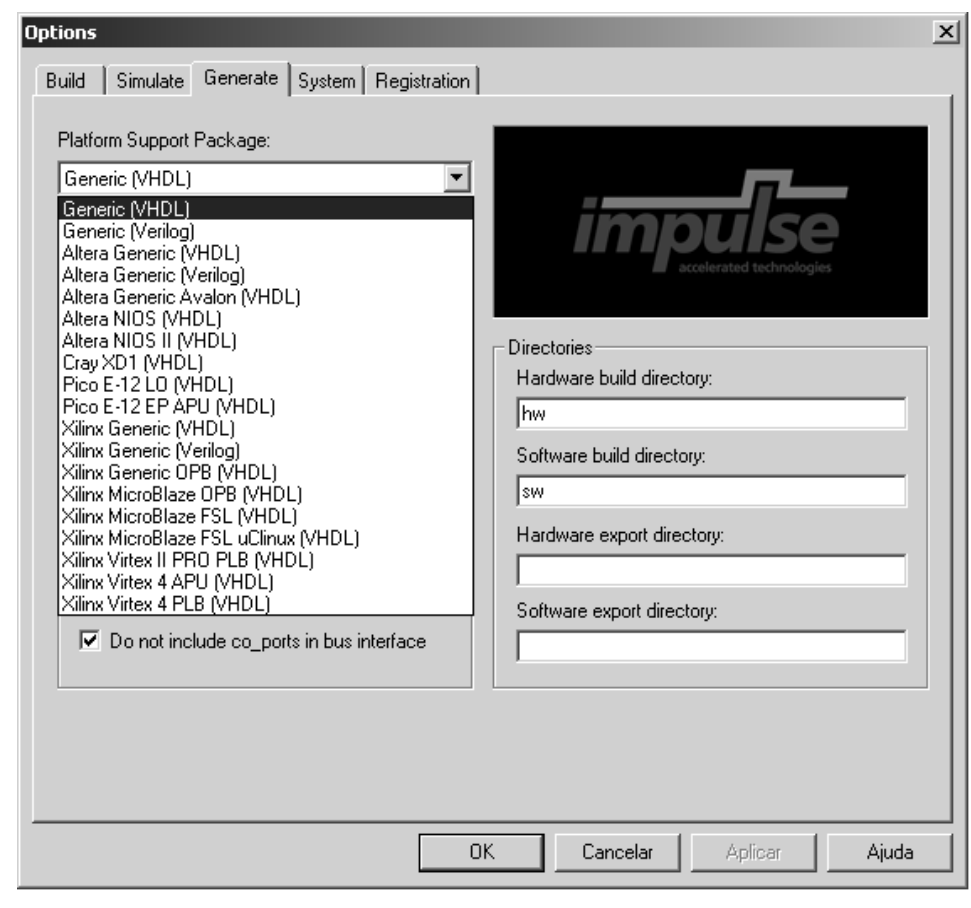

Figura 41. Plataform Support Package

Como pode ser visto na Figura 41, o PSP permite ao projetista selecionar alguns fabricantes de FPGAs, o formato $H D L$ para gerar as interfaces de hardware, o tipo do processador embarcado, quando disponível para a plataforma FPGA e o barramento de dados utilizado pela plataforma FPGA para fazer a interface dos diversos componentes do FPGA.

Como mostra a Figura 42, além de selecionar o FGPA no PSP, o usuário também pode selecionar e especificar algumas opções de otimizações a serem feitas pelo compilador. Entre as opções de otimizações que podem ser especificadas pelo usuário estão: constant propagation, scalarize array variables, loop unrolling, reduction, common subexpression elimination, pipelining, descritos a seguir.

A opção constant Propagation propaga os valores das constantes. Com essa opção, as expressões podem ser calculadas em tempo de compilação e substituídas pelos valores calculados.

Com a opção propagação de constantes habilitada, o compilador pode, dependendo das circunstancias, reduzir o código abaixo para $\mathrm{x}=2$;

Exemplo: 

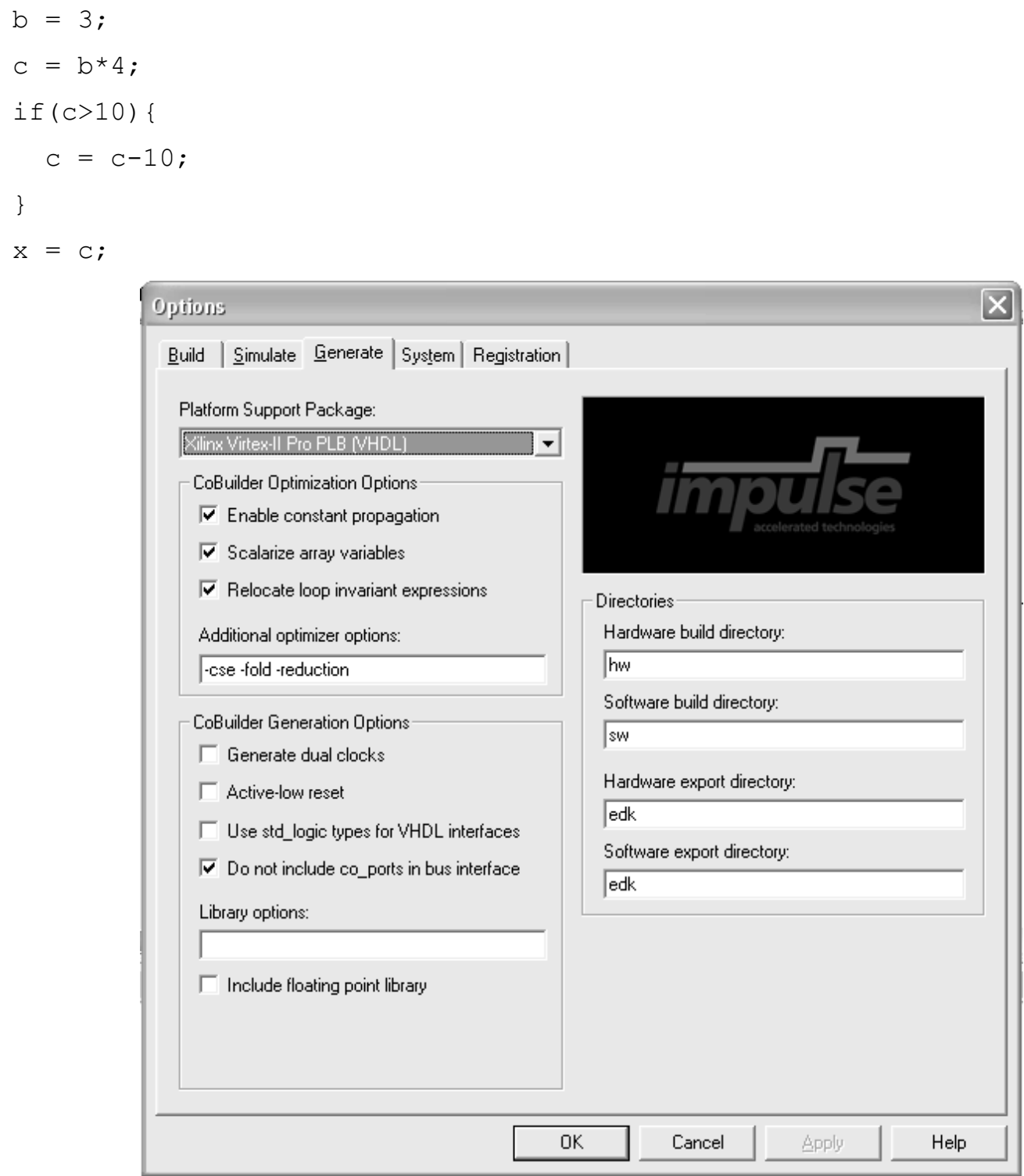

Figura 42. PSP e opções de otimização selecionadas pelo usuário

Com a opção scalarize array variables habilitada, o compilador tentará substituir vetores locais em variáveis, de modo que elas possam ser implementadas em registradores ao invés de memórias. Quando um vetor é implementado em registradores, qualquer número de elementos podem ser escritos ou lidos simultaneamente, permitindo um alto nível de paralelismo.

A opção loop unrolling move certas expressões para fora do escopo do loop. A opção unrolling pode ser habilitada pela instrução \#pragma CO UNROLL. Um exemplo da opção loop unrolling pode ser visto abaixo:

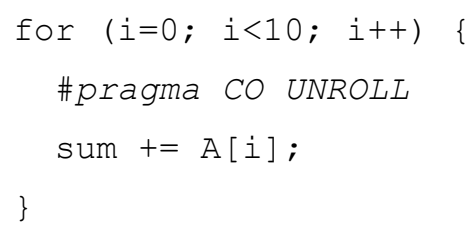


Com a opção loop unrolling o compilador elimina o bloco do loop e duplica o corpo dele para todos os valores de " $i$ ”. No exemplo acima, com a opção loop unrolling habilitada, o resultado é mostrado abaixo:

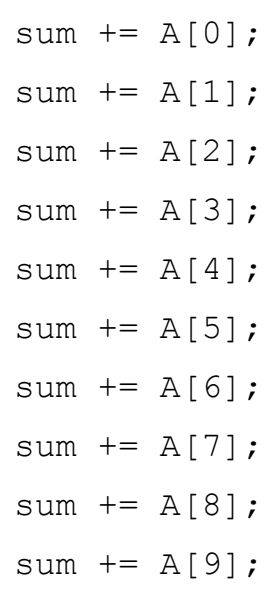

Como visto no exemplo acima, 10 somadores foram gerados e cada um é usado apenas uma vez durante a execução do loop. Segundo (Pellerin, et al., 2005), na maioria das vezes, como no exemplo acima, a opção loop unrolling sozinha não traz melhorias significativas, porque apenas um valor do vetor " $A$ " pode ser lido em um dado ciclo, ou seja, nesse exemplo, mesmo com a opção loop unrolling, o exemplo acima requer 10 ciclos de clock para executar e 10 somadores tem que ser gerados. Porém, se a opção scalarize array variables for usada junto com a opção loop unrolling, os elementos do vetor são substituídos por variáveis escalares. Então o resultado é equivalente a:

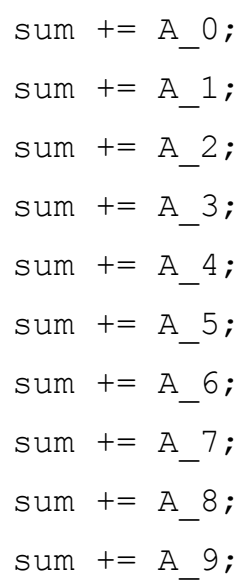

Ao invés de ser gerado uma memória para o vetor " $A$ ", registradores são gerados para cada um dos 10 elementos do vetor. Então, os 10 registradores podem ser lidos simultaneamente e assim esse loop inteiro pode ser executado com apenas 1 ciclo de clock.

Segundo (Pellerin, et al., 2005), o uso da opção unrolling requer alguns cuidados, porque uma grande quantidade de lógica pode ser gerada e o cycle delay pode aumentar, diminuendo assim a máxima freqüência do clock (maximum clock frequency). 
A opção reduction executa algumas otimizações de redução nos loops.

A opção pipelining permite que múltiplas iterações de um loop sejam executada em paralelo. A instrução pipelining deve ser inserida manualmente no código pelo projetista, ou seja, ela não é feita de forma automática pelo compilador. A instrução pipelining deve ser incluída em um corpo de loop e anterior a qualquer outra instrução nele. A opção pipeline pode ser habilitada pela instrução \#pragma CO PIPELINE. Exemplo:

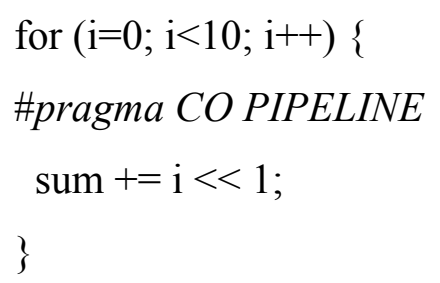

A Figura 43 mostra a ferramenta Stage Master Debugger, onde é possível depurar a execução do hardware, ciclo por ciclo. É possível ver o nível de otimização aplicado pelo compilador, ver as instruções sendo executadas concorrentemente e onde é o gargalo do hardware. Com isso, o projetista pode reescrever seu código e melhorar o desempenho do hardware a ser gerado, por exemplo, aplicando técnicas de otimização do compilador, tais como pipeline, loop unroling.

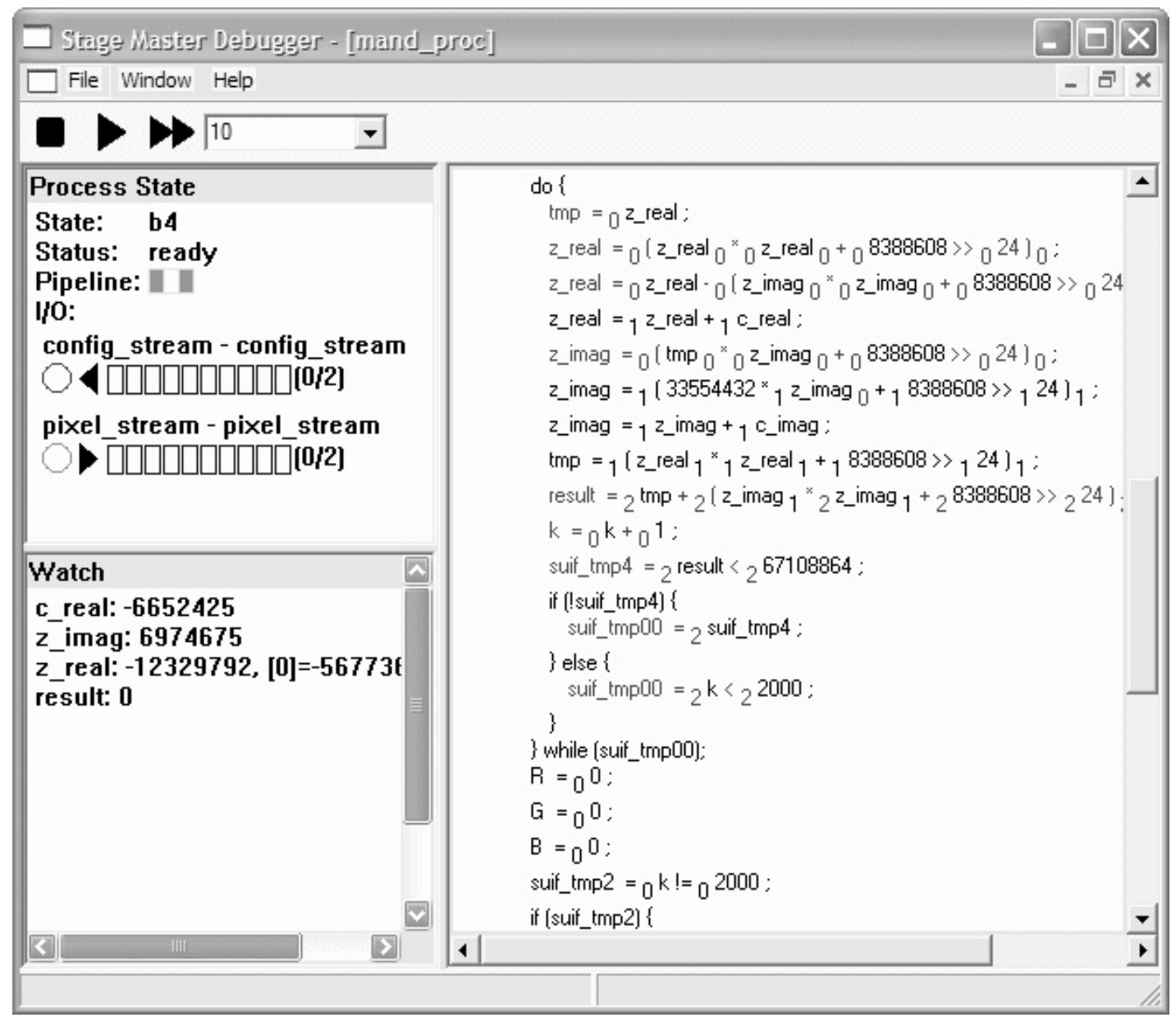


Figura 43. Ferramenta Stage Master Debugger

A Figura 44 mostra a ferramenta Stage Master Explorer, que permite visualizar o processo de hardware e fornece uma estimativa de atraso, loop latencies and effective pipeline rates as appropriate.

Na Figura 45 é mostrada ainda a ferramenta Stage Master Exeplorer onde é possível ver uma análise detalhada sobre a estrutura do hardware paralelo e o grafo Dataflow de cada bloco do hardware. Esse grafo permite observar ciclo por ciclo, como as instruções da linguagem C são decompostas em operações paralelas.

Há certas operações que são expressas em $C$ que são difíceis ou impraticáveis para serem implementadas em $F P G A$. Um exemplo é a divisão inteira, a qual o usuário gasta uma quantia muito grande de lógica do FPGA. (Pellerin, et al., 2005)

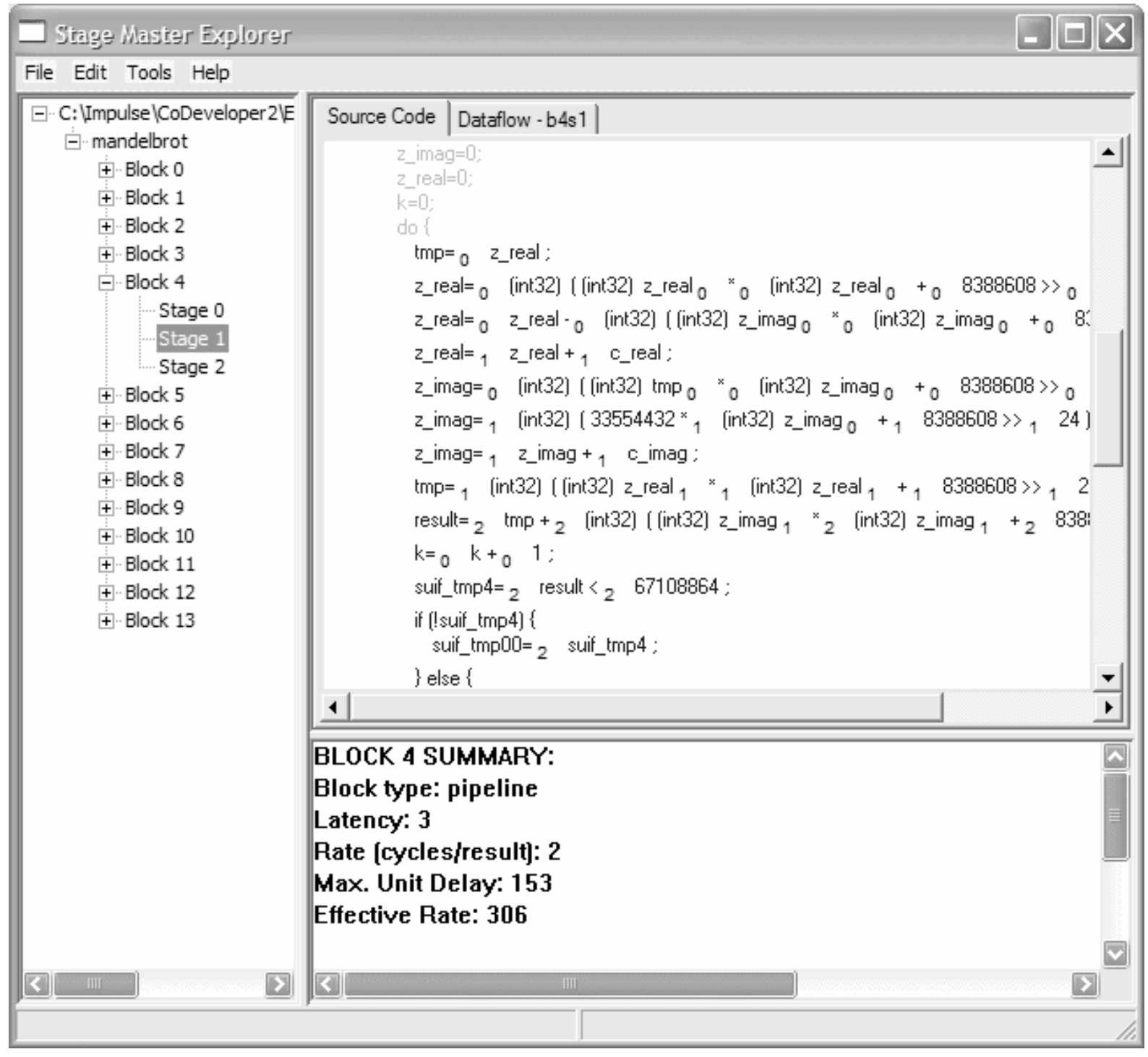

Figura 44. Ferramenta Stage Master Explorer 
Os seguintes tipos de instruções em $C$ e construções não são suportadas ou são minimamente suportadas em processos FPGA:

- Sem recursão: um processo de hardware não pode chamar ele mesmo, direta ou indiretamente;

- Sem chamada de funções: com exceção das funções pré-definidas pelo Impulse $C$;

- Os ponteiros devem ser resolvidos em tempo de compilação;

- Sem suporte a records ou estruturas: apenas são permitidos inteiros e arrays;

- Sem suporte a variáveis globais: deve-se usar streams, sinais e memórias compartilhadas para fazer a comunicação entre processos.

A Figura 45 mostra os detalhes do dataflow gerado para cada bloco do processo de hardware. Conforme mostrado acima, com esse dataflow é possível o projetista ter uma visão clara sobre as dependências dos operandos no processo de hardware, assim, o projetista pode eliminar algumas dependências melhorando o desempenho do hardware a ser gerado pelo CoBuilder.

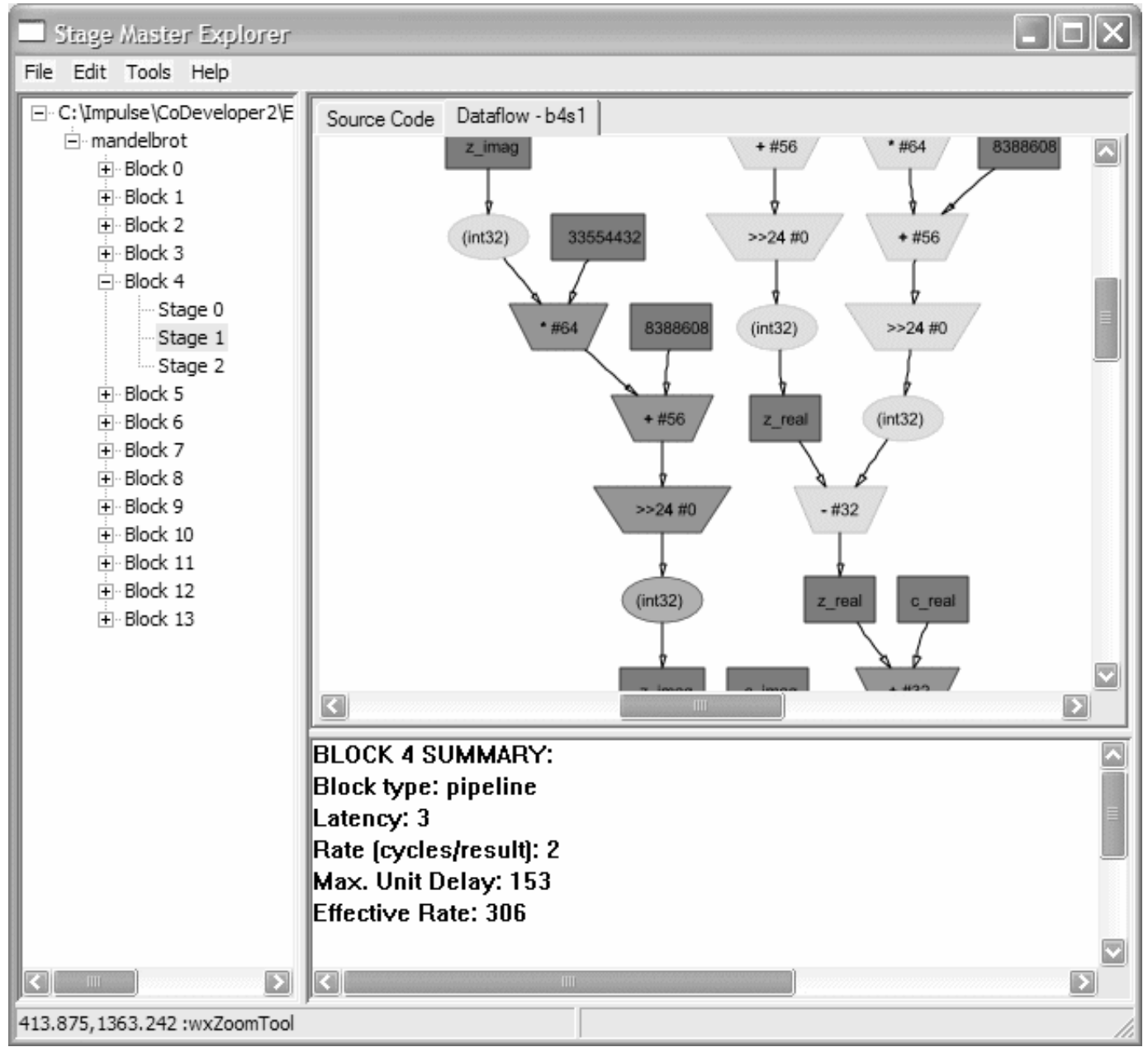

Figura 45. Ferramenta Stage Master Explorer - análise mais detalhada sobre o hardware gerado 
No APÊNDICE B será mostrado como o algorítmo de ordenação do APÊNDICE A póde ser escrito em Impulse C e os resultados em VHDL que essa ferramenta gera. O objetivo dos APÊNDICES A e B é confrontar os resultados gerados pelas duas ferramentas: Spark e Impulse C, a partir de um mesmo algoritmo de entrada, reescrito para atender as exigências de ambas as ferramentas. 


\section{Capítulo 5}

\section{Descrições dos benchmarks}

Esse capítulo mostra alguns benchmarks que serão usados para analisar o Impulse $C$, quanto aos arquivos gerados e desempenho no FPGA. O objetivo dos benchmarks é comparar os resultados alcançados pelo Impulse $C$, usando-se para isso ferramentas CAD e a plataforma de desenvolvimento da Digilent utilizada nessa dissertação: XUP V2P.

Aqui será apresentado os três benchmarks. Segundo (Altera, 2006), a industria de FPGAs não tem uma metodologia padrão de benchmarks.

Nos tópicos a seguir, serão apresentados os benchmarks que serão reescritos em Impulse C e compilados com o CoBuilder.

Os benchmarks escolhidos são utilizados nas áreas de processamento de imagens e multimídia.

\subsection{Transformada Rápida de Fourier - FFT}

As transformadas de Fourier têm muitas aplicações na área científica: em física, teoria dos números, análise combinatória, processamento de sinal, criptografia entre outras áreas. Nos campos relacionados com o processamento de sinal, a transformada de Fourier é tipicamente utilizada para decompor um sinal nas suas componentes em freqüência e suas amplitudes.

Um sinal pode ser analisado no domínio temporal ou no domínio de freqüências (análise espectral). (Duarte, 2006) 


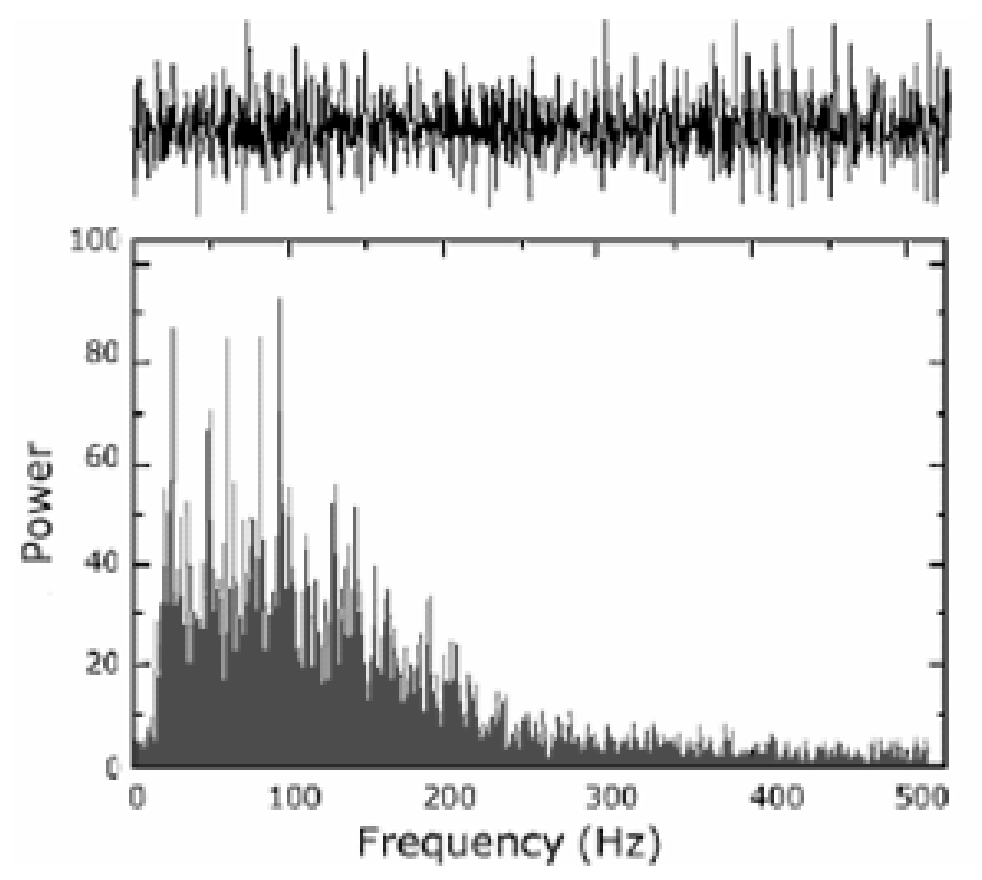

Figura 46. Exemplo de um sinal no domínio do tempo e no domínio da freqüência

As transformadas de Fourier são utilizadas em processamento de sinais digitais para encontrar a freqüência contida em um dado sinal de entrada. Um exemplo da transformada de Fourier pode ser visto na Figura 46. O sinal de entrada é uma função polinomial com amplitudes aleatórias e componentes de freqüência senoidal. (Ynoguti, 2004)

Qualquer sinal ou função matemática pode ser expresso como uma soma de senos e cossenos (Análise de Fourier).

Computacionalmente, a decomposição do sinal em senos e cossenos pela análise de Fourier é implementada por um algoritmo conhecido como FFT. (Duarte, 2006)

A análise de Fourier fornece três informações:

1. Os valores das freqüências que compõem o sinal (freqüências dos senos e cossenos);

2. As amplitudes destas freqüências e

3. As fases destas freqüências.

A análise de Fourier é uma família de técnicas matemáticas, todas elas baseadas na decomposição de sinais em senóides. (Ynoguti, 2004)

A Transformada Discreta de Fourier, em inglês DFT (Discrete Fourier Transform) é o membro da família utilizado para sinais digitalizados.

Todos os membros da família de transformadas de Fourier assumem que os sinais sob análise têm duração infinita. 
Para analisar os sinais com um computador com processador de uso geral ou $D S P$, os sinais têm necessariamente que ter duração finita.

Desta forma, tem-se que fazer com que os sinais "pareçam" ter duração infinita.

Isso pode ser feito considerando-se que o sinal se repete periodicamente (periódico $D F T)$.

As informações contidas no domínio da freqüência são exatamente as mesmas do domínio do tempo, só que de forma diferente. (Ynoguti, 2004)

Para se transformar do domínio de tempo para o domínio de freqüência, usa-se decomposição, análise, DFT direta. (Ynoguti, 2004)

Para se transformar do domínio da freqüência para o domínio do tempo, usa-se síntese, DFT inversa. (Ynoguti, 2004)

Segundo (Filho, et al., 1999) a transformada rápida de Fourier é um algoritmo cujo principal objetivo é reduzir o custo computacional do cálculo da transformada discreta de Fourier de $N$ pontos, substituindo o processo convencional de cálculo, no qual o número de multiplicações e adições é proporcional a $N^{2}$ por um engenhoso arranjo que combina diversas transformadas parciais, cada qual com pequeno número de pontos, em que o número de adições e multiplicações é proporcional a $\operatorname{Nog}_{2} N$.

Ainda segundo (Filho, et al., 1999), a diferença de velocidade entre os algoritmos de transformada discreta de Fourier e transformada rápida de Fourier é de 56 vezes para $N=512$ pontos.

A redução em proporcionalidade de $N^{2}$ para $N \log _{2} N$ operações representa uma economia significativa no esforço computacional, principalmente quando $N$ for relativamente grande. Segundo (Gongalez, et al., 2003), suponha que a FFT de um vetor de 8.192 pontos requer $5 s$ de tempo de computação em um computador de propósito geral. A mesma maquina levaria cerca de 600 vezes mais tempo $(50 \mathrm{~min})$ para computar a transformada de Fourier do mesmo vetor.

Para grandes valores de $N$, a quantidade de operações complexas torna o cálculo da transformada discreta de Fourier inviável. (Novo Jr, 2006)

Segundo (Novo Jr, 2006), existem vários tipos de algoritmos FFT que via de regra se equivalem entre si. 
As transformadas rápidas de Fourier são de grande importância em uma vasta gama de aplicações, de processamento digital de sinais (Gongalez, et al., 2003) para a resolução de equações diferenciais parciais a algoritmos para multiplicação de grandes inteiros.

Tabela 5. Gasto computacional de alguns algoritmos FFT

\begin{tabular}{|ccccc|} 
& $\begin{array}{c}\text { Pontos de } \\
\text { entrada } \\
\text { FFT }\end{array}$ & $\begin{array}{c}\text { Multiplicação } \\
\text { (real) }\end{array}$ & $\begin{array}{c}\text { Soma } \\
\text { (real) }\end{array}$ & $\begin{array}{c}\text { Multiplicação } \\
\text { + Soma }\end{array}$ \\
\hline Radix 2 & 1024 & 10248 & 30728 & 40976 \\
Split Radix & 1024 & 7172 & 27652 & 34824 \\
Prime Factor & 1008 & 5804 & 29100 & 34904 \\
Winograd Fourier Transform & 1008 & 3548 & 34416 & 37964 \\
\hline
\end{tabular}

A Tabela 5 (Jones, 2006) mostra o gasto computacional de alguns algoritmos FFT. Os algoritmos Prime Factor e Winograd Fourier Transform requerem um pouco menos de multiplicação, mas a diferença não é suficiente para justificar a dificuldade extra de programação. O algoritmo Winograd Fourier Transform é particularmente difícil de programar e raramente utilizado na pratica. (Jones, 2006).

Segundo a Tabela 5, o algoritmo Split Radix utiliza menos multiplicação e menos soma, comparado com Radix 2, quando os dois tem o mesmo número de pontos de entrada.

O benchmark apresentado nesse tópico processa 16 pontos em ponto flutuante da transformada rápida de Fourier, usando o algoritmo split radix. (Martinian, 2006).

O algoritmo split radix usado nessa dissertação para validar os resultados do Impulse C, requer 79 somas e 10 multiplicação, para processar 16 pontos reais em um processador de propósito geral. (Martinian, 2006)

Como nesse algoritmo não estava especificado um exemplo de valores de entradas e saídas, então, foi usado o Scilab versão 4.0 (Scilab, 2006) para validar esse algoritmo.

Como pode ser observado na Tabela 6 e Figura 47, o algoritmo FFT utilizado possui 16 pontos de entrada e gera os respectivos 16 pontos de saída.

O Scilab é um pacote de software científico para computação numérica semelhante ao Matlab (MathWorks, Inc, 2006) que provê um poderoso ambiente computacional aberto para aplicações científicas e em engenharia. (Scilab, 2006). Desenvolvido desde 1990 pelos pesquisadores do INRIA (Institut National de Recherche en Informatique et en Automatique) e do ENPC (École Nationale des Ponts et Chaussées), é agora mantido e desenvolvido pelo Consorcio Scilab desde sua criação em Maio de 2003 . Distribuído gratuitamente e em código 
aberto via Internet desde 1994, o Scilab é atualmente usado em diversos ambientes industriais e educacionais pelo mundo.

Tabela 6. Valores gerados pela função FFT usando Scilab versão 4

\begin{tabular}{|c|cc|}
$\begin{array}{c}\text { Valores Gerados } \\
\text { pela função main() } \\
\text { Valores de Entrada }\end{array}$ & \multicolumn{2}{|c|}{ Valores gerados pela função FFT } \\
\hline 0 & 381.000000 & 0.000000 \\
27 & -88.131 .526 & -6.3609184 \\
9 & -37.849 .242 & -24.476659 \\
39 & -57.268 .552 & -40.681275 \\
28 & 54.000000 & 13.000000 \\
23 & -19.317 .234 & -24.438634 \\
16 & -81.507 .576 & -50.476659 \\
43 & 87.173 .123 & -14.118278 \\
39 & -85.000000 & 0.000000 \\
36 & 87.173 .123 & +14.118278 \\
8 & -81.507 .576 & +50.476659 \\
41 & -19.317 .234 & +24.438634 \\
34 & 54.000000 & -13.000000 \\
24 & -57.268 .552 & +40.681275 \\
14 & -37.849 .242 & +24.476659 \\
0 & -88.131 .526 & +6.3609184 \\
\hline
\end{tabular}

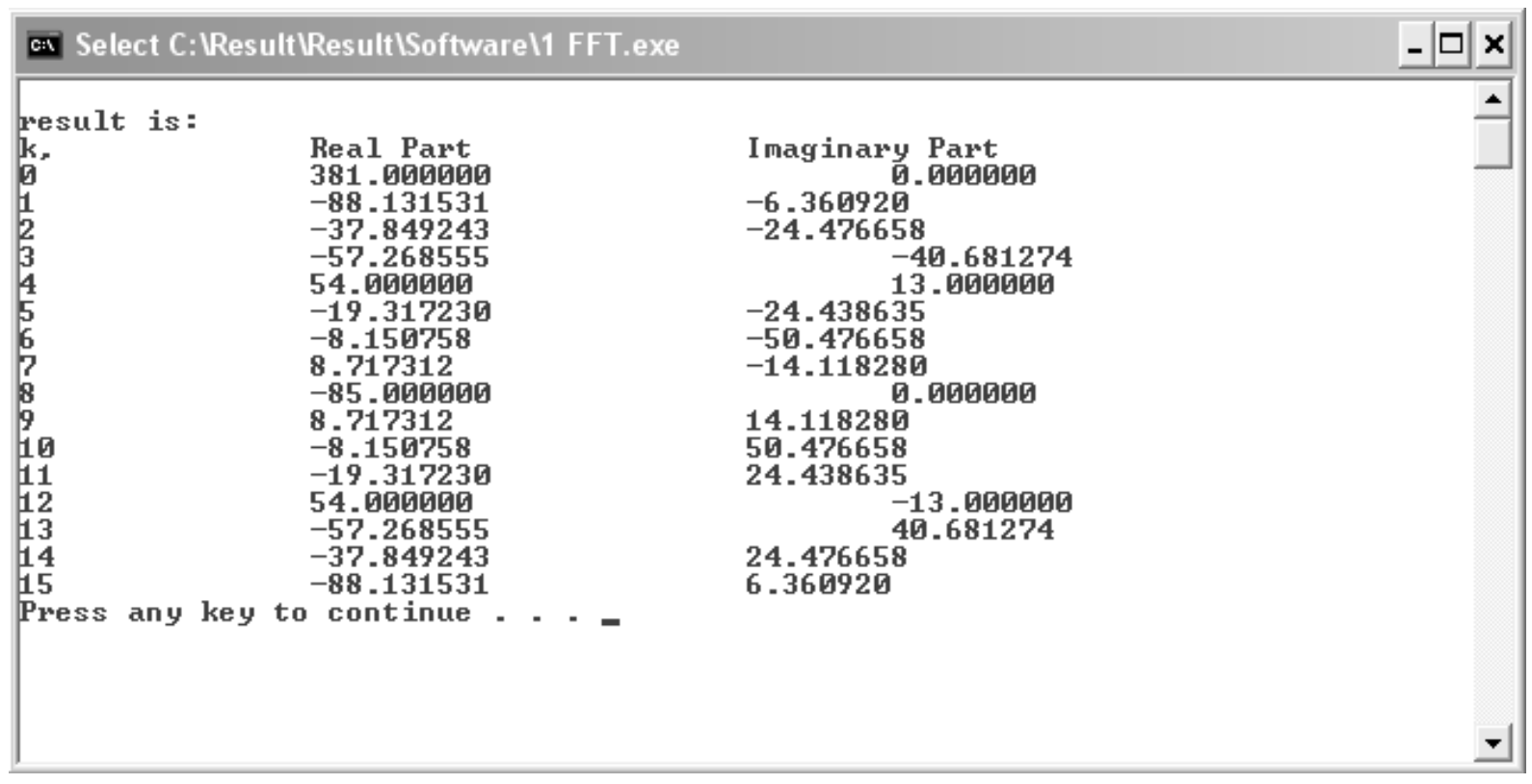

Figura 47. Resultado gerado pelo algoritmo split radix do (Martinian, 2006) 


\subsection{Adaptative Differencial Pulse Code Modula-}

\section{tion - ADPCM}

Sinais de áudio, de imagens gráficas e de vídeo usam uma grande quantidade de dados para sua representação. Existem três razões principais para que os dados em sistemas multimídia sejam comprimidos: (a) necessidade de grande espaço de armazenamento, (b) dispositivos de armazenamento lentos que não permitem fornecer os dados (por exemplo, vídeo) em tempo real, e (c) a baixa capacidade da rede que não permite a transmissão de vídeos em tempo real. (Siscoutto, 1997) Modernas técnicas de compressão para vídeo e imagens oferecem uma solução para este problema, reduzindo essa enorme necessidade de armazenamento.

Existem muitas técnicas usadas para comprimir áudio digital. Algumas das comumente utilizadas estão descritas abaixo. Tipicamente, essas técnicas podem realizar compressão e descompressão em tempo real via software ou hardware barato. (Siscoutto, 1997) Algumas técnicas utilizam qualquer tipo de sinal de áudio e algumas são destinadas especialmente para sinais de voz. (Siscoutto, 1997)

Na modulação por código de pulso, em inglês PCM (Pulse code modulation), segundo (Santos, 2006), um sinal é representado por uma seqüência de pulsos codificados, o que é conseguido através da representação do sinal na forma discreta, no tempo e na amplitude. As operações básicas realizadas no transmissor de um sistema PCM são: amostragem, quantização e codificação. As operações de quantização e codificação são realizadas normalmente pelo mesmo circuito, que é chamado de conversor analógico/digital.

Matematicamente, o processo de amostragem pode ser definido como o resultado da multiplicação de um trem de pulsos periódicos de amplitude 1, Figura 48-b, pelo sinal original a ser amostrado, Figura 48-a. Este processo leva à representação do sinal na forma PAM (Pulse Amplitude Modulation), Figura 48-c. (Santos, 2006) 


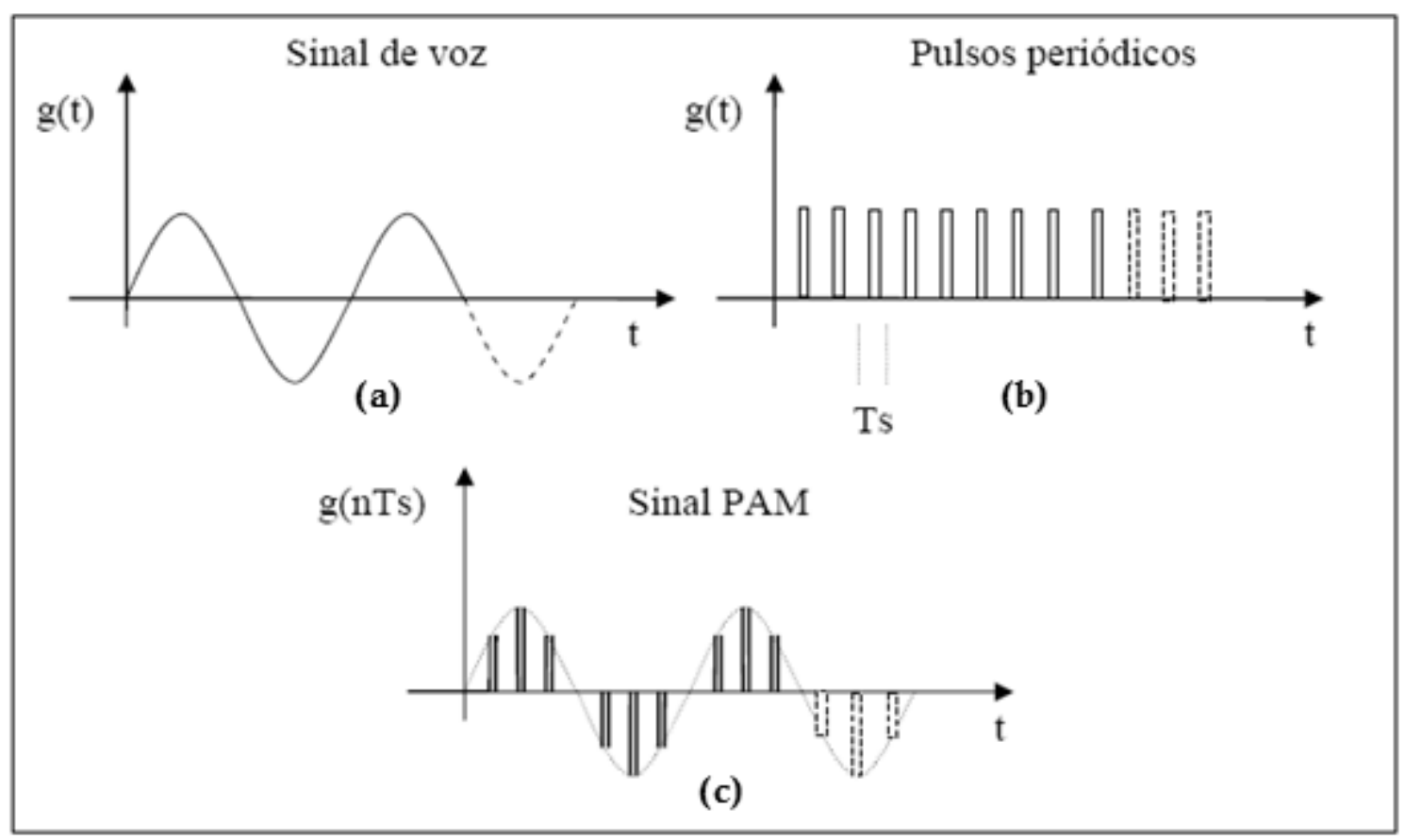

Figura 48. Processo de amostragem

Segundo (Santos, 2006), após o processo de amostragem, Figura 48-c, a versão amostrada do sinal é então quantizada, Figura 49, obtendo-se desta forma, uma nova representação do sinal, que é discreta no tempo e na amplitude. (Santos, 2006)

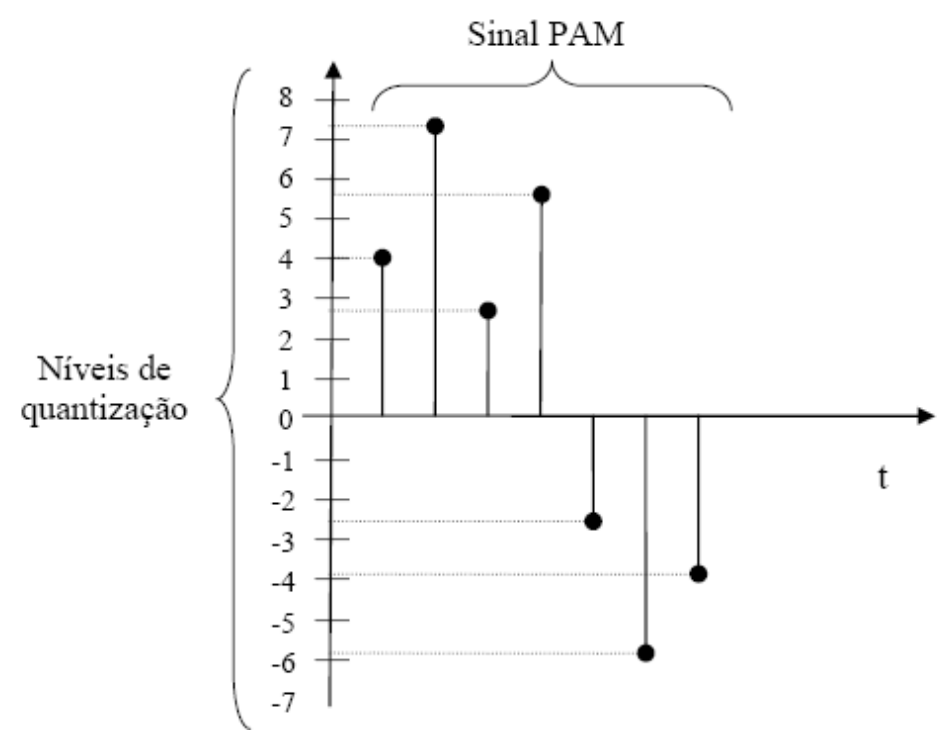

Figura 49. Sinal PAM quantizado

Após os processos de amostragem e quantização, o sinal original passa a ser representado através de um conjunto de valores discretos, Figura 49, mas essa não é a melhor forma de transmiti-lo através do meio de transmissão. Para representar cada conjunto de valores amostrados, é utilizado um processo de codificação, Figura 50. Cada um dos eventos discretos de um código é chamado de símbolo. Um valor distinto do conjunto de valores discretos 
pode ser representado por uma seqüência de símbolos, que formam uma palavra ou caractere.

$$
\begin{aligned}
& \text { Codificação } \\
& \begin{array}{|c|c|}
\hline-7 \rightarrow \mathbf{1 1 1 1} \\
\mathbf{- 6} \rightarrow \mathbf{1 1 1 0} \\
\mathbf{- 5} \rightarrow \mathbf{1 1 0 1} \\
\mathbf{- 4} \rightarrow \mathbf{1 1 0 0} \\
\mathbf{- 3} \rightarrow \mathbf{1 0 1 1} \\
-2 \rightarrow \mathbf{1 0 1 0} \\
-1 \rightarrow \mathbf{1 0 0 1} \\
0 \rightarrow 0000 \\
1 \rightarrow 0001 \\
2 \rightarrow 0010 \\
\mathbf{3} \rightarrow 0011 \\
4 \rightarrow 0100 \\
5 \rightarrow 0101 \\
6 \rightarrow 0110 \\
7 \rightarrow 0111 \\
\hline
\end{array}
\end{aligned}
$$

Figura 50. Processo de codificação

Segundo (Santos, 2006) codecs PCM tais como o ITU G.711 (Corporate Communication Unit, 1999), enviam amostras individuais até o destino, onde a forma de onda original é reconstruída. As variações de voz, entretanto, segundo ele, ocorrem relativamente devagar, e é possível prever o valor de uma determinada amostra baseando-se no valor de amostras anteriores. Então, necessita-se transmitir apenas a diferença entre o valor previsto, e o valor real da amostra. Como no receptor está sendo realizada a mesma previsão, ele pode determinar o valor da amostra original, caso seja informado o valor da diferença entre o sinal previsto e o valor real da amostra. Esta técnica é conhecida como PCM diferencial, em inglês DPCM (Differential pulse code modulation).

Uma versão mais avançada do DPCM, segundo (Santos, 2006) é o DPCM Adaptativo, em inglês ADPCM (Adaptive differential pulse code modulation). O ADPCM tipicamente faz a previsão das amostras baseando-se nas amostras anteriores, e também levando em conta o conhecimento de como a voz varia ao longo do tempo. O erro entre a amostra real e a prevista é quantizado e então enviado ao receptor.

O benchmark escolhido como código para ADPMC foi o encontrado em (Guthaus, et al., 2001). Esse benchmark é composto pelo codificador e decodificador ADPCM.

Como pode ser observado na Tabela 7, o algoritmo ADPCM utilizado possui 16 pontos de entrada e gera os respectivos 16 pontos de saída. 
Tabela 7. Valores gerados pelo ADPCM no computador desktop

\begin{tabular}{|c|c|} 
Valores Gerados & Valores gerados pela função \\
pela função main() & ADPCM - Decodificadora \\
\cline { 2 - 2 } Valores de Entrada & \\
\hline 41 & 45 \\
35 & 29 \\
-66 & -73 \\
-124 & -112 \\
-31 & -28 \\
108 & 115 \\
-42 & -61 \\
-82 & -84 \\
82 & 66 \\
-112 & -110 \\
73 & 55 \\
-15 & -9 \\
-15 & -28 \\
-69 & -80 \\
-23 & -32 \\
-21 & -18 \\
\hline
\end{tabular}

\subsection{Forward Discrete Cosine Transform - FDCT}

Com o uso cada vez maior de documentos eletrônicos, descobriu-se rapidamente que os usuários enfrentariam dificuldades para armazenar, manipular e transmitir imagens digitais.

Uma imagem digital é uma matriz $N \times N$ de números inteiros, ou elementos de imagem, que exige $N^{2} B$ bits para sua representação, onde $B$ é o número de bits por elemento. (Rigotti, 2004)

O processo de compressão de imagens objetiva-se na redução dos dados redundantes na imagem digital, a qual deve ser feita antes do armazenamento ou transmissão da imagem. A percepção das cores pelo mecanismo de visão do ser humano tem papel importante no estabelecimento destas redundâncias, uma vez que podem ser removidas as tonalidades, por exemplo, imperceptíveis ao olho humano.

Segundo (Rigotti, 2004), as imagens contêm uma grande parcela de redundância, ou seja, é grande a correlação entre os pixels formadores da imagem. Os processos de codificação por transformada reduzem correlação. Técnicas que aplicam transformadas geralmente dividem a imagem em blocos para diminuir a complexidade do algoritmo. A imagem é dividida em blocos de tamanho fixo, geralmente $8 \times 8,16 \times 16$, assim por diante. Cada bloco é tra- 
tado como um vetor $\alpha$ e codificado com a transformada, independentemente dos outros blocos. Posteriormente, para fazer a decodificação, este vetor é processado com a operação inversa da transformada, produzindo o vetor reconstruído $\alpha^{*}$. Os blocos reconstruídos são reunidos novamente para formar a imagem.

A eliminação de dados psicovisualmente redundantes resulta em uma perda de informação e é comumente denominada quantização. Como essa operação é irreversível, ou seja, informação visual é perdida, a quantização resulta em compressão de dados com perda. (Gongalez, et al., 2003)

A codificação DCT (Discrete Cosine Transform) é uma importante ferramenta utilizada na compressão de imagens.

A DCT é explorada de forma prática, por exemplo, no padrão JPEG para codificação de imagens estáticas e no MPEG (Moving Pictures Experts Group) para imagens em movimento. Um exemplo para a utilização do MPEG é a tecnologia de DVD (Digital Versatile Disc). (Rigotti, 2004)

Dentre os sistemas de compressão mais populares pode-se destacar o padrão definido pelo JPEG (Joint Photographic Experts Group), que é um sistema de compressão baseado na transformada discreta do cosseno DCT. (Carvalho, et al., 2003)

No caso particular da compressão JPEG, a transformação utilizada é a transformada discreta do cosseno DCT. Esta transformada tem a importante característica de reduzir a redundância espectral dos pixels da imagem, além de consistir em algoritmo relativamente fácil de ser implementado. (Carvalho, et al., 2003)

A transformação, tal como o $D C T$, compacta a informação de energia em um número reduzido de amostras. (Rigotti, 2004)

“A função DCT ajuda a separar a imagem em partes (ou sub-bandas espectrais) de diferentes importâncias (relativamente à qualidade visual). Ela transforma a imagem do domínio espacial para o domínio de freqüência." (Carvalho, et al., 2003)

No algoritmo JPEG, a função de transformação $D C T$ é aplicada sobre blocos de imagem de 8x8 pixels.

“No caso particular da compressão JPEG, a transformação utilizada é a DCT. Esta transformada tem a importante característica de reduzir a redundância espectral dos pixels da imagem, além de consistir em algoritmo relativamente fácil de ser implementado." (Carvalho, et al., 2003) 
A FDCT, é a $D C T$ otimizada que reduz os cálculos. A DCT exige 56 adições e 64 multiplicações. Na forma otimizada são feitas apenas 26 adições e 14 multiplicações. (Carvalho, et al., 2003)

O DCT é similar ao FFT, mas pode aproximar melhor as linhas com menos coeficientes. (Marshall, 2001)

O algoritmo benchmark usado nesse tópico é o FDCT usado para verificar o processador Qrisc e estimar o seu desempenho. O Qrisc é um open source core de um processador em linguagem $V H D L$, que é configurado em tempo de compilação e pode ser usado como um módulo IP em um FPSoC. (Campi, 2001)

O algoritmo FDCT trabalha em blocos de imagem de $8 \times 8$ pixels, cada pixel é representado por um número inteiro. Nele são iniciado os 64 valores inteiros e sob a forma de comentário é mostrado os 64 números de saída para os respectivos números de entrada.

O FDCT é composto por dois laços principais de repetição. É importante falar da estrutura de programação desse algoritmo, porque a forma de implementação dele determina a forma de implementação usando o Impulse C e a qualidade dos resultados gerados.

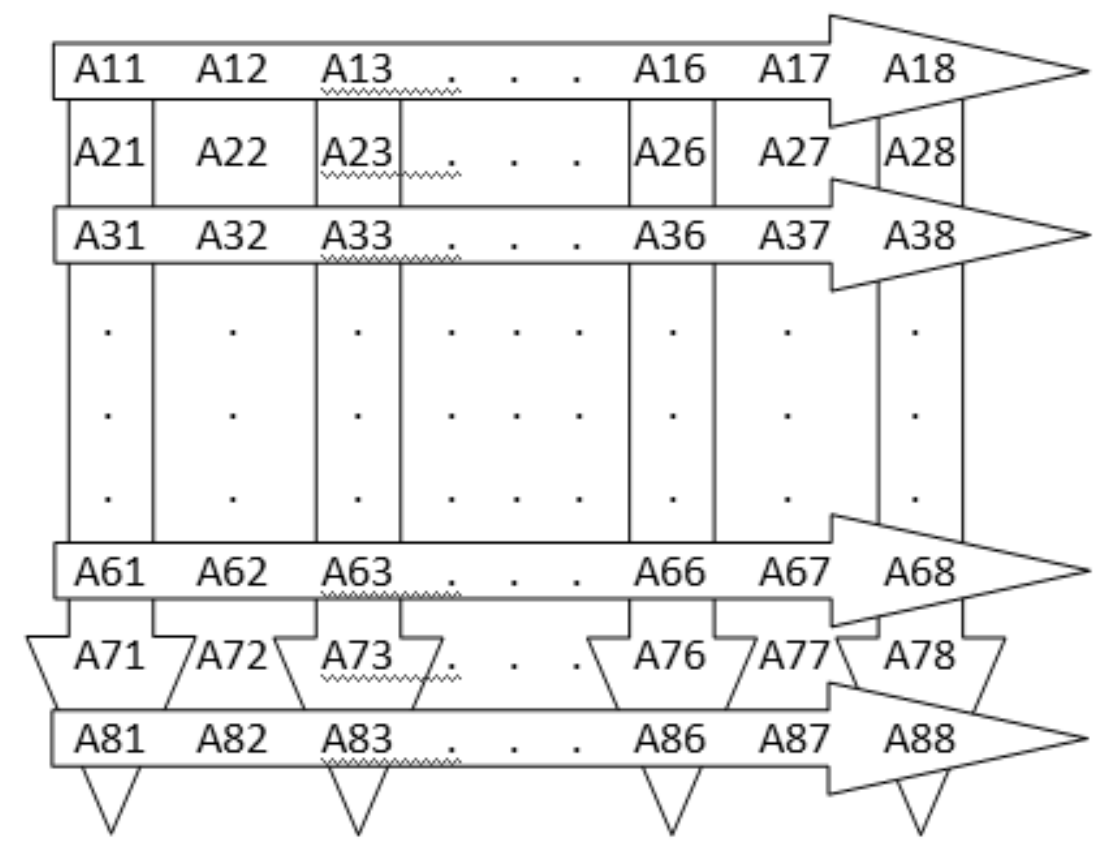

Figura 51. Bloco de imagem de $8 \times 8$ pixels

A Figura 51 representa um bloco de 8x8 pixels. O algoritmo FDCT (Campi, 2001) usado nesse tópico, como dito acima ,é composto por dois laços principais de repetição. O primeiro laço faz o processamento em todas as linhas do bloco. O segundo laço faz o processamento 
de todas as colunas e é dependente dos valores processados pelo primeiro laço. Como será explicado no próximo capítulo a limitação imposta por essa restrição é que os dois laços não podem ser executados em paralelo.

Como pode ser observado na Tabela 8, o algoritmo FDCT utilizado possui 64 pontos de entrada e gera os respectivos 64 pontos de saída.

Tabela 8. Valores gerados pelo FDCT no computador desktop

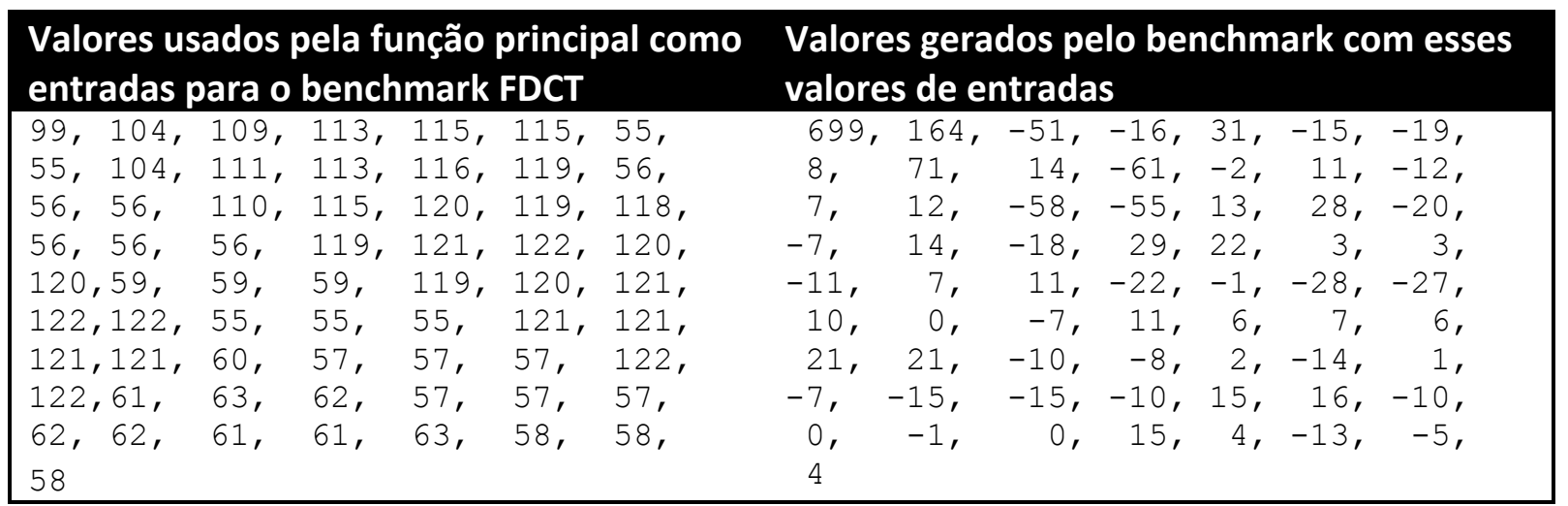




\section{Capítulo 6}

\section{Análise de desempenho baseado nos benchmarks}

Nesse capítulo será apresentado o desempenho dos benchmarks executados na plataforma de desenvolvimento XUP V2P.

Inicialmente os benchmarks serão compilados e executados nos processadores embarcados Microblaze e PowerPC.

Em seguida, os benchmarks serão escritos em Impulse $C$ e compilados pelo Cobuilder, sob a forma de hardware/software codesign. Para essa análise, porém, o processador embarcado escolhido será o que tiver o melhor desempenho na análise anterior.

Para análise de desempenho dos benchmarks será medido o tempo de execução deles na plataforma de desenvolvimento XUP V2P, com a ajuda da ferramenta Gprof (Fenlason, et al., 1998), disponível no ambiente de desenvolvimento EDK da Xilinx.

Nos tópicos a seguir, serão mostrados os desempenhos alcançados pelos benchmarks nos diversos meios de processamento, bem como a explicação sobre a implementação feita.

\subsection{Análise dos benchmarks nos processadores}

\section{embarcados}

Para verificar a correta funcionalidade dos benchmarks nos processadores embarcados, foram comparados os benchmarks compilados pela ferramenta $D E V$-C++ versão 4.9.9.2 e executados em um processador de propósito geral, tal como PENTIUM da Intel com os resultados gerados pelos benchmarks compilados pelo compilador GCC 3.4.1 para os proces- 
sadores Microblaze e PowerPC, presentes na ferramenta EDK da Xilinx e executados por eles na placa de prototipação XUP V2P. Os resultados gerados pelos processadores embarcados, na placa de prototipação XUP V2P são mostrados pelo programa HyperTerminal presente no sistema operacional Windows da Microsoft, através da conexão serial RS232 presente na placa de prototipação e a porta serial COM1, presente no computador desktop. Porém, para a obtenção do desempenho dos benchmarks, nenhum resultado foi gerado pela RS232, afim de que a comunicação por $E / S$ não interferisse no desempenho da execução dos benchmarks. Quando necessário apenas uma mensagem de "fim de execução" era gerada, ao final da execução do processamento dos benchmarks nos processadores embarcados. Essas mensagens de saída pela serial RS232 são feitas pelo processador embarcado, quando ele encontra uma instrução ANSI-C "printf".

O processador embarcado Microblaze, como já mostrado no capítulo 3, é um software core processador RISC de 32 bits, ou seja, ele não é fixo no FPGA, mas configurado e compilado pela ferramenta EDK da Xilinx. Para essa dissertação foi utilizado a ferramenta EDK versão 7.1.2, que possui o IP Core do processador Microblaze na versão 4.0. O processador Microblaze foi configurado na ferramenta EDK da seguinte forma, (Xilinx, 2006):

- Freqüência do processador: $100 \mathrm{MHz}$, essa freqüência não pode ser alterada, dentro do assistente de configuração do processador e segundo o manual do $E D K$, essa freqüência é a produzida pelo oscilador presente na placa de prototipação.

- Freqüência do barramento do processador: $100 \mathrm{MHz}$, essa freqüência pode ser diferente da freqüência do processador, ou seja, podem-se selecionar os seguintes valores de freqüência: $100 \mathrm{MHz}, 75 \mathrm{MHz}, 66,67 \mathrm{MHz}, 50 \mathrm{MHz}, 33,33 \mathrm{MHz}, 25 \mathrm{MHz}$. O manual do $E D K$ especifica que a freqüência do barramento e do processador devem ser as mesmas, porém, em testes realizados, freqüências menores para o barramento não apresentaram grandes problemas, a não ser na fase de profiling, na qual freqüências menores do que $100 \mathrm{MHz}$ ocasionaram travamento do sistema. (Xilinx, 2006)

As configurações do processador Microblaze permitem selecionar até $128 \mathrm{~Kb}$ para memória embarcada no chip (On Chip Memory). Essa memória está dividida em duas partes: memória local para dados e instruções: memória embarcada (on-chip memory) utilizada para acesso a dados e instruções através do barramento $L M B$ e BRAM IF CNTLR: memó- 
ria embarcada usada quando a opção cache do Microblaze for habilitada. A opção de cache faz com que a execução de programas no processador seja mais rápida.

- Cache de Dados: $16 K B$, ligado no barramento $L M B$;

- Cache de instruções: $4 K B$, ligado no barramento $L M B$;

- Memória On Chip: 64 KB, ou seja, 32 KB para dados e instruções e 32 KB para cache;

- Uso de cache habilitado: O cache ajuda a acelerar a execução dos programas no processador Microblaze e ele pode ser configurado com as opções: OPB cache: o cache é executado através do barramento $O P B$. Com isso, pode-se usar a memória embarcada BRAM IF CNTLR ou a memória externa na placa, ou seja, memória DDR presente no slot da placa de prototipação, as duas executarão sob o barramento OPB e CacheLink: o cache é executado através do barramento FSL, entre o processador Microblaze e um controlador de memória multicanal, ou seja, com essa opção, há necessidade de se adicionar pelo menos um controlador de memória multicanal no sistema, se essa opção for selecionada. A opção CacheLink está apenas disponível se a placa de prototipação possuir um dispositivo de memória, no caso da placa de prototipação XUP V2P, essa opção está disponível para as memórias $D D R$ de $128 \mathrm{MB}$ a $512 \mathrm{MB}$;

- Uso do periférico RS232_Uart_1, configurado a 57600 bits por segundo, ligado no barramento $O P B$;

- Memória Off Chip: 256 MB (DDR_SDRAM_32Mx64), ligado no barramento OPB.

No caso do processador embarcado PowerPC, suas configurações permitem selecionar a freqüência do processador de $100 \mathrm{MHz}$ a $300 \mathrm{MHz}$. (Xilinx, 2007)

A freqüência do barramento pode ser $100 \mathrm{MHz}, 50 \mathrm{MHz}, 33,33 \mathrm{MHz}$ e $25 \mathrm{MHz}$, com a freqüência do processador a $100 \mathrm{MHz}$; apenas $50 \mathrm{MHz}$ para a freqüência do processador a $150 \mathrm{MHz} ; 100 \mathrm{MHz}, 66.67 \mathrm{MHz}$ ou $50 \mathrm{MHz}$ para a freqüência do processador a $200 \mathrm{MHz}$ e finalmente apenas $100 \mathrm{MHz}$ para a freqüência do processador a $300 \mathrm{MHz}$. Porém, o assistente de configuração não permite selecionar freqüências diferentes para barramentos individuais (PLB, OPB e OCM). Embora possam ser selecionadas diferentes freqüências para o barramento, assim como aconteceu ao Microblaze, quando configurado o barramento com freqüência menor que $100 \mathrm{MHz}$ na fase de profiling ocorreram travamentos do sistema.

O processador embarcado PowerPC foi configurado de duas formas:

- Freqüência do processador: $100 \mathrm{MHz}$ 
- Freqüência do Barramento (Bus clock frequency): $100 \mathrm{MHz}$

- Cache de dados: $32 K B$, controlado pelo OCM, que serve como uma interface dedicada entre blocos de RAMs no FPGA e sinais OCM disponíveis no core do processador embarcado PowerPC. Os sinais OCM no bloco do processador são designados para prover um rápido acesso a uma quantidade fixa de memórias de instruções e dados. Em aplicações com pequeno código e espaço de dados, o OCM permite ao processador usar os blocos de memória para instruções e dados, sem a necessidade de ter um barramento, o que resulta em economia de recursos e aumento de desempenho do sistema. (Xilinx, 2005), (Xilinx, 2007),

- Cache de instruções: 32KB, controlado pelo OCM;

- Memória On Chip: 192 KB, ou seja, 64KB usado para instruções e dados e 128 Kb selecionados para o BRAM IF CNTRL. O assistente deixa selecionar até $320 K B$ de memória embarcada, ou seja, 192KB para instruções e dados e 128KB para BRAM IF CN$T R L$.

- Uso de cache habilitado, o qual foi selecionado para ser usado com a BRAM IF CNTRL de $128 K B$, no barramento PLB. Para a opção cache, poderia ser selecionada ao invés da memória embarcada, a memória externa $D D R$.

- Uso do periférico RS232_Uart_1, configurado a 57600 bits por segundo, ligado no barramento $O P B$, mas no caso do PowerPC, esse periférico poderia ser colocado nos barramentos: (OPB ou PLB);

- Memória externa (off chip): 256 MB (DDR_SDRAM_32Mx64), ligada ao barramento $P L B$, mas poderia ser ligada ao barramento $O P B$;

A segunda forma que o processador embarcado PowerPC foi configurado é igual à forma acima, com exceção da freqüência do processador que passou de $100 \mathrm{MHz}$ para 300 $\mathrm{MHz}$.

A ferramenta Gprof citada no início deste capítulo, produz um perfil de execução de programas em $C, C++$, Pascal ou Fortran77. Foi usado nesse projeto para traçar o desempenho dos benchmarks executados nos processadores embarcados.

Gprof permite ao programador saber a porcentagem de tempo gasto por cada rotina de seu programa na $C P U$, o tempo gasto por cada uma, quantas vezes cada rotina foi chamada, o tempo total gasto para executar o programa. 
Essa ferramenta ajuda o programador a descobrir "gargalos" em seu programa, assim, o programador pode reescrevê-lo, a fim de tirar ou diminuir esse "gargalo".

Os dados do perfil são tirados do diagrama de chamadas (call graph profile) no arquivo padrão "gmon.out" que é criado pelos programas compilados com opção "-pg". (Fenlason, et al., 1998)

A ferramenta mostra quanto tempo o programa gastou em cada função (flat profile) e quantas vezes essa função foi chamada. (Fenlason, et al., 1998)

Tabela 9. Exemplo do Perfil plano (flat profile) gerado pelo Gprof

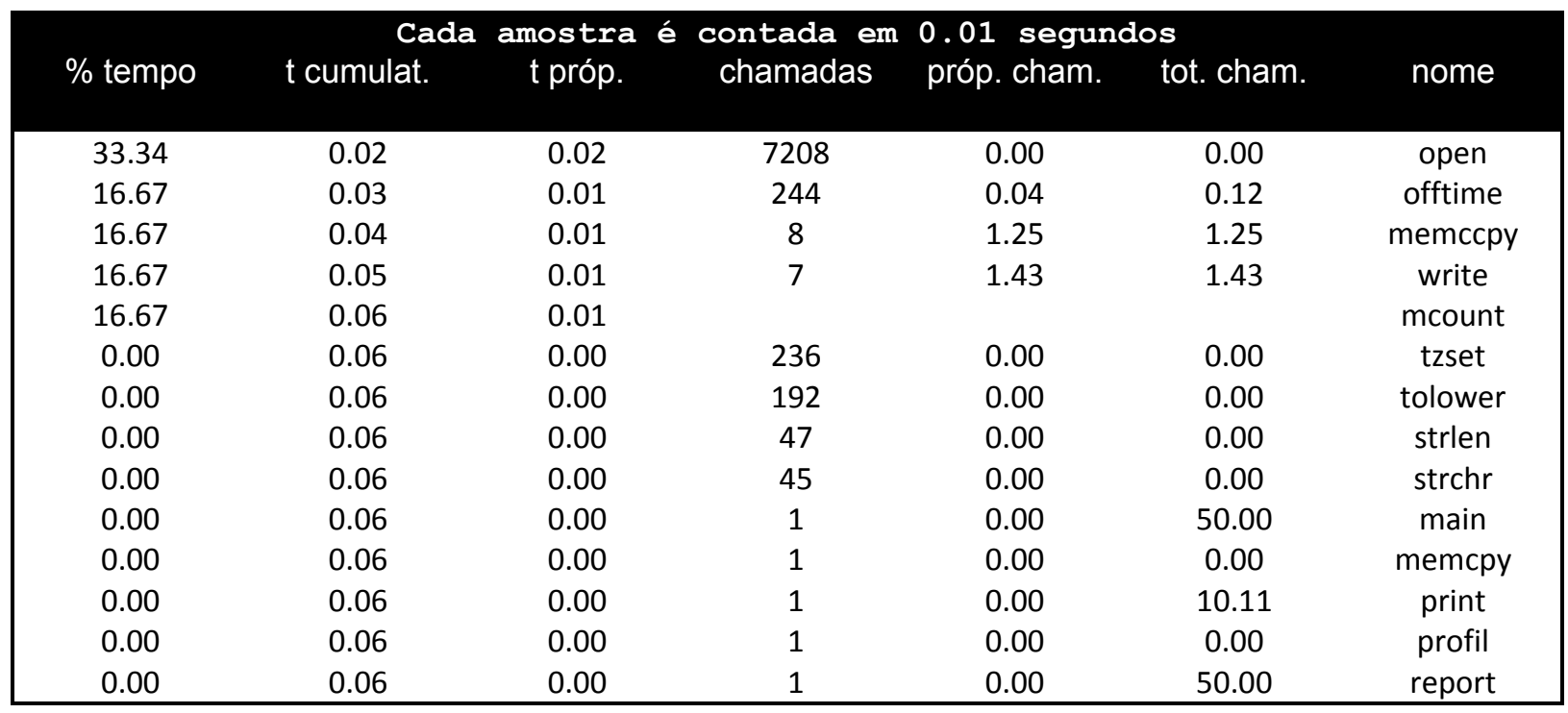

A Tabela 9 mostra um exemplo do perfil plano gerado pelo gprof.

O significado de cada coluna é mostrado abaixo:

- tempo: porcentagem do tempo total de execução usado por esta função;

- t. cumulat: soma cumulativa do tempo gasto nesta função e nas funções acima desta;

- t. próp: tempo gasto somente nesta função. Este é o dado mais importante desta saída;

- chamadas: número de vezes que esta função foi chamada;

- próp. Cham.: tempo médio (em $m s$ ) gasto nesta função;

- tot. cham: tempo médio (em $m s$ ) gastos nesta função e em seus descendentes;

- nome: nome das funções que foram analisadas.

O tempo total gasto na execução do programa mostrado na Tabela 9 foi de 0.06 segundos, como indicado na coluna t. cumulat. 


\subsubsection{Analise do desempenho da FFT}

Como visto no capítulo 5, o algoritmo FFT utilizado nessa dissertação tem como entrada e saída 16 pontos, em ponto flutuante. O algoritmo aceita um vetor de 16 pontos em ponto flutuante, calcula o FFT e gera um vetor de 16 pontos como saída em ponto flutuante.

Para análise do desempenho do benchmark na plataforma XUP V2P, o benchmark foi reescrito para calcular 5000 vetores de 16 pontos cada, ou seja, o algoritmo calculará 80000 pontos.

Todas as tabelas de desempenho nos tópicos seguintes são as médias aritméticas de 5 tabelas geradas pela ferramenta Gprof para cada uma das configurações dos processadores, mostradas nos itens 6.1 .1 e 6.1.2.

\section{Desempenho do FFT no Microblaze}

Tabela 10. Tempo de execução do benchmark FFT no processador Microblaze

\begin{tabular}{|c|c|c|c|c|c|c|}
\hline $\begin{array}{c}\% \\
\text { tempo }\end{array}$ & $\begin{array}{l}\text { t cumulat. } \\
\text { (segundos) }\end{array}$ & $\begin{array}{l}\text { Cada am } \\
\text { t próp. } \\
\text { (segundos) }\end{array}$ & $\begin{array}{c}\text { stra é co } \\
\text { chamadas }\end{array}$ & $\begin{array}{c}\text { tada em } 0.00 \\
\text { próp. cham. } \\
\text { (milessegundos) }\end{array}$ & $\begin{array}{l}\text { segundos } \\
\text { tot. cham. } \\
\text { (milessegundos) }\end{array}$ & Nome \\
\hline 21.63 & 110.57 & 110.57 & & & _unpack_d & 21.63 \\
\hline 19.60 & 210.76 & 100.19 & & & _muldi3 & 19.60 \\
\hline 13.93 & 281.99 & 71.23 & & & _muldf3 & 13.93 \\
\hline 11.42 & 340.39 & 58.40 & & & _pack_d & 11.42 \\
\hline 5.39 & 367.97 & 27.57 & & & floatsidf & 5.39 \\
\hline 4.90 & 393.01 & 25.04 & & & fpadd_parts & 4.90 \\
\hline 3.76 & 412.24 & 19.24 & & & __pack_f & 3.76 \\
\hline 3.35 & 429.36 & 17.12 & & & _unpack_f & 3.35 \\
\hline 3.25 & 445.99 & 16.63 & & & $\overline{\text { fpadd_parts }}$ & 3.25 \\
\hline 3.14 & 462.06 & 16.07 & & & divdf3 & 3.14 \\
\hline 2.44 & 474.51 & 12.45 & & & _mulsi3 & 2.44 \\
\hline 1.63 & 482.87 & 8.35 & & & _truncdfsf2 & 1.63 \\
\hline 1.02 & 488.08 & 5.22 & 1 & 5216.48 & 9191.88 main & 1.02 \\
\hline 0.86 & 492.49 & 4.40 & & & __ subsf3 & 0.86 \\
\hline 0.80 & 496.59 & 4.10 & & & extendsfdf2 & 0.80 \\
\hline 0.78 & 500.56 & 3.98 & 5000 & 0.80 & 0.80 R16SRFFT & 0.78 \\
\hline 0.69 & 504.11 & 3.54 & & & _adddf3 & 0.69 \\
\hline 0.68 & 507.59 & 3.49 & & & _addsf3 & 0.68 \\
\hline 0.48 & 510.03 & 2.44 & & & _make_fp & 0.48 \\
\hline 0.15 & 510.82 & 0.79 & & & _make_dp & 0.15 \\
\hline 0.07 & 511.20 & 0.38 & & & _ subdf3 & 0.07 \\
\hline 0.01 & 511.27 & 0.07 & & & _exception_han & 0.01 \\
\hline 0.00 & 511.27 & 0.00 & & & crtinit & 0.00 \\
\hline
\end{tabular}

De acordo com as informações fornecidas pelo Gprof na Tabela 10, o processador embarcado Microblaze levou cerca de 511.27 segundos para processar os 80000 pontos. 


\section{Desempenho do FFT no PowerPC a $100 \mathrm{MHz}$}

Tabela 11. Tempo de execução do benchmark FFT no processador PowerPC a $100 \mathrm{MHz}$

\begin{tabular}{|c|c|c|c|c|c|c|}
\hline $\begin{array}{c}\% \\
\text { tempo }\end{array}$ & $\begin{array}{l}t \text { cumulat. } \\
\text { (segundos) }\end{array}$ & $\begin{array}{c}\text { Cada a } \\
\text { t próp. } \\
\text { (segundos) }\end{array}$ & $\begin{array}{l}\text { amostra é c } \\
\text { chamadas }\end{array}$ & $\begin{array}{l}\text { tada em } 0.0001 \\
\text { próp. cham. } \\
\text { (milessegundos) }\end{array}$ & $\begin{array}{l}1 \text { segundos } \\
\text { tot. cham. } \\
\text { (milessegundos) }\end{array}$ & nome \\
\hline 21.19 & 31.26 & 31.26 & & & _ divdf3 & 21.19 \\
\hline 17.70 & 57.37 & 26.12 & & & _pack_d & 17.70 \\
\hline 13.89 & 77.87 & 20.50 & & & __muldf3 & 13.89 \\
\hline 9.57 & 91.98 & 14.11 & & & _floatsidf & 9.57 \\
\hline 7.19 & 102.59 & 10.61 & & & _unpack_d & 7.19 \\
\hline 6.38 & 112.00 & 9.41 & & & _fpadd_parts & 6.38 \\
\hline 5.07 & 119.48 & 7.48 & & & _pack_f & 5.07 \\
\hline 5.01 & 126.87 & 7.39 & & & _fpadd_parts & 5.01 \\
\hline 3.73 & 132.38 & 5.51 & & & _unpack_f & 3.73 \\
\hline 2.13 & 135.51 & 3.14 & 1 & 3.14 & 5.07 main & 2.13 \\
\hline 1.74 & 138.08 & 2.57 & & & _ subsf3 & 1.74 \\
\hline 1.62 & 140.46 & 2.39 & & & _adddf3 & 1.62 \\
\hline 1.31 & 142.40 & 1.94 & 5000 & 0.00 & 0.00 R16SRFFT & 1.31 \\
\hline 1.09 & 144.00 & 1.60 & & & _truncdfsf2 & 1.09 \\
\hline 1.04 & 145.54 & 1.53 & & & __addsf3 & 1.04 \\
\hline 0.52 & 146.30 & 0.76 & & & __extendsfdf2 & 0.52 \\
\hline 0.49 & 147.02 & 0.72 & & & __make_fp & 0.49 \\
\hline 0.24 & 147.37 & 0.35 & & & _make_dp & 0.24 \\
\hline 0.07 & 147.47 & 0.10 & & & __subdf3 & 0.07 \\
\hline 0.00 & 147.47 & 0.00 & & & _exit & 0.00 \\
\hline 0.00 & 147.48 & 0.00 & & & _start & 0.00 \\
\hline 0.00 & 147.48 & 0.00 & & & powerpc405_init & 0.00 \\
\hline 0.00 & 147.48 & 0.00 & & & profile_intr_handler & 0.00 \\
\hline
\end{tabular}

De acordo com as informações fornecidas pelo Gprof na Tabela 11, o processador embarcado PowerPC levou cerca de 147.48 segundos para processar os 80000 pontos. 


\section{Desempenho do FFT no PowerPC a $300 \mathrm{MHz}$}

Tabela 12. Tempo de execução do benchmark FFT no processador PowerPC a 300MHz

\begin{tabular}{|c|c|c|c|c|c|c|}
\hline $\begin{array}{c}\% \\
\text { tempo }\end{array}$ & $\begin{array}{l}\text { t cumulat. } \\
\text { (segundos) }\end{array}$ & $\begin{array}{l}\text { Cada } \\
\text { t próp. } \\
\text { (segundos) }\end{array}$ & $\begin{array}{l}\text { mostra é } \\
\text { chamadas }\end{array}$ & $\begin{array}{l}\text { ontada em } 0 \text {. } \\
\text { próp. cham. } \\
\text { (milessegundos) }\end{array}$ & $\begin{array}{c}001 \text { segundos } \\
\text { tot. cham. } \\
\text { (milessegundos) }\end{array}$ & nome \\
\hline 30.29 & 14.83 & 14.83 & & & _floatsidf & 30.29 \\
\hline 14.67 & 22.02 & 7.18 & & & __pack_d & 14.67 \\
\hline 14.45 & 29.09 & 7.08 & & & _divdf3 & 14.45 \\
\hline 11.04 & 34.50 & 5.40 & & & _ muldf3 & 11.04 \\
\hline 6.17 & 37.52 & 3.02 & & & _unpack_d & 6.17 \\
\hline 4.83 & 39.88 & 2.36 & & & _fpadd_parts & 4.83 \\
\hline 3.92 & 41.80 & 1.92 & & & _fpadd_parts & 3.92 \\
\hline 3.71 & 43.62 & 1.82 & & & _pack_f & 3.71 \\
\hline 2.89 & 45.03 & 1.41 & & & __unpack_f & 2.89 \\
\hline 1.46 & 45.75 & 0.72 & & & _ subsf3 & 1.46 \\
\hline 1.46 & 46.46 & 0.71 & 1 & 0.71 & 1.17 main & 1.46 \\
\hline 1.41 & 47.15 & 0.69 & & & _adddf3 & 1.41 \\
\hline 0.94 & 47.61 & 0.46 & 5000 & 0.00 & 0.00 R16SRFFT & 0.94 \\
\hline 0.88 & 48.05 & 0.43 & & & _truncdfsf2 & 0.88 \\
\hline 0.87 & 48.47 & 0.43 & & & _addsf3 & 0.87 \\
\hline 0.40 & 48.67 & 0.20 & & & _extendsfdf2 & 0.40 \\
\hline 0.39 & 48.86 & 0.19 & & & __make_fp & 0.39 \\
\hline 0.21 & 48.96 & 0.10 & & & _make_dp & 0.21 \\
\hline 0.00 & 48.96 & 0.00 & & & _ subdf3 & 0.00 \\
\hline 0.00 & 48.96 & 0.00 & & & _exit & 0.00 \\
\hline 0.00 & 48.96 & 0.00 & & & _start & 0.00 \\
\hline 0.00 & 48.96 & 0.00 & & & powerpc405_init & 0.00 \\
\hline 0.00 & 48.96 & 0.00 & & & profile_intr_handler & 0.00 \\
\hline
\end{tabular}

De acordo com as informações fornecidas pelo Gprof na Tabela 12, o processador embarcado PowerPC levou cerca de 48.96 segundos para processar os 80000 pontos.

\subsubsection{Analise do desempenho da FDCT}

Como visto no capitulo anterior, o algoritmo FDCT utilizado nessa dissertação tem como entrada e saída 64 pontos em ponto fixo, ou seja, blocos de $8 \times 8$ pontos. 0 algoritmo pega um vetor com os 64 pontos, calcula o FDCT e gera um vetor de 64 pontos como saída.

Para análise do desempenho do benchmark na plataforma XUP V2P, o benchmark foi reescrito para calcular 5000 vetores de 64 pontos cada, ou seja, o algoritmo calculará 320000 pontos em ponto fixo.

Todas as tabelas abaixo são as médias de 5 tabelas geradas pela ferramenta Gprof para cada configuração de processador mostrada nos ítens 6.1.1 e 6.1.2. 


\section{Desempenho do FDCT no Microblaze}

Tabela 13. Tempo de execução do benchmark FDCT no processador Microblaze

\begin{tabular}{|c|c|c|c|c|c|c|}
\hline $\begin{array}{c}\% \\
\text { tempo }\end{array}$ & $\begin{array}{l}\text { t cumulat. } \\
\text { (segundos) }\end{array}$ & $\begin{array}{l}\text { Cada a } \\
\text { t próp. } \\
\text { (segundos) }\end{array}$ & $\begin{array}{c}\text { lostra é c } \\
\text { chamadas }\end{array}$ & $\begin{array}{c}\text { ntada em } 0.0 \\
\text { próp. cham. } \\
\text { (milessegundos) }\end{array}$ & $\begin{array}{l}1 \text { segundos } \\
\text { tot. cham. } \\
\text { (milessegundos) }\end{array}$ & nome \\
\hline 27.82 & 108.10 & 108.10 & & & & _muldi3 \\
\hline 22.70 & 196.32 & 88.21 & & & & _unpack_d \\
\hline 20.23 & 274.95 & 78.63 & & & & __muldf3 \\
\hline 10.79 & 316.89 & 41.94 & & & & __pack_d \\
\hline 5.51 & 338.30 & 21.41 & & & & _floatsidf \\
\hline 5.05 & 357.92 & 19.62 & & & & _mulsi3 \\
\hline 4.66 & 376.04 & 18.11 & & & & _fixdfsi \\
\hline 2.09 & 384.16 & 8.12 & 5000 & 1.62 & 1.62 & fdct \\
\hline 0.99 & 388.00 & 3.85 & 1 & 3847.50 & 11965.52 & main \\
\hline 0.16 & 388.62 & 0.62 & & & & _exception_handler \\
\hline 0.00 & 388.62 & 0.00 & & & & _crtinit \\
\hline
\end{tabular}

De acordo com as informações fornecidas pelo Gprof na Tabela 13, o processador embarcado Microblaze levou cerca de 388.62 segundos para processar os 320000 pontos.

\section{Desempenho do FDCT no PowerPC a $100 \mathrm{MHz}$}

Tabela 14. Tempo de execução do benchmark FDCT no processador PowerPC a 100MHz

\begin{tabular}{|c|c|c|c|c|c|c|}
\hline $\begin{array}{c}\% \\
\text { tempo }\end{array}$ & $\begin{array}{l}\text { t cumulat. } \\
\text { (segundos) }\end{array}$ & $\begin{array}{l}\text { Cada a } \\
\text { t próp. } \\
\text { (segundos) }\end{array}$ & $\begin{array}{c}\text { nostra é c } \\
\text { chamadas }\end{array}$ & $\begin{array}{c}\text { ntada em } 0.0 \\
\text { próp. cham. } \\
\text { (milessegundos) }\end{array}$ & $\begin{array}{l}1 \text { segundos } \\
\text { tot. cham. } \\
\text { (milessegundos) }\end{array}$ & nome \\
\hline 25.80 & 23.28 & 23.28 & & & & _ muldf3 \\
\hline 20.02 & 41.33 & 18.06 & & & & floatsidf \\
\hline 18.91 & 58.39 & 17.06 & & & & __pack_d \\
\hline 13.03 & 70.15 & 11.75 & 5000 & 0.00 & 0.00 & $\mathrm{fdct}$ \\
\hline 9.79 & 78.98 & 8.83 & & & & _unpack_d \\
\hline 5.44 & 83.89 & 4.91 & & & & fixdfsi \\
\hline 4.40 & 87.86 & 3.97 & 1 & 3.97 & 15.72 & main \\
\hline 2.59 & 90.20 & 2.34 & & & & _Ishrdi3 \\
\hline 0.01 & 90.21 & 0.01 & & & & $\overline{\text { searchpc }}$ \\
\hline 0.01 & 90.21 & 0.00 & & & & profile_intr_handler \\
\hline 0.00 & 90.21 & 0.00 & & & & _exit \\
\hline 0.00 & 90.22 & 0.00 & & & & _start \\
\hline 0.00 & 90.22 & 0.00 & & & & powerpc405_init \\
\hline
\end{tabular}

De acordo com as informações fornecidas pelo Gprof na Tabela 14, o processador embarcado PowerPC levou cerca de 90.22 segundos para processar os 320000 pontos. 


\section{Desempenho do FDCT no PowerPC a $300 \mathrm{MHz}$}

Tabela 15. Tempo de execução do benchmark FDCT no processador PowerPC a $300 \mathrm{MHz}$

\begin{tabular}{|c|c|c|c|c|c|c|}
\hline $\begin{array}{c}\% \\
\text { tempo }\end{array}$ & $\begin{array}{l}\mathrm{t} \text { cumulat. } \\
\text { (segundos) }\end{array}$ & $\begin{array}{c}\text { Cada a } \\
\text { t próp. } \\
\text { (segundos) }\end{array}$ & $\begin{array}{c}\text { mostra é } \\
\text { chamadas }\end{array}$ & $\begin{array}{c}\text { ontada em } 0.00 \\
\text { próp. cham. } \\
\text { (milessegundos) }\end{array}$ & $\begin{array}{l}01 \text { segundos } \\
\text { tot. cham. } \\
\text { (milessegundos) }\end{array}$ & nome \\
\hline 45.94 & 17.20 & 17.20 & & & & _floatsidf \\
\hline 15.98 & 23.18 & 5.98 & & & & _ muldf3 \\
\hline 12.87 & 28.00 & 4.82 & & & & _ppack_d \\
\hline 10.60 & 31.97 & 3.97 & 5000 & 0.00 & 0.00 & fdct \\
\hline 6.60 & 34.44 & 2.47 & & & & _unpack_d \\
\hline 3.22 & 35.65 & 1.21 & & & & fixdfsi \\
\hline 3.19 & 36.84 & 1.19 & 1 & 1.19 & 5.16 & main \\
\hline 1.60 & 37.44 & 0.60 & & & & _Ishrdi3 \\
\hline 0.00 & 37.44 & 0.00 & & & & searchpc \\
\hline 0.00 & 37.44 & 0.00 & & & & profile_intr_handler \\
\hline 0.00 & 37.44 & 0.00 & & & & _exit \\
\hline 0.00 & 37.44 & 0.00 & & & & _start \\
\hline 0.00 & 37.44 & 0.00 & & & & powerpc405_init \\
\hline
\end{tabular}

De acordo com as informações fornecidas pelo Gprof na Tabela 15, o processador embarcado PowerPC levou cerca de 37.44 segundos para processar os 320000 pontos.

\subsubsection{Analise do desempenho da ADPCM}

O benchmark $A D P C M$ foi configurado para processar um vetor de 16 pontos em ponto fixo. O vetor de 16 pontos de entrada é processado pelo ADPCM codificador e a saída gerada por ele é a entrada no ADPCM decodificador, que processa e gera o vetor final de 16 pontos, também em ponto fixo.

Para analise do benchmark ADPCM nos processadores embarcados, ele foi configurado para processar 5000 vetores de 16 pontos. Assim, serão processados 80000 pontos pelo codificador e pelo decodificador.

Todas as tabelas abaixo são as médias de 5 tabelas geradas pela ferramenta Gprof para cada configuração de processador, mostradas nos itens 6.1.1 e 6.1.2. 


\section{Desempenho do ADPCM no Microblaze}

Tabela 16. Tempo de execução do benchmark ADPCM no processador Microblaze

\begin{tabular}{|c|c|c|c|c|c|c|}
\hline $\begin{array}{c}\% \\
\text { tempo }\end{array}$ & $\begin{array}{l}\text { t cumulat. } \\
\text { (segundos) }\end{array}$ & $\begin{array}{l}\text { Cada ar } \\
\text { t próp. } \\
\text { (segundos) }\end{array}$ & $\begin{array}{c}\text { ostra é c } \\
\text { chamadas }\end{array}$ & $\begin{array}{c}\text { ntada em } 0.0 \\
\text { próp. cham. } \\
\text { (milessegundos) }\end{array}$ & $\begin{array}{c}1 \text { segundos } \\
\text { tot. cham. } \\
\text { (milessegundos) }\end{array}$ & nome \\
\hline 25.91 & 39.30 & 39.30 & & & & _muldi3 \\
\hline 15.27 & 62.46 & 23.15 & & & & unpack_d \\
\hline 12.78 & 81.84 & 19.38 & & & & muldf3 \\
\hline 10.11 & 97.18 & 15.34 & & & & _floatsidf \\
\hline 9.54 & 111.64 & 14.46 & & & & _mulsi3 \\
\hline 8.44 & 124.45 & 12.80 & & & & _ fixdfsi \\
\hline 6.79 & 134.74 & 10.29 & & & & _pack_d \\
\hline 5.07 & 142.43 & 7.69 & 5000 & 1.54 & 1.54 & adpcm_coder \\
\hline 4.17 & 148.74 & 6.32 & 5000 & 1.26 & 1.26 & adpcm_decoder \\
\hline 1.52 & 151.05 & 2.31 & 1 & 2308.78 & 16312.60 & main \\
\hline 0.40 & 151.66 & 0.61 & & & & _exception_handler \\
\hline 0.00 & 151.67 & 0.00 & & & & crtinit \\
\hline
\end{tabular}

De acordo com as informações fornecidas pelo Gprof na Tabela 16, o processador embarcado Microblaze levou cerca de 151.67 segundos, no total para processar os 80000 pontos no $A D P C M$ codificador e $A D P C M$ decodificador.

\section{Desempenho do ADPCM no PowerPC a $100 \mathrm{MHz}$}

Tabela 17. Tempo de execução do benchmark ADPCM no processador PowerPC a $100 \mathrm{MHz}$

\begin{tabular}{|c|c|c|c|c|c|c|}
\hline $\begin{array}{c}\% \\
\text { tempo }\end{array}$ & $\begin{array}{l}\text { t cumulat. } \\
\text { (segundos) }\end{array}$ & $\begin{array}{c}\text { Cada } \\
\text { t próp. } \\
\text { (segundos) }\end{array}$ & $\begin{array}{l}\text { mostra é } \\
\text { chamadas }\end{array}$ & $\begin{array}{c}\text { ontada em } 0 . \\
\text { próp. cham. } \\
\text { (milessegundos) }\end{array}$ & $\begin{array}{l}01 \text { segundos } \\
\text { tot. cham. } \\
\text { (milessegundos) }\end{array}$ & nome \\
\hline 34.25 & 12.30 & 12.30 & & & & floatsidf \\
\hline 16.66 & 18.29 & 5.98 & & & & _muldf3 \\
\hline 12.71 & 22.85 & 4.56 & & & & __pack_d \\
\hline 12.65 & 27.39 & 4.54 & 5000 & 0.00 & 0.00 & adpcm_coder \\
\hline 9.93 & 30.96 & 3.57 & 5000 & 0.00 & 0.00 & adpcm_decoder \\
\hline 5.59 & 32.97 & 2.01 & & & & _unpack_d \\
\hline 3.86 & 34.35 & 1.39 & 1 & 1.39 & 9.50 & main \\
\hline 3.10 & 35.47 & 1.11 & & & & _fixdfsi \\
\hline 1.20 & 35.90 & 0.43 & & & & _Ishrdi3 \\
\hline 0.00 & 35.90 & 0.00 & & & & _exit \\
\hline 0.00 & 35.90 & 0.00 & & & & XExc_RegisterHandler \\
\hline 0.00 & 35.90 & 0.00 & & & & powerpc405_init \\
\hline 0.00 & 35.90 & 0.00 & & & & profile_intr_handler \\
\hline 0.00 & 35.90 & 0.00 & & & & NullHandler \\
\hline
\end{tabular}

De acordo com as informações fornecidas pelo Gprof na Tabela 17, o processador em-

barcado PowerPC levou cerca de 35.90 segundos, no total para processar os 80000 pontos no $A D P C M$ codificador e $A D P C M$ decodificador. 


\section{Desempenho do ADPCM no PowerPC a $300 \mathrm{MHz}$}

Tabela 18. Tempo de execução do benchmark ADPCM no processador PowerPC a 300MHz

\begin{tabular}{|c|c|c|c|c|c|c|}
\hline $\begin{array}{c}\% \\
\text { tempo }\end{array}$ & $\begin{array}{l}\text { t cumulat. } \\
\text { (segundos) }\end{array}$ & $\begin{array}{l}\text { Cada am } \\
\text { t próp. } \\
\text { (segundos) }\end{array}$ & $\begin{array}{l}\text { tra é cor } \\
\text { chamadas }\end{array}$ & $\begin{array}{l}\text { da em } 0.00 \\
\text { próp. cham. } \\
\text { (milessegun- } \\
\text { dos) }\end{array}$ & $\begin{array}{l}1 \text { segundos } \\
\text { tot. cham. } \\
\text { (milessegundos) }\end{array}$ & nome \\
\hline 42.97 & 4.94 & 4.94 & & & & _floatsidf \\
\hline 13.14 & 6.46 & 1.51 & & & & _ muldf3 \\
\hline 12.51 & 7.89 & 1.44 & 5000 & 0.00 & 0.00 & adpcm_coder \\
\hline 11.07 & 9.17 & 1.27 & & & & _pack_d \\
\hline 9.54 & 10.27 & 1.10 & 5000 & 0.00 & 0.00 & adpcm_decoder \\
\hline 4.33 & 10.76 & 0.50 & & & & _unpack_d \\
\hline 2.94 & 11.10 & 0.34 & 1 & 0.34 & 2.87 & main \\
\hline 2.58 & 11.40 & 0.30 & & & & fixdfsi \\
\hline 0.85 & 11.50 & 0.10 & & & & _Ishrdi3 \\
\hline 0.00 & 11.50 & 0.00 & & & & _exit \\
\hline 0.00 & 11.50 & 0.00 & & & & powerpc405_init \\
\hline 0.00 & 11.50 & 0.00 & & & & profile_intr_handler \\
\hline
\end{tabular}

De acordo com as informações fornecidas pelo Gprof na Tabela 18, o processador embarcado PowerPC levou cerca de 11.50 segundos, no total para processar os 80000 pontos no $A D P C M$ codificador e $A D P C M$ decodificador.

\subsubsection{Resultados de desempenho nos Processadores em- barcados}

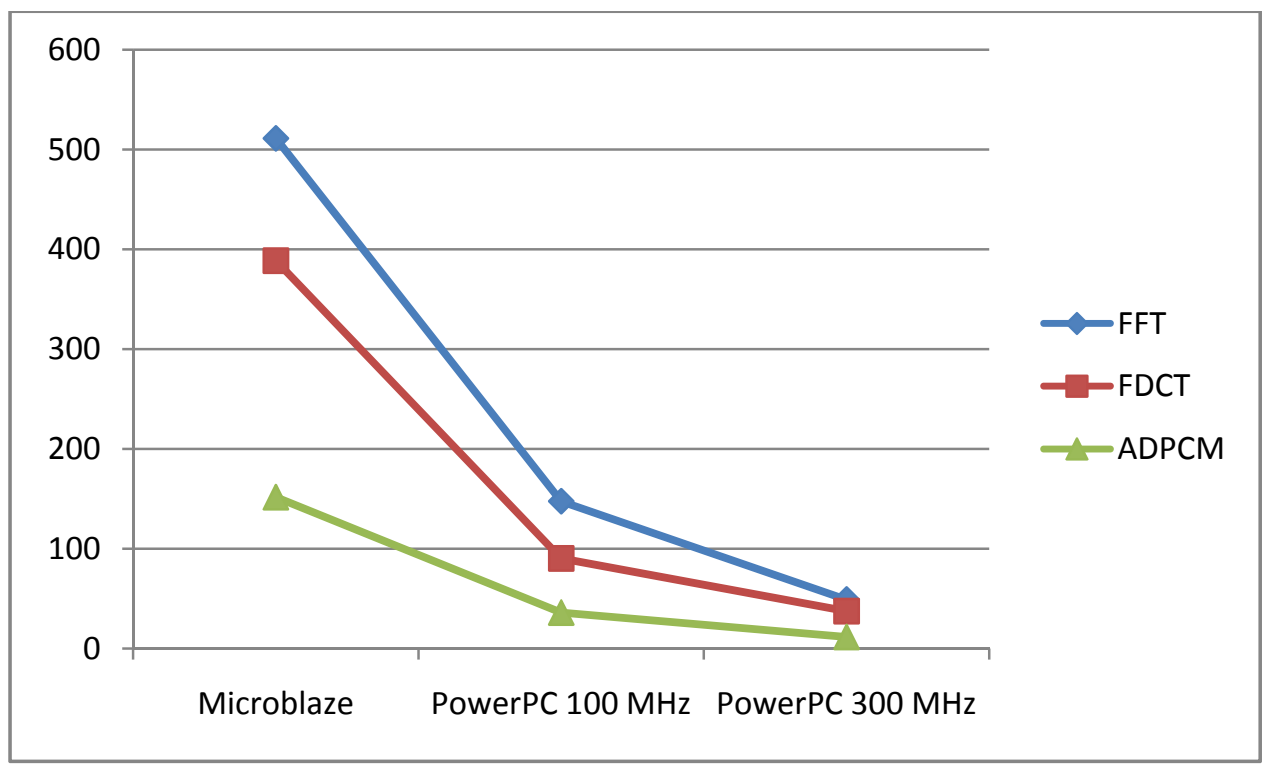

Figura 52. Gráfico de desempenho dos benchmarks sob diferentes configurações de processadores embarcados

Como apresentado nas Tabelas de 10 a 18, o melhor desempenho dos benchmarks foi com o processador PowerPC, configurado a $300 \mathrm{MHz}$. Esse resultado já era esperado pelo fato de que esse processador foi configurado a $300 \mathrm{MHz}$, enquanto que a configuração anteri- 
or do PowerPC foi de $100 \mathrm{MHz}$, assim como a do processador Microblaze. Na Figura 52 é descrito de forma gráfica os resultados de desempenho apresentados nos itens anteriores.

O eixo vertical do gráfico na Figura 52 representa os tempos em minutos, gastos pelos benchmarks executados nos processadores embarcados.

\subsection{Análise dos benchmarks no Impulse C}

O Impulse $C$ foi usado para gerar um sistema composto por módulos que executam em um processador embarcado e módulos que executam diretamente no FPGA, sob a forma de hardware/software codesign. Esses módulos se comunicam por streams de dados e sinais, conforme mostrado na Figura 53. Os benchmarks escritos originalmente em linguagem ANSI$C$ foram reescritos usando Impulse $C$, que como já visto nos capítulos anteriores é formado por funções de bibliotecas, compiladores e ferramentas de depuração. Essas bibliotecas e ferramentas são compatíveis com ANSI-C e com as ferramentas de desenvolvimento em linguagem $C$ tais como Visual Studio e gcc.

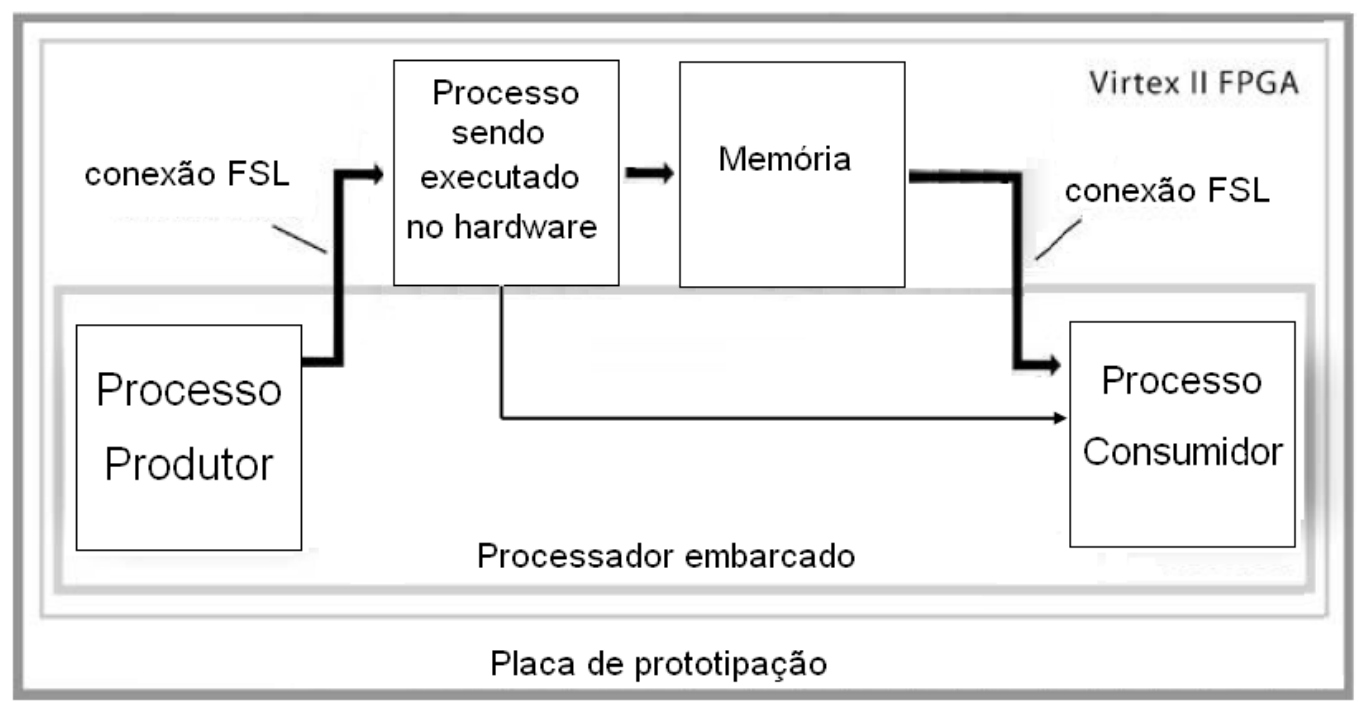

Figura 53. Comunicação entre processos presentes no FPGA e no processador embarcado

A Figura 53 mostra a comunicação dos processos presentes no FPGA e no processador embarcado, por meio de sinais e streams. Como pode ser observado, o processo produtor está em execução em um processador embarcado, tal como PowerPC e é responsável por enviar dados ao "processo sendo executado em hardware", que por sua vez faz algum processamento com esses dados e os envia a uma memória compartilhada, implementada no FPGA. Após enviar os dados processados para a memória, o "processo sendo executado em hardware" envia um sinal ao processo consumidor, presente no processador embarcado. 0 
processo consumidor é responsável, nessa implementação, por mostrar os dados ao projetista, por exemplo, através da saída serial RS232 ou saída de vídeo, presentes na placa de prototipação.

Assim como os benchmarks implementados diretamente nos processadores embarcados, os benchmarks reescritos em Impulse C que possuem módulos em hardware e software foram escritos primeiramente para validar o funcionamento do sistema gerado pelo Impulse C, tanto a nível de simulação usando Desktop Simulation, a nível de hardware usando simuladores de $V H D L$ e por fim usando os recursos de entrada/saída da placa de prototipação, tal como a saída serial RS232, como mostra a Figura 54.

Após a comprovação da correta funcionalidade dos arquivos gerados pelo Impulse $C$, a saída gerada na serial pelo processo consumidor foi substituída por uma mensagem de "fim de execução" ao invés de imprimir todos os valores gerados. Isso garante que o desempenho do sistema não sofra as interferências das saídas dos valores. O Impulse $C$ usado para gerar o sistema hardware/software codesign usado nessa dissertação foi a versão: 2.20.e.6, lançada em 26 de janeiro de 2007.

O processador usado para a execução dos processos em software é o processador PowerPC configurado a $300 \mathrm{MHz}$, mostrado no item 6.1.2.

A Figura 54 mostra um exemplo de como a placa de prototipação pode ser ligada a diversos computadores desktop. Na Figura 54-a, é representado um exemplo de comunicação serial entre o computador desktop e a placa de prototipação. A placa pode enviar ou receber dados vindos da porta serial RS232. A Figura 54-b representa um exemplo de um arquivo de imagem sendo enviado ou recebido do computador desktop. Como esse modelo de placa de prototipação possui conector de rede, então ele pode ser usado para enviar e receber dados do computador desktop, em uma velocidade superior ao da RS232. A Figura 54-c representa o computador desktop responsável por programar a placa de prototipação.

Em particular nesse projeto foi utilizado os modelos descritos na Figura 54-a e Figura 54-c. 


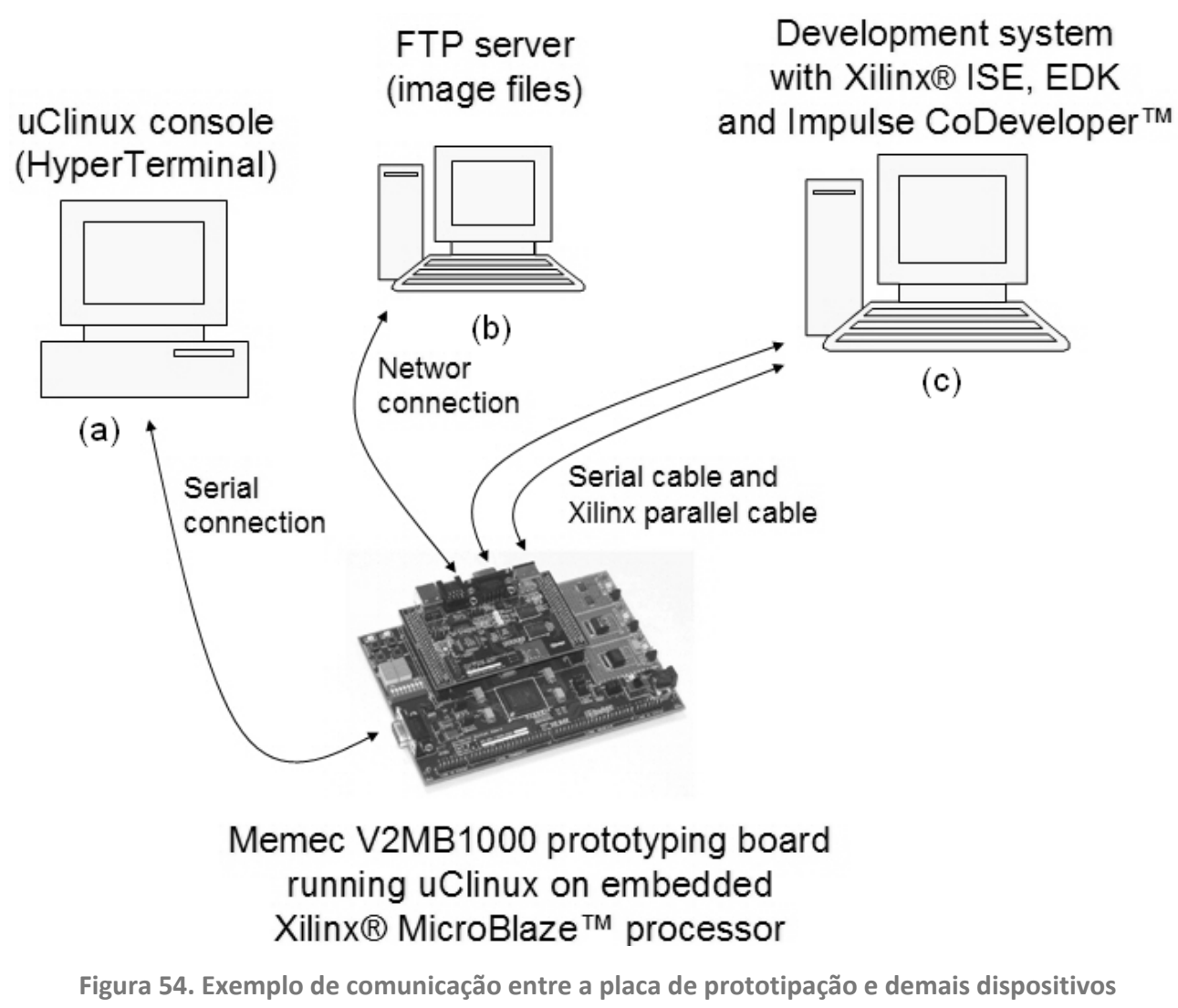

\subsubsection{Implementação do benchmark FFT no Impulse $C$}

A implementação do benchmark FFT no Impulse $C$ foi a mais trabalhosa, porque o algoritmo foi escrito para trabalhar com pontos flutuantes. Embora o Impulse $C$ tenha a opção "Include floating point library", a ferramenta $E D K$ 7.1.2, a qual foi usada para configurar o processador PowerPC não possui a unidade auxiliar de ponto flutuante e seu compilador também não suporta tipos de dados com essas características. (Xilinx, Inc, 2006)

Por esse motivo, o benchmark teve que ser reescrito usando aritmética de ponto fixo, a qual é suportada pelo Impulse $C$, que possui uma combinação de tipos de dados e macros para operações aritméticas, formatação em ponto fixo e macros para conversão de ponto fixo para ponto flutuante, útil para simulação e teste das funcionalidades do sistema. A aritmética de ponto fixo, bem como os macros implementadas pelo Impulse $C$ estão descritos no APÊNDICE C.

O formato do ponto fixo escolhido para a implementação do benchmark FFT no Impulse $C$ foi $1 s$ 11.20. Esse formato foi escolhido após verificar a precisão dos dados de saída do

\footnotetext{
${ }^{7}$ Esta opção especifica que a biblioteca de ponto flutuante seja incluída no HDL gerado e que os tipos de dados em ponto flutuante sejam permitidos durante a compilação
} 
benchmark compilado e executado no computador desktop. Assim, com esse formato em ponto fixo, são aceitos dados na faixa de valores de -2047.1048574 até 2047.1048575.

Assim como a implementação do benchmark no computador desktop, no Impulse C também ele foi projetado para aceitar 5000 vetores de 16 pontos cada.

Como o benchmark FFT possui muitas operações de soma, subtração e multiplicação, os dados de entrada foram cuidadosamente gerados para que não causassem overflow ou underflow.

A Figura 55 representa a implementação do benchmark FFT no Impulse $C$ e foi gerada pelo Application Monitor o qual mostra a execução dos processos. Nessa imagem, verifica-se que foram gerados três processos: producer, representando o processo produtor, processo codificador, representando a implementação do cálculo FFT e o processo consumer, representando o processo consumidor.

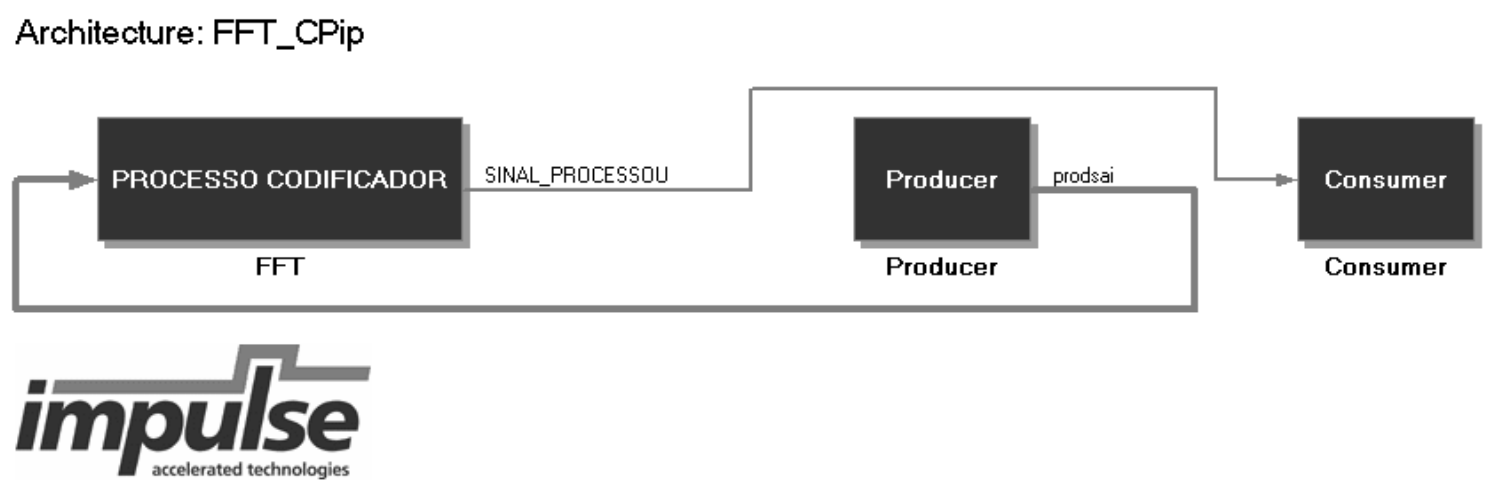

Figura 55. Imagem do Application Monitor da implementação do FFT

O processo produtor foi configurado para executar no processador embarcado, no caso o PowerPC. Ele é responsável por gerar 5000 vetores de 16 pontos e enviar esses valores ao processo codificador.

O trecho de código abaixo representa o cálculo dos 80000 pontos a serem enviados ao processo codificador.

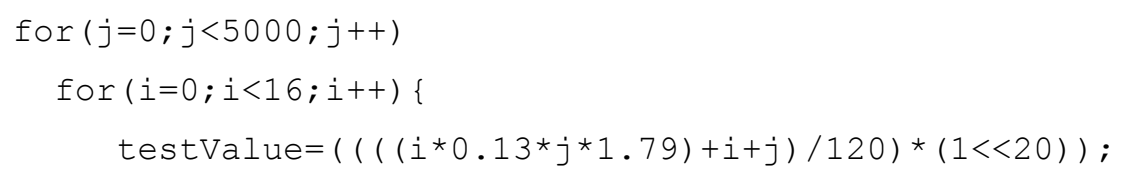

A expressão $\left(\left(\left(\left(i^{*} 0.13 * j * 1.79\right)+i+j\right) / 120\right) *(1<<20)\right)$ foi escolhida ao acaso e gera números aleatórios e pequenos, como entrada para o processo codificador. A escolha dos números de entrada é importante para não causar overflow ou underflow nos resultados gerados. Os processos produtor e codificador são sincronizados por streams, a qual indica ao processo codificador quando o processo produtor para de enviar pontos. Quando o processo produtor acabar de gerar os 80000 pontos, ele executará uma função do Impulse $C$ chamada 
HW_STREAM_CLOSE, que fecha a stream de comunicação entre ele e o processo codificador (fft em hardware);

O processo codificador é responsável por receber o vetor de 16 pontos do processo produtor, calcular o FFT sob esses pontos e gera um vetor de saída para o processo consumidor. Esse processo é formado basicamente por um bloco de repetição (while), responsável por receber o vetor de entrada do processo produtor, gerar a saída e aguardar o próximo vetor. Uma variável foi usada para controlar o número de pontos recebidos. $\mathrm{O}$ processo codificador ao receber o código indicando que a stream entre ele e o processo produtor foi fechada sairá da execução do bloco de repetição while e executará o comando co_signal_post, o qual será recebido pelo processo consumidor.

O processo consumidor, nessa implementação, ficará bloqueado pela função co_signal_wait e aguardará até que o processo codificador envie um sinal pelo comando co_signal_post, indicando o término do processamento dos 80000 pontos. Assim, o processo consumidor exibirá uma mensagem ao usuário indicando "fim de processo". Os processos codificador e consumidor são sincronizados, como mostrados, por funções de sinais.

Os tópicos abaixo mostram a simulação do benchmark FFT no Impulse C, no simulador $V H D L$, por fim os tempos de desempenho com as implementações feitas.

\section{Simulação do benchmark FFT no Impulse}

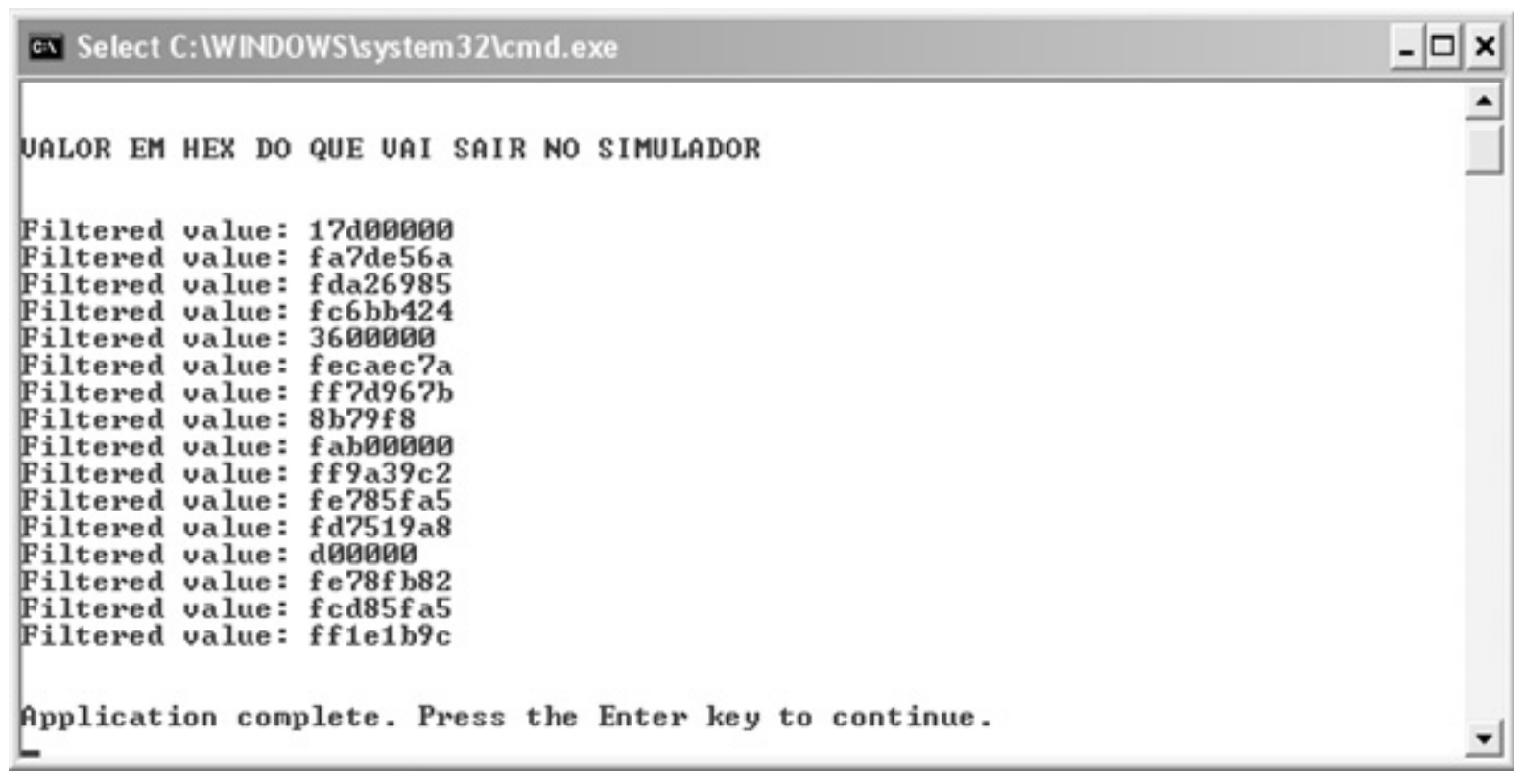


Architecture: SimulaFFT32_arch

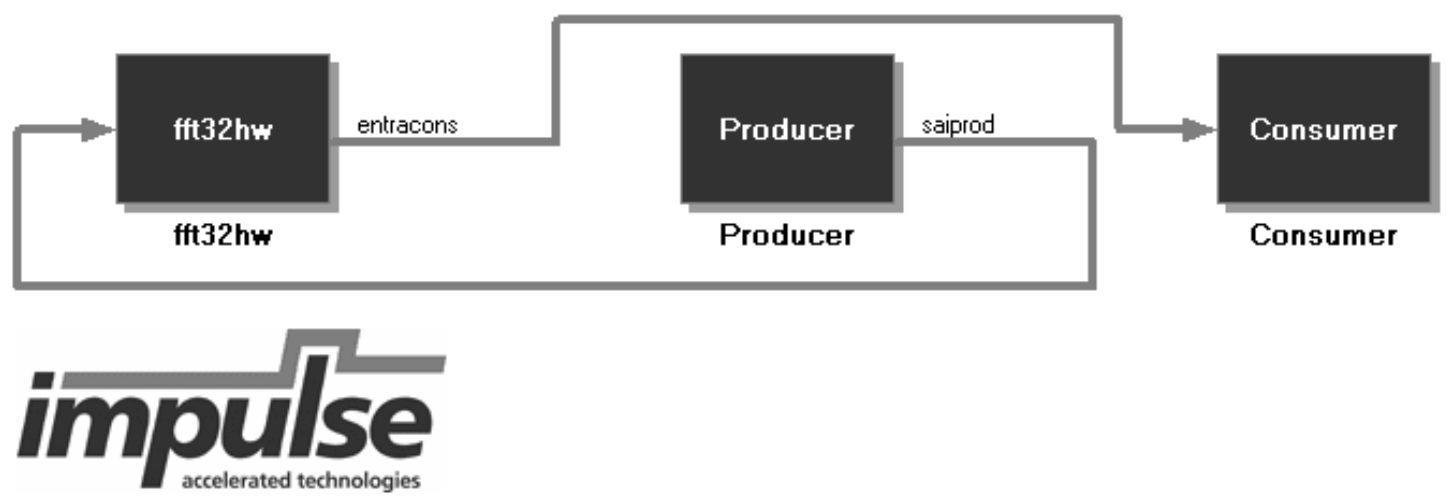

Figura 57. Diagrama de bloco feito pelo Application Monitor, mostrando o funcionamento do FFT

As Figuras 56 e 57 demonstram a execução do benchmark FFT no Impulse C, como pode ser visto na Figura 56, o Impulse $C$ mostra o correto funcionamento do sistema de acordo com resultados gerados pela ferramenta Scilab, mostrado na Figura 47, usando as funções de ponto fixo. Com isso, o projetista pode simular os resultados do hardware gerado, com as mesmas entradas usadas pelo processo produtor (producer) e ver se as saídas são equivalentes. Além disso, o projetista pode executar o sistema completo na placa de prototipação suportada pelo PSP no Impulse C. O Application Monitor mostra as comunicações entre os processos implementados no Impulse $C$ e a troca de dados entre eles. Para a simulação, a comunicação entre os processos é feita por streams de dados. As saídas mostradas na Figura 56 estão em hexadecimais. No caso da Figura 47 os dados são apresentados de forma decimal e na Figura 56 os mesmos dados são apresentados na forma hexadecimal.

\section{Simulação feita no VHDL Simili}

A simulação da funcionalidade dos arquivos $V H D L$ gerados pelo Impulse $C$ foram feitas com o software da empresa Symphony EDA VHDL Simili 3.0.14. (Symphony EDA, 2005)

A Figura 58 mostra o correto funcionamento do hardware gerado pelo Impulse C. Os resultados mostrados nessa Figura 58 estão em hexadecimais e podem ser confrontados com os resultados gerados pela simulação, mostrada na Figura 56. Como pode ser visto na Figura 58, há uma série de sinais criados pelo Impulse $C$. Alguns detalhes sobre esses sinais serão mostrados no APÊNDICE B. 


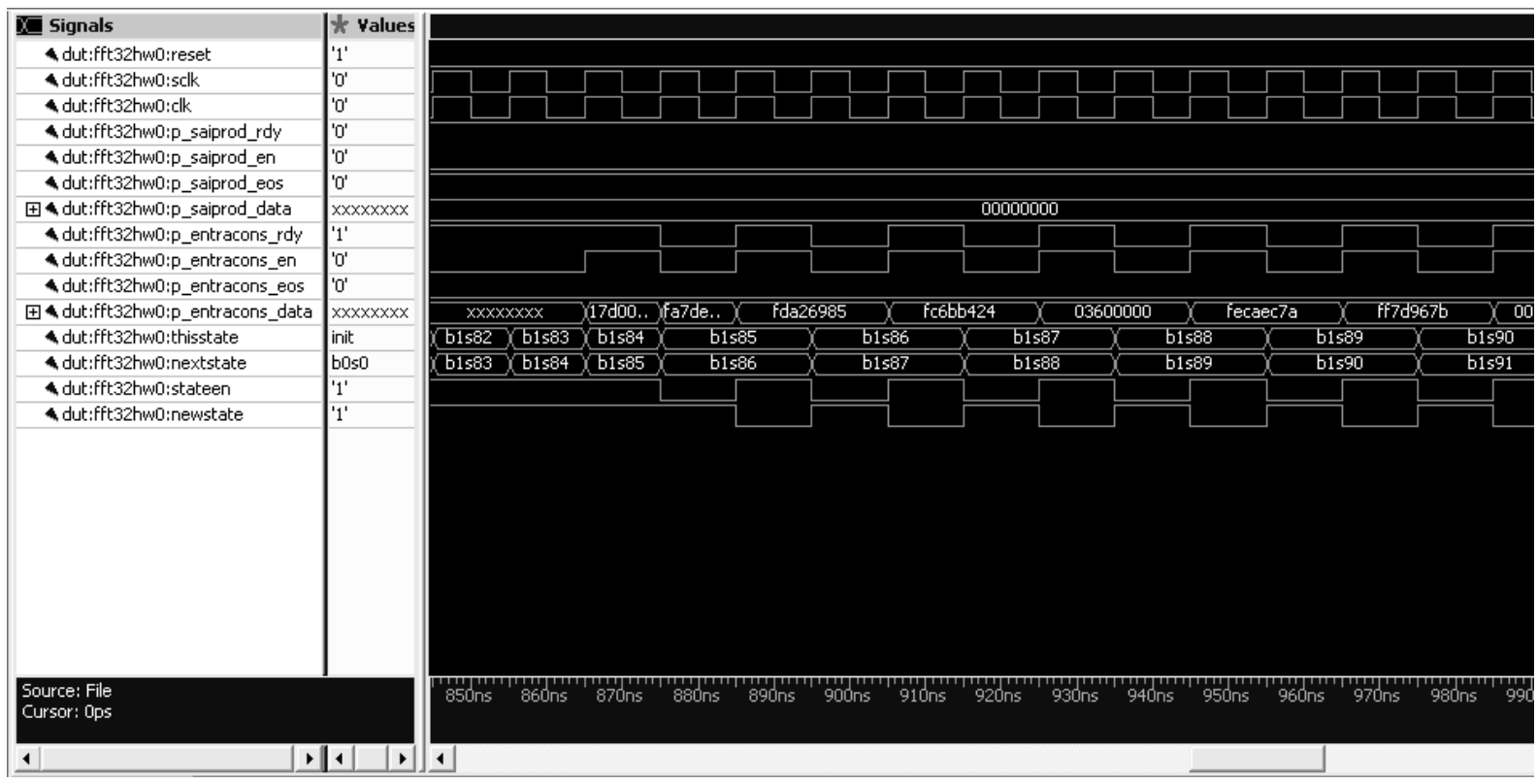

Figura 58. Simulação do hardware gerado pelo Impulse do benchmark FFT pela ferramenta VHDL Simili

Desempenho do benchmark na placa de prototipação XUP V2P

Para a fase de obtenção do desempenho do benchmark FFT na placa de prototipação, duas implementações foram feitas. As mudanças feitas nas duas implementações são basicamente a inclusão do comando \#pragma CO PIPELINE no bloco de repetição do processo de hardware do FFT. Essas mudanças foram feitas sob a implementação mostrada na Figura 55.

No PSB do Impulse $C$, foi selecionado para a ferramenta gerar o hardware/software codesign no formato VHDL para o barramento PLB, no FPGA Virtex-II Pro.

Assim, foram gerados arquivos VHDL que implementam o processo selecionado como hardware, os demais arquivos VHDL que implementam as interfaces de comunicação entre os processos, tais como streams, sinais, entre outros e a interface entre os blocos de hardware e o barramento PLB. Além disso, foram gerados os processos selecionados como software e os drivers para a comunicação entre os processos de software e o processo em hardware pelo barramento PLB.

A Tabela 19 mostra os recursos de hardware disponíveis no FPGA Virtex-Il Pro e o gasto desses recursos para a implementação do Core FFT com pipeline. Esses resultados foram gerados pela ferramenta EDK da Xilinx. 
Tabela 19. Resumo dos recursos de hardware usado pelo benchmark FFT com o uso do pipeline

\begin{tabular}{|c|c|c|c|}
\hline \multicolumn{4}{|c|}{ Resumo dos recursos de hardware gastos pelo benchmark } \\
Tipo de recurso & Uso & Disponível no FPGA & Porcentagem usada \\
\hline Slices & 54 & 13696 & 0 \\
Slice Flip Flops & 59 & 27392 & 0 \\
4 input LUTs & 89 & 27392 & 0 \\
bonded IOBs & 217 & 556 & 39 \\
\hline
\end{tabular}

A Tabela 20 mostra os recursos de hardware disponíveis no FPGA Virtex-Il Pro e o gasto desses recursos para a implementação do Core FFT sem o uso de pipeline.

Tabela 20. Resumo dos recursos de hardware usado pelo benchmark FFT sem o uso do pipeline

\begin{tabular}{|c|c|c|c|}
\hline \multicolumn{4}{|c|}{ Resumo dos recursos de hardware gastos pelo benchmark } \\
Tipo de recurso & Uso & Disponível no FPGA & Porcentagem usada \\
\hline Slices & 35 & 13696 & 0 \\
Slice Flip Flops & 40 & 27392 & 0 \\
4 input LUTs & 52 & 27392 & 0 \\
bonded IOBs & 217 & 556 & 39 \\
\hline
\end{tabular}

Os tempos de desempenho de ambas as implementações foram os seguintes:

A Tabela 21 mostra o desempenho gerado pelo FFT, com pipeline, executado na placa de prototipação, sob a forma de hardware/software codesign. Segundo a Tabela 21, o tempo necessário para executar os 80000 pontos foi de 40.35 segundos.

A Tabela 22 mostra o desempenho gerado pelo FFT, sem pipeline, executado na placa de prototipação, sob a forma de hardware/software codesign. Segundo a Tabela 22, o tempo necessário para executar os 80000 pontos foi de 40.35 segundos.

Como visto nas Tabelas 21 e 22, embora o hardware requerido para o FFT sem pipeline foi menor do que o requerido para o FFT com pipeline, o tempo de execução para ambas as implementações foi de 40.35 segundos. Por isso, a melhor escolha de implementação foi a do FFT sem pipeline, o qual consumiu menos recursos de hardware.

Como o desempenho do benchmark FFT no processador PowerPC foi aproximadamente 49 segundos, para calcular os 80000 pontos, ou seja, apenas 9 segundos de vantagem, foram feitas outras duas implementações, apenas para verificar o gargalo do sistema.

A primeira implementação é uma implementação tradicional com processos produtor, hardware e consumidor; a segunda é uma implementação que possui apenas os processos de hardware e o processo consumidor, ou seja, o processo de hardware nessa implementação será responsável por gerar e calcular o FFT sobre esses pontos. O processo consumidor, 
como nos outros casos, será responsável por mostrar uma mensagem de "fim de processamento".

Tabela 21. Tempo de execução do FFT hardware/software codesign com pipeline executado na XUP-V2P

\begin{tabular}{|c|c|c|c|c|c|c|}
\hline $\begin{array}{c}\% \\
\text { tempo }\end{array}$ & $\begin{array}{l}\text { t cumulat. } \\
\text { (segundos) }\end{array}$ & $\begin{array}{l}\text { Cada a } \\
\text { t próp. } \\
\text { (segundos) }\end{array}$ & $\begin{array}{c}\text { nostra é } \\
\text { Chamadas }\end{array}$ & $\begin{array}{c}\text { ntada em } 0.0 \\
\text { próp. cham. } \\
\text { (milessegundos) }\end{array}$ & $\begin{array}{c}1 \text { segundos } \\
\text { tot. cham. } \\
\text { (milessegundos) }\end{array}$ & nome \\
\hline 34.83 & 14.05 & 14.05 & & & & floatsidf \\
\hline 17.88 & 21.27 & 7.22 & & & & __pack_d \\
\hline 17.73 & 28.42 & 7.15 & & & & - divdf3 \\
\hline 15.08 & 34.51 & 6.08 & & & & _muldf3 \\
\hline 5.21 & 36.61 & 2.10 & & & & _unpack_d \\
\hline 4.32 & 38.35 & 1.74 & & & & $\overline{f p}$ _padd_parts \\
\hline 2.05 & 39.18 & 0.83 & 1 & 825.60 & 825.60 & Producer \\
\hline 1.56 & 39.81 & 0.63 & & & & _adddf3 \\
\hline 0.78 & 40.12 & 0.31 & & & & _ fixdfsi \\
\hline 0.28 & 40.23 & 0.11 & & & & Ishrdi3 \\
\hline 0.14 & 40.29 & 0.06 & & & & __subdf3 \\
\hline 0.06 & 40.31 & 0.02 & & & & Xlo_Out32 \\
\hline 0.04 & 40.33 & 0.02 & & & & Xlo_In 32 \\
\hline 0.02 & 40.34 & 0.01 & & & & Xlo_Out16 \\
\hline 0.02 & 40.34 & 0.01 & & & & XUartLite_SendByte \\
\hline 0.01 & 40.35 & 0.01 & & & & Xlo_In16 \\
\hline 0.00 & 40.35 & 0.00 & & & & _malloc_r \\
\hline 0.00 & 40.35 & 0.00 & & & & xil_printf \\
\hline 0.00 & 40.35 & 0.00 & & & & _sfvwrite \\
\hline 0.00 & 40.35 & 0.00 & & & & smakebuf \\
\hline 0.00 & 40.35 & 0.00 & & & & _mbtowc_r \\
\hline 0.00 & 40.35 & 0.00 & & & & _strdup_r $r$ \\
\hline 0.00 & 40.35 & 0.00 & & & & powerpc405_init \\
\hline 0.00 & 40.35 & 0.00 & 1 & 0.00 & 0.00 & Consumer \\
\hline 0.00 & 40.35 & 0.00 & 1 & 0.00 & 0.00 & co_initialize \\
\hline 0.00 & 40.35 & 0.00 & 1 & 0.00 & 0.00 & Main \\
\hline
\end{tabular}

As duas implementações calculam apenas 450 vetores de 16 pontos, porque a expressão no processo produtor, usada para gerar os pontos $((((i * 0.13 * j * 1.79)+i+j) / 120) *(1<<20))$ ficou muito complexa quando implementada em aritmética de ponto fixo em hardware. Acima de 450 pontos os resultados apresentaram overflow e como o objetivo era apenas verificar o gargalo do sistema, nenhuma mudança foi feita com relação ao padrão escolhido 1.s11.20.

A implementação da expressão acima em hardware ficou:

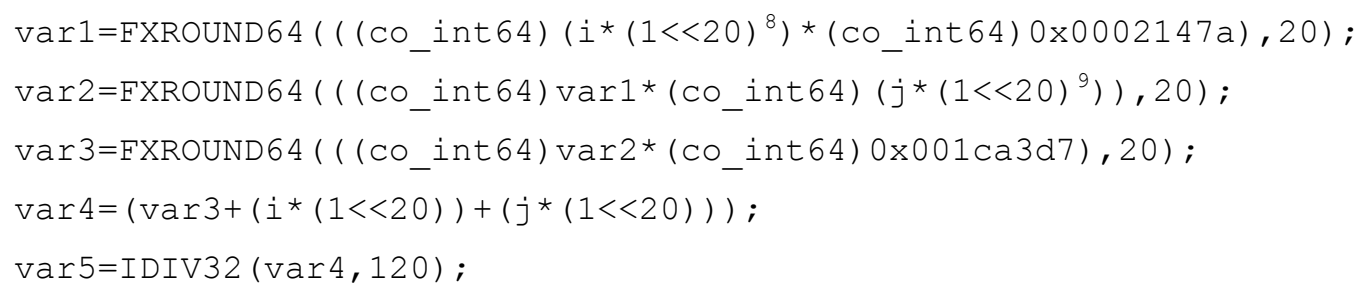

\footnotetext{
${ }^{8}$ Usado para converter a variável "i" em ponto fixo no formato 1 s11.20

${ }^{9}$ Usado para converter a variável "j" em ponto fixo no formato 1 s11.20
} 
Tabela 22. Tempo de execução do FFT hardware/software codesign sem pipeline executado na XUP-V2P

\begin{tabular}{|c|c|c|c|c|c|c|}
\hline $\begin{array}{c}\% \\
\text { tempo }\end{array}$ & $\begin{array}{l}\text { t cumulat. } \\
\text { (segundos) }\end{array}$ & $\begin{array}{l}\text { Cada a } \\
\text { t próp. } \\
\text { (segundos) }\end{array}$ & $\begin{array}{c}\text { nostra é c } \\
\text { chamadas }\end{array}$ & $\begin{array}{c}\text { ntada em } 0.0 \\
\text { próp. cham. } \\
\text { (milessegundos) }\end{array}$ & $\begin{array}{l}1 \text { segundos } \\
\text { tot. cham. } \\
\text { (milessegundos) }\end{array}$ & Nome \\
\hline 34.83 & 14.06 & 14.06 & & & & _floatsidf \\
\hline 17.89 & 21.27 & 7.22 & & & & __pack_d \\
\hline 17.73 & 28.43 & 7.15 & & & & _ divdf3 \\
\hline 15.08 & 34.51 & 6.08 & & & & _muldf3 \\
\hline 5.21 & 36.61 & 2.10 & & & & _unpack_d \\
\hline 4.32 & 38.35 & 1.74 & & & & fpadd_parts \\
\hline 2.05 & 39.18 & 0.83 & 1 & 826.20 & 826.20 & Producer \\
\hline 1.56 & 39.81 & 0.63 & & & & _ adddf3 \\
\hline 0.77 & 40.12 & 0.31 & & & & fixdfsi \\
\hline 0.28 & 40.23 & 0.11 & & & & __Ishrdi3 \\
\hline 0.14 & 40.29 & 0.05 & & & & __subdf3 \\
\hline 0.06 & 40.31 & 0.02 & & & & Xlo_Out32 \\
\hline 0.04 & 40.33 & 0.01 & & & & XIo_In32 \\
\hline 0.02 & 40.33 & 0.01 & & & & Xlo_Out16 \\
\hline 0.02 & 40.34 & 0.01 & & & & XUartLite_SendByte \\
\hline 0.01 & 40.35 & 0.01 & & & & XIo_In16 \\
\hline 0.00 & 40.35 & 0.00 & & & & _malloc_r \\
\hline 0.00 & 40.35 & 0.00 & & & & outbyte \\
\hline 0.00 & 40.35 & 0.00 & & & & _sfvwrite \\
\hline 0.00 & 40.35 & 0.00 & & & & __smakebuf \\
\hline 0.00 & 40.35 & 0.00 & & & & _mbtowc_r \\
\hline 0.00 & 40.35 & 0.00 & & & & _strdup_r $\bar{r}$ \\
\hline 0.00 & 40.35 & 0.00 & & & & powerpc405_init \\
\hline 0.00 & 40.35 & 0.00 & & & & xil_printf \\
\hline 0.00 & 40.35 & 0.00 & 1 & 0.00 & 0.00 & Consumer \\
\hline 0.00 & 40.35 & 0.00 & 1 & 0.00 & 0.00 & co_initialize \\
\hline 0.00 & 40.35 & 0.00 & 1 & 0.00 & 0.00 & main \\
\hline
\end{tabular}

O problema da expressão acima foi a macro IDIV32, responsável por dividir a expressão $((i * 0.13 * j * 1.79)+i+j)$ por 120 . Até 480 vetores de 16 pontos, os resultados gerados pelo hardware coincidiram com os resultados gerados pelo Desktop Simulation. A Figura 59 mostra a implementação do benchmark FFT em hardware.

Architecture: ffthw_hw

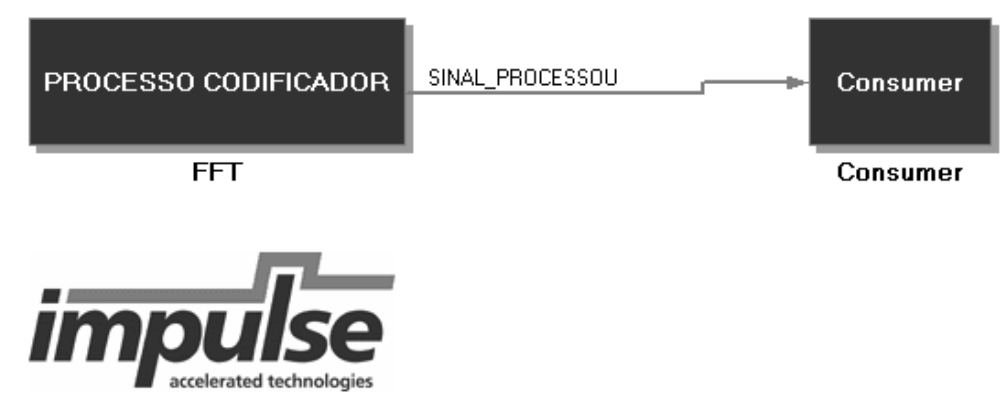

Figura 59. Implementação do benchmark FFT em hardware

Os resultados de desempenho das duas implementações com os 450 vetores de 16 pontos foram as seguintes: 
Para a implementação do processo tradicional: processo produtor, responsável por gerar os 450 vetores de 16 pontos, executando no processador PowerPC, processo codificador, responsável por calcular o FFT sobre os 16 pontos e o processo consumidor responsável por “avisar" ao usuário sobre o termino do processamento. A Tabela 23 mostra o resultado do tempo gasto para executar a primeira implementação na placa de prototipação.

Tabela 23. Implementação tradicional do benchmark FFT envolvendo os processos produtor, hardware e consumidor

\begin{tabular}{|c|c|c|c|c|c|c|}
\hline $\begin{array}{c}\% \\
\text { tempo }\end{array}$ & $\begin{array}{l}\text { t cumulat. } \\
\text { (segundos) }\end{array}$ & $\begin{array}{c}\text { Cada } \\
\text { t próp. } \\
\text { (segundos) }\end{array}$ & $\begin{array}{l}\text { nostra é } \\
\text { chamadas }\end{array}$ & $\begin{array}{l}\text { prtada em } 0 . \\
\text { próp. cham. } \\
\text { (milessegundos) }\end{array}$ & $\begin{array}{l}01 \text { segundos } \\
\text { tot. cham. } \\
\text { (milessegundos) }\end{array}$ & nome \\
\hline 49.47 & 2.33 & 2.33 & & & & _floatsidf \\
\hline 13.92 & 2.98 & 0.66 & & & & __pack_d \\
\hline 13.80 & 3.63 & 0.65 & & & & __divdf3 \\
\hline 10.93 & 4.15 & 0.51 & & & & _ muldf3 \\
\hline 4.88 & 4.38 & 0.23 & & & & _unpack_d \\
\hline 2.94 & 4.52 & 0.14 & & & & _fpadd_parts \\
\hline 1.55 & 4.59 & 0.07 & 1 & 73.10 & 73.10 & Producer \\
\hline 0.87 & 4.63 & 0.04 & & & & _adddf3 \\
\hline 0.57 & 4.66 & 0.03 & & & & IIshrdi3 \\
\hline 0.56 & 4.68 & 0.03 & & & & _fixdfsi \\
\hline 0.18 & 4.69 & 0.01 & & & & XUartLite_SendByte \\
\hline 0.09 & 4.70 & 0.00 & & & & Xlo_In32 \\
\hline 0.07 & 4.70 & 0.00 & 1 & 3.52 & 3.52 & main \\
\hline 0.07 & 4.70 & 0.00 & & & & _ subdf3 \\
\hline 0.04 & 4.71 & 0.00 & & & & Xlo_Out32 \\
\hline 0.03 & 4.71 & 0.00 & & & & Xlo_InSwap16 \\
\hline 0.01 & 4.71 & 0.00 & & & & Xlo_EndianSwap16OLD \\
\hline 0.01 & 4.71 & 0.00 & & & & _malloc_r \\
\hline 0.00 & 4.71 & 0.00 & & & & _mbtowc_r \\
\hline 0.00 & 4.71 & 0.00 & & & & _vfprintf_r \\
\hline 0.00 & 4.71 & 0.00 & & & & co_process_create \\
\hline 0.00 & 4.71 & 0.00 & & & & outbyte \\
\hline 0.00 & 4.71 & 0.00 & & & & powerpc405_init \\
\hline 0.00 & 4.71 & 0.00 & & & & write \\
\hline 0.00 & 4.71 & 0.00 & 1 & 0.00 & 0.00 & Consumer \\
\hline 0.00 & 4.71 & 0.00 & 1 & 0.00 & 0.00 & co_initialize \\
\hline
\end{tabular}

Segundo a Tabela 23, o tempo gasto foi de 4.71 segundos.

A Tabela 24 mostra o tempo gasto para executar a segunda implementação na placa de prototipação.

A Tabela 24 mostra que para essa implementação do benchmark FFT, o tempo gasto foi de 0.01 segundo. Então, com essas duas implementações, prova-se que o "gargalo" do sistema é o processo produtor, porque o processador embarcado tem que gerar 450 vezes 16 pontos, isso faz com que o processo de hardware fica parado "esperando" esses pontos serem calculados, mesmo porque o benchmark FFT exige que os 16 pontos estejam presentes para ele calcular o FFT. Outra razão é que uma stream de dados foi eliminada, essa stream é responsável pela "comunicação" entre o processo produtor no processador embarcado e o processo $F F T$ 
executando no FPGA. Como a stream é síncrona, ela faz com que o processo FFT em hardware fique parado até que o processo produtor tenha gerado algum ponto. Para evitar esses problemas, outras implementações poderiam ser feitas. Por exemplo, uma implementação, na qual os 450 pontos já estariam calculados e presentes em uma memória. Então, o processo em hardware teria apenas que pegar esses pontos, calcular o FFT e gerar os resultados para o processo consumidor. Esse tipo de implementação é típica de uma aplicação real, na qual o FFT é calculado com os dados de uma imagem presente na memória, por exemplo.

Tabela 24. Implementação do benchmark FFT envolvendo os processos hardware e consumidor

\begin{tabular}{|c|c|c|c|c|c|c|}
\hline $\begin{array}{c}\% \\
\text { tem- } \\
\text { po }\end{array}$ & $\begin{array}{l}\text { t cumulat. } \\
\text { (segundos) }\end{array}$ & $\begin{array}{l}\text { Cada ar } \\
\text { t próp. } \\
\text { (segundos) }\end{array}$ & $\begin{array}{l}\text { ostra é c } \\
\text { chamadas }\end{array}$ & $\begin{array}{c}\text { ntada em } 0.00 \\
\text { próp. cham. } \\
\text { (milessegundos) }\end{array}$ & $\begin{array}{l}1 \text { segundos } \\
\text { tot. cham. } \\
\text { (milessegundos) }\end{array}$ & nome \\
\hline 69.66 & 0.01 & 0.01 & & & & XUartLite_SendByte \\
\hline 17.82 & 0.01 & 0.00 & & & & Xlo_In32 \\
\hline 2.97 & 0.01 & 0.00 & & & & Xlo_In16 \\
\hline 2.97 & 0.01 & 0.00 & & & & Xlo_InSwap16 \\
\hline 0.82 & 0.01 & 0.00 & 1 & 99.98 & 99.98 & main \\
\hline 0.82 & 0.01 & 0.00 & & & & _malloc_r \\
\hline 0.82 & 0.01 & 0.00 & & & & _mbtowc_r \\
\hline 0.82 & 0.01 & 0.00 & & & & _vfprintf_r \\
\hline 0.82 & 0.01 & 0.00 & & & & co_process_create \\
\hline 0.82 & 0.01 & 0.00 & & & & powerpc405_init \\
\hline 0.82 & 0.01 & 0.00 & & & & std \\
\hline 0.61 & 0.01 & 0.00 & & & & Xlo_Out32 \\
\hline 0.10 & 0.01 & 0.00 & & & & Xlo_EndianSwap160LD \\
\hline 0.10 & 0.01 & 0.00 & & & & Xlo_Out16 \\
\hline 0.00 & 0.01 & 0.00 & 1 & 0.00 & 0.00 & Consumer \\
\hline 0.00 & 0.01 & 0.00 & 1 & 0.00 & 0.00 & co_initialize \\
\hline
\end{tabular}

\subsubsection{Implementação do benchmark FDCT no Impulse $C$}

O benchmark FDCT, como mostrado em capítulos 5, trabalha em blocos de imagem de $8 \times 8$ pixels, no qual cada pixel é representado por um número inteiro.

O FDCT é composto por dois laços principais de repetição, um para processar as linhas e outro para processar as colunas do bloco de pixels da imagem.

Então, por esse motivo, foram feitas 2 implementações principais desse benchmark no Impulse $C$.

A primeira implementação, como mostrado na Figura 60, possui 3 processos: o processo produtor (producer), responsável por gerar 5000 blocos de 64 pixels, cada um, 
fdct_1hw_2loops, o qual faz os cálculos FDCT e por fim o processo consumidor responsável por mostrar uma mensagem de "fim de processo" ao usuário.

Architecture: fdct_3

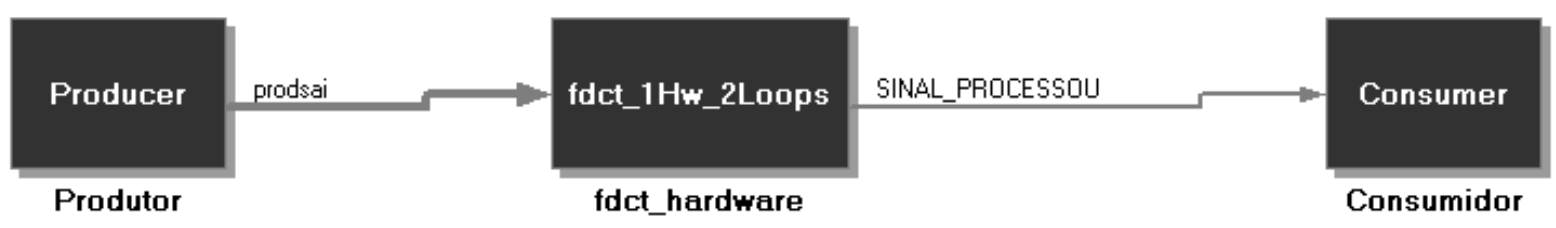

\section{impulse}

Figura 60. Primeira implementação do benchmark FDCT no Impulse C

Os processos produtor e consumidor foram configurados para serem executados no processador embarcado, enquanto que o processo fdct_1hw_2loops foi configurados para ser executado diretamente no FPGA, sob a forma de lógica customizada.

O processo produtor foi configurado para executar no processador embarcado, no caso o PowerPC. Ele é responsável por gerar 5000 vetores de 64 pontos, os quais representam blocos de pixels e enviar esses valores ao processo codificador.

O trecho de código abaixo representa o cálculo dos 320000 pontos a serem enviados ao processo fdct_1hw_2loops.

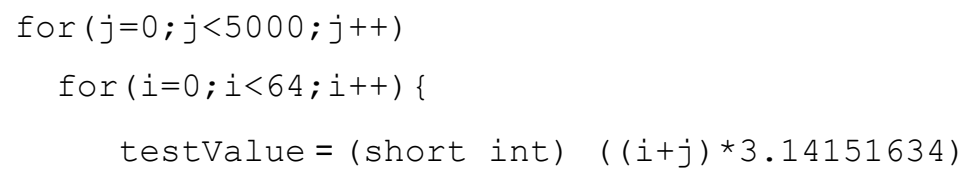

A expressão (short int) $((i+j) * 3.14151634)$ foi escolhida ao acaso e gera números aleatórios e embora possua uma multiplicação em ponto flutuante, o resultado dela é um número do tipo de dado "short int", ou seja, ela retorna um número inteiro de 2 bytes. O tipo de dado "short int" foi preservado do benchmark original FDCT;

O processo fdct_1hw_2loops é responsável por receber 64 números inteiros do processo produtor, calcular a FDCT e gerar os 64 números resultantes. Os processos produtor e fdct_1hw_2loops são sincronizados por streams de dados. Nessa primeira implementação do benchmark FDCT no Impulse $C$, esse processo possui os dois laços de repetição, responsáveis pelos cálculos no bloco 8x8 pixels; 
O processo consumidor, na fase de cálculo do desempenho, é bloqueado pela função co_signal_wait e aguarda até que o processo decodificador envie um sinal, indicando o término do processamento dos 320000 pontos. Assim, o processo consumidor exibe uma mensagem ao usuário indicando "fim de processo".

A segunda implementação, como mostrado na Figura 61, possui 4 processos: o processo produtor (producer), responsável por gerar 5000 blocos de 64 pixels, cada um, o processo fdct_linha, , o processo fdct_coluna, e por fim, o processo consumidor é responsável por mostrar uma mensagem de "fim de processo" ao usuário.

Architecture: fdct_1

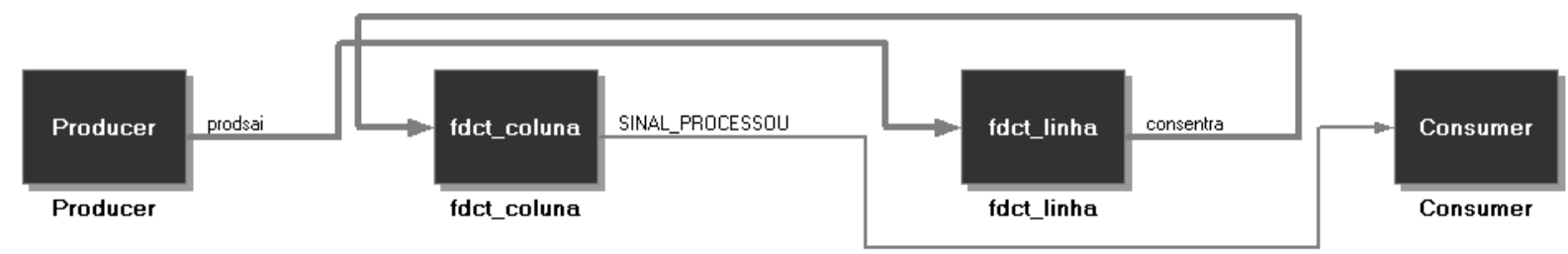

\section{impulse}

Figura 61. Segunda implementação do benchmark FDCT no Impulse C

Os processos produtor e consumidor foram configurados para serem executados no processador embarcado, enquanto que os processos fdct_linha e fdct_coluna foram configurados para ser executados diretamente no FPGA, sob a forma de lógica customizada. A diferença dessa implementação para as outras é que fdct_linha e fdct_coluna representam dois blocos de hardware independentes dentro do FPGA e teoricamente, poderiam executar em paralelo.

O processo produtor foi configurado para executar no processador embarcado, no caso o PowerPC. Ele é responsável por gerar 5000 vetores de 64 pontos, os quais representam blocos de pixels e enviar esses valores ao processo codificador.

O trecho de código abaixo representa o cálculo dos 320000 pontos a serem enviados ao processo fdct_1hw_2loops.

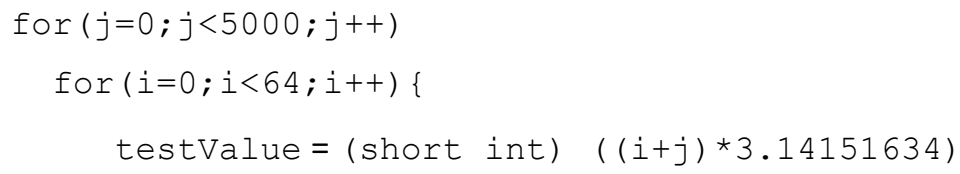

A expressão (short int) $((i+j) * 3.14151634)$ foi escolhida ao acaso e gera números aleatórios e embora possua uma multiplicação em ponto flutuante, o resultado dela é um nú- 
mero do tipo de dado "short int", ou seja, ela retorna um número inteiro de 2 bytes. 0 tipo de dado "short int" foi preservado do benchmark original FDCT;

O processo fdct_linha representa o primeiro loop do benchmark FDCT é responsável por receber o bloco de $8 \times 8$ pixels do processo produtor, calcular a FDCT nas linhas e gerar o bloco de $8 \times 8$ pixels resultantes, que por sua vez serão usados pelo processo fdct_coluna para calcular a FDCT nas colunas, resultando assim no bloco de 8x8 pixels com o cálculo completo da FDCT. Após calcular 5000 blocos de $8 \times 8$ pixels. O processo fdct_coluna representa o segundo loop presente no benchmark FDCT.

O processo consumidor, na fase de cálculo do desempenho, é bloqueado pela função co_signal_wait e aguarda até que o processo fdct_coluna envie um sinal, indicando o término do processamento dos 320000 pontos. Assim, o processo consumidor exibe uma mensagem ao usuário indicando "fim de processo".

Os tópicos abaixo mostram a simulação do benchmark FDCT no Impulse $C$, no simulador VHDL, por fim os tempos de desempenho com as implementações feitas. 
Simulação do benchmark FDCT no Impulse

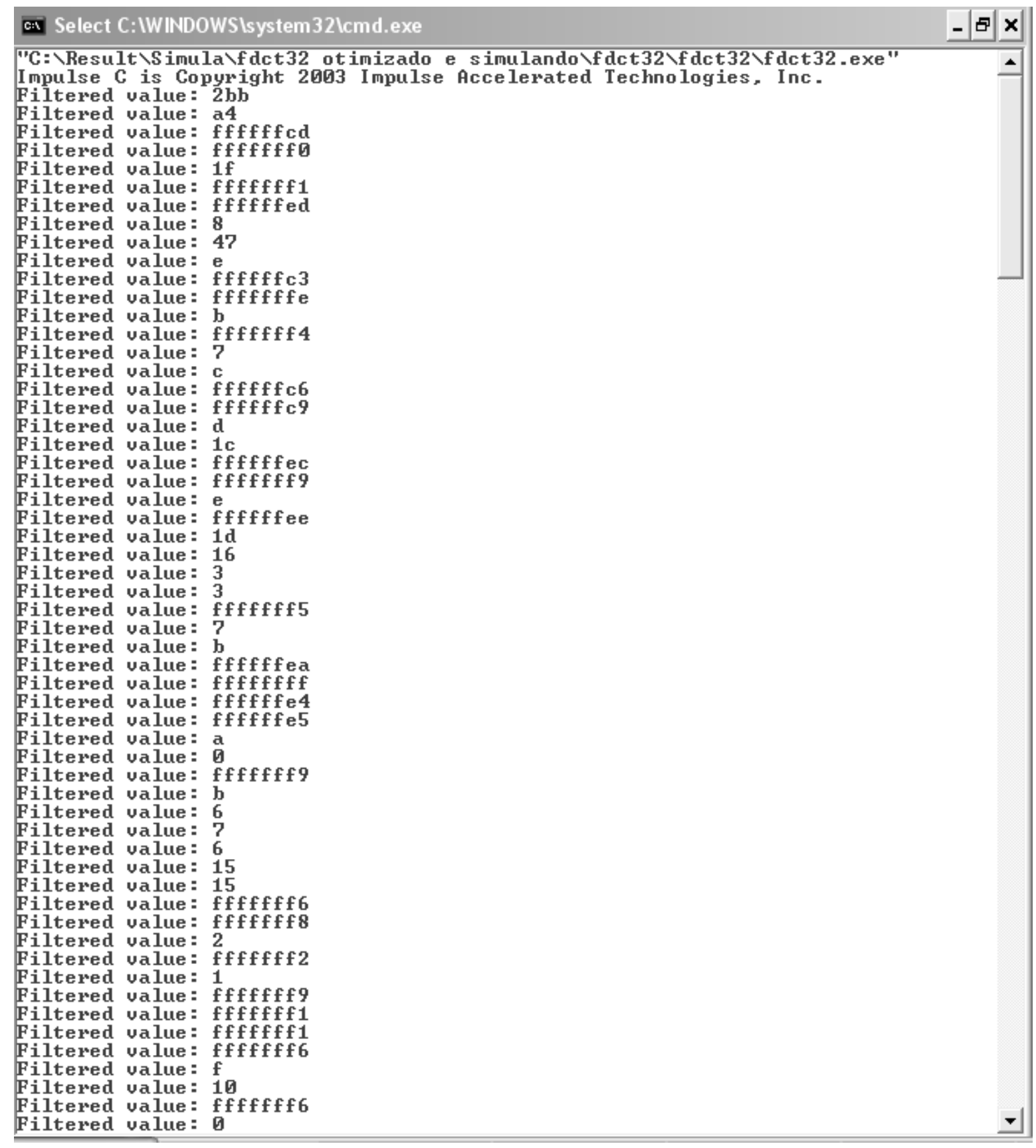

Figura 62. Simulação do FDCT no Impulse C

A Figura 62 mostra uma simulação do benchmark FDCT para as duas implementações feitas, porque, os resultados das simulações de ambas as implementações são os mesmos. 
Architecture: fdct_3

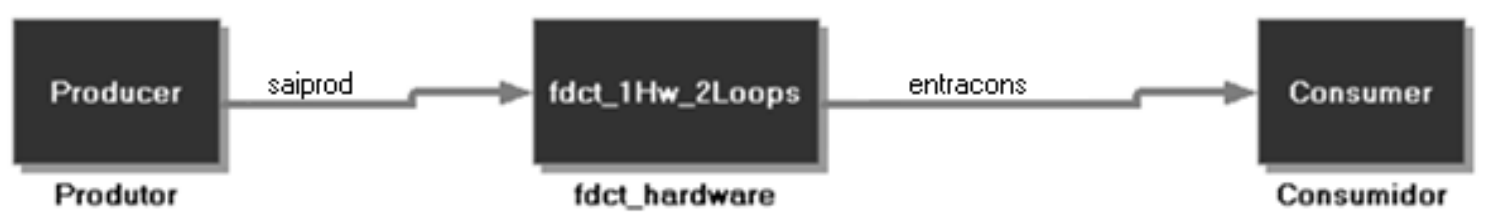

\section{impulse}

Figura 63. Diagrama de bloco feito pelo Application Monitor, mostrando o funcionamento da primeira implementação do FDCT

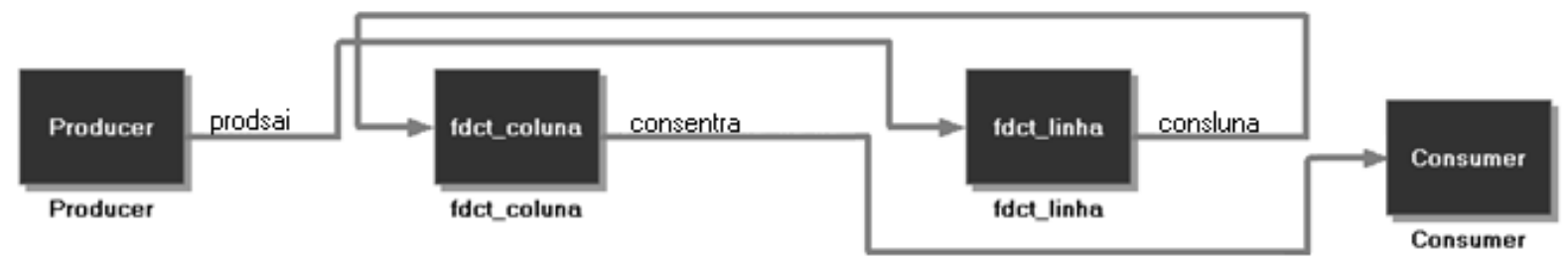

\section{impulse}

Figura 64. Diagrama de bloco feito pelo Application Monitor, mostrando o funcionamento da segunda implementação do FDCT

As Figuras 62, 63 e 64 demonstram a execução do benchmark FDCT no Impulse C, como pode ser visto na Figura 62, o Impulse C mostra o correto funcionamento do sistema. Com isso, o projetista pode simular os resultados do hardware gerado, com as mesmas entradas usadas pelo processo produtor (producer) e ver se as saídas são equivalentes. Além disso, o projetista pode executar o sistema completo na placa de prototipação suportada pelo PSP no Impulse C. O Application Monitor mostra as comunicações entre os processos implementados no Impulse $C$ e a troca de dados entre eles. Para a simulação, a comunicação entre os processos é feita por streams de dados. As saídas mostradas na Figura 62 estão em hexadecimais.

\section{Simulação feita no VHDL Simili}

A simulação da funcionalidade dos arquivos $V H D L$ gerados pelo Impulse $C$ foram feitas com o software da empresa Symphony EDA VHDL Simili 3.0.14. (Symphony EDA, 2005) 


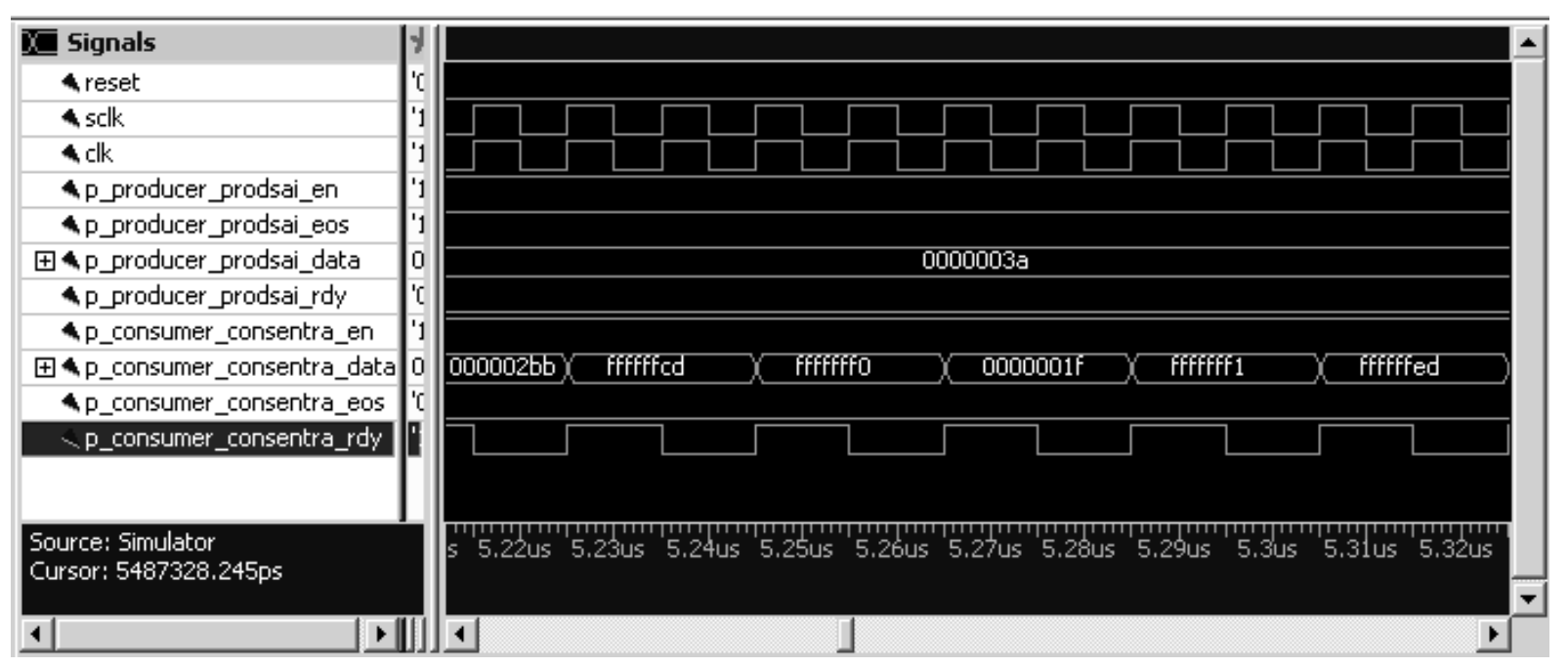

Figura 65. Simulação do hardware gerado pelo Impulse do benchmark ADPCM pela ferramenta VHDL Simili

A Figura 65 mostra o correto funcionamento do hardware gerado pelo Impulse C. Os resultados mostrados nessa figura estão em hexadecimais e podem ser confrontados com os resultados em hexadecimais mostrados na Figura 62.

\section{Desempenho do benchmark na placa de prototipação XUP V2P}

Para a fase de obtenção do desempenho do benchmark FDCT na placa de prototipação, 6 implementações foram feitas. Foram feitas duas implementações maiores, que são as discutidas acima: a primeira com um processo de hardware e dois laços de repetição, Figura 60 e a segunda com dois processos de hardware, e um laço de repetição cada, Figura 61. Então, para cada uma dessas duas implementações, outras três implementações menores foram geradas. Essas implementações menores são basicamente a inclusão do comando \#pragma CO PIPELINE em todos os laços de repetição do(s) processo(s) de hardware do FDCT; a inclusão do comando \#pragma CO UNROLL em todos os laços de repetição do(s) processo(s) de hardware do FDCT e a terceira implementação não possui qualquer comando de otimização nos laços de repetição do(s) processo(s) de hardware do FDCT.

No PSB do Impulse C, foi selecionado para a ferramenta gerar o hardware/software codesign no formato VHDL para o barramento PLB, no FPGA Virtex-II Pro.

A Tabela 25 descreve os recursos de hardware utilizados no FPGA Virtex-II Pro, segundo a ferramenta $E D K$, para a primeira implementação do Core $F D C T$, Figura 60, com a opção de otimização \#pragma CO PIPELINE habilitada em todos os laços de repetição do processo de hardware no Core FDCT. 
Tabela 25. Resumo dos recursos de hardware usado pelo benchmark FDCT, na primeira implementação, com o uso do pipeline

\begin{tabular}{|c|c|c|c|}
\hline \multicolumn{4}{|c|}{ Resumo dos recursos de hardware gastos pelo benchmark } \\
Tipo de recurso & Uso & Disponível no FPGA & Porcentagem usada \\
\hline Slices & 210 & 13696 & 1 \\
Slice Flip Flops & 202 & 27392 & 0 \\
4 input LUTs & 371 & 27392 & 1 \\
bonded IOBs & 217 & 556 & 39 \\
\hline
\end{tabular}

A Tabela 26 descreve os recursos de hardware utilizados no FPGA Virtex-II Pro, segundo a ferramenta $E D K$, para a primeira implementação do Core FDCT, Figura 60, com a opção de otimização \#pragma CO UNROLL habilitada em todos os laços de repetição do processo de hardware no Core FDCT.

Tabela 26. Resumo dos recursos de hardware usado pelo benchmark FDCT, na primeira implementação, com o uso do unroll

\begin{tabular}{|c|c|c|c|}
\hline \multicolumn{4}{|c|}{ Resumo dos recursos de hardware gastos pelo benchmark } \\
Tipo de recurso & Uso & Disponível no FPGA & Porcentagem usada \\
\hline Slices & 163 & 13696 & 1 \\
Slice Flip Flops & 236 & 27392 & 0 \\
4 input LUTs & 120 & 27392 & 0 \\
bonded IOBs & 217 & 556 & 39 \\
\hline
\end{tabular}

A Tabela 27 descreve os recursos de hardware utilizados no FPGA Virtex-II Pro, segundo a ferramenta $E D K$, para a primeira implementação do Core FDCT, Figura 60, sem opções de otimizações nos laços de repetições do processo de hardware.

Tabela 27. Resumo dos recursos de hardware usado pelo benchmark FDCT, na primeira implementação, sem opções de otimização nos laços de repetição

\begin{tabular}{|c|c|c|c|}
\hline \multicolumn{4}{|c|}{ Resumo dos recursos de hardware gastos pelo benchmark } \\
Tipo de recurso & Uso & Disponível no FPGA & Porcentagem usada \\
\hline Slices & 158 & 13696 & 1 \\
Slice Flip Flops & 152 & 27392 & 0 \\
4 input LUTs & 272 & 27392 & 0 \\
bonded IOBs & 217 & 556 & 39 \\
\hline
\end{tabular}

A Tabela 28 mostra o tempo gasto pelos Cores FDCT, nas três primeiras implementações, executados na placa de prototipação, sob a forma de hardware/software codesign. Segundo essa tabela, o tempo necessário para executar os 320000 pontos foi de 30.01 segundos. 
Tabela 28. Tempo de execução do FDCT hardware/software codesign para as três primeiras implementações executados na XUP-V2P

\begin{tabular}{|c|c|c|c|c|c|c|}
\hline $\begin{array}{c}\% \\
\text { tempo }\end{array}$ & $\begin{array}{l}\mathrm{t} \text { cumulat. } \\
\text { (segundos) }\end{array}$ & $\begin{array}{c}\text { Cada } \\
\text { t próp. } \\
\text { (segundos) }\end{array}$ & $\begin{array}{r}\text { amostra é } \\
\text { chamadas }\end{array}$ & $\begin{array}{c}\text { contada em } 0 . \\
\text { próp. cham. } \\
\text { (milessegundos) }\end{array}$ & $\begin{array}{l}01 \text { segundos } \\
\text { tot. cham. } \\
\text { (milessegundos) }\end{array}$ & nome \\
\hline 44.29 & 13.29 & 13.29 & & & & _floatsidf \\
\hline 20.34 & 19.39 & 6.10 & & & & muldf3 \\
\hline 17.74 & 24.72 & 5.32 & & & & _pack_d \\
\hline 5.83 & 26.47 & 1.75 & 1 & 1.75 & 1.75 & Producer \\
\hline 5.70 & 28.18 & 1.71 & & & & __unpack_d \\
\hline 3.92 & 29.35 & 1.18 & & & & _fixdfsi \\
\hline 1.32 & 29.75 & 0.40 & & & & _Ishrdi3 \\
\hline 0.33 & 29.85 & 0.10 & & & & Xlo_Out32 \\
\hline 0.21 & 29.91 & 0.06 & & & & Xlo_In32 \\
\hline 0.12 & 29.95 & 0.04 & 1 & 0.04 & 0.04 & main \\
\hline 0.11 & 29.98 & 0.03 & & & & Xlo_Out16 \\
\hline 0.07 & 30.00 & 0.02 & & & & Xlo_In16 \\
\hline 0.01 & 30.00 & 0.00 & & & & XUartLite_SendByte \\
\hline 0.00 & 30.00 & 0.00 & & & & _malloc_r \\
\hline 0.00 & 30.01 & 0.00 & & & & outbyte \\
\hline 0.00 & 30.01 & 0.00 & & & & _strdup_r \\
\hline 0.00 & 30.01 & 0.00 & & & & powerpc405_init \\
\hline 0.00 & 30.01 & 0.00 & & & & print \\
\hline 0.00 & 30.01 & 0.00 & 1 & 0.00 & 0.00 & Consumer \\
\hline 0.00 & 30.01 & 0.00 & 1 & 0.00 & 0.00 & co initialize \\
\hline
\end{tabular}

Como visto nas Tabelas 25, 26 e 27, o hardware requerido para o Core FDCT com a opção co unroll, na média, foi menor do que as duas outras implementações. A Tabela 28 representa o desempenho das três primeiras implementações, já que a tabela gerada pelo Gprof foi a mesma para as três.

A Tabela 29 descreve os recursos de hardware utilizados no FPGA Virtex-II Pro, segundo a ferramenta EDK para a segunda implementação do Core FDCT, Figura 61, com a opção de otimização \#pragma CO PIPELINE habilitada em todos os laços de repetição dos dois processos de hardware no Core FDCT.

Tabela 29. Resumo dos recursos de hardware usado pelo benchmark FDCT, na segunda implementação, com o uso do pipeline

\begin{tabular}{|c|c|c|c|}
\hline \multicolumn{3}{|c|}{ Resumo dos recursos de hardware gastos pelo benchmark } \\
Tipo de recurso & Uso & Disponível no FPGA & Porcentagem usada \\
\hline Slices & 306 & 13696 & 2 \\
Slice Flip Flops & 271 & 27392 & 0 \\
4 input LUTs & 549 & 27392 & 2 \\
bonded IOBs & 217 & 556 & 39 \\
\hline
\end{tabular}

A Tabela 30 descreve os recursos de hardware utilizados no FPGA Virtex-Il Pro, segundo a ferramenta EDK para a segunda implementação do Core FDCT, Figura 61, com a opção 
de otimização \#pragma CO UNROLL habilitada em todos os laços de repetição do processo de hardware no Core FDCT.

Tabela 30. Resumo dos recursos de hardware usado pelo benchmark FDCT, na segunda implementação, com o uso do unroll

\begin{tabular}{|c|c|c|c|}
\hline \multicolumn{4}{|c|}{ Resumo dos recursos de hardware gastos pelo benchmark } \\
Tipo de recurso & Uso & Disponível no FPGA & Porcentagem usada \\
\hline Slices & 257 & 13696 & 1 \\
Slice Flip Flops & 310 & 27392 & 1 \\
4 input LUTs & 299 & 27392 & 1 \\
bonded IOBs & 217 & 556 & 39 \\
\hline
\end{tabular}

A Tabela 31 descreve os recursos de hardware utilizados no FPGA Virtex-II Pro, segundo a ferramenta EDK para a segunda implementação do Core FCDT, Figura 61, sem opções de otimização nos laços de repetição do processo de hardware no Core FDCT.

Tabela 31. Resumo dos recursos de hardware usado pelo benchmark FDCT, na segunda implementação, sem opções de otimização nos laços de repetição

\begin{tabular}{|c|c|c|c|}
\hline \multicolumn{3}{|c|}{ Resumo dos recursos de hardware gastos pelo benchmark } \\
Tipo de recurso & Uso & Disponível no FPGA & Porcentagem usada \\
\hline Slices & 253 & 13696 & 1 \\
Slice Flip Flops & 225 & 27392 & 0 \\
4 input LUTs & 454 & 27392 & 1 \\
bonded IOBs & 217 & 556 & 39 \\
\hline
\end{tabular}

A Tabela 32 mostra o tempo gasto pelos Cores FDCT nas três últimas implementações, executados na placa de prototipação, sob a forma de hardware/software codesign.

Tabela 32. Tempo de execução do FDCT hardware/software codesign para as três últimas implementações executados na XUP-V2P

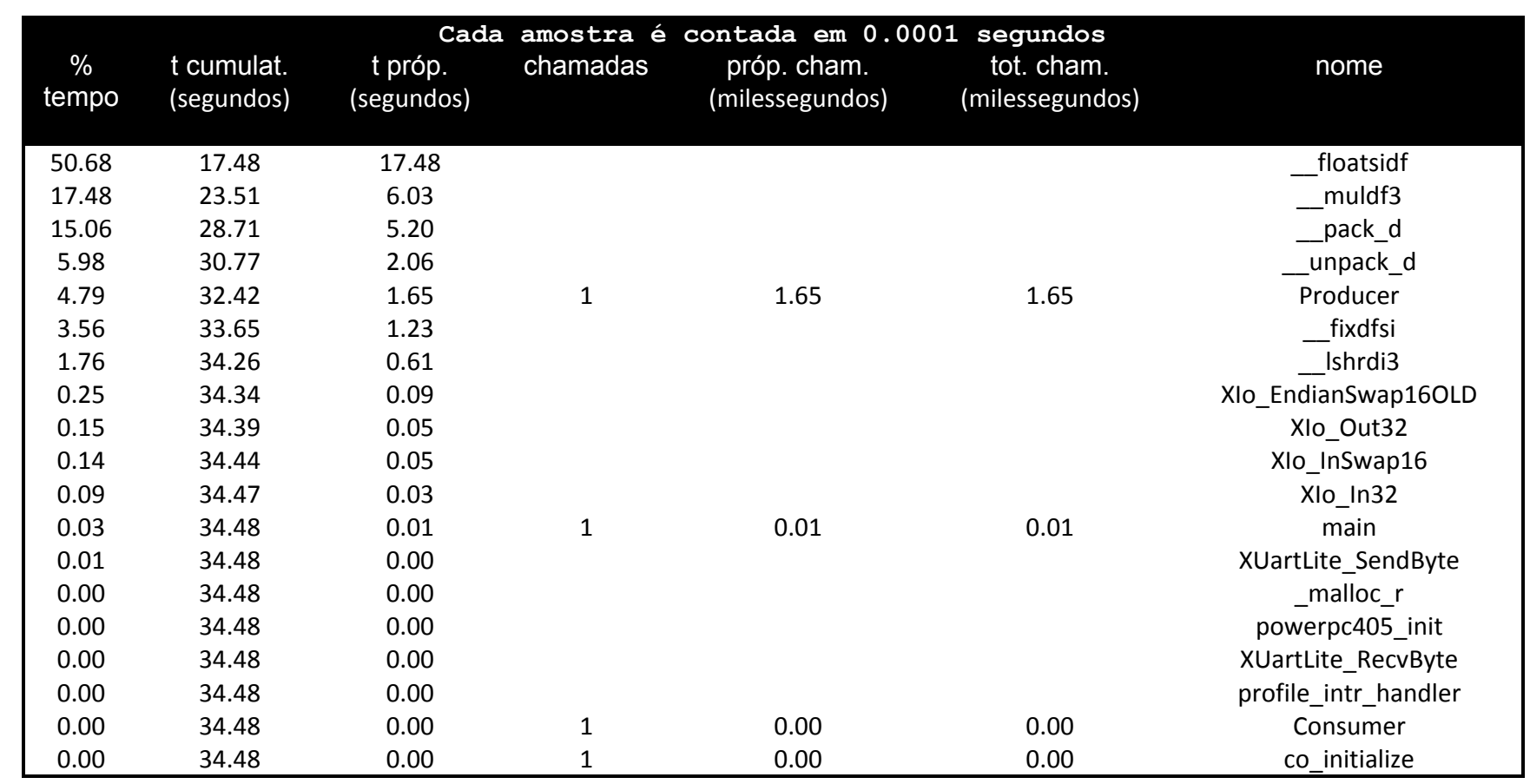


Segundo a Tabela 32, o tempo necessário para executar os 320000 pontos foi de 34.48 segundos.

Como visto nas Tabelas 29, 30 e 31, o hardware requerido para o Core FDCT com unroll, na média, foi menor do que as duas outras implementações. A Tabela 32 representa o desempenho das três últimas implementações, já que a tabela gerada pelo Gprof foi a mesma para as três.

Um comparativo entre as duas maiores implementações feitas, Figuras 60 e 61 e as suas respectivas tabelas de desempenho, Tabelas 28 e 32, mostram que a primeira implementação foi a que teve um desempenho melhor para o calculo do FDCT com os 5000 blocos de 8x8 pixels. Comparando as Tabelas 30, 31 e 32 com as Tabelas 34, 35 e 36, conclui-se que na média a primeira implementação obteve menor gasto de hardware do que a segunda para a implementação desse benchmark.

\subsubsection{Implementação do benchmark ADPCM no Impulse $C$}

O benchmark ADPCM é composto pelo codificador e decodificador ADPCM. Ele aceita 16 pontos do tipo inteiro do processo produtor, codifica-os e envia ao processo decodificador, o qual os decodifica, enviando-os assim ao processo consumidor.

Os processos produtor e consumidor foram configurados para serem executados no processador embarcado, enquanto que os processos codificador e decodificador foram configurados para serem executados diretamente no FPGA, sob a forma de lógica customizada.

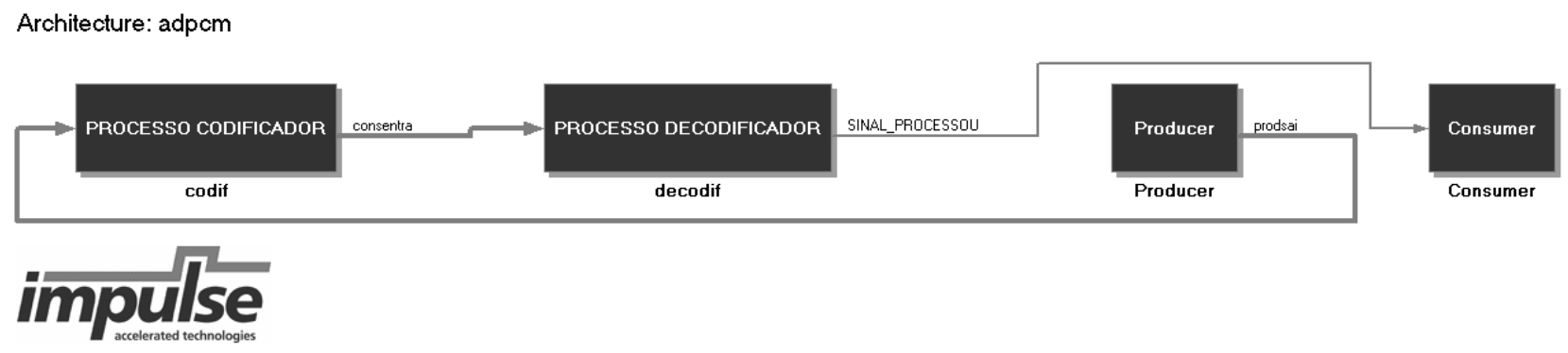

Figura 66. Implementação do benchmark ADPCM no Impulse C

A Figura 66 mostra a implementação do $A D P C M$ no Impulse $C$, sob a forma de hardware/software codesign.

O processo produtor foi configurado para executar no processador embarcado, no caso o PowerPC. Ele é responsável por gerar 5000 vetores de 16 pontos e enviar esses valores ao processo codificador. 
O trecho de código abaixo representa o cálculo dos 80000 pontos a serem enviados ao processo decodificador.

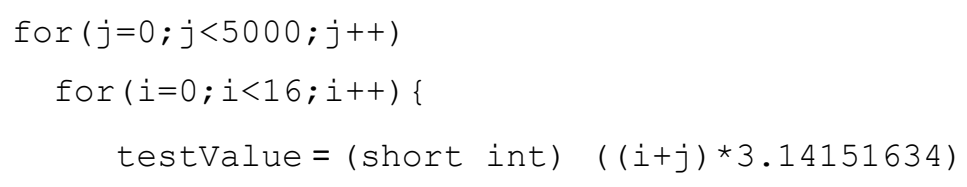

A expressão (short int) $((i+j) * 3.14151634)$ foi escolhida ao acaso e gera números aleatórios e embora possua uma multiplicação em ponto flutuante, o resultado dela é um número do tipo de dado "short int", ou seja, ela retorna um número inteiro de 2 bytes. O tipo de dado "short int" foi preservado do benchmark original ADPCM.

O processo codificador é responsável por receber 16 valores do processo produtor, codificar eles no formato ADPCM e gerar um vetor de 16 valores ao processo decodificador.

O processo decodificador é responsável por receber os 16 valores gerados pelo processo codificador e decodificá-los. Os processos: consumidor, codificador e decodificador são sincronizados pela stream. Quando o processo produtor acabar de gerar os 80000 pontos, ele executa uma função do Impulse C chamada HW_STREAM_CLOSE, que fecha a stream de comunicação entre os processos produtor e codificador. Isso é feito sucessivamente pelos processos seguintes. O processo decodificador ao receber o sinal de stream fechada ele envia um sinal co_signal_post ao processo consumidor, "acordando-o".

O processo consumidor, na fase de cálculo do desempenho, é bloqueado pela função co_signal_wait e aguarda até que o processo decodificador envie um sinal, indicando o término do processamento dos 80000 pontos. Assim, o processo consumidor exibe uma mensagem ao usuário indicando "fim de processo". Os tópicos abaixo mostram a simulação do benchmark $A D P C M$ no Impulse $C$, no simulador $V H D L$, por fim os tempos de desempenho com as implementações feitas.

Architecture: adpcm32_arch
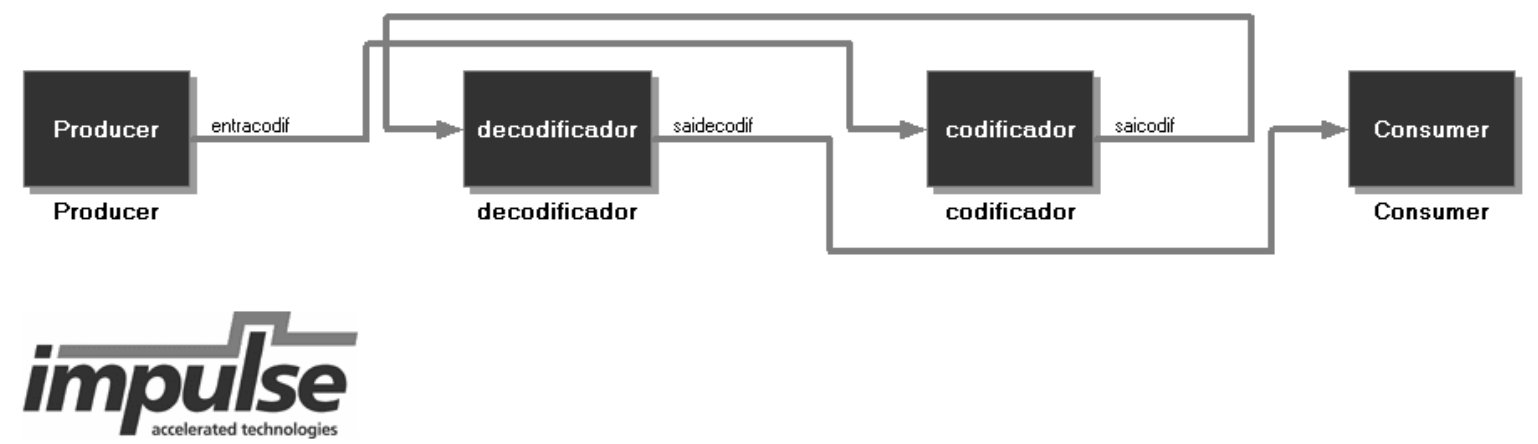

Figura 67. Diagrama de bloco feito pelo Application Monitor, mostrando o funcionamento do ADPCM 
Simulação do benchmark ADPCM no Impulse

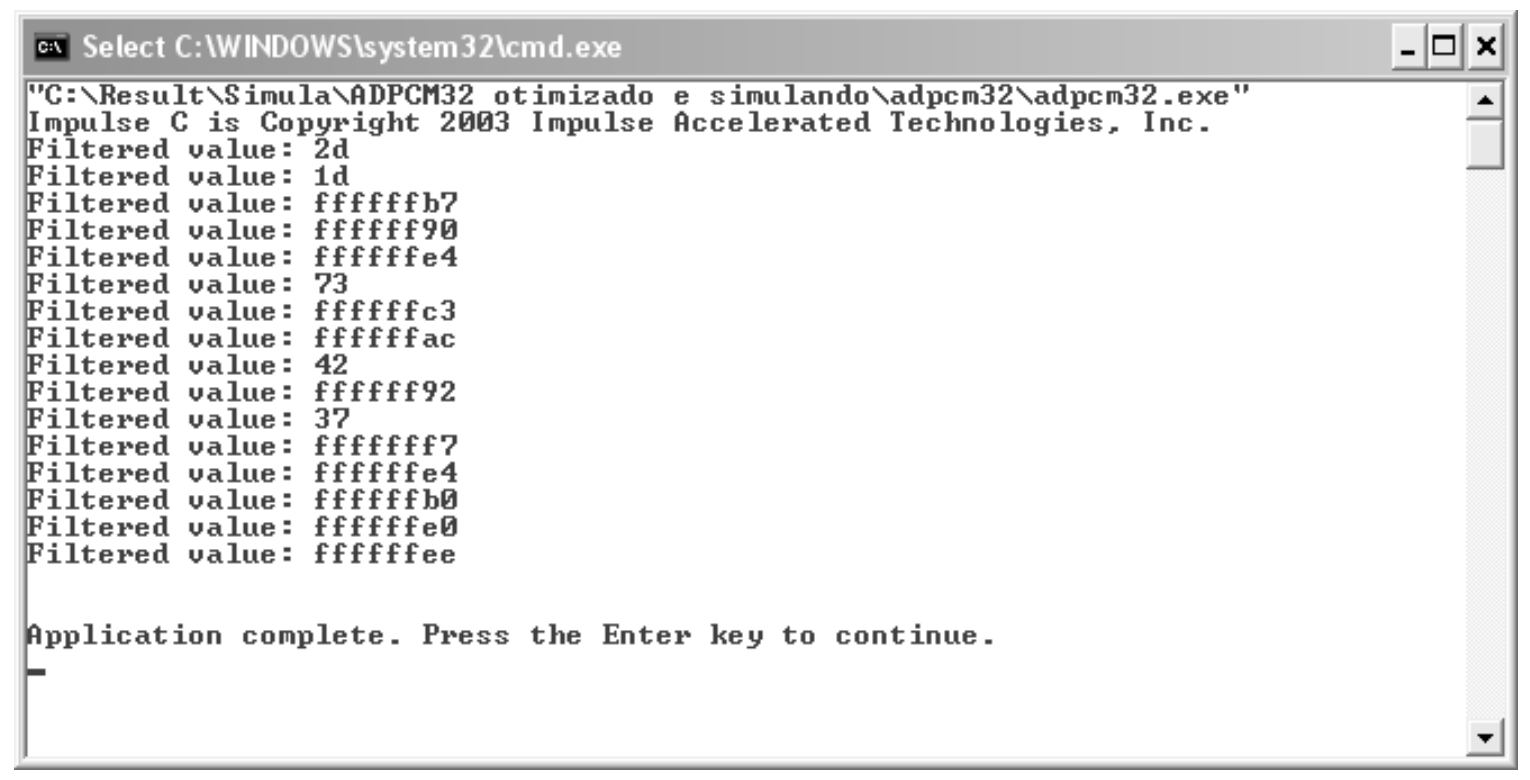

Figura 68. Simulação do ADPCM no Impulse C

As Figuras 67 e 68 demonstram a execução do benchmark ADPCM no Impulse $C$, como pode ser visto na Figura 68. O projetista pode simular os resultados do hardware gerado, com as mesmas entradas usadas pelo processo produtor (producer) e ver se as saídas são equivalentes. Além disso, o projetista pode executar o sistema completo na placa de prototipação suportada pelo PSP no Impulse C. O Application Monitor mostra as comunicações entre os processos implementados no Impulse $C$ e a troca de dados entre eles. Para a simulação, a comunicação entre os processos é feita por streams de dados. As saídas mostradas na Figura 68 estão em hexadecimais.

\section{Simulação feita no VHDL Simili}

A simulação da funcionalidade dos arquivos VHDL gerados pelo Impulse $C$ foram feitas com o software da empresa Symphony EDA VHDL Simili 3.0.14. (Symphony EDA, 2005)

A Figura 69 mostra o correto funcionamento do hardware gerado pelo Impulse C. Os resultados mostrados nessa figura estão em hexadecimais e podem ser confrontados com os resultados gerados pelo Desktop Simulation, mostrados na Figura 68. 


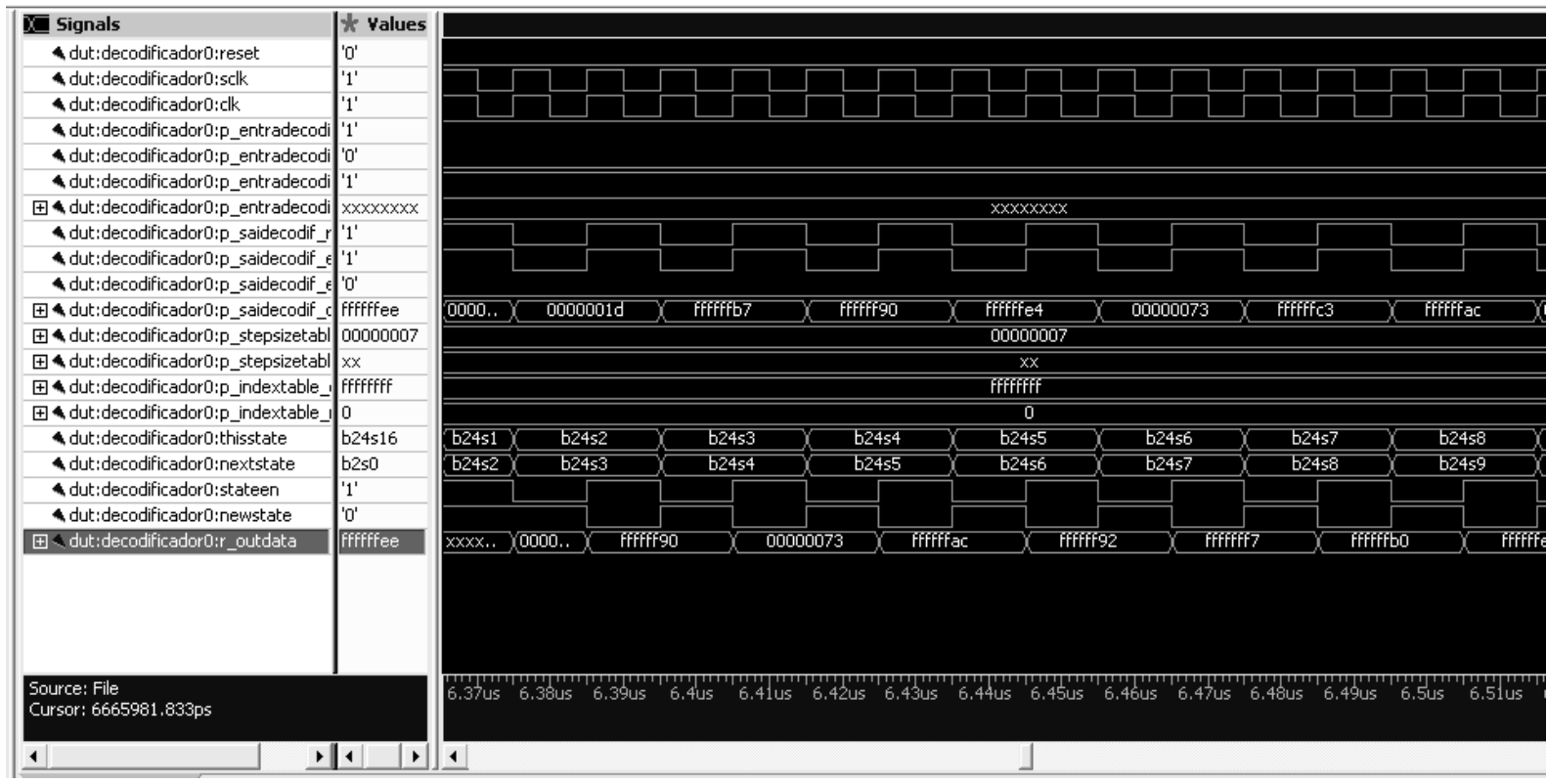

Figura 69. Simulação do hardware gerado pelo Impulse do benchmark ADPCM pela ferramenta VHDL Simili

\section{Desempenho do benchmark na placa de prototipação XUP V2P}

Para a fase de obtenção do desempenho do benchmark ADPCM na placa de prototipação, assim como no $F F T$, duas implementações foram feitas. As mudanças feitas nas duas implementações são basicamente a inclusão do comando \#pragma CO PIPELINE em todos os blocos de repetição do processo de hardware do ADPCM, ou seja, uma implementação sem a inclusão de nenhum comando de otimização e outra com o comando acima.

A Figura 66 mostra como foi implementado o ADPCM no Impulse $C$ para a obtenção do desempenho.

No $P S B$ do Impulse $C$, foi selecionado para a ferramenta gerar o hardware/software codesign no formato VHDL para o barramento PLB, no FPGA Virtex-II Pro.

A Tabela 33 descreve os recursos de hardware utilizados no FPGA Virtex-II Pro, e o gasto para a implementação do Core ADPCM com o uso de pipeline.

Tabela 33. Resumo dos recursos de hardware usado pelo benchmark ADPCM com o uso do pipeline

\begin{tabular}{|c|c|c|c|}
\hline \multicolumn{3}{|c|}{ Resumo dos recursos de hardware gastos pelo benchmark } \\
Tipo de recurso & Uso & Disponível no FPGA & Porcentagem usada \\
\hline Slices & 229 & 13696 & 1 \\
Slice Flip Flops & 220 & 27392 & 0 \\
4 input LUTs & 343 & 27392 & 1 \\
bonded IOBs & 217 & 556 & 39 \\
\hline
\end{tabular}

A Tabela 34 descreve os recursos de hardware utilizados no FPGA Virtex-II Pro, e o gasto para a implementação do Core do ADPCM sem o uso de pipeline. 
Tabela 34. Resumo dos recursos de hardware usado pelo benchmark FFT sem o uso do pipeline

\begin{tabular}{|c|c|c|c|}
\hline \multicolumn{4}{|c|}{ Resumo dos recursos de hardware gastos pelo benchmark } \\
Tipo de recurso & Uso & Disponível no FPGA & Porcentagem usada \\
\hline Slices & 1155 & 13696 & 8 \\
Slice Flip Flops & 795 & 27392 & 2 \\
4 input LUTs & 1814 & 27392 & 6 \\
bonded IOBs & 217 & 556 & 39 \\
BRAMs & 7 & 136 & 5 \\
\hline
\end{tabular}

A Tabela 35 mostra o tempo gasto pelo Core ADPCM, com pipeline, executado na placa de prototipação, sob a forma de hardware/software codesign. Segundo esas tabela, o tempo necessário para executar os 80000 pontos foi de 10.29 segundos.

Tabela 35. Tempo de execução do ADPCM hardware/software codesign com pipeline executado na XUP-V2P

\begin{tabular}{|c|c|c|c|c|c|c|}
\hline $\begin{array}{c}\% \\
\text { tempo }\end{array}$ & $\begin{array}{l}\text { t cumulat. } \\
\text { (segundos) }\end{array}$ & $\begin{array}{l}\text { Cada } \\
\text { t próp. } \\
\text { (segundos) }\end{array}$ & $\begin{array}{r}\text { amostra é } \\
\text { chamadas }\end{array}$ & $\begin{array}{c}\text { contada em } 0 \text {. } \\
\text { próp. cham. } \\
\text { (milessegundos) }\end{array}$ & $\begin{array}{l}01 \text { segundos } \\
\text { tot. cham. } \\
\text { (milessegundos) }\end{array}$ & nome \\
\hline 58.30 & 6.00 & 6.00 & & & & floatsidf \\
\hline 14.63 & 7.51 & 1.51 & & & & _muldf3 \\
\hline 12.67 & 8.81 & 1.30 & & & & _pack_d \\
\hline 5.21 & 9.35 & 0.54 & & & & _unpack_d \\
\hline 4.13 & 9.77 & 0.42 & 1 & 424.95 & 424.95 & Producer \\
\hline 3.02 & 10.08 & 0.31 & & & & _fixdfsi \\
\hline 1.46 & 10.23 & 0.15 & & & & Ishrdi3 \\
\hline 0.19 & 10.25 & 0.02 & & & & XIo_EndianSwap16OLD \\
\hline 0.13 & 10.26 & 0.01 & & & & Xlo_InSwap16 \\
\hline 0.11 & 10.28 & 0.01 & & & & Xlo_Out32 \\
\hline 0.08 & 10.28 & 0.01 & & & & Xlo_In32 \\
\hline 0.02 & 10.29 & 0.00 & 1 & 2.51 & 2.51 & co_initialize \\
\hline 0.02 & 10.29 & 0.00 & & & & XUartLite_SendByte \\
\hline 0.00 & 10.29 & 0.00 & & & & _malloc_r \\
\hline 0.00 & 10.29 & 0.00 & & & & xil_printf \\
\hline 0.00 & 10.29 & 0.00 & & & & powerpc405_init \\
\hline 0.00 & 10.29 & 0.00 & & & & profile_intr_handler \\
\hline 0.00 & 10.29 & 0.00 & 1 & 0.00 & 0.00 & Consumer \\
\hline 0.00 & 10.29 & 0.00 & 1 & 0.00 & 2.51 & main \\
\hline
\end{tabular}

A Tabela 36 mostra o tempo de gasto pelo Core ADPCM, sem pipeline, executado na placa de prototipação, sob a forma de hardware/software codesign. Segundo essa tabela, o tempo necessário para executar os 80000 pontos foi de 10.29 segundos. 
Tabela 36. Tempo de execução do ADPCM hardware/software codesign sem pipeline executado na XUP-V2P

\begin{tabular}{|c|c|c|c|c|c|c|}
\hline $\begin{array}{c}\% \\
\text { tempo }\end{array}$ & $\begin{array}{l}\text { t cumulat. } \\
\text { (segundos) }\end{array}$ & $\begin{array}{l}\text { Cada } \\
\text { t próp. } \\
\text { (segundos) }\end{array}$ & $\begin{array}{r}\text { amostra é } \\
\text { chamadas }\end{array}$ & $\begin{array}{c}\text { contada em } 0 \\
\text { próp. cham. } \\
\text { (milessegundos) }\end{array}$ & $\begin{array}{l}01 \text { segundos } \\
\text { tot. cham. } \\
\text { (milessegundos) }\end{array}$ & nome \\
\hline 58.30 & 6.00 & 6.00 & & & & _floatsidf \\
\hline 14.65 & 7.51 & 1.51 & & & & _muldf3 \\
\hline 12.64 & 8.81 & 1.30 & & & & __pack_d \\
\hline 5.19 & 9.34 & 0.53 & & & & _unpack_d \\
\hline 4.14 & 9.77 & 0.43 & 1 & 426.55 & 426.55 & Producer \\
\hline 3.01 & 10.08 & 0.31 & & & & _fixdfsi \\
\hline 1.47 & 10.23 & 0.15 & & & & I Ishrdi3 \\
\hline 0.19 & 10.25 & 0.02 & & & & Xlo_EndianSwap160LD \\
\hline 0.13 & 10.26 & 0.01 & & & & Xlo_InSwap16 \\
\hline 0.11 & 10.28 & 0.01 & & & & Xlo_Out32 \\
\hline 0.08 & 10.28 & 0.01 & & & & XIo_In32 \\
\hline 0.02 & 10.29 & 0.00 & 1 & 2.42 & 2.42 & co_initialize \\
\hline 0.02 & 10.29 & 0.00 & & & & XUartLite_SendByte \\
\hline 0.00 & 10.29 & 0.00 & & & & _malloc_r \\
\hline 0.00 & 10.29 & 0.00 & & & & xil_printf \\
\hline 0.00 & 10.29 & 0.00 & & & & powerpc405_init \\
\hline 0.00 & 10.29 & 0.00 & & & & profile_intr_handler \\
\hline 0.00 & 10.29 & 0.00 & 1 & 0.00 & 0.00 & Consumer \\
\hline 0.00 & 10.29 & 0.00 & 1 & 0.00 & 2.42 & main \\
\hline
\end{tabular}

Como visto nas Tabelas 33 e 34, o hardware requerido para o Core ADPCM sem pipeline foi maior do que a o Core ADPCM com pipeline. As Tabelas 35 e 36 mostram que o tempo de desempenho foi o mesmo para ambas as implementações em hardware. Como os tempos requeridos para a execução foram os mesmos, conclui-se que o Core ADPCM com pipeline é a melhor escolha, porque obteve menor gasto de hardware.

\subsubsection{Resultados de desempenho no Impulse C}

Os resultados das Tabelas 19, 20, 25, 26, 27, 29, 30, 31, 33 e 34 mostram que a melhor opção de otimização no código implementado no Impluse $C$ são especificas da implementação individual. Por exemplo, a opção de otimização \#pragma co pipeline obteve maior gasto de hardware utilizado na implementação do benchmark FFT, já na implemementação do benchmark ADPCM, a inclusão da opção de otimização \#pragma co pipeline obteve uma economia significativa de consumo de hardware do que a implementação sem pipeline. A opção de otimização \#pragma co unroll não foi possível ser aplicada nos benchmarks FFT e ADPCM, porque esses benchmarks não apresentavam as condições necessárias para tal. Entre outros motivos, está o fato desses benchmarks não possuírem um laço de repetição com tamanho conhecido, por exemplo, usando-se o laço "for", laço de repetição muito complexo ou ainda laço de repetição dentro de outros laços. Ou seja, as opções de otimização depen- 
dem da implementacao feita pelo projetista para serem usadas e como tal, produzem mais ou menos gasto de hardware. A Figura 70 mostra de forma gráfica a utilização dos recursos de hardware gastos pelos benchmarks implementados em FPGA. O Exito vertical do gráfico mostra os valores dos gastos de hardware usados pelas implementações.

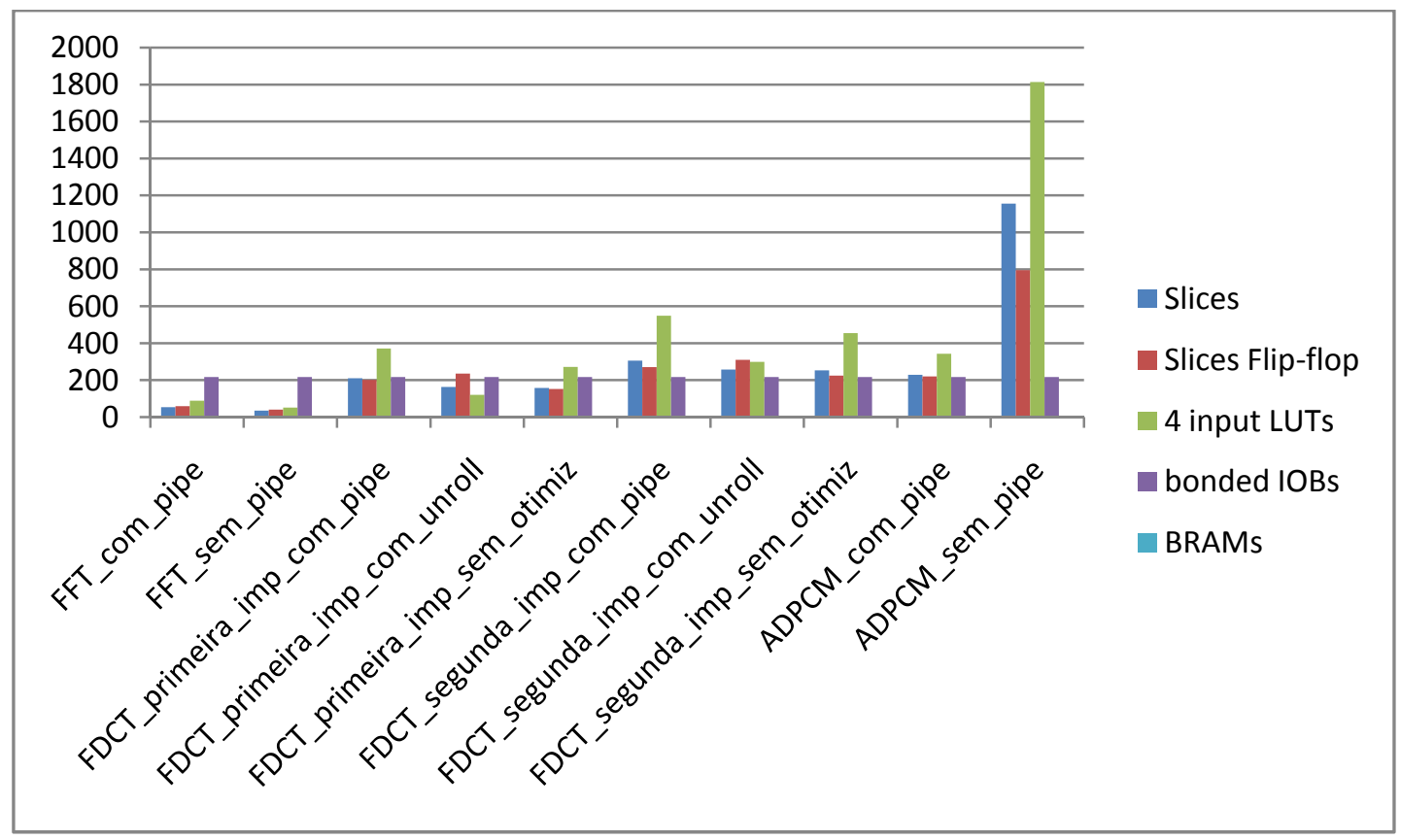

Figura 70. Gráfico de utilização de recursos de hardware gastos pelos benchmarks no FPGA

A Figura 71 mostra de forma gráfica o tempo gasto pelos benchmarks para execução sob a forma de hardware/software codesign. O eixo vertical do gráfico, conforme visto nas tabelas de tempo, mostra os tempos em segundos.

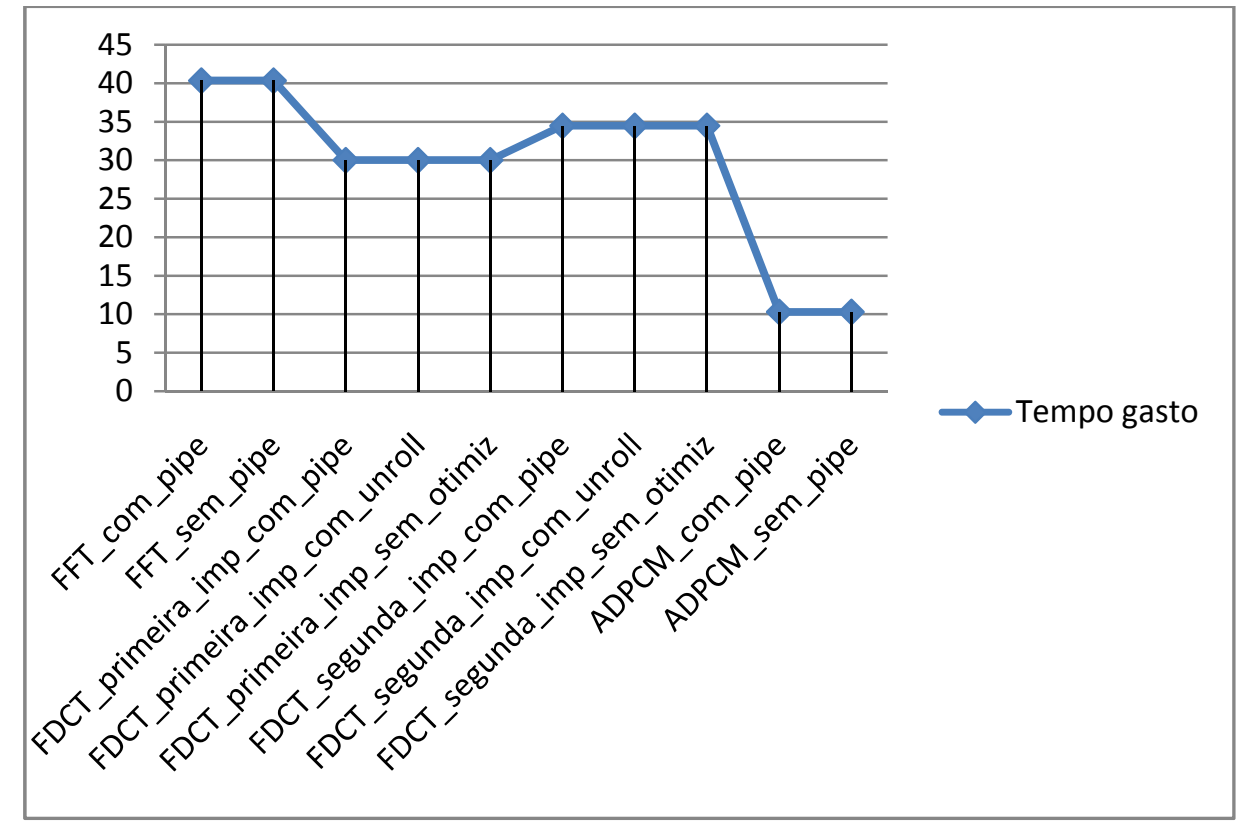

Figura 71. Gráfico de utilização de tempo de processamento gastos pelos benchmarks no FPGA 


\section{3 - Análise comparativa entre os processadores embar- cados e o Impulse $\mathrm{C}$}

Analisando os resultados obtidos na execução dos benchmarks, considerando processadores embarcados, na plataforma XUP V2P, foi possível gerar a Figura 52, onde foi destacado que o PowerPC $300 \mathrm{MHz}$ foi o que apresentou melhor desempenho.

$\mathrm{Na}$ análise da execução dos mesmos benchmarks, ainda na plataforma XUP V2P, agora através do Impulse $C$, foi possível gerar a Figura 71 , considerando diferentes modelos de arquiteturas, onde foi possível destacar que os resultados mostram que a melhor opção de otimização no código implementado no Impulse C são especificas da implementação individual, pois se pode ter maior gasto de hardware, consequentemente maior consumo para uma determinada implementação, e menor para outra.

Na Figura 72 foi feita a junção entre os resultados mostrados nos gráficos da Figura 52 e Figura 71. Com esse gráfico é possível ver a vantagem de execução dos benchmarks gerados pelo Impulse $\mathrm{C}$ em relação dos mesmos benchmarks executados sob a forma de software nos processadores embarcados na placa XUP V2P.

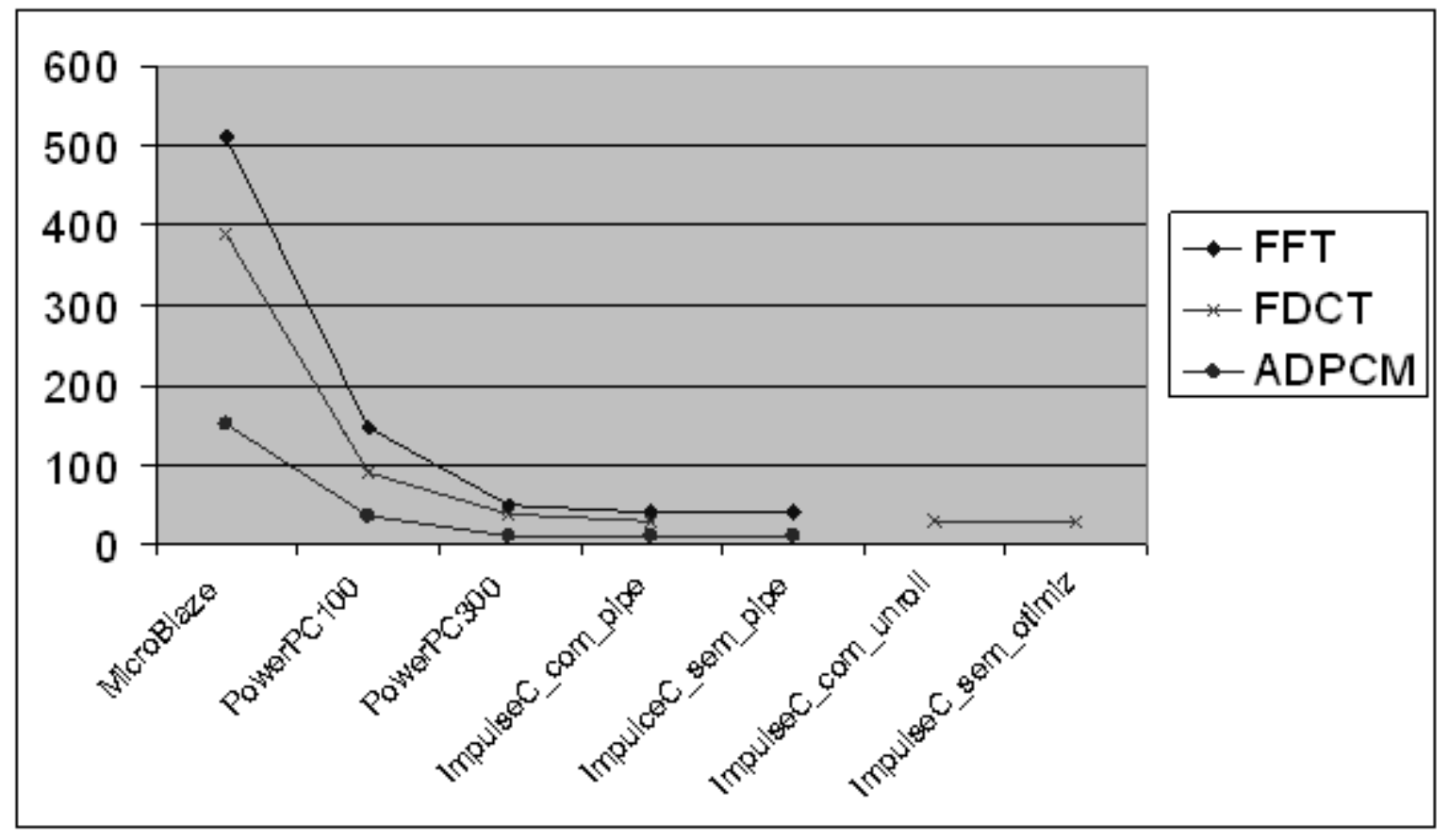

Figura 72. Análise Global dos Resultados para Processador Embarcado e Impulse C 


\section{Capítulo 7}

\section{Conclusões}

A partir dos objetivos desse projeto, que eram basicamente estudar algumas ferramentas de conversão C, C++ ou Java para hardware reconfigurável; estudar benchmarks para serem executadas nessas ferramentas com o objetivo de obter desempenho das mesmas, e ter o domínio dos conceitos na conversão de linguagens de alto nível para hardware reconfigurável, na plataforma XUP V2P, são descritos a seguir os resultados obtidos com o desenvolvimento do projeto.

Inicialmente no projeto foi apresentada uma relação entre as características dos GPPS (General Purpose Processor) processadores de uso geral, ASICs (circuitos integrados com aplicações específicas), e finalmente os FPGAs (Field Porgrammable Gate Array), dando destaque ao uso dos FPGAs, seus modelos de programação, capacidades, plataformas e ferramentas EDA (Eletronic Design Automation), destacando aqui a Plataforma XUP V2P que possui Virtex-Il pro da empresa Xilinx, que foi a base desse projeto.

Em seguida, foram apresentadas as características das principais ferramentas de programação $C$ em ambiente reconfigurável. Em particular, Pico Express; Galadriel e Nenya; Compilador Chichkov; Spark; DK - Design Suit; e Impulse $C$, incluindo alguns exemplos de implementação, descritos nos apêndices A e B.

A partir dessa descrição, foram apresentados os benchmarks FFT (Fast Fourier Transform), FDCT (Forward Discrete Cosine Transform) e ADPCM (Adaptive Differential Pulse Code Modulation), que foram utilizados para a execução na plataforma do projeto. Destaca-se 
aqui que esses benchmaks são os utilizados pelas empresas produtoras de FPGA atualmente para testar desempenho em seus sistemas.

Antes da execução propriamente dita dos benchmaks para obtenção de resultados de desempenho, foi necessário o domínio das ferramentas sendo executadas na plataforma XUP V2P. Além das diferentes abordagens (embarcados, hardware/software codesign) para a execução e teste das ferramentas, ainda seria necessário obter as ferramentas originais de conversão C em hardware/software codesign para essa execução. Como citado durante a descrição do projeto, algumas ferramentas já são comerciais (Spark, Celoxica, Impulse C), mas não foi possivel acesso a versões que realmente funcionassem e outras ferramentas ainda eram resultados de pesquisa (Galadriel e Nenya, entre outras), restando apenas o Impulse $C$, que foi conseguido por forma de demonstração (trial).

Com o Impulse $C$ e a plataforma disponível, foram realizados diversos testes, para diferentes configurações, até ter o domínio da execução da ferramenta tanto na forma embarcado como na forma hardware/software codesign.

Uma vez tendo o domínio da ferramenta, foram executados os benchmarks e gerado os resultados de desempenho necessário para mostrar o desempenho de compiladores em hardware reconfigurável.

Diferentes execuções foram realizadas dos benchmarks, considerando os dois modelos descritos acima, e o resultado mostrou que o modelo hardware/software codesign é mais vantajoso, comprovando uma tendência de que o modelo embarcado é melhor que a execução pura em um processador tradicional como Pentium, e que o modelo hardware/software codesign, que mistura execução em software e execução diretos no hardware gera melhor desempenho.

Como trabalhos futuros destacam-se a experiência adquirida no domínio das ferramentas aqui descritas, da plataforma utilizada e da utilização dos benchmarks, para dar continuidade a um projeto que vem sendo desenvolvido no Laboratório de Computação Reconfigurável, que é uma ferramenta de execução de algoritmos orientado a fluxo de dados, envolvendo questões de compiladores, a relação hardware/software codesign, arquiteturas reconfiguráveis, destacando a reconfiguração em tempo parcial (existente na plataforma XUP V2P), e benchmarks para gerar desempenho do sistema. 


\section{Referências bibliográficas}

\section{Bibliografia}

Altera FPGA Performance Benchmarking Methodology [Online] // Altera Literature. - Novembro de 2006. - 1.5. - Fevereiro de 2007. - http://www.altera.com/literature/lit-index.html.

Altera Stratix II Device Handbook (Complete Two-Volume Set) [Online] // Literature: Stratix II Devices. - Agosto de 2006. - Janeiro de 2007. - http://www.altera.com/literature/lit-stx2.jsp.

Aragão Antônio Carlos de Oliveira Souza Uma Arquitetura Sistólica para Solução de Sistemas Lineares Implementada com circuitos FPGAs [Dissertação]. - São Carlos, 1998.

Bodenner Ralph Fixed-Point Arithmetic in Impulse C. - 2005.

Bolsens Ivo Technical Talks and Presentations - MPSOC'06 - Programming Modern FPGAs [Online] // Xilinx University Program. - Xilinx Inc., Agosto de 2006. - Março de 2007. http://www.xilinx.com/univ/.

Bonato Vanderlei Projeto de um módulo de aquisição e pré-processamento de imagem colorida baseado em computação reconfigurável e aplicado a robôs móveis [Dissertação]. - São Carlos, 2004.

Calderón Humberto, Elena Christian e Vassiliadis Stamatis Soft Core Processors and Embedded Processing: a survey and analysis [Relatório]. - 2005.

Campi Fabio The Qrisc open source Processor Core SOFTWARE BENCHMARKS [Online]. - Setembro de 2001. - Abril de 2006. - http://www.micro.deis.unibo.it/ campi/XiRisc/index.html.

Cappelatt Ewerton Artur Implementação do Padrão e Barramento PCI para Interação Hardware/Software em Dispositivos Reconfiguráveis [Relatório]. - 2001.

Cardoso J e Neto H Compilation for FPGA-Based Reconfigurable [Artigo] // Hardware. IEEE Design \& Test of Computers Magazine. - 2003.

Cardoso João Manuel Paiva COMPILAÇÃO DE ALGORITMOS EM JAVA PARA SISTEMAS COMPUTACIONAIS RECONFIGURÁVEIS COM EXPLORAÇÃO DO PARALELISMO AO NÍVEL DAS OPERAÇÕES [Dissertação para a obtenção do grau de Doutor em Engenharia Electrotécnica e de Computadores]. - [s.I.] : UNIVERSIDADE TÉCNICA DE LISBOA, Outubro de 2000. 
Carvalho Cassio A., Junior Messias Meneguette e Silva Erivaldo Antonio A INFLUÊNCIA DO ESPAÇO DE CORES NA COMPRESSÃO JPEG DE IMAGENS ORBITAIS [Periódico] // Revista Brasileira de Cartografia. - 2003. - pp. 39-47.

Celoxica Ltd Introducing Software Paradigms To Hardware Design [Online] // Technical Library White Papers. - Agosto de 2002. - 1.1. - Outubro de 2006. http://www.celoxica.com/techlib/default.asp?Action=1\&CatID=23\&CatType=1\&OrderBy=1.

Celoxica Ltd Software Product Description for DK version 4.0 SP2 [Online] // DK Design Suite Software Product Description (SPD). - 18 de Outubro de 2006. - Novembro de 2006. http://www.celoxica.com/support/view_article.asp?ArticleID=521.

Celoxica Ltd The application of retiming to the synthesis of $\mathrm{C}$ based languages using the Celoxica DK Design Suit [Online] // Technical Library - White Papers. - Março de 2004. - 1.0. - Novembro de 2006. - http://www.celoxica.com/techlib/default.asp?Action=1\&CatID=23\&CatType=1\&OrderBy=1.

Celoxica Ltd. Handel-C Language Reference Manual [Online] // Technical Library - Handel-C. - 2004. 3. - Janeiro de 2007. -

http://www.celoxica.com/techlib/default.asp?Action=1\&CatID=9\&CatType=2\&OrderBy=1.

Chappell Stephen e Sullivan Chris Handel-C for co-processing \& co-design of Field Programmable System on Chip [Online] // Technical Library. - Setembro de 2002. - Novembro de 2006. http://www.celoxica.com/techlib/default.asp?Action=1\&CatID=23\&CatType=1\&OrderBy=1.

Chichkov Anton V. e Almeida Carlos Beltrán A hardware/software partitioning algorithm for custom computing machines [Artigo] // Lecture Notes In Computer Science; Vol. 1304. - Germany : [s.n.], 1997. - pp. 274 - 283. - 3-540-63465-7.

Chichkov Anton Velinov e Almeida Carlos Beltrán A Tool for Mapping a C Description into a Hardware Configuration using VHDL at RTL [Artigo] // DCIS'98 - XIII DESIGN OF CIRCUITS AND INTEGRATED SYSTEMS CONFERENCE. - MADRID : [s.n.], 17-20 de Novembro de 1998.

Compton Katherine e Hauck Scott An Introduction to Reconfigurable Computing [Artigo] // Invited Paper IEEE Computer. - 2000.

Corporate Communication Unit International Telecommunication Union [Online]. - 1999. - Fevereiro de 2007. - http://www.itu.int/rec/T-REC-G.711-199909-I!Appl/en.

Duarte Marcos Laboratory of Biophysics [Online] // Digital signal processing (DSP). - 2006. http://lob.incubadora.fapesp.br/portal/t/dsp.pdf.

Duarte Neimar Marques Implementando sistemas DSP em FPGA [Online] // Code:DSP. PiComponentes, 03 de Janeiro de 2006. - Janeiro de 2007. http://www.picomponentes.com.br/viewnoticias.asp?idnot=197.

Fenlason Jay e Stallman Richard GNU gprof - The GNU Profiler [Online]. - 07 de Novembro de 1998. Fevereiro de 2007. - http://www.gnu.org/software/binutils/manual/gprof-2.9.1/gprof.html.

Filho Ogê Marques e Neto Hugo Vieira Processamento digital de imagens [Livro]. - [s.l.] : Brasport, 1999. 
Gokhale Maya Streams-C: Stream-Oriented C Programming for FPGAs [Online] // Los Alamos National Laboratory. - Los Alamos National Laboratory, 2006. - Fevereiro de 2007. http://www.streams-c.lanl.gov/.

Gongalez Rafael C. e Woods Richard E. Processamento de imagens digitais [Livro]. - [s.I.] : Edgard Blücher Ltda, 2003.

Gupta Sumit [et al.] Spark - A Parallelizing Approach to the High-Level Synthesis of Digital Circuits [Livro]. - [s.I.] : Kluwer Academic Publishers, 2004.

Guthaus Matthew [et al.] MiBench: a free, commercially representative embedded benchmark suite [Online]. - 11 de Setembro de 2001. - Março de 2006. - http://www.eecs.umich.edu/mibench/.

Hartenst Reiner W. Hartenstein, Becker Jurgen e Herz Michael Co-Design and High Performance Computing: Scenes and Crisis [Artigo] // In Proc. of the Reconfigurable Technology for Rapid Product Development \& Computing, Part of SPIE's International Symposium '96. - Boston : [s.n.], Novembro de 1996.

Hauck S Reconfigurable Computing: A Survey of Systems and Software [Artigo] // ACM Computing Surveys. - 2002. - 2 : Vol. 34. - pp. 171-210.

Hauck S The Roles of FPGAs in Reprogrammable Systems [Artigo] // Proceedings of the IEEE. - Abril de 1998. - 4 : Vol. 86. - pp. 615-638.

Hauck S. [et al.] Totem: Domain-Specific Reconfigurable Logic [Periódico] // submitted to IEEE Transactions on VLSI Systems. - 2006.

Jones Douglas L. Choosing the Best FFT Algorithm [Online]. - 26 de Agosto de 2006. - 1.2. - Fevereiro de 2007. - http://cnx.org/content/m12060/latest/.

Marshall Dave The Discrete Cosine Transform (DCT) [Online]. - 10 de Abril de 2001. - 15 de Setembro de 2005. - http://www.cs.cf.ac.uk/Dave/Multimedia/node231.html.

Martinian Emin Emin's Page [Online]. - 2006. - 13 de 06 de 2006. -

http://web.mit.edu/ emin/www/index.html.

MathWorks, Inc The MathWorks - Accelerating the pace of engineering and science [Online]. 2006. - Fevereiro de 2007. - http://www.mathworks.com/.

Mesquita Daniel Gomes Contribuições para reconfiguração parcial, remota e dinâmica de FPGAs. [Dissertação]- Porto Alegre, Março de 2002.

Novo Jr José Eduardo Fornari Apêndice 1: A DFT e a FFT. [Online] // Jose E. Fornari N. Jr. - Março de 2006. - Fevereiro de 2007. - http://www.nics.unicamp.br/ fornari/.

Palma José Carlos [et al.] INTERFACE DE COMUNICAÇÃO DE CORES EM FPGAS [Artigo] // VIII WORKSHOP IBERCHIP. - 2002.

Pellerin David e Thibault Scott Practical FPGA Programming in C [Livro]. - [s.I.] : Prentice Hall PTR, 2005. 
Piacentino Michael R., Wal Gooitzen S. Van der e Hansen Michael W. Reconfigurable Elements for a Video Pipeline Processor [Artigo] // IEEE Symposium on FPGAs for Custom Computing Machines. 1999. - pp. 1-10.

Plotkin Alex Individual Projects [Online] // The CSC 5551 Parallel Architecture Group's Research. - 30 de Abril de 2003. - Janeiro de 2007. -

http://carbon.cudenver.edu/csprojects/CSC5551/StudentWeb/Parallel_Architecture_Group/Projects /Plotkin_Alex/2003_04_30_CSC_5551_Semester_Project_Presentation.ppt.

Radunovic B. e Milutinovic V. A Survey of Reconfigurable Computing Architectures [Artigo] // Tutorial in 8th Int. Workshop on Field Programmable Logic and Applications (FPL'98). - 1998. Published in Springer-Verlag LNCS 1482, Hartenstein and Keevallik eds, Berlin, Germany, 1998, pp. 376-385..

Ribeiro Alexandre Alves de Lima Reconfigurabilidade dinâmica e remota de FPGAs [Artigo]. - São Carlos : [s.n.], 2002.

Ribeiro Alexandre Alves de Lima Reconfigurabilidade Dinâmica e Remota de FPGAs [Artigo] // Workshop de Teses e Dissertações. - 2003.

Rigotti Humberto Goulart Codificação de Imagem Usando Transformada Cosseno Discreta. - [s.l.] : Universidade Federal de Mato Grosso do Sul, 24 de Fevereiro de 2004.

Romer Andreas [et al.] Reconfigurable FPGA Processor [Relatório]. - 2000.

Santos Marcelo Nascimento dos Medidas de qualidade de voz em redes IP. - Curitiba : [s.n.], 2006.

Scilab The open source platform for numerical computation [Online]. - 2006. - 2006. http://www.scilab.org/.

Siscoutto Robson Augusto Sistema de videoconferência em redes de computadores. - São Carlos : [s.n.], Fevereiro de 1997.

Stanford Compiler Group Suif Compiler System [Online]. - 1994. - 10 de Janeiro de 2007. http://suif.stanford.edu/.

Symphony EDA Symphony EDA - VHDL Simili [Online]. - 2005. - Outubro de 2006. http://www.symphonyeda.com/products.htm.

Synfora Picp Express [Online] // Synfora Revolutionizing Complex SoC Design. - Synfora, 2007. Janeiro de 2007. - http://www.synfora.com/products/picoexpress.html.

Szewinski Jaroslaw [et al.] Software for development and communication with FPGA based hardware [Relatório]. - 2005.

Villasenor J e Smith W, H, M Configurable Computing [Artigo] // Scientific American. - Junho de 1997.

Xilinx Inc. Virtex-5 Multi-Platform FPGA [Online] // Xilinx. - Xilinx Inc., 2007. - Março de 2007. http://www.xilinx.com/products/silicon_solutions/fpgas/virtex/virtex5/index.htm. 
Xilinx Inc. XC6000 Field Programmable Gate Arrays [Online]. - Xilinx, 27 de Abril de 1997. - Agosto de 2006. - www.xilinx.com.

Xilinx ISE - The design suite voted \#1 by FPGA Engineers for a third consecutive year. [Online] // Logic Design. - Xilinx Inc., 2007. - Janeiro de 2007. http://www.xilinx.com/ise/logic_design_prod/index.htm.

Xilinx MicroBlaze Processor Reference Guide [Online] // MicroBlaze Soft Processor Core. - Xilinx Inc., Junho de 2006. - Janeiro de 2007. -

http://www.xilinx.com/xlnx/xebiz/designResources/ip_product_details.jsp?iLanguagelD=1\&key=micr o_blaze.

Xilinx PowerPC 405 Processor Block Reference Guide [Online] // PowerPC 405 Processor. - Xilinx Inc., 20 de Julho de 2005. - Janeiro de 2007. -

http://www.xilinx.com/products/silicon_solutions/fpgas/virtex/virtex_ii_pro_fpgas/capabilities/pow erpc.htm.

Xilinx The Embedded Development Kit (EDK) is an all encompassing solution for designing embedded programmable systems [Online] // Platform Studio and the EDK . - Xilinx Inc., 2007. - Janeiro de 2007. - http://www.xilinx.com/ise/embedded_design_prod/platform_studio.htm.

Xilinx Virtex-II Pro / Virtex-II Pro X Complete Data Sheet (All four modules) [Online] // Virtex-II Pro Data Sheets . - Xilinx, Inc., 10 de Outubro de 2005. - Março de 2006. http://www.xilinx.com/xlnx/xweb/xil_publications_display.jsp?iLanguagelD=1\&category=19228\&sGlobalNavPick=\&sSecondaryNavPick=.

Xilinx Xilinx XUP Virtex II Pro Development System [Online]. - Xilinx Inc., 2007. - Janeiro de 2007. http://www.xilinx.com/univ/xupv2p.html.

Xilinx, Inc Floating-Point Unit for the PowerPC (Single Precision) Xilinx IP Core [Online]. - 2006. Fevereiro de 2007. -

http://www.xilinx.com/xInx/xebiz/designResources/ip_product_details.jsp?key=DO-DI-FPU-SP.

Xilinx, Inc Xilinx: The Programmable Logic Company [Online] // Xilinx. - Xilinx, Inc, 2007. - Janeiro de 2007. - http://www.xilinx.com/.

Ynoguti Carlos Alberto Transformada Discreta de Fourier [Online] // Processamento Digital de Sinais. - 2004. - http://www.inatel.br/docentes/ynoguti/e724/. 


\section{APÊNDICE A}

\section{Arquivo VHDL gerado pelo Spark}

O objetivo desse apêndice é mostrar os resultados gerados pelo compilador Spark versão 1.3 a partir de um algorítmo de ordenação, escrito em linguagem $A N S I-C$.

O algorítmo abaixo é responsável por fazer uma ordenação crescente a partir do vetor de entrada "a".

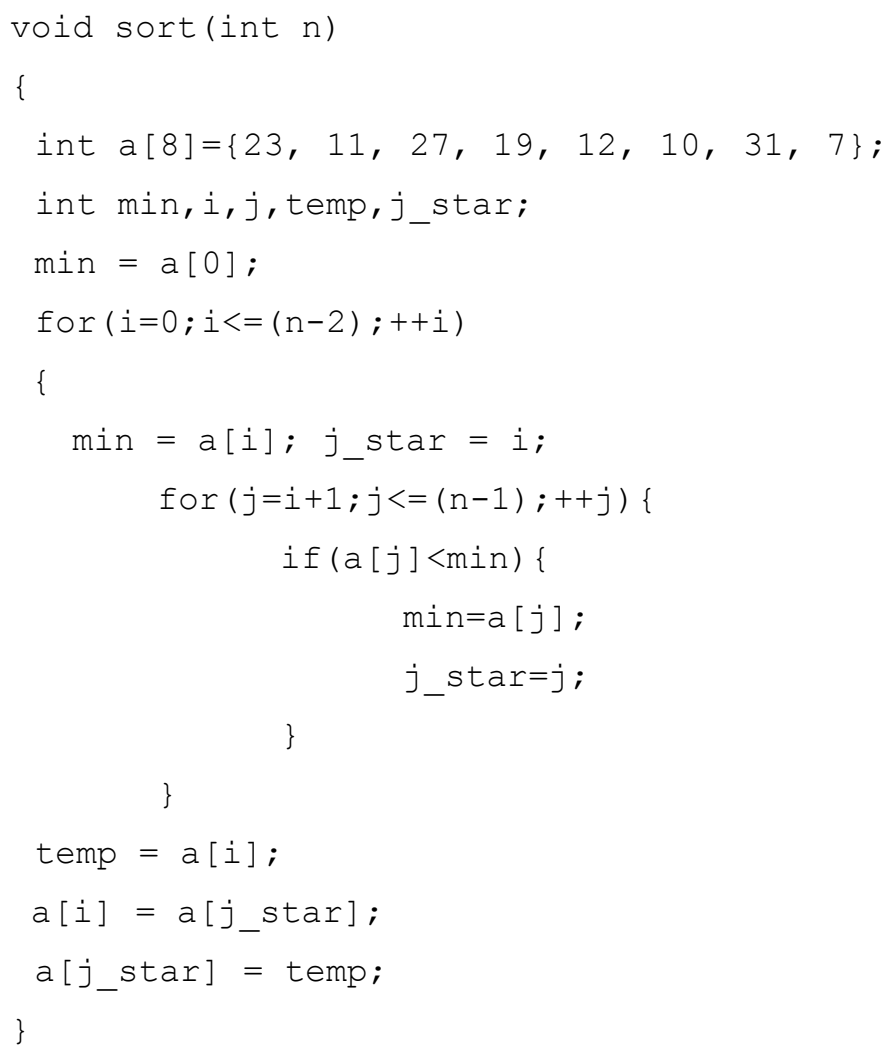

A partir do algorítmo acima, o compilador Spark gera alguns arquivos que são, dependendo das opções definidas pelo usuário, o arquivo $V H D L$, arquivos correspondente aos grafos gerados pelo compilador nas fases de compilacao e um arquivo .c reescrito pelo compilador Spark, para o projetista verificar as transformações aplicadas pelo compilador. 


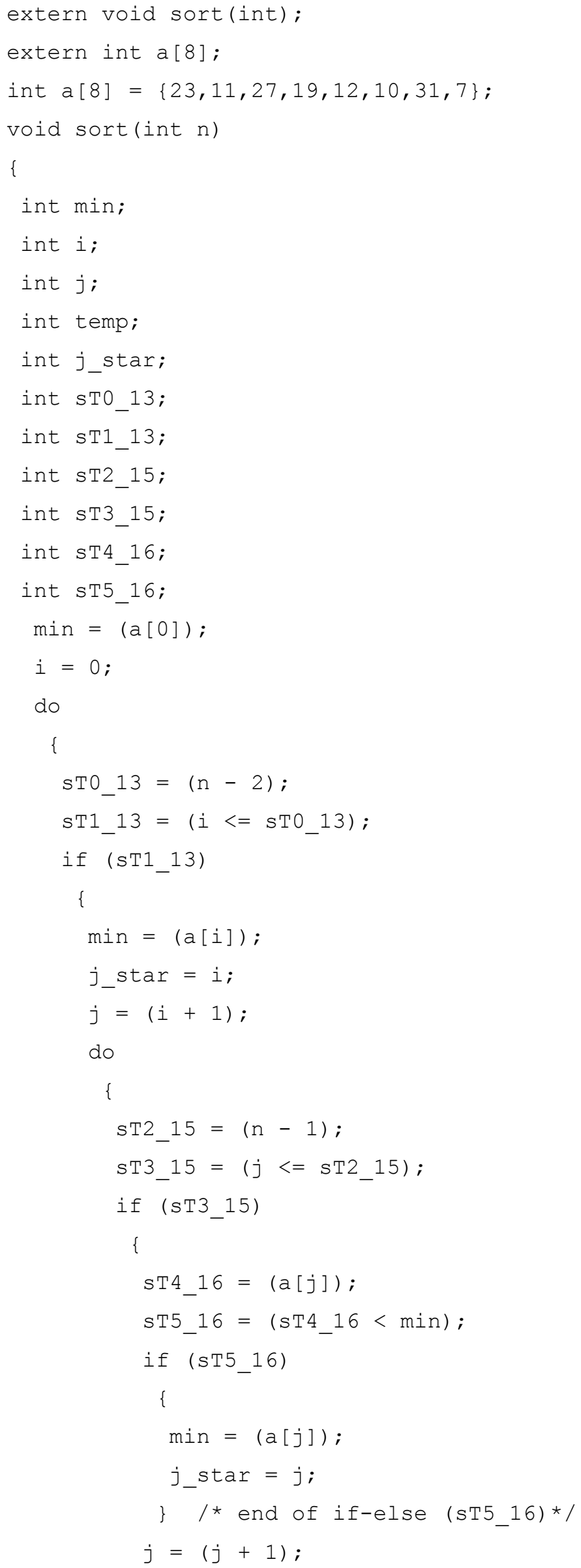




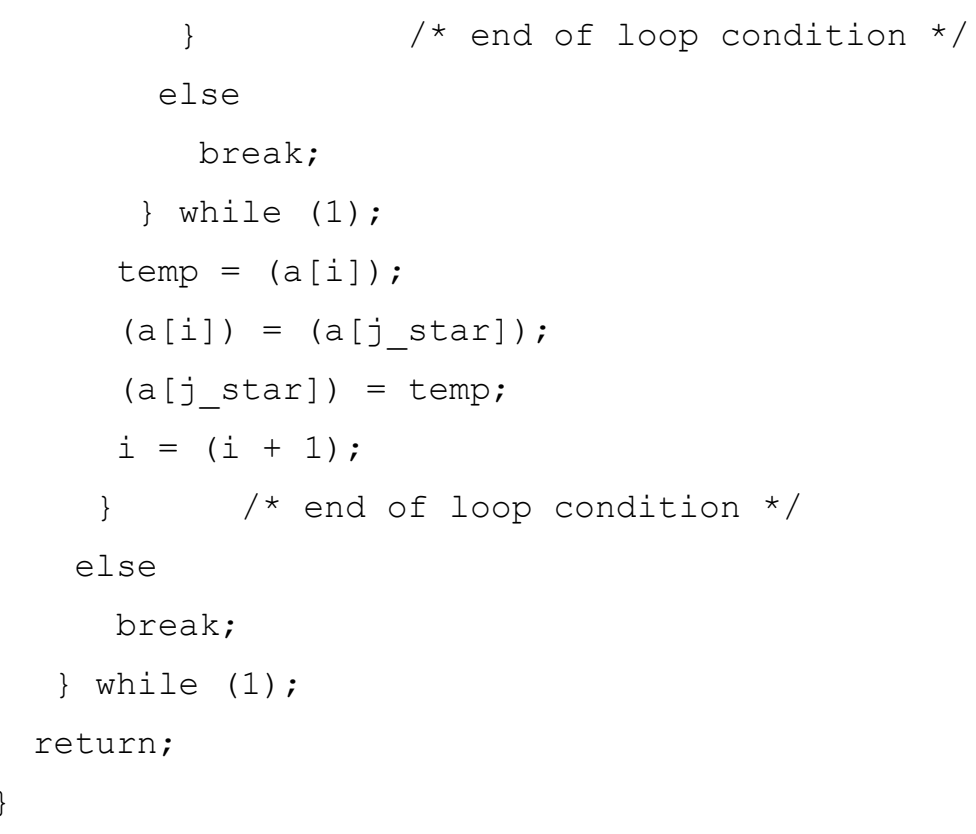

Os grafos não puderam ser colocados no apêndice devido o tamanho de cada um.

-- Sun Feb 25 19:54:02 2007, source file : minsort.c

-- 'SPARK' should be defined as the user package

PACKAGE spark pkg is

TYPE integer_vector IS ARRAY ( NATURAL RANGE $<>$ ) OF integer;

TYPE boolean vector IS ARRAY ( NATURAL RANGE $<>$ ) OF boolean;

FUNCTION integer wired or ( arr int : integer vector) RETURN integer;

FUNCTION boolean_wired_or ( arr_bool : boolean_vector) RETURN boolean;

SUBTYPE wiredorInt IS integer wired or integer ;

SUBTYPE wiredOrBoolean IS boolean wired_or boolean;

TYPE ARRAY_7_0_65535_0 is ARRAY (7 DOWNTO 0 ) of wiredorInt range 0 to 65535; END spark pkḡ;

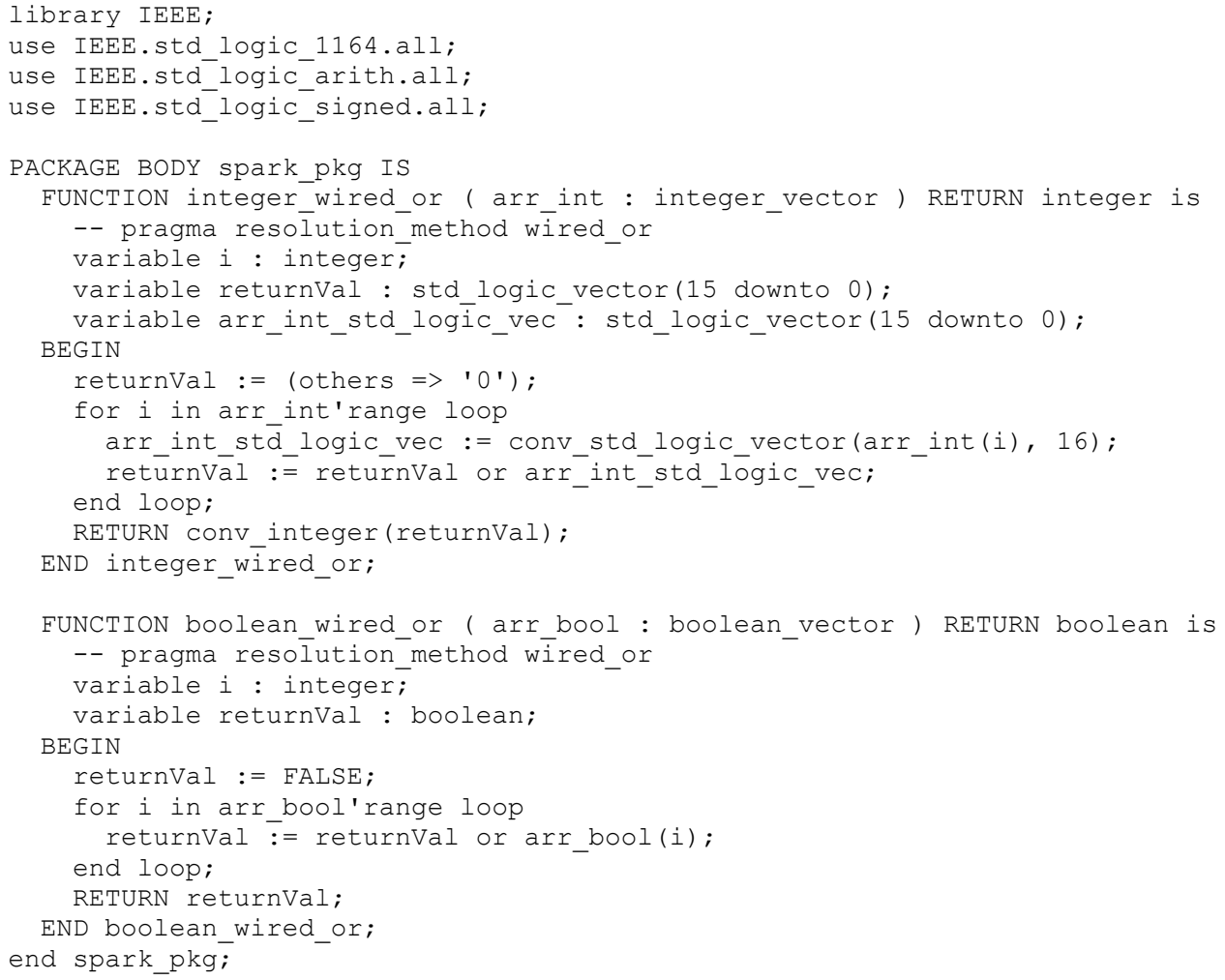




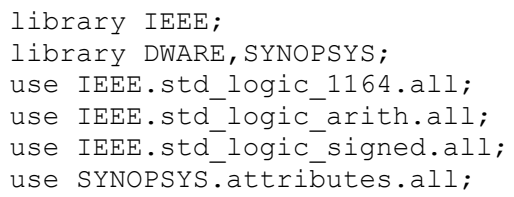

library work;

use work.spark_pkg.all;

ENTITY sort IS

port (

$\mathrm{n}$ : IN wiredOrInt range 0 to 65535 ;

-- global variables are

a : INOUT ARRAY 70655350 ;

CLOCK : IN std_- $\log i \bar{C}$;

RESET : IN std ${ }^{-} \operatorname{logic}$;

done : OUT std logic);

END sort;

ARCHITECTURE rtI OF sort IS

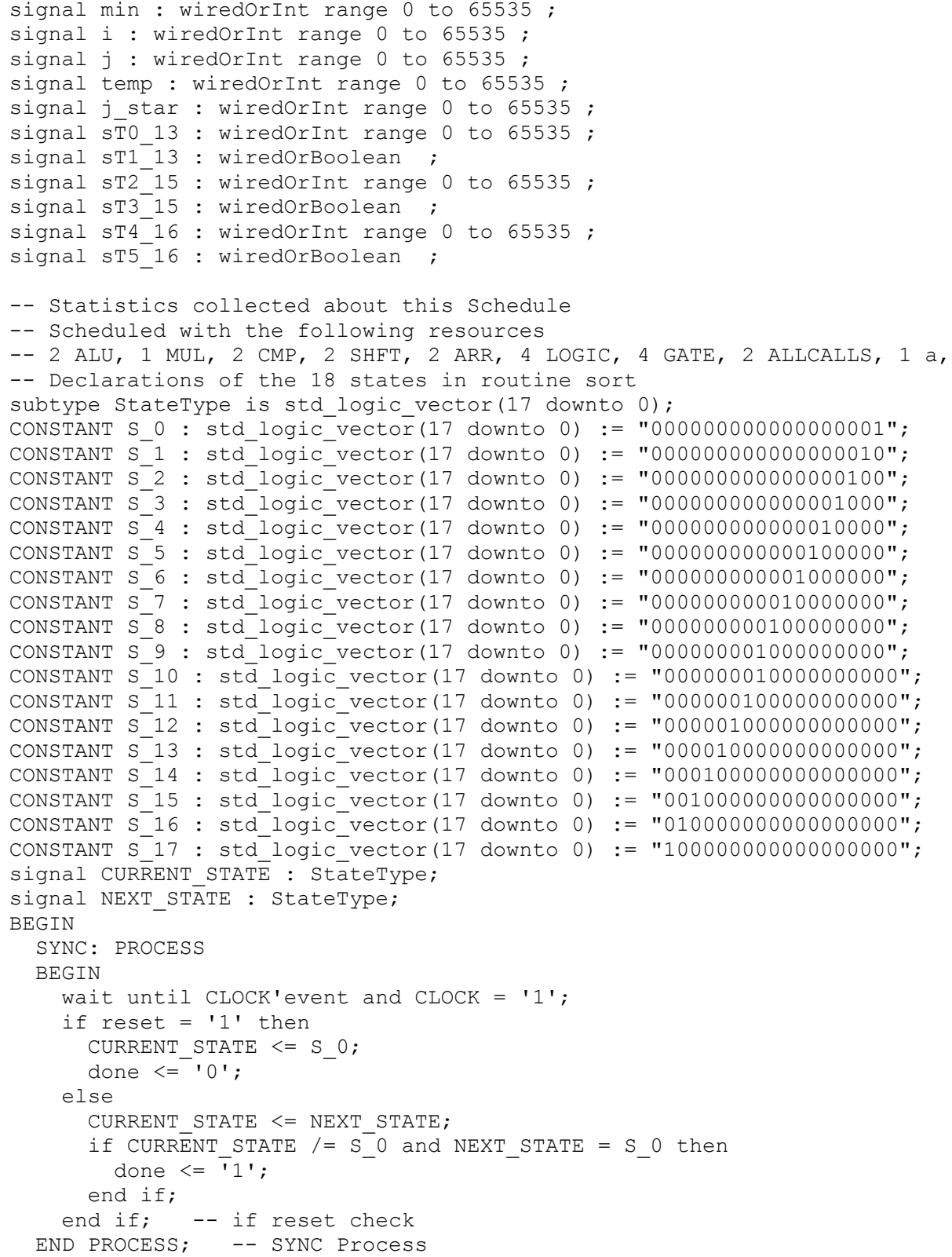




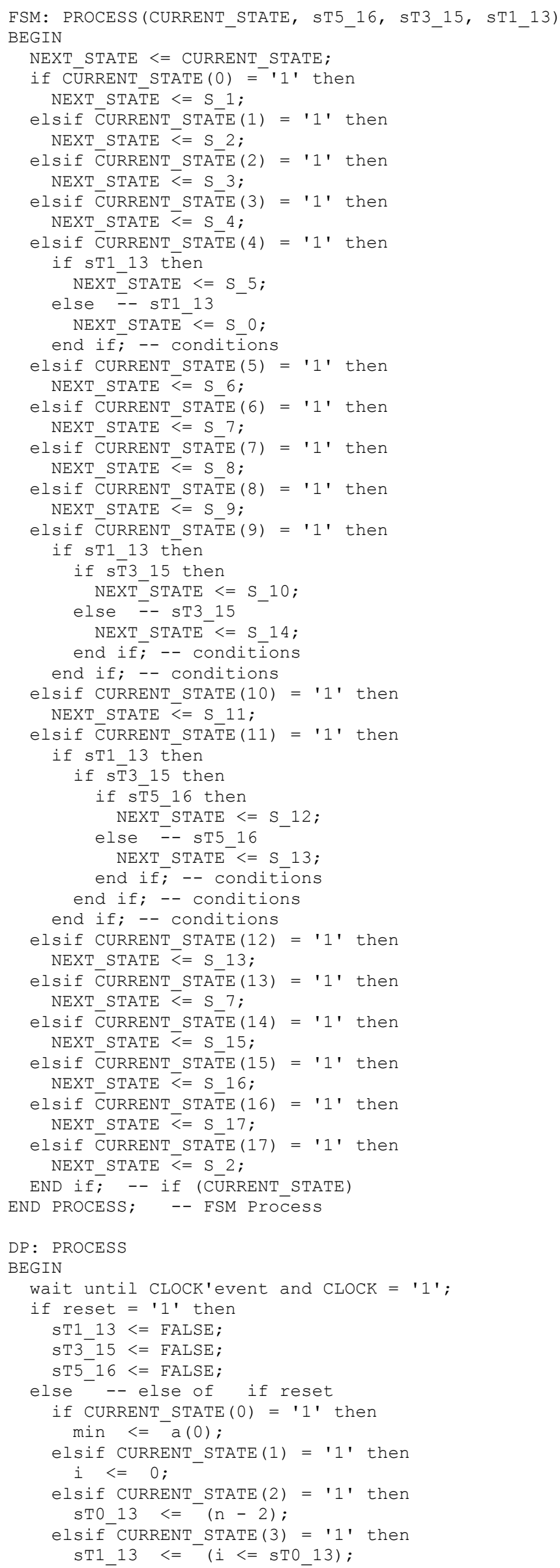




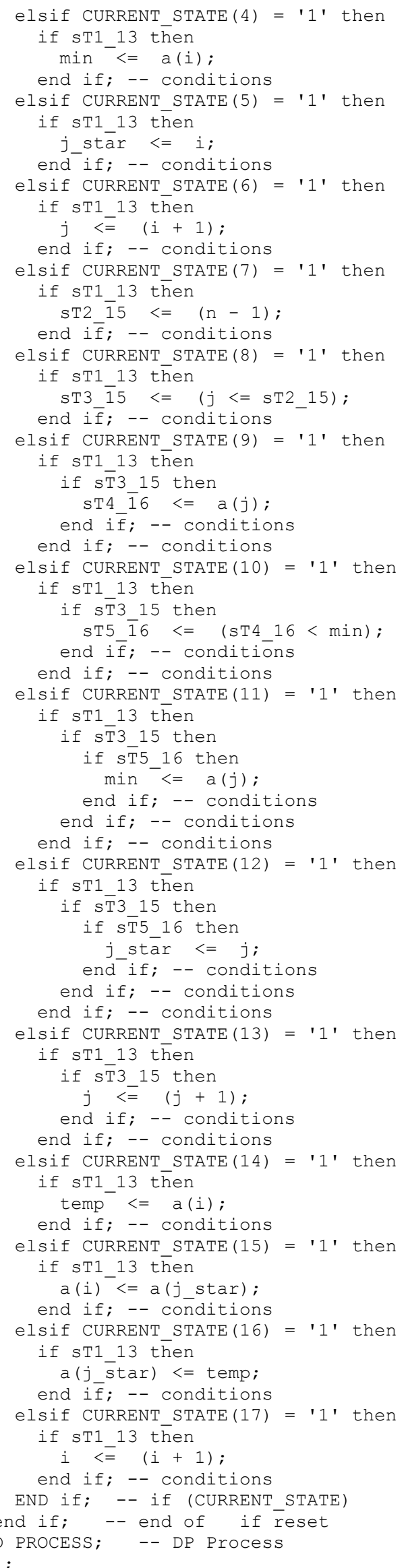




\section{APÊNDICE B}

\section{Arquivo VHDL gerado pelo Impulse C}

O objetivo desse apêndice é mostrar o resultado gerado pelo compilador Impulse $C$ versão 2.20.e.6 a partir de um algorítmo mostrado no apêndice A.

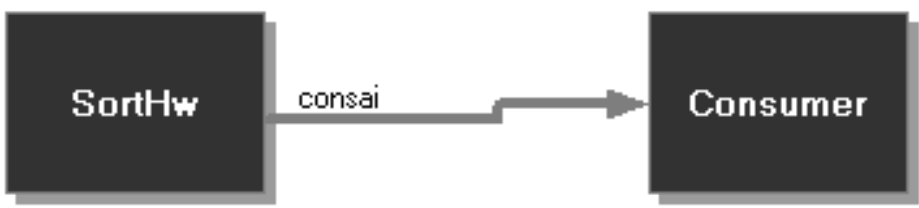

SortHw

Consumer

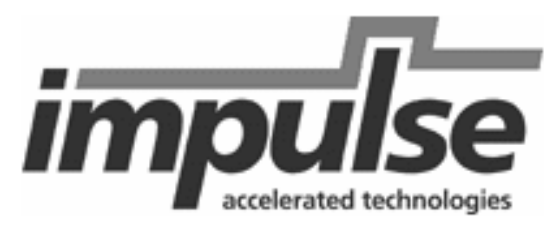

Figura 73. Implementação do algoritmo de ordenação implementado no Impulse C

Nessa implementação, Figura 72, foi retirado o processo produtor para preservar o algoritmo original mostrado no apêndice A. A mudança mais significativa nessa implementação foi a saída dos resultados gerados pelo processo sortl-lw, o qual representa o algorítmo original no apêndice A, no processo consumer. Além do arquivo $V H D L$ abaixo, o qual representa a lógica do algoritmo original, o Impulse $C$ também gera mais ou menos outros 12 arquivos $V H D L$, responsáveis pelas interfaces de comunicação entre os processos, sincronização, entre outros.

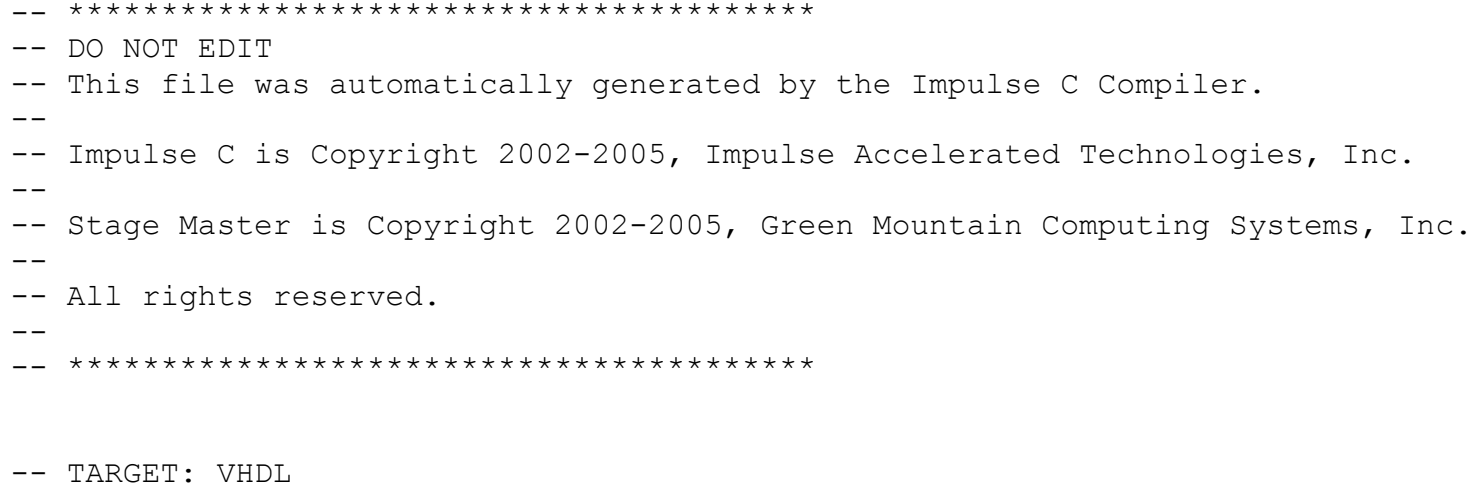




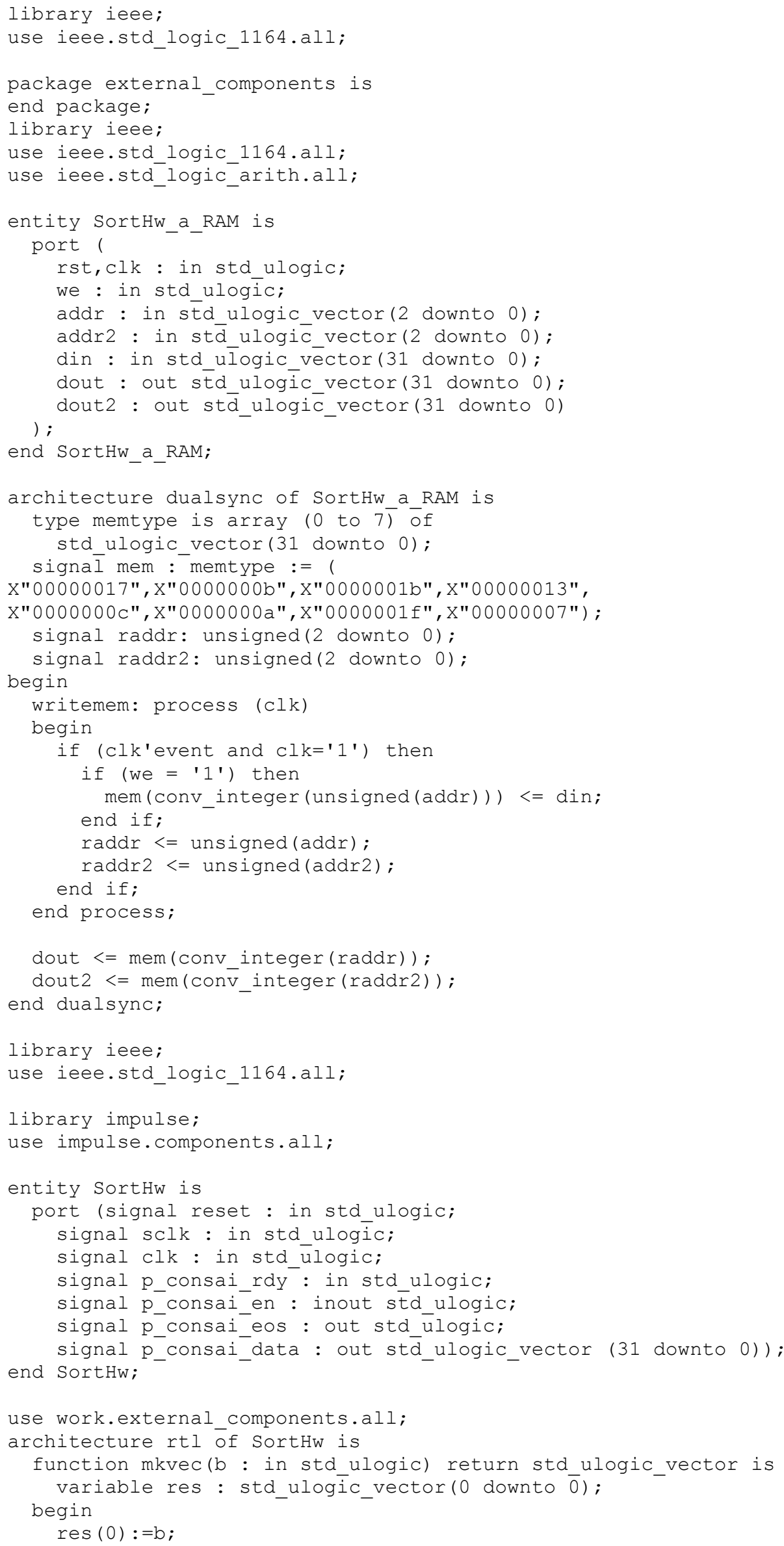




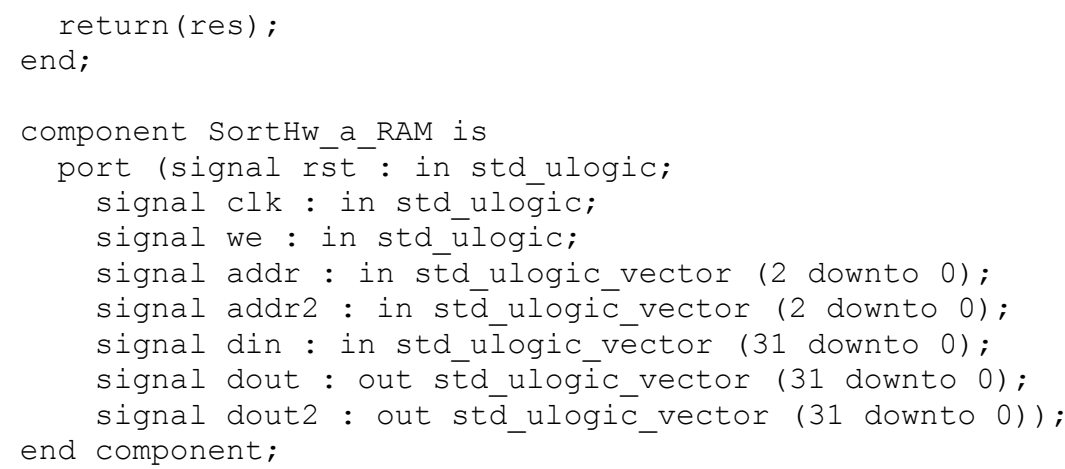

type stateType is (init, b0s0, b0s1, b1s0, b1s1, b2s0, b2s1, b3s0, b3s1, b4s0, b5s0, b5s1, b5s2, b6s0, finished);

signal thisstate : stateType;

signal nextState : stateType;

signal stateEn : std_ulogic;

signal newState : stō ulogic;

signal r_a : std_ulogíc_vector (31 downto 0);

signal nī7 a : st̄d ulogíc vector (31 downto 0);

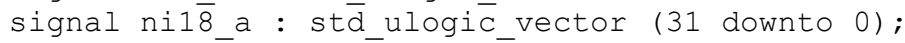

signal ni33-a : std ulogic vector (31 downto 0);

signal ni39-a : std ulogic_vector (31 downto 0);

signal ni56-a : std ulogic vector (31 downto 0);

signal ni60_a : std_ulogic_vector (31 downto 0);

signal ni64_a : std_ulogic_vector (31 downto 0);

signal ni68_a : std_ulogic_vector (31 downto 0);

signal ni88_a : std_ulogic_vector (31 downto 0);

signal p_a we : std-ulogic;

signal p_a_din : stō_ulogic_vector (31 downto 0);

signal p_a_dout : st $\bar{d}$ ulogi $\bar{c}$ vector (31 downto 0);

signal p_a_addr: std_ulogic_vector (2 downto 0);

signal p_a_addr2 : st $\bar{d}$ _ulogic_vector (2 downto 0);

signal p_a_dout2 : std_ulogic_vector (31 downto 0);

signal p_a_imm : std_ulogic_vēctor (31 downto 0);

signal p_a_re: std_ülogic;

signal r $\overline{2}-\bar{a}$ : std_ulogic_vector (31 downto 0);

signal p_à_imm2 : std_ulogic_vector (31 downto 0);

signal p_a_re2 : std_ūlogic;

signal r min : std ulogic vector (31 downto 0);

signal nī135_min : std_ulogic_vector (31 downto 0);

signal ni138_min : std_ulogic_vector (31 downto 0);

signal nil43_min : std_ulogic_vector (31 downto 0);

signal $r i$ : std ulogic vector (31 downto 0);

signal nī136_i : std_ulogic_vector (31 downto 0);

signal ni148_i : std_ulogic_vector (31 downto 0);

signal r_j : std_ulogic_vector (31 downto 0);

signal nī140_j: std_ulogic_vector (31 downto 0);

signal ni145 j : std ulogic_vector (31 downto 0);

signal r_temp : std_ülogic_vector (31 downto 0);

signal nīi46_temp : std_ulōogic_vector (31 downto 0);

signal r_j_star : std_ulogic_vēctor (31 downto 0);

signal nījo_j_star : std_ulogic_vector (31 downto 0);

signal ni144_j_star : std_ulogic_vector (31 downto 0);

signal rsuiff_tmp : std_ulogic_vector (31 downto 0);

signal nī137_suif_tmp :- std_ulogic_vector (31 downto 0);

signal r_suif́t_tmp $\overline{0}$ : std_ulogic_vector (31 downto 0 );

signal nī147_suif_tmpo :- std_ulogic_vector (31 downto 0);

signal r_suif́ttmp $\overline{1}$ : std_ulogic_vector (31 downto 0);

signal nîlus_suif tmpl : std_ulogic_vector (31 downto 0);

signal r_suiff_tmp $\overline{2}$ : std_ulogic_vector (31 downto 0$)$;

signal nīi42 suif tmp2 : std ulogic vector (31 downto 0);

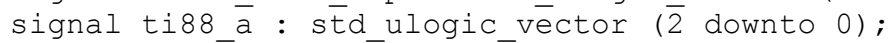

signal t_1 : std_ulogic_vector (2 downto 0);

signal t 0 : std ulogic vector (2 downto 0$)$;

signal tíi4_a : std_ulogic_vector (2 downto 0$)$; 


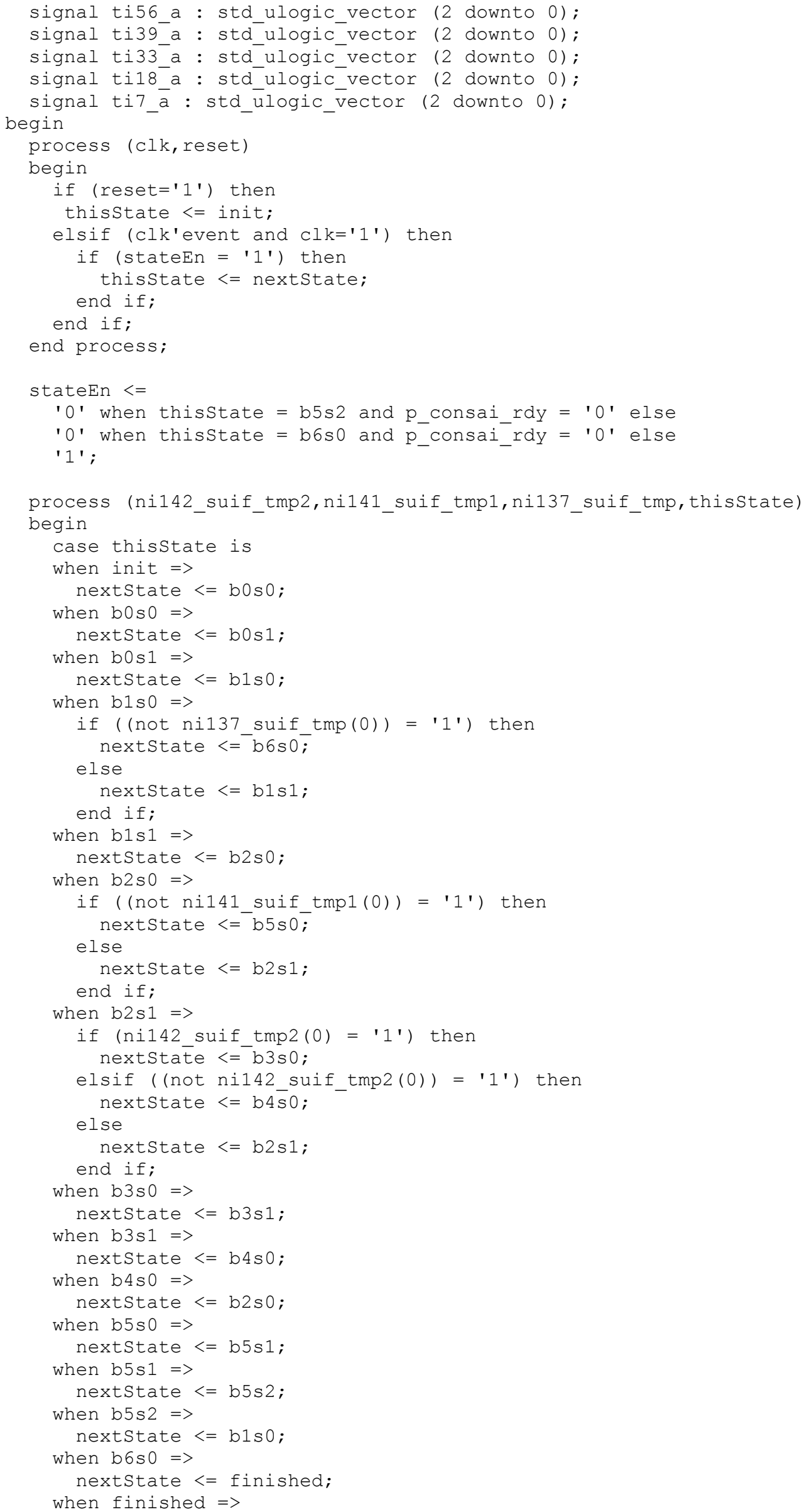




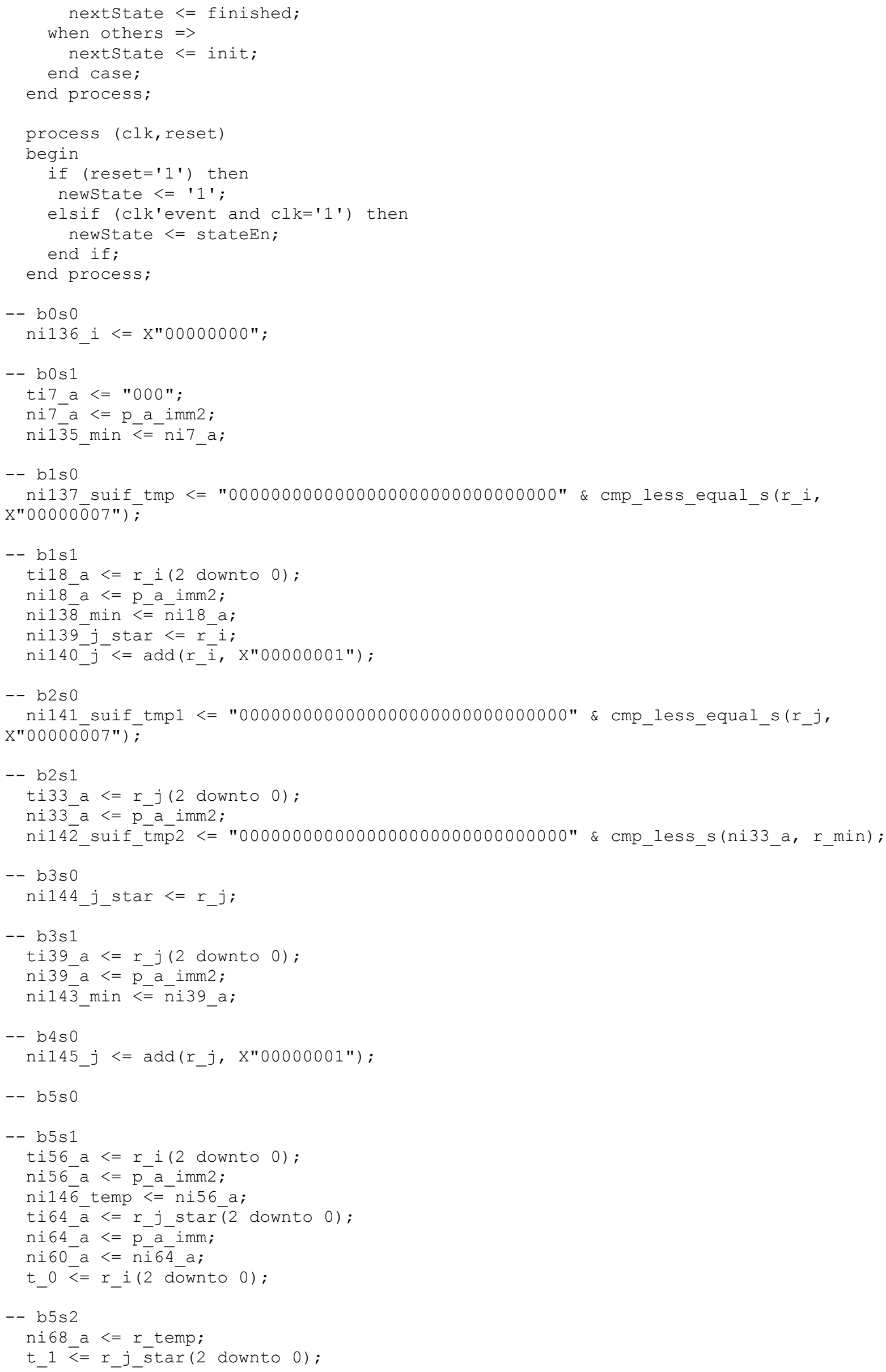




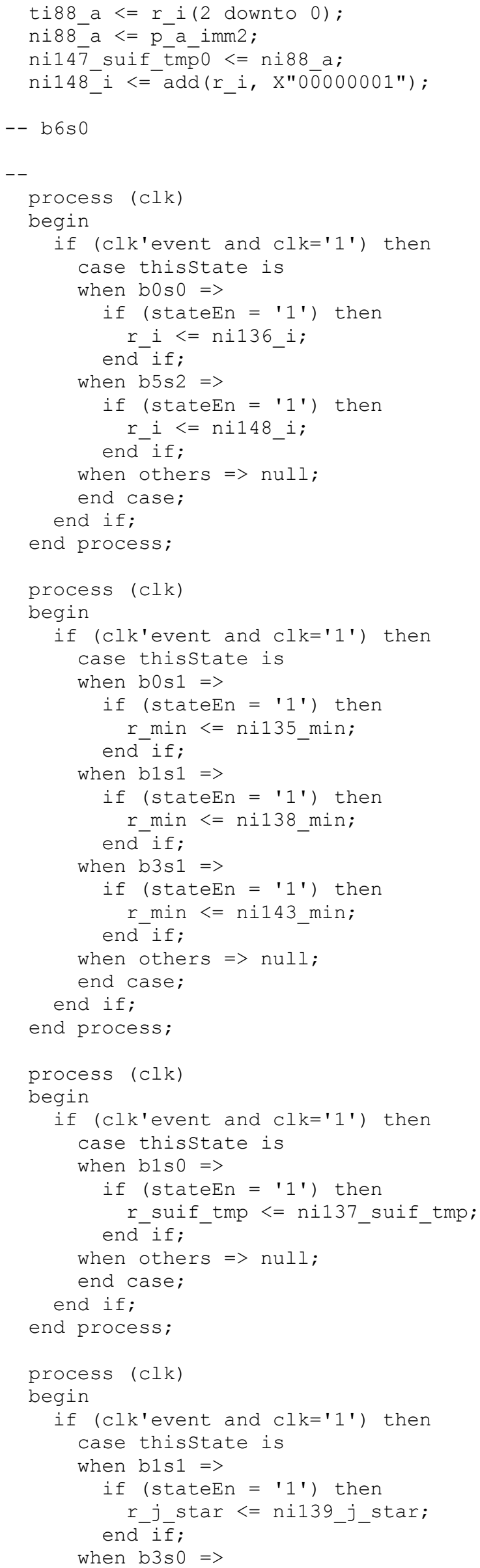




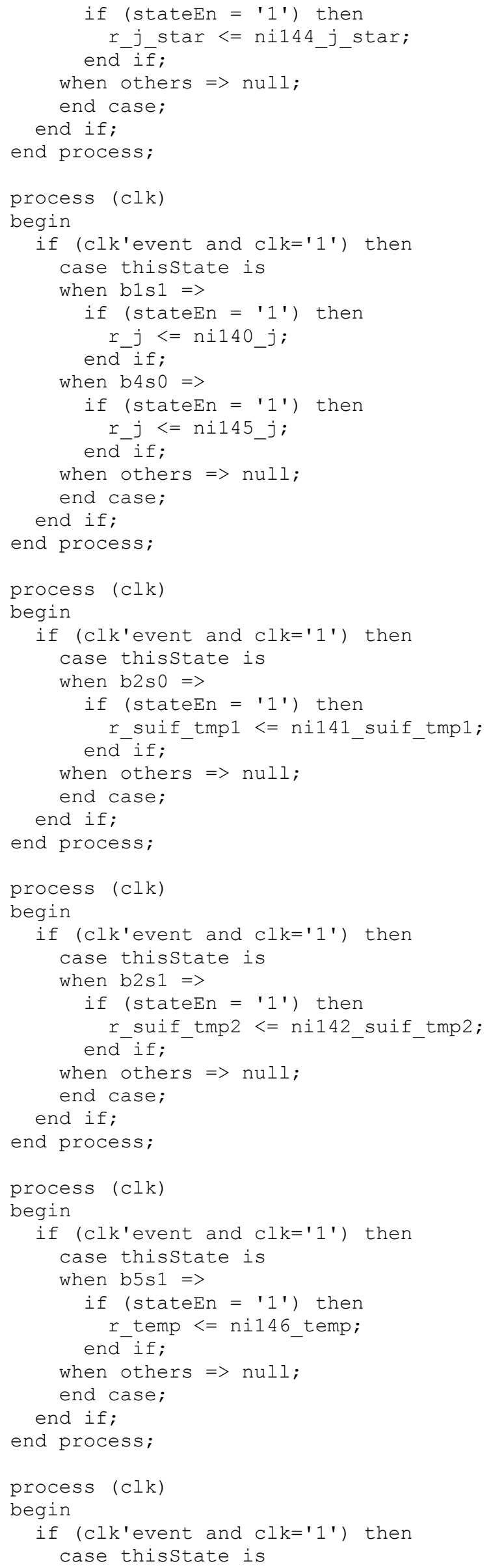




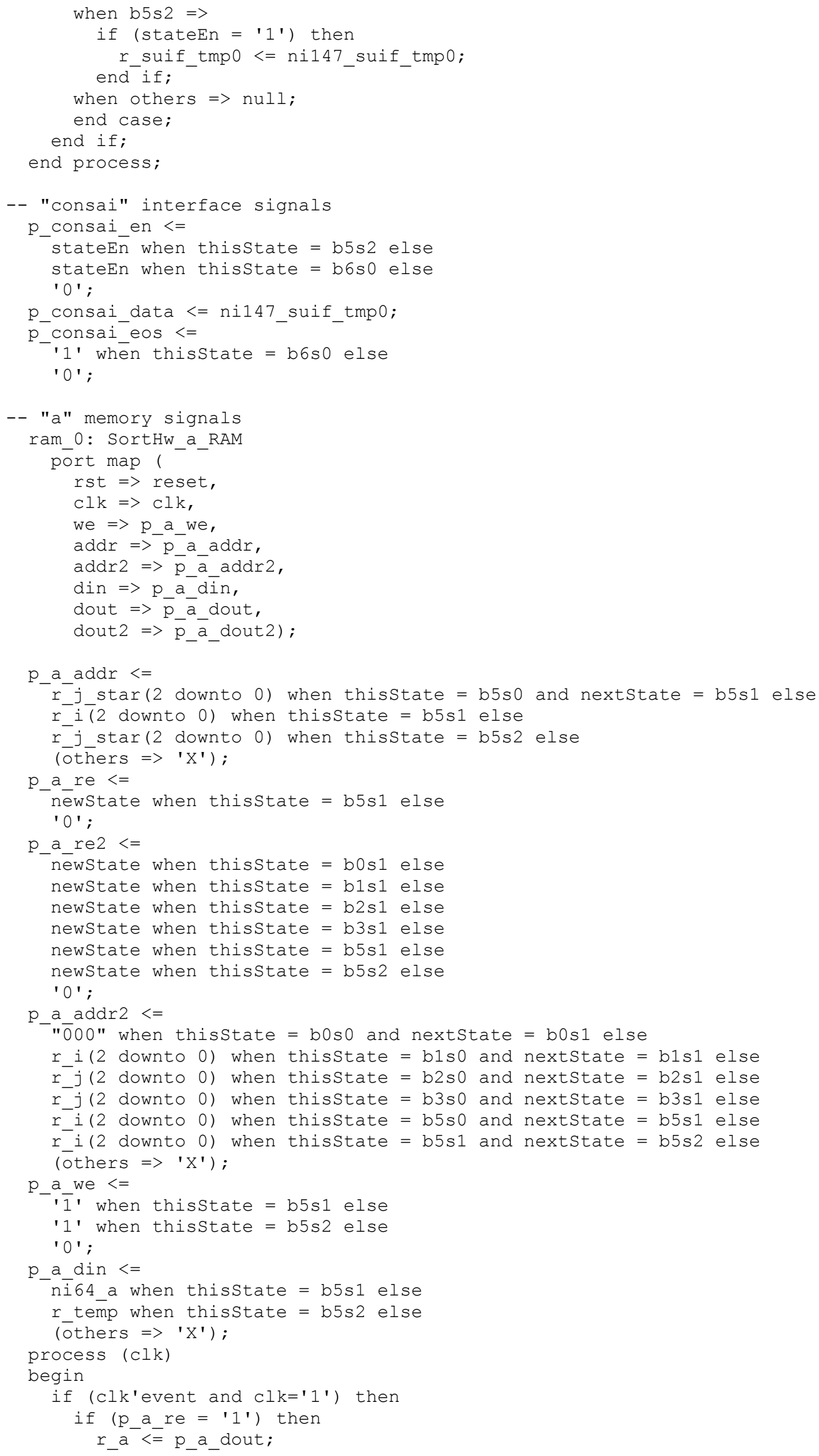




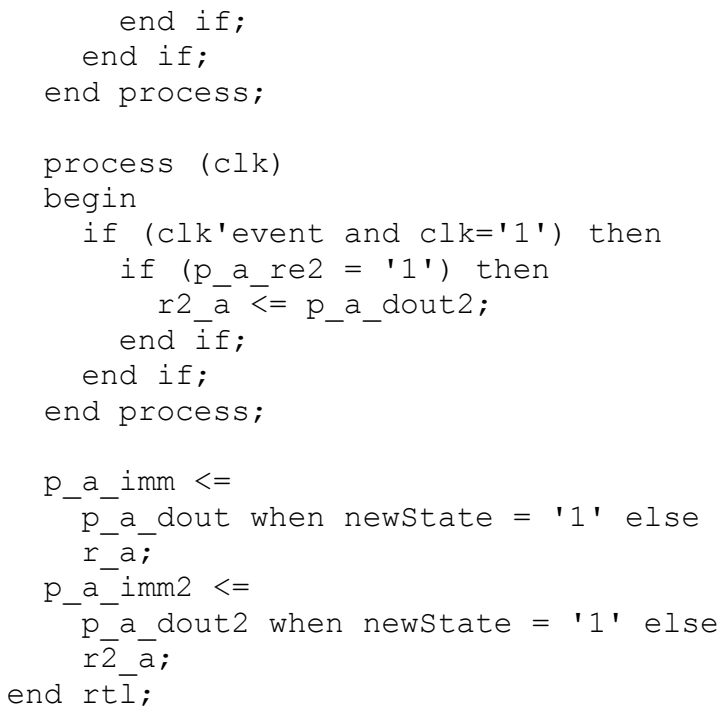

\section{A estrutura gerada pelo Impulse $C$ nos arquivos}

\section{VHDL}

Os arquivos de descrição de hardware VHDL gerados pelo Impulse C irão ser diferentes algumas vezes dependendo da plataforma selecionada no PSP do Impulse C, mas cada Core gerado no projeto de hardware incluem o módulo $H D L$ em top-level e um ou mais módulos $H D L$ em baixo nível representando os processos de hardware.

Quando os processos escritos usando as bibliotecas do Impulse $C$ são compiladas para hardware, arquivos $H D L$ são gerados, representando os vários processos, streams e outros elementos descritos no arquivo fonte c. O hardware gerado pode representar um sistema em hardware completo (como talvez no caso em que as streams são conectadas a microprocessadores externos) ou podem fazer interface com outros elementos de hardware, tais como interfaces seriais de alta velocidade, através das interfaces de streams, sinais e memorias.

Dependendo dos requesitos da aplicacao, as interfaces de stream e sinal podem ser usadas para diretamente conectar diferentes porocessos de hardware, por exemplo, para criar um sistema em pipeline ou pode ser usados para conectar processos de hardware executando em FPGA com outros processos executando como software em um processador embarcado no FPGA.

Para conexões entre processos de hardware protocolos de streams e sinais são relativamente diretos e são descritos abaixo. Conexões entre processos de hardware e processos 
de software são algumas vezes mais complexas e são especificas da plataforma de hardware escolhida no PSP.

Se o projetista estiver usando as plataformas de hardware suportadas no PSP, as interfaces de streams e sinais, necessárias entre os processos de hardware e software ou hardware e hardware serão geradas automaticamente pela ferramenta.

\section{Protocolos de streams e sinais}

O compilador Impulse $C$ usa protocolos bem definidos quando gera as interfaces de hardware para stream e sinais.

\section{Top-level HDL module (entity)}

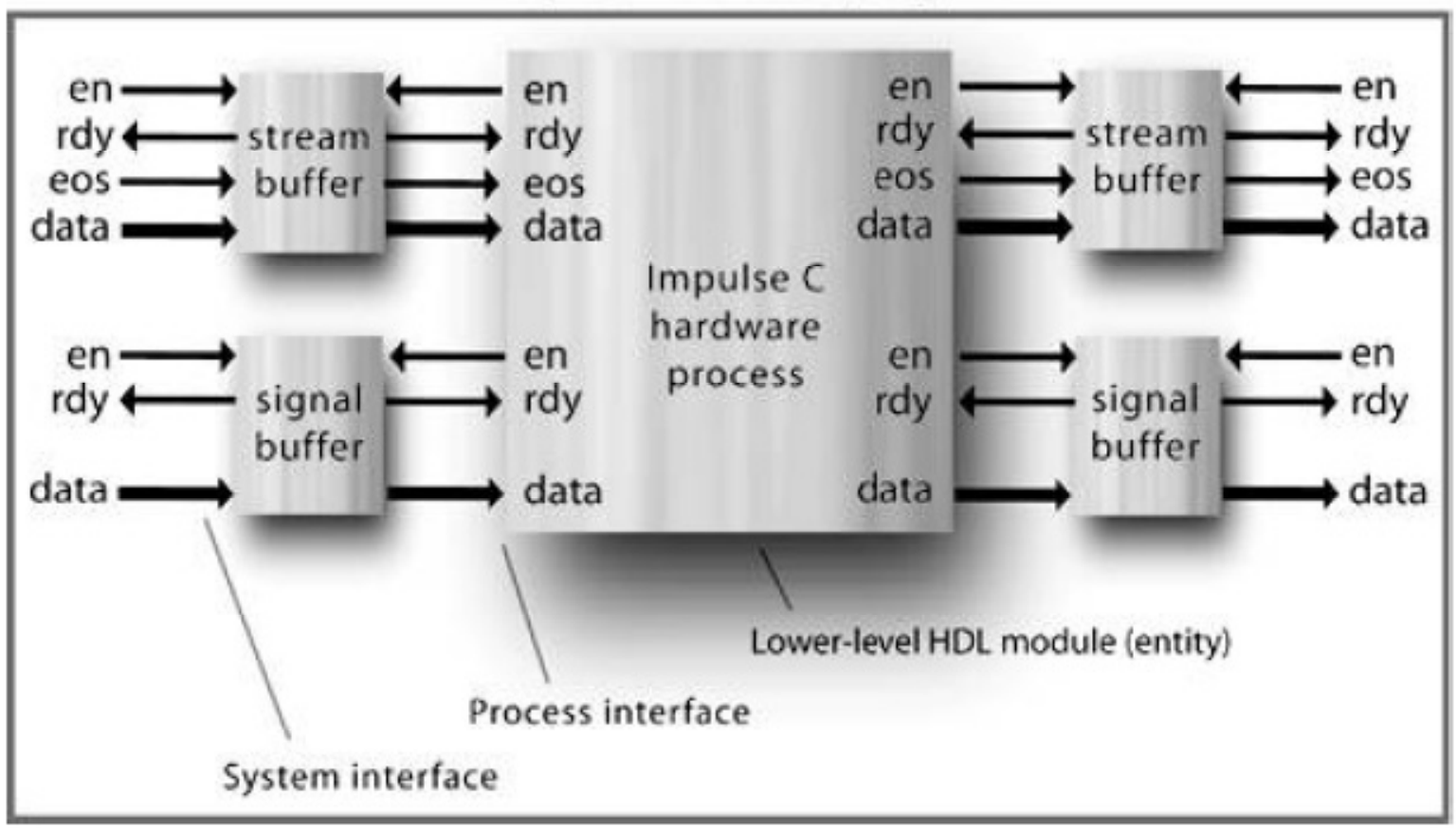

Figura 74. Relação entre os componentes gerados como HDL pelo Impulse C

A Figura 73 ilustra a relação entre os componentes criados pelo Impulse $C$, tais como componentes em baixo nível com a lógica customizada representando a aplicação implementada no Impulse $C$ e os arquivos top-level, responsáveis pelas interligações entre eles. Como mostra a figura, cada stream é gerada com uma linha de dado e três linhas de controle no lado da entrada e quatro linhas no lado da saída.

O sinal $r d y$ indica que a stream está pronta para ler ou escrever um dado. Quando o sinal $r d y$ for ativo, o sistema ou o processo conectado na stream pode ler ou escrever os dados de ou para a stream, movendo eles para ou da linha de dados. Por exemplo, o sinal $r d y$ pode 
ser setado pelo stream buffer, para indicar ao processo produtor quando o buffer está cheio ou vazio. Se $r d y$ for igual a 1, indica buffer vazio, então o processo produtor pode enviar os dados e setar o sinal em para 1, para que a stream buffer aceite os dados.

O sinal en indica ao processo hardware que pode aceitar ou não os dados em data. Se en for igual a zero os dados em data não são aceitos, caso contrário, os dados são aceitos. Tanto o processo produtor quanto o processo consumidor configuram en igual a 1, quando querem enviar ou receber dados.

O sinal eos controla o fluxo de dados na stream e indica ao processo consumidor que o processo produtor fechou a stream pela função co_stream_close. Se o sinal eos for igual a 1, então a stream está fechada caso contrario, a stream está aberta.

A interface sinal é similar, com a exceção do sinal eos que não existe e diferentes regras relacionadas como as mensagens serão postadas.

No caso de uma interface hardware para hardware, os processos produtor e consumidor trocam uma interface stream ou sinal comum, como mostra a Figura 74.

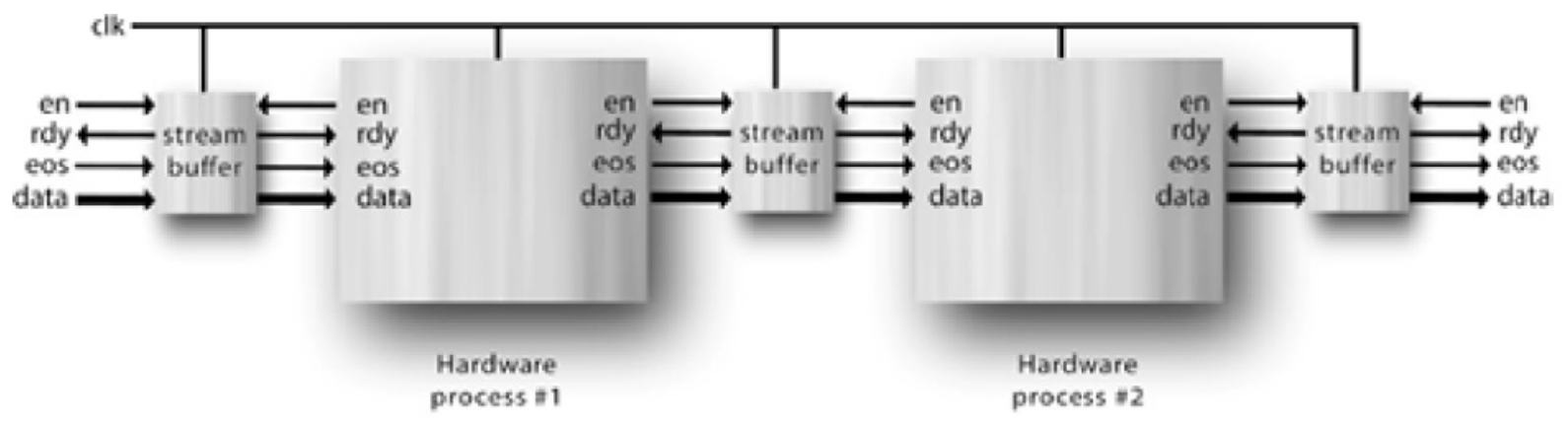

Figura 75. Múltiplos processos de hardware conectados via buffer de stream compartilhadas

Streams usadas em modo de escrita

Quando usadas em modo de escrita, como indicado pelo uso de o_wronly na função co_stream_open, as interfaces de stream são geradas com os seguintes portos e sinais correspondentes:

$<$ stream_name $>$ _rdy : OUT - Pronto para aceitar dados.

$<$ stream_name $>$ en : IN - Habilitado para a escrita.

$<$ stream_name>_eos: IN -- Write is EOS.

$<$ stream_name $>$ data: IN -- Write data. 


\section{Streams usadas em modo de leitura}

Quando usadas em modo de leitura, como indicado pelo uso de o_rdonly na função co_stream_open, as interfaces de stream são geradas com os seguintes portos e sinais correspondentes:

$<$ stream_name $>$ _rdy : OUT - Dado está disponivel.

$<$ stream_name $>$ en : IN - Habilitado para leitura.

$<$ stream_name $>$ _eos : OUT -- Read is EOS

$<$ stream_name $>$ data : OUT -- Read data.

Signals usados no modo Post (escrita)

Quando usados no modo escrita (indicado pelo uso da funcao co_signal_post), as interfaces de sinal são geradas do seguinte modo:

$<$ signal_name $>$ _en : IN - Escrita habilitada

$<$ signal_name $>$ data: IN - Escrita de dado.

Signals usados no modo Wait (leitura)

Quando usados no modo leitura (indicado pelo uso da função co_signal_wait), as interfaces de sinal são geradas do seguinte modo:

$<$ signal_name $>$ _rdy : OUT - Sinal é postado.

$<$ signal_name>_en : IN - Habilitar leitura.

$<$ signal_name $>$ data : OUT - Ler dado. 


\section{APÊNDICE C}

\section{Aritmética de ponto fixo}

Aritmética de ponto fixo é um método de representação e cálculo de números reais usando tipos de dados inteiros e hardware (Bodenner, 2005). Ponto fixo é uma alternativa para representar ponto flutuante. Ponto flutuante oferece uma grande variação de valores e maior precisão, mas isso também significa maior gasto, em termos de tempo de computação e hardware requerido. Ponto fixo é usado em sistemas embarcados e projetos $D S P$, porque eles conseguem alcançar maior velocidade e reduzido gasto em hardware. (Bodenner, 2005)

Segundo (Bodenner, 2005), não há um padrão comumente aceitado para representar números de ponto fixo. O projetista é quem determina os parâmetros do projeto, que inclui a precisão, arredondamento e saturação dos números representados em ponto fixo. Ponto flutuante, por outro lado, é codificado no padrão IEEE 754, o qual define as representações binárias de precisão simples e dupla nos tipos de dados, bem como o comportamento das operações aritméticas através da variação de precisão e representação dos valores.

A representação de ponto fixo geralmente divide uma largura fixa de bits em três partes: sinal $(\mathrm{S})$, parte inteira do número $(\mathrm{I})$ e a parte fracionária do número $(\mathrm{F})$.

Assim como em (Bodenner, 2005), nessa dissertação será adotada a seguinte notação para denotar o formato do número em ponto fixo: SSI.F. Por exemplo, um número de ponto fixo com 1 bit representando o sinal, 8 bits representando a parte inteira e 23 bits representando a parte fracionária será denotado por $1 s 8.23$.

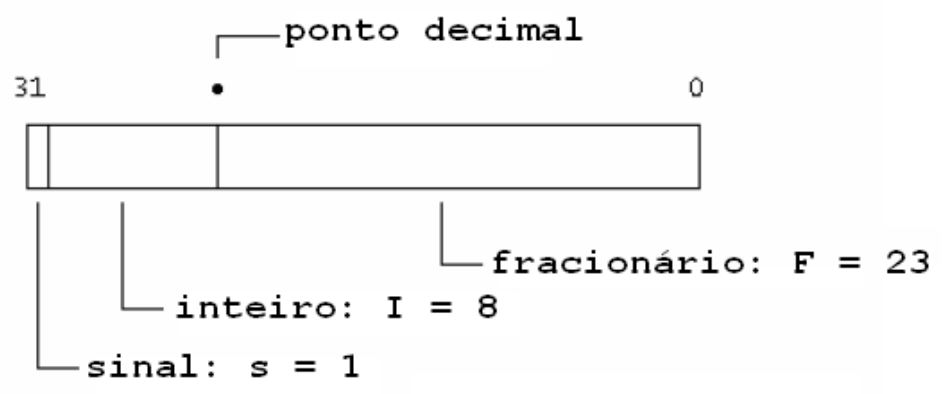

Figura 76. Representação do número denotado por 1s8.23

Na Figura 75 é visto 32 bits divididos em três partes para representar um número em ponto fixo, no formato $1 s 8.23$. Com isso, pode-se representar o número flutuante de 255 . 8388606 até -255.8388607. 
O processo de conversão de uma aplicação em ponto flutuante para aritmética de ponto fixo é demorado e envolve controle na precisão dos dados, por exemplo, em aplicações de multiplicação e divisão, além de cuidado no desempenho e tamanho do hardware gerado.

O Impulse $C$ provê suporte a aritmética em ponto fixo na forma de macros e tipos de dados que permitem ao projetista expressar as operações em ponto fixo em $A N S I-C$ e executar essas aplicações em um computador desktop, processador embarcado ou como módulos de hardware executados em uma lógica no FPGA.

Impulse $C$ atualmente suporta pontos fixos em 8 bits, 16 bits e 32 bits. Os tipos de dados co_int8, co_int16 e co_int32 são usados para números de ponto fixo com sinais, enquanto co_uint8, co_uint16 e co_uint32 são usados para números em ponto fixos sem sinais. Quando esses tipos de dados são usados com classes apropriadas de macros, operandos de um dado tipo irão ser traduzidos pelo compilador CoBuilder para hardware em um datapath de mesma largura, com duas exceções: para operações de multiplicação e divisão, na qual o CoBuilder irá gerar datapaths intermediários com o dobro do tamanho de seus operandos.

Os macros de aritmética de ponto fixo são definidos no arquivo de biblioteca co_math.h do Impulse $C$. Cada macro aceita dois ou três argumentos: um ou dois operandos do mesmo formato de ponto fixo e uma constante inteira $D W$, a qual representa o número de bits usados na parte fracionária do operando e resultado. O projetista é responsável por adequar o tamanho dos operandos apropriadamente para evitar overflow e underflow.

Entre os macros fornecidos pelo Impulse $C$ para manipulação em ponto fixo estão:

FXCONST32 $(a, D W)$, FXCONST64 $(a, D W)$ : usadas para converterem um número inteiro (a) em formato de ponto fixo de 32 ou 64 bits, resultando em um número inteiro sem sinal (unsigned) do tipo de dado co_uint32 ou co_uint64, respectivamente, com a dada parte fracionada formada por $D W$ bits de largura.

FXCONST32FL $(a, D W), F X C O N S T 64 F L(a, D W)$ : usadas para converterem um número flutuante (a) em formato de ponto fixo de 32 ou 64 bits, resultando em um número inteiro sem sinal (unsigned) do tipo de dado co_uint32 ou co_uint64, respectivamente, com a parte fracionaria de tamanho $D W$ bits de largura.

Dois números com o tipo de dado co_int32, ao serem multiplicados, resultam em um número de 64 bits. Exemplo: o número inteiro -15 multiplicado pelo número em ponto flutuante 2.77, seriam multiplicados em hardware da seguinte forma, após o projetista converter esses números de formato inteiro e ponto flutuante para o formato em ponto fixo, ambos no formato 1.s6.25, por exemplo, usando os macros acima: $F$ - 
XROUND64(IMUL64(dis1,dis2),25), onde IMUL64 é o macro para multiplicar dois números de 32 bits, 25 é a largura de bits da parte fracionária e FXROUND64 é a função de arredondamento, responsável por fazer o número resultante dessa multiplicação ficar no formato 1.s6.25. Assim, esse número poderia ser guardado em uma variável do tipo de dado co_int32.

Se após essa multiplicação, o projetista desejasse dividir esse número por 2, ele faria da seguinte forma: IDIV32((FXROUND64(IMUL64(dis1,dis2),25)),2), onde IDIV32 é o macro para divisão do número FXROUND64(IMUL64(dis1,dis2),25) de 32 bits pelo número 2. Como observado na expressão acima, o IDIV32 mantém o formato do número em ponto fixo.

Essas somas e divisões poderiam ser feitas com números do tipo co_uint32, pelos macros: UMUL64, UDIV32. O Impulse C possui macros para larguras de bits de 1 a 64 bits, ou seja, ele possui o IMUL8, IMUL13, UMUL45, UMUL64, IDIV5, IDIV64, UDIV32, e assim por diante.

Existem macros para soma e subtração e macros para conversão de números em ponto fixo para ponto flutuante, exemplo:

FX2REAL32 $(a, D W), F X 2 R E A L 64(a, D W)$ : usadas para converter um número em formato de ponto fixo para um número em formato em ponto flutuante, com essa macro, o projetista pode exibir os dados, usando a função do ANSI-C "printf", com a opção " $f$ " para exibir o número real, tanto para simulação quanto por um processo consumidor, no processador embarcado, usado para mostrar os resultados gerados pelo hardware.

O usuário é responsável por verificar se o macro usado para a manipulação do ponto fixo é suficiente para armazenar todos os possíveis cálculos do algoritmo, sem que haja overflow e underflow. Por exemplo, uma mesma variável pode ser usada para armazenar o resultado de uma soma, de uma divisão, multiplicação, entre outras. Nesse caso, o projetista tem que atentar ao fato de que para armazenar o resultado de uma multiplicação, a macro usada deveria ter pelo menos duas vezes o tamanho dos tipos de dados de cada operando.

O benchmark FFT implementado no Impulse C, como discutido nos capítulos anteriores, possui 16 pontos de entrada e gera 16 pontos de saída, ambos em ponto flutuante. Como o benchmark original foi implementado com o tipo flutuante (float), ANSI-C e como este tipo de dado possui 4 bytes, o benchmark implementado no Impulse $C$ usa o tipo fixo co_int32. 